THE WALK OUT OF THE RURAL KITCHEN

TOWARDS PLANNING ENERGY SERVICES FOR SUSTAINABLE RURAL LIVELIHOODS IN SUDAN

\title{
DISSERTATION
}

\section{to obtain}

the degree of doctor at the University of Twente, on the authority of the rector magnificus, prof.dr. W.H.M. Zijm, on account of the decision of the graduation committee, to be publicly defended on Wednesday the $10^{\text {th }}$ of December at 13.15 hours

by

Nouralla Yassin Ahmed Bakhiet Born on the $15^{\text {th }}$ of November 1960 in Ed Duim, Sudan 
This thesis has been approved by the promoter Prof.dr. N.G. Schulte Nordholt

and the assistant promoter

Dr. J.S. Clancy 
Committee:

Voorzitter:

Prof.dr. P.J.J.M. van Loon

University of Twente

Secretaris:

Prof.dr. P.J.J.M. van Loon

University of Twente

Promotor:

Prof.dr. N.G. Schulte Nordholt

University of Twente

Ass. Promotor: Dr. J.S. Clancy

Leden:

Prof.dr.ir. M.J. Groeneveld

University of Twente

Prof.dr.ir. J.J. Krabbendam

University of Twente

Dr. A. Musch

University of Twente

Prof.dr. L.O.K. Larsson

VNG

University of Skövde, Sweden

Referent:

J. A. Barnett, Honorary Fellow

SPRU, United Kingdom 


\section{(5) \\ University of Twente Enschede - The Netherlands}

University of Twente

School of Management and Governance

Center for Clean Technology and Environmental Policy / TSD

Enschede, The Netherlands

(C) Nouralla Yassin Ahmed Bakhiet

isbn 9789036527774 


\section{Content}

List of Tables, List of Maps, List of Figures and Boxes .............................................v

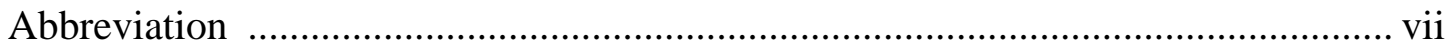

Glossary of Arabic words ..................................................................................... ix

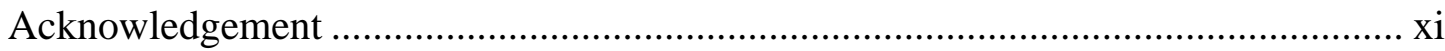

$1 \quad$ Background and problem formulation .............................................................................1

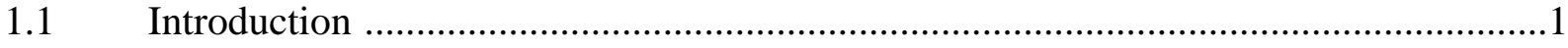

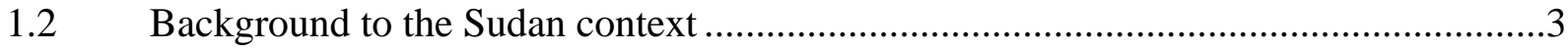

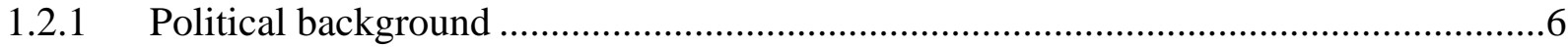

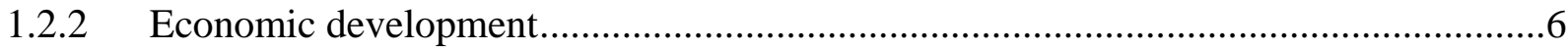

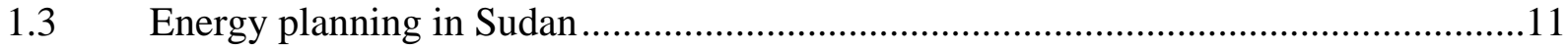

$1.4 \quad$ Introduction to the livelihoods framework ..........................................................17

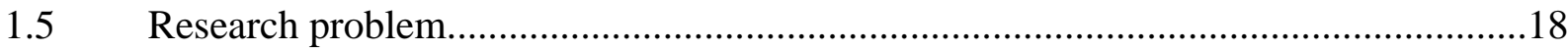

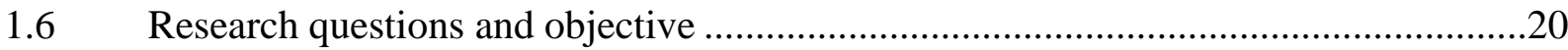

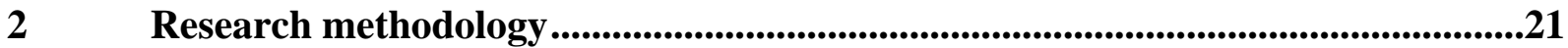

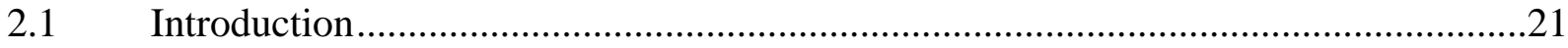

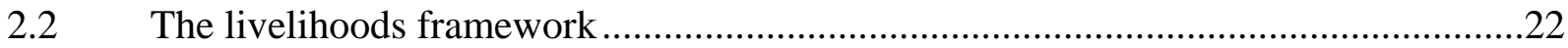

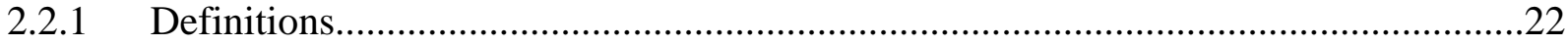

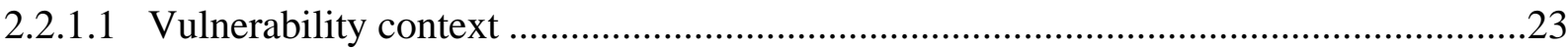

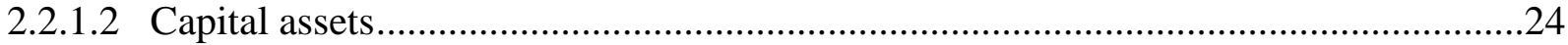

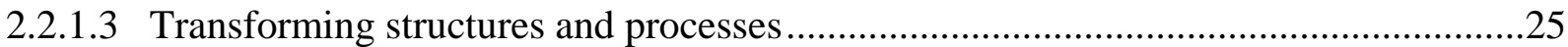

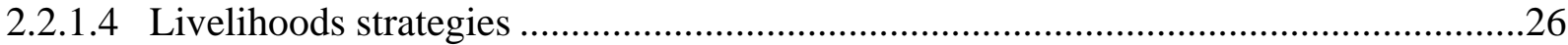

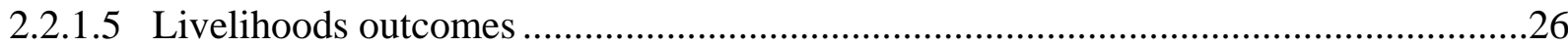

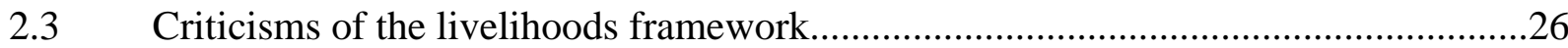

2.4 The Livelihoods framework as a tool in planning energy services ............................28

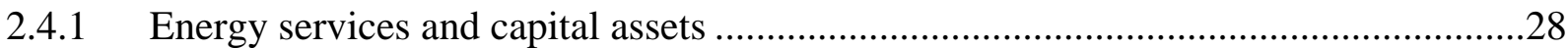

2.4.2 Energy services and the other livelihoods components .............................................32

2.5 The links between the stock of energy services and the pentagon of capitols.............34

2.6 Participation as a tool for energy data gathering ....................................................36

2.7 Participatory research method as applied in this study ............................................36

2.8 Criticisms of participatory techniques as a data gathering method ............................39

2.9 Relevance of livelihoods framework and participatory approaches for investigating problems related to energy services in Sudan 
2.10 Points of juncture between the livelihoods framework and participation methods .....43

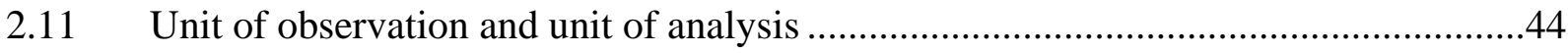

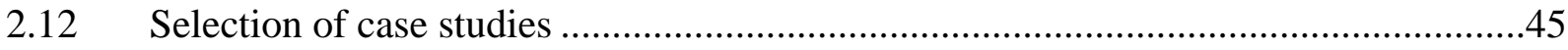

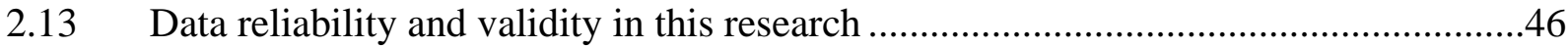

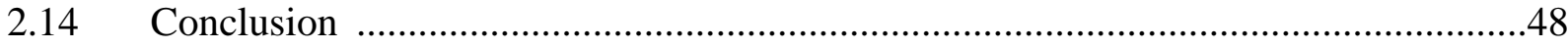

$3 \quad$ Vulnerability and transforming structures and processes...................................49

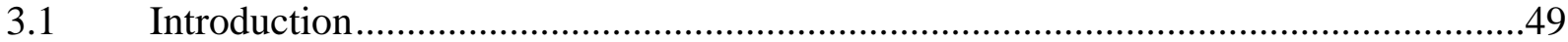

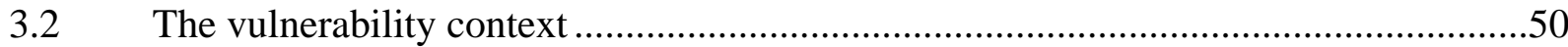

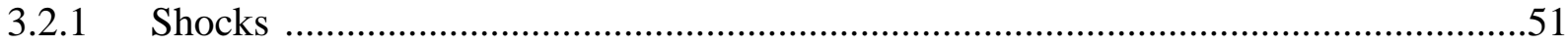

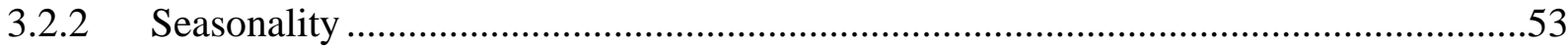

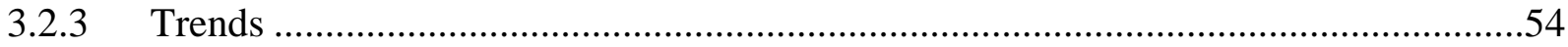

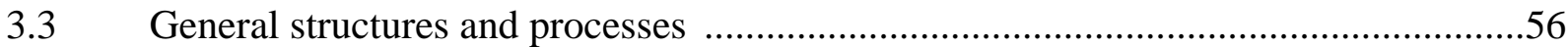

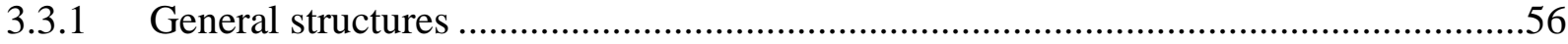

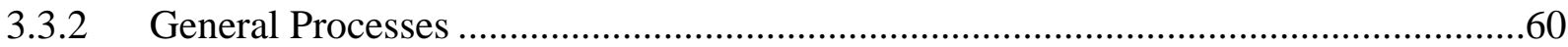

3.4 Structures and processes of the energy sector.............................................................66

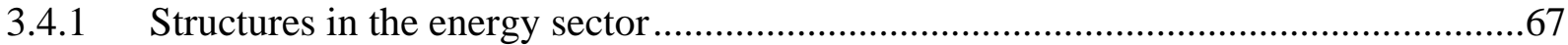

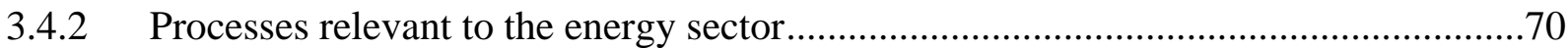

3.4.3 The role of NGOs and international agencies in energy services in Sudan ...............77

3.4.4 Links between energy institutions in Sudan ...........................................................79

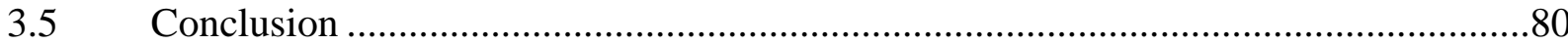

$4 \quad$ Variation in access to energy services in rural Sudan ..............................................83

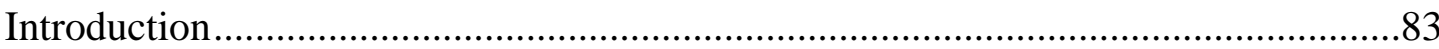

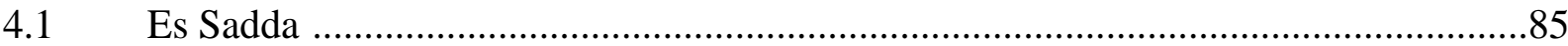

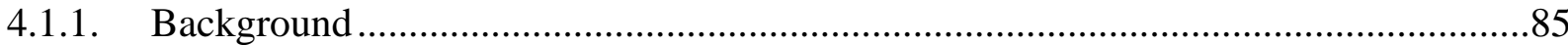

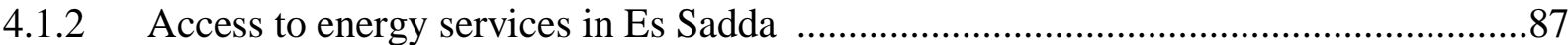

4.1.3 Energy services priorities in Es Sadda village ...........................................................89

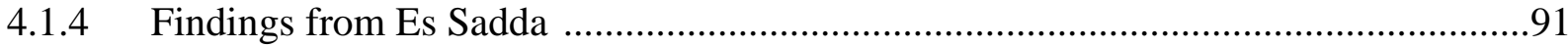

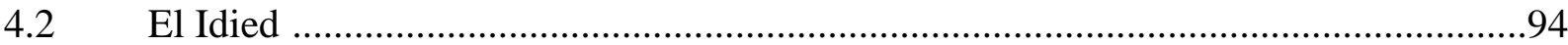

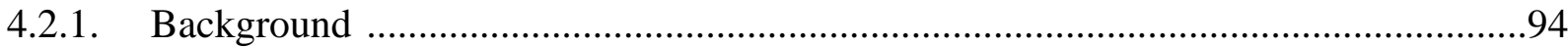

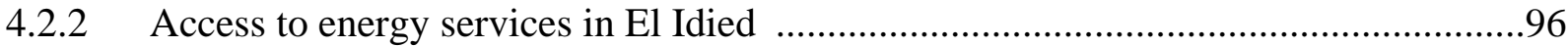

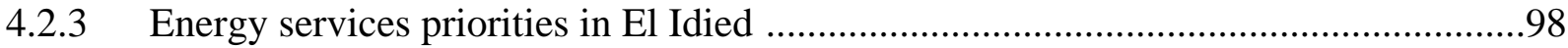

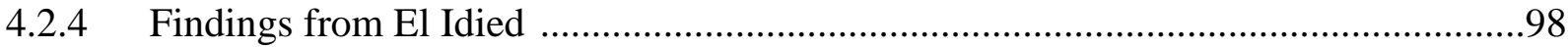

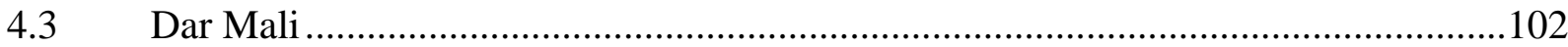

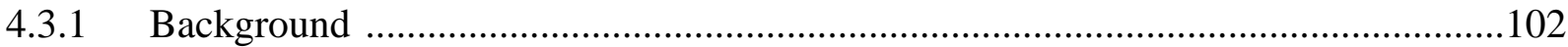

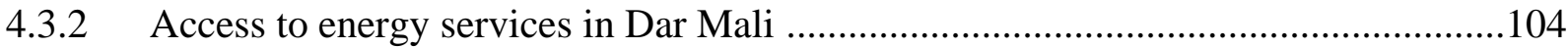




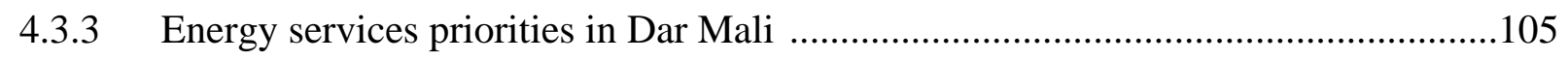

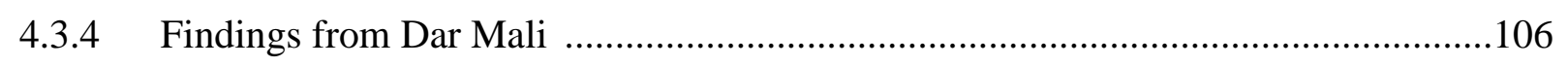

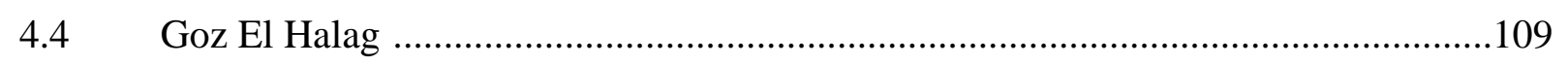

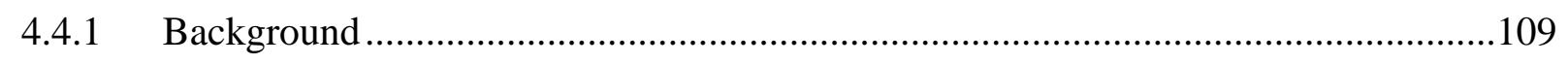

4.4.2 Access to energy services in Goz El Halag .....................................................110

4.4.3 Energy services priorities in Goz El Halag.........................................................111

4.4.4 Findings from Goz El Halag ..........................................................................112

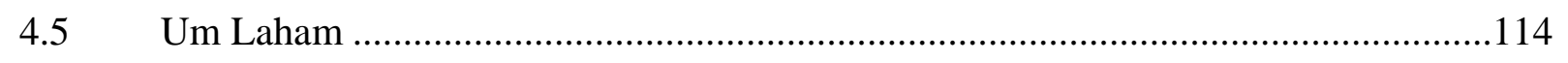

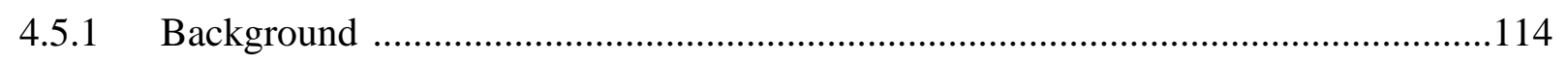

4.5.2 Access to energy services in Um Laham ........................................................116

4.5.3 Energy service priorities in Um Laham ............................................................117

4.5.4 Findings from Um Laham........................................................................118

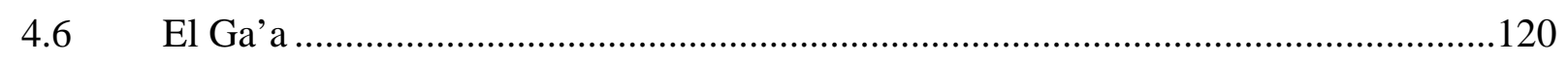

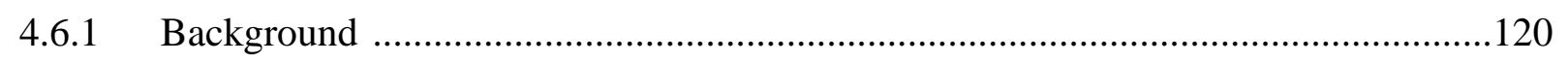

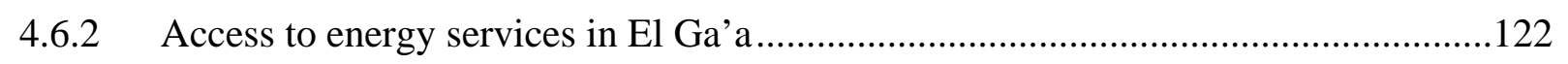

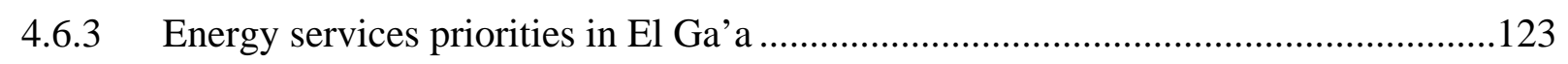

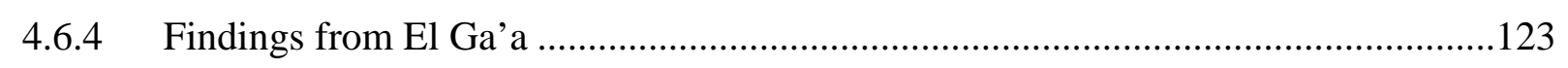

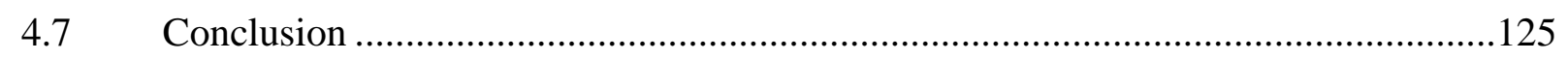

4.7.1 Differences in access to energy services between the six villages ...........................125

4.7.2 Differences in access to energy services for different activities within the six villages

5 Analytical comparison of energy services and livelihood outcomes between the six villages ......................................................................................................131

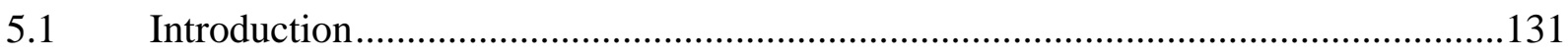

$5.2 \quad$ Impacts of the vulnerability context on energy services..........................................132

5.2.1 Impacts of shock factors on energy services............................................................132

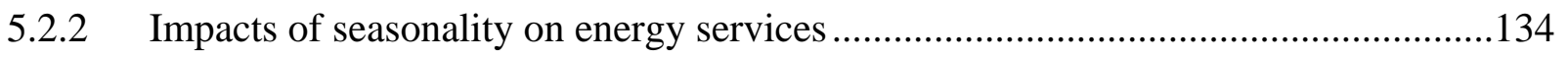

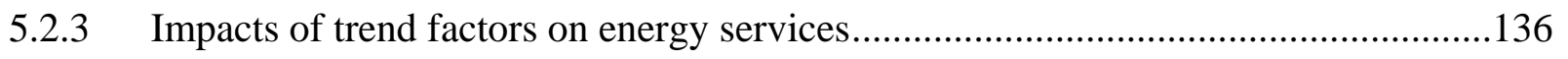

5.3 The links between access to capitals assets and energy services..............................136

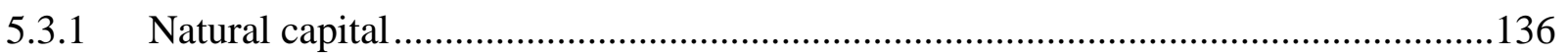

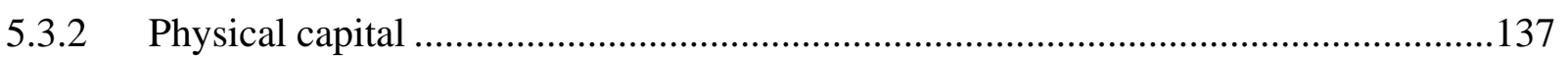

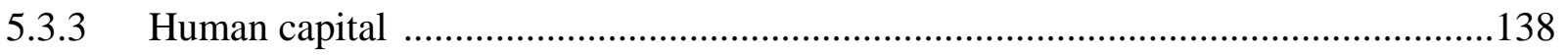

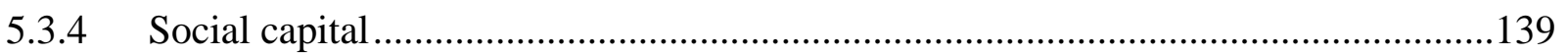

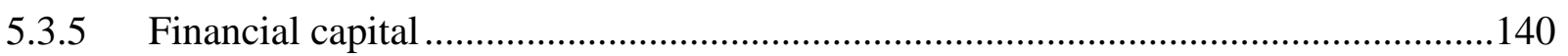

5.3.6 The energy circle and the pentagon of capitals....................................................141

5.4 Impacts of the vulnerability context on the flow of energy services ........................141 
$6 \quad$ Conclusion and recommendations..................................................................147

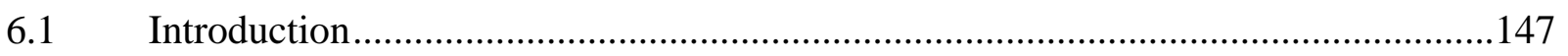

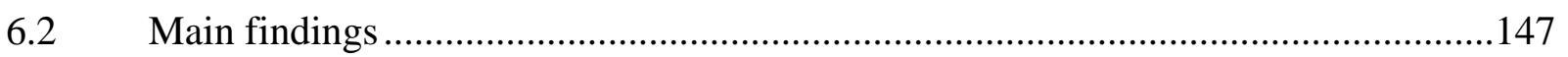

6.2.1 Vulnerability as a determinant of rural energy services in Sudan ............................147

6.2.2 Methods used in building the EDS for energy policies and planning purposes in

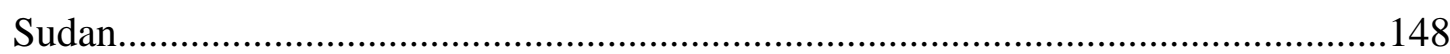

6.2.3 The functioning of the transforming structures and processes in the energy sector..150

6.2.4 Differences in access to energy services in rural areas...........................................151

6.2.5 The need to plan additional modern energy carriers in rural areas...........................152

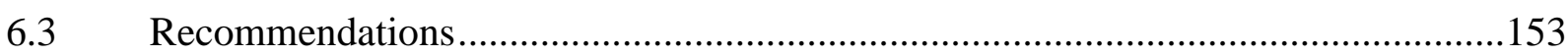

6.3.1 Change from shared kitchen to shared livelihoods as unit of observation ...............153

6.3.2 Adopt a broader view of energy services in the analysis........................................154

6.3.3 Change focus from supply of modern energy to problem solving............................154

6.3.4 Change from exclusion to inclusion of traditional economics..................................156

6.3.5 Develop specific structures within energy institutions for rural services ..................157

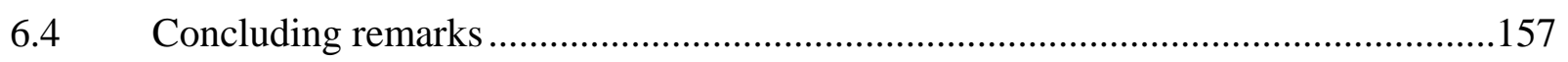

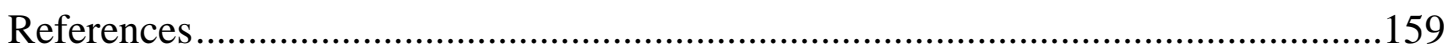

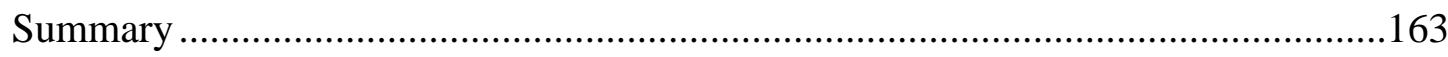

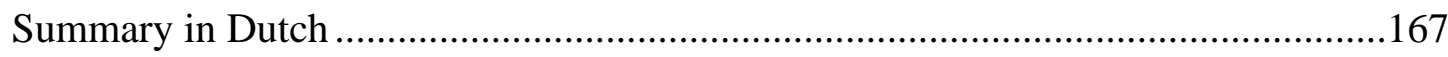

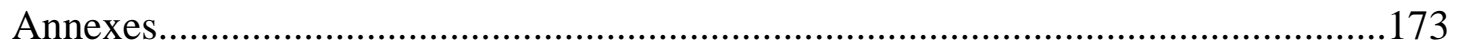




\section{List of Tables}

Table 2.1 The main spatial and economic characteristics of the selected villages 46

Table 3.1 Types of ruling regimes in Sudan since independence 57

Table 3.2 Establishment and operation costs (in 1997 prices) for different types of power generation in Sudan

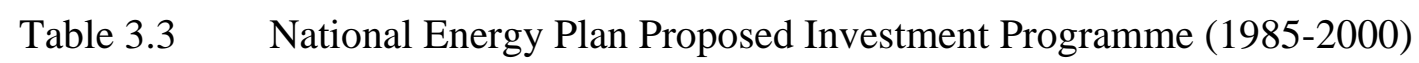
in Million US Dollars

Table 3.4 Characteristics and Categories for areas qualified for NEC Support 76

Table 4.1.1 Wealth criteria and wealth categories in Es Sadda 87

Table 4.2.1 Wealth criteria and wealth categories in El Idied 96

Table 4.3.1 Wealth criteria and wealth categories in Dar Mali 103

Table 4.4.1 Wealth criteria and wealth categories in Goz El Halag 110

Table 4.5.1 Wealth criteria and wealth categories in Um Laham (including El Rukab) 115

Table 4.6.1 Wealth criteria and wealth categories in El Ga'a 121

Table 4.7.1 Energy carriers used to generate energy services in the six villages 127

Table 5.1 Analysis of occurrences of drought and flood events in the six villages and their impacts on energy services 133

Table 5.2 Impacts of seasonality on the availability of energy carriers and the flow $\begin{array}{ll}\text { of energy service } & 135\end{array}$

\section{List of Maps}

Map $1.1 \quad$ Climate and vegetation regions of Sudan

Map 1.2 Locations of villages selected for this study

Map 3.1 The administrative map of Sudan 59

Map 3.2 Locations of National Grid and large thermal power plants in the Sudan

\section{List of Figures and Boxes}

Figure 2.1 Livelihood Framework

Figure 2.2 Stock and quality of energy services at the centre of the pentagon

Box 3.1 Division of political power and financial resources as stipulated in the 1998 constitution

Box 3.2 Division of financial resources as stipulated in the Constitution 1998 and Interim Constitution of Sudan 2005

Figure 5.1 Schematic representation of combinations of natural and physical capitals in transformation of energy services and levels of vulnerability

Figure 5.2 Casual relation of energy services and sustainable livelihood 


\section{Abbreviation}

ABS Agricultural Bank of Sudan

ADB African Development Bank

APDC Asian and Pacific Development Centre

ADS Area Development Scheme

BRWDS Bawadina Rural Women Development Society

CPA Comprehensive Peace Agreement

DFID Department For International Development

ECA Energy Commodity Account

EDS Energy Data System

EPI Extended Programme of Immunization

ERI Energy Research Institute

ESMAP Energy Sector Management Assistance Program

FAO Food and Agriculture Organization

GDP Gross Domestic Product

GOs Governmental Organization

GPC General Petroleum Corporation

IDPs Internally Displaced Peoples

IFAD International Fund for Agricultural Development

JAM Joint Assessment Mission

LPG Liquefied Petroleum Gas

MAF Ministry of Agriculture and Forestry

MEM Ministry of Energy and Mining

MOST Ministry of Science and Technology

NCR National Council for Research

NDA National Democratic Alliances-Sudan

NEA National Energy Administration

NEC National Electrical Corporation

NFA National Forestry Administration

NGOs Non-Governmental Organizations

NIDB Nilein Industrial Development Bank

NRWC National Rural Water Corporation

NSSF National States Support Fund

OEB Overall Energy Balance

RES Reference Energy System

RSED Rural Solar Energy Development Project 
SCOVA Sudan Council of Voluntary Organization

SDG Sudanese pound (Gunaih Sudani) which replaced the old Sudanese Dinars and came into circulation in July 2007

SECS Sudanese Environmental Conservation Society

SEP Special Energy Program

SFM Swedish Free Mission

SREP Sudan Renewable Energy Program

SSA Swedish Sudanese Friendship Association

SSDB Saving and Social Development Bank

SSS Solar School in Sudan

SSU Sudanese Socialist Union

UN United Nations

UNDP United Nations Development Programme

UNEP United Nations Environmental Programme

UNHCR United Nations Higher Commissioner for Refugee

UNICEF United Nations Infants and Children Fund

VAT Value Added Tax

VDC Village Development Committee / Village Development Council

VPC Village Popular Committee

WB The World Bank

WFP World Food Program

WHO World Health Organization 


\section{Glossary of Arabic words}

Dahawa Span of time spend by labour hire for certain work usually starts from about 6 am in the morning and ends about 11:00 am

Damar The place where the nomads temporary stay during certain moths of the year. So, those months are called the Damar time and the place is the Damar place.

El Far Rat and mice

El Idd The place where wells are dug or where water is collected

Fanus Wick lamp

Fedan Measurement of land area which is equal to 4200 square meters or 0.42 hectare.

Girba Water containers made from animal leather and used for carrying transporting water on camel or donkeys

Girare Highly fertile soil type found in land closer to the Nile or rivers.

Gutiya Thatched hut made of grasses

Haffir Large earth water reservoirs excavated to store rain water for use

Karo Less fertile soil lies away from the Nile and rivers bank

Khalwa Kuranic school in which the Quran is taught to children

Maloud Hand tools used for doing the weeding operation in agricultural farms

Masraga Oil lamp

Matara Hand dug wells from which water is pumped to irrigate

Sagia Animal drawn pump

Salaouka Hand tools made from wood used to making holes for sowing crop seeds

Sandug Funds

Shadouf Manual water lifting device

Sheikh Village chief or a religious man

Toria Hand hoe

Tugaba Blot of wood fired for lighting particularly used in khalwa education

Urtawazi Borehole

Wadi Valley

Wasoug Hand tool made from wood for doing the farm levelling manually. 


\section{Acknowledgment}

This thesis is developed over long processes in which many people have contributed something valuable. I would like here to thanks those individuals and institutions without their input this research can not be accomplished. First I am immensely grateful for invaluable assistance I received from my both supervisors professor Nico Schulte Nordholt and Dr. Joy S. Clancy. This research would not have been possible without their incredible patient, support and assistance throughout the development of this thesis.

The Swedish Free Mission (SFM) for their generous financial support. SFM provided most of the finance for in-country travels to the study areas and my travels to the Netherlands. I would like also to thank Mr. Peter Kammensjo the country representative for SFM in Sudan and his successor Mr. Esbjorn Thordeman for their friendship and support throughout my study. I would like also to thank Professor Leif Larsson the former chairman of SFM in Sweden and his support and encouragement to go for this study.

I am grateful to my research assistants Omima El Ibeid, Faroum Jermaya and Mariah Sabir from Swedish Free Mission and Fatima Hussein, from the Energy Research Institute for their assistance in carrying out the filed work in the six villages. They facilitated the participatory sessions held in the villages and collection of data and comments. Many thanks to them for being good friends and form a homogenous study group and knowledgeable assistants. I would like also to appreciating the cooperation and supports I received from many people in my study villages. As representative from each villages I would Like to extends my thanks to Ahmed Suliman from Dar Mali, El Awad Mohmed from Goz El Halg, Mohmed El Khaliefa El Awad from Es Sadda, Ahmed Mohmed from El Idied, Mohmed El Ibied from Um Laham and Ibrahim Musa from El Ga'a. I would like to appreciate their cooperation in facilitating the entry to their villages, organising participants workshops and focus groups and the accommodation during all the time we spent in their villages. I am greatly indebted to Julia Ardesch and Annemiek van Breugle, from the TSD secretariat, for their cooperation in facilitating my entry visas, accommodations and for editing my thesis.

I am also grateful to Giles Stacy for editing my manuscript and straighten it in a good English language structure and format. Giles provided many helps throughout this research. Not least, the visit Giles and Joy made to Sudan and their participation and advice during the filed work in Dar Mali.

I would like to acknowledge the prayers and good wishes of my mother Asha El Shiekh, the support and encouragement that I received from my wife Ratieba Abd El Gadir, my wonderful daughters Asgad and Rahaf and to my sisters and brothers along our extended families.

Nouralla Yassin

Enschede, the Netherlands

December 2008. 


\section{Chapter One: Background and problem formulation}

"Truly there is plenty of everything, plenty of hungry people and homeless, plenty of food and water, plenty of problems at home, plenty of help from abroad. The only difficulty is bringing all the plenties together, so they cancel each other." (Sudan Now Magazine, October 1985: 3).

\subsection{Introduction}

Sebitosi and Pillay (2004) postulated that the deficit of energy services in SubSaharan Africa might be a cause of poverty rather than a consequence of it. Sudan is one of the Sub-Saharan countries where the poverty rate is estimated at $50 \%$ to $60 \%$. That is, of its total population of 32 million, half live on less than one dollar per day, particularly in the rural areas where about $70 \%$ of the population live (IFAD, 2004). The Sudan Interim Poverty Reduction Strategy Paper 2004-2006 prepared by the World Food Program (WFP), shows that the high level of poverty in rural areas of Sudan can be linked to the lack of certain energy services, such as access to electricity, safe drinking water, and sanitation, as well as the dependence on biomass energy. The percentages of the rural population with no access to electricity, no access to safe drinking water, with poor sanitation and those dependent on biomass energy are $87.4 \%, 53.0 \%, 53.3 \%$ and $92.6 \%$ respectively (WFP, 2004: 6). Some of the causes of the high poverty rate in rural Sudan cited by the International Fund for Agricultural Development (IFAD) and WFP are the prevalence of low input/low output traditional agricultural and similar activities (rain fed agriculture, animals grazing on natural pastures, rain water collected for drinking and wood from the forest for cooking) and the limited government investment in such traditional agricultural and practices. This mode of rural living is also characterized by frequent disturbances due to natural disasters such as drought. The UNEP considers severe drought ${ }^{1}$ events to have occurred six times in Sudan during the period 1974 to 1985 (UNEP, 1990: 502). The severest event was the 1983/85 drought which destroyed the natural vegetation that formed the basis of rural services (food, pasture for animals, fuel) and resulted in a massive displacement of the rural population ${ }^{2}$ from drought-stricken areas to areas that were not affected ${ }^{3}$. Drought has also been reported in later years with similar probabilities of occurrence. As a consequence of the drought, there was a complete failure of production and service systems in rural areas (Abdel Ati, 2001). Since the rural population depends to a large extent on the natural environment to access important services such as water, food and fuel, any disturbances in the natural environment such as those that accompanied the 1983/85 drought can leave large numbers of the rural population without access to these services. The United Nations (UN), for example, estimated that around 5.5 million people were affected by the drought in 1992, and in urgent need of food, water, and medical services. However, in 1993, when there was a good rainy season, the number of the population affected fell to 1.1 million (UNDP, 1993). This shows the high sensitivity of services that support rural livelihoods in Sudan to natural conditions. Alternative options, such as obtaining

\footnotetext{
${ }^{1}$ UNEP defines a drought event as receiving less than $60 \%$ of the normal precipitation.

${ }^{2}$ UN Reports (No. 1 to No. 11, 4 Jan.- 5 Dec. 1985) estimated that the number of the rural population displaced, during the 1983/85 drought, to have reached four million.

${ }^{3}$ These areas are found along the Niles and other rivers crossing Sudan and the areas south to the semidesert region (Map 1.1)
} 
these services from physical capital ${ }^{4}$, are not yet in place in rural areas. There are no substitutes available for the degraded natural capital ${ }^{5}$, due to drought, for the provision of products such as water, food, and energy. Although, during the drought period of 1983-1985, Sudan was formulating its national energy plan, there was no reference to these problems in the final plan (NEA, Sudan, National Energy Plan, 1985). One of the immediate rural problems accompanying the 1983/84 drought was the lack of food and water, due not only to the lack of rainfall but also to a failure of the services system and that, in turn, led to a massive displacement of the rural population. The consequences of drought in the 1980s on rural livelihoods drew worldwide attention ${ }^{6}$ to the plight of rural people in Sub-Saharan Africa, including Sudan, and appeals to save them from the fate of death from thirst, hunger and diseases. Nevertheless, the lack of energy resources in rural areas to obtain such vital services were not identified within the problems tackled by a later National Energy Plan for 1985-2000. So, a problem well known to the whole world was ignored in formulating of the National Energy Plan in Sudan. Why are such rural problems excluded from national energy planning in Sudan and what are the consequences of this exclusion? These questions stand central in this thesis.

One suggestion is that there is little interest shown by the successive governments in Sudan in servicing rural areas, where traditional economic practices predominate. To formulate a research problem around the exclusion of rural areas from energy planning, the contextual background to the political and economical development of Sudan is given in Sections 1.2.1 and 1.2.2 respectively. The political environment is important because Sudan has witnessed frequent changes in its political system (having alternated between democratic and military regimes since independence in 1956) and by their nature each system has had different approaches to involving people in setting national objectives and the exercise of political will. In Section 1.2.2 a short elaboration is provided on the context of economic developments in Sudan and its claimed national objectives. This is important as it shows the general objectives around which the economy has been planned, which set the basis for each sub-sector's planning. The need for energy is a derived need ${ }^{7}$ from these set national objectives, i.e. higher objectives (economic or social) are identified first, and then the energy sector objectives are derived to realize these higher objectives. The set objectives for planning in the energy sector in Sudan are derived from the urgent need to lift the economy from stagnation by increasing the export of commodities (World Bank, 1983). In setting such economic objectives, the inclusion of those segments of the population whose economic activities do not contribute to the production of export

\footnotetext{
${ }^{4}$ Physical capital is a concept used in livelihoods analysis which forms part of the methodology used in the research reported here. Physical capital refers to basic infrastructure (such as transport, water, energy, shelter, communications) and the production equipment and means that enable people to pursue livelihoods. See Chapter 2 for a further discussion on livelihoods analysis.

${ }^{5}$ Natural capital is defined in livelihoods analysis as the stock of naturally available resources and minerals which people rely on to derive the services they need for survival (such as land, forest, pastures, water (See Chapter 2 for a further discussion on livelihoods analysis).

6 "We are the World" was the famous song that led campaigns to support rural Africa during the serious drought in 1983/85. While, in Sudan, the Sudan Call campaign was launched by local NGOs in 1984 to support drought-stricken areas.

${ }^{7}$ It is a derived need because energy is used to achieve other desired objectives, and so the need for energy is derived from wanting to meet these objectives. For example, the need to pump a certain volume of water determines the type and quantity of energy needed. So, energy needs are derived from the tasks to be performed.
} 
commodities is seen as just a burden on the energy bill and hence the exclusion of their energy needs in planning the energy sector becomes economically justifiable. The consequences of such exclusion, together with other factors, are the low economic and social investments in the rural areas. These low investments force rural people to rely on natural resources for meeting their livelihood needs. Since natural resources often fail to provide the services needed by the rural people, conflicts and civil strife over the control of the available natural resources arise (IFAD, 2004). Such problems can be seen in rural Sudan, such as the current conflicts in Darfur which to an extent originated over the control of natural resources by different groups; such as animal herders against cultivators, and nomads against the fixed population (Young et al., 2005).

Moving from the general to the particular of energy sector planning, Section 1.3 describes how the objectives for the energy sector planning in Sudan were derived, which energy related problems were identified, and how the energy data used for planning were obtained. Issues raised in that section are seen as providing the basis for rural exclusion specifically linked to energy sector planning. Emphasis is given to the approaches used in the investigation and analysis of energy needs (data identification, collection and assembling) for energy planning. The shortcomings of the investigation and analysis are demonstrated. Then, an alternative is introduced in Section 1.4 which is considered to provide a more holistic view of rural energy problems and hence could provide a firmer foundation on which to base energy planning. The research problem is formulated in Section 1.5 and, subsequently, the research objective and question are presented in Section 1.6 based on the proceeding sections .

\subsection{Background to the Sudan context}

Sudan is a vast country with an area of 2.5 million square kilometres, roughly equal to one quarter of the land mass of the whole of Europe. The estimated population in 2008 is 38 million $^{8}$.

Across its vast area, the climate of Sudan varies widely from an extreme dry desert region in the north to a tropical region (with high rainfall) in the south. The result of this variation in temperature and rainfall is the existence of five main ecological zones with different levels of rainfall, temperature, and vegetation: the desert zone, the semidesert zone, the low rainfall zone, the high rainfall zone, and the flood plain zone (Harrison and Jackson, 1958). These major ecological zones are further divided into sub-zones with some variation in ecological characteristics due to soil types, land slopes, and undulation (Map 1.1). Additionally, the ecology of Sudan is affected by the River Nile and its tributaries which traverse the country from south to north. The White Nile and the Blue Nile meet just north of Khartoum to form the River Nile, which is then joined by the River Atbara further north, and heads north crossing the desert and through Egypt to end by flowing into the Mediterranean Sea. Further, there are several seasonal streams that flow into these major rivers. As shown on Map 1.2,

\footnotetext{
${ }^{8}$ The last population census was carried out in 1993 which suggested a total population of around 26 million and a growth rate of $2.6 \%$. The estimated current population is extrapolated from these figures.
} 
all the selected villages for this study lie within the semi-desert zone (see also Section 2.12 in the next chapter).

The ecological variation has linkages to the availability, transformation, and accessibility of biomass energy resources (woodfuel ${ }^{9}$, crop residues, animal dung) which provides about $71 \%$ of the total household energy consumption in Sudan (FAO, 1994). These UN Food and Agricultural Organisation's (FAO) estimates were carried out before the exploitation of Sudan's oil reserve started and this is expected to make LPG and other petroleum products available and change the proportion of biomass sources in the total energy consumption of Sudan. The various ecological zones have different stocks of biomass energy resources. A clear example is the lack of woody and other biomass fuels in the desert, semi desert and low rainfall zones, in contrast with their abundance in the high rainfall and the flood plain zones. These deficit/abundance differences influence the cost of biomass energy resources and their accessibility. There is a high monetary cost involved for the people in the deficit zones, whereas biomass is freely accessible to people in the abundant zones. Similarly, other services also differ between the zones. For example, water is scarce in the desert, semi-desert, and low rainfall zones and this leads to high energy inputs to harness the water sources for services (drawing/pumping from deep wells, transporting water from faraway areas). In the other zones, water is abundant (on the surface as running streams) and requires little effort to convert sources into services.

This variation in ecological conditions across the country results in diverse population densities, economic activities, and modes of living. Although Sudan has a relatively low population density the population distribution shows wide variations across the ecological zones. The population density is highest in the acacia wooded grassland and bushland zones with between 25 and 64 inhabitants $/ \mathrm{km}^{2}$ while, in the desert and other zones, the density ranges from 2 to 20 inhabitants $/ \mathrm{km}^{2}$. Economic activities also vary among climatic zones. Modern agriculture (irrigated and mechanized) is found along the rivers and in high rainfall zones whereas traditional agriculture (rain-fed crop production and animal grazing) is confined to low rainfall, semi-desert and desert zones. The ways of living vary widely among rural and urban population groups. Further, within each group there are large variations in terms of livelihoods depending on the means of production. This is particularly so within rural areas which can be subdivided into those with market-oriented modes of production (modern agriculture) and those based on subsistence production (traditional agriculture).

This diversity suggests that a flexible framework is required for energy planning in order to capture the energy needs derived from such variations in ecological zones, economic activities and ways of living. Hence, in this study, a holistic framework (Section 2.2) is used to capture and to present some of these diversities from multiple case studies in six villages (shown on Map 1.2). The six villages are located within three states: the Nile State, the Gedarif State, and the North Kordofan State. These three states include different ecological sub-zones. Moving from north to south, the Nile State starts with absolute desert in the north followed by a sub-zone of desert dunes without perennial cover $^{10}$ and ends in its southern part with a sub-zone of semi-

\footnotetext{
${ }^{9}$ Wood fuels is the term used for fuelwood and charcoal.

${ }^{10}$ The ecological sub-zones are taken from Map 1.1 which is reproduced directly from the source. The legend contains the sub-zone "desert dunes without perennials". For ease of reading the text, the word “cover” has been added after "perennials”.
} 
desert land and shrubland. Further, the state is intersected by both the River Nile and the River Atbara as well as small seasonal streams that create strips with different sub-ecological settings (see pictures in Annexes 7.3 and 7.4). The Gedarif State also includes different sub-zones: semi-desert and shrubland in its northern part moving to acacia wooded grassland and bushland, and ending with a transition from woodland to bushland in its southern part. The North Kordofan State extends from a sub-zone of desert dunes without perennial cover in its north-western part, through to semi-desert grassland and shrubland, acacia wooded grassland and bushland, woodland, transition woodland to bushland and pockets of edaphic grassland mosaics with trees. The locations of the six villages reflect some of these ecological diversities (see Annex 7 for detailed descriptions of the ecology). Dar Mali is located along the Nile in the desert dunes without perennial cover sub-zone, and Goz El Halag is located along the River Atbara within the semi-desert land and shrubland sub-zone. Es Sadda and El Idied are located within the semi-desert and shrubland, and acacia grassland and bushland sub-zones respectively. Um Laham and El Ga'a are located within the acacia grassland and bushland, and the semi-desert and shrubland sub-zones respectively.

Map 1.1

Climate and vegetation regions of Sudan

$\square$ Absolute desert

$\square$ Desert dunes without perennial

$\square$ Semi-desert grassland and shrubland

$\square$ Acacia wooded grassland and bushland

$\square$ Woodland

Edaphic grassland mosaics with trees

Transition woodland to bushland

Grassland with semi-aquatic vegetation

Mosaic of lowland rainforest and grassland

$\square$ Deciduous bushland and thicket

Sahelmontane vegetation

Source: FAO 2003

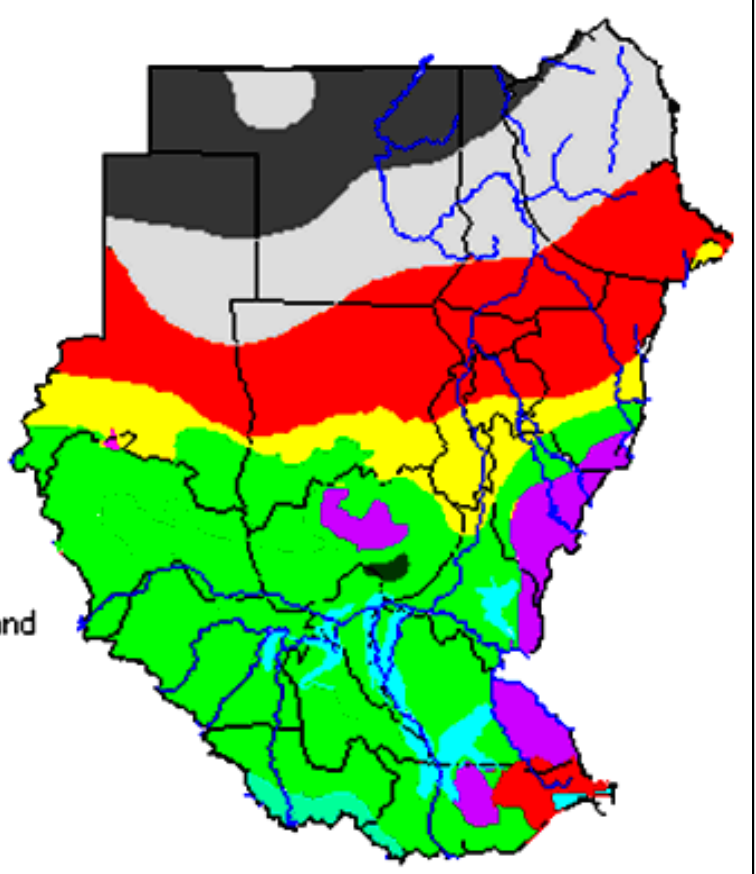




\subsubsection{Political background}

Sudan obtained its independence from Britain in 1956. Since then, Sudan has continuously exhibited political instability with frequent civil unrest in several parts of the country. Another factor contributing to political instability is the frequent change of government system. Since independence, Sudan has witnessed dramatic changes in its ruling systems. The parliamentary government formed after independence was quickly overthrown by a military coup in 1958, and this ended in 1964 through popular opposition when a second civilian democratic government was formed. This civilian government was terminated by a military coup in 1969. Again, this military system ended in a popular uprising in 1985 and was replaced by a civilian government in 1986 which, in turn, also ended in 1989 by a third military coup. This military regime is still in power at the time of writing. However, many changes have occurred since 1989. Perhaps the most significant of these changes have been the gradual move towards civilian government, the formation of a federal system, and the sharing of wealth and power with other parties after the Comprehensive Peace Agreement (CPA) was signed on January 9, 2005 between the government and the opposition in the South.

Besides the political instability in the central government system, Sudan has also experienced internal conflicts and instabilities in several regions of the country. The long-lasting conflict in Southern Sudan ${ }^{11}$, (1955 -2005), and the recent conflicts in Darfur and in the eastern region have added to the country's instability. However, the CPA which ended the southern conflict can be used as a model framework, together with the protocols for wealth and power sharing, to help solve problems in the other regions of conflict. The political background will be discussed further in Chapter 3 where the practice of sharing political power and the economic wealth of the country will be stressed as a mechanism for ending the exclusion of rural communities through the application of participatory approaches to define rural goals and objectives. Such an approach is central to this thesis, since participation is seen as a mechanism for more equitable planning in the energy sector in Sudan.

\subsubsection{Economic development}

Agriculture underpins the economy of Sudan: it contributes about $40 \%$ of the Gross Domestic Product (GDP) and provides employment for about $80 \%$ of the population (World Bank, 2003). Agriculture in Sudan can be divided into two sub-sectors. First the modern sub-sector (large irrigated schemes and large rainfed mechanized schemes) which uses modern technology to carry out farming operations and other services. Further, a finance system exists to facilitate the purchase of equipment and a scientific administration to conduct appropriate research and to use resources efficiently. Irrigated schemes are located along the Blue Nile, the White Nile and the Atbara river ${ }^{12}$ and the mechanized rainfed schemes are located in areas of high rainfall south of the acacia wooded grassland and bushland (see Map 1.1). Second, the traditional sub-sector which is found widely and is based on manual operations, with a high dependence on the natural environment for services and very little use of

\footnotetext{
${ }^{11}$ The Southern Sudan conflict started in 1955 and was ended in 1972 by the Addis Ababa Peace Agreement only to erupt again in 1983. It was finally ended by the Machakus Peace Agreement in 2005.

${ }^{12}$ The irrigated schemes consist of the cotton schemes of Geziera, Rahad, and New Halfa, and the sugar schemes of Sennar, Gumied, Assalya, and Kenana.
} 
technology (Abu Sin and El Samani, 1987). Accurate data on the contributions of the modern and traditional sub-sectors are not available since the last agriculture census was carried out in 1968 and the last national household income survey was carried out in 1978 (World Bank, 2003). Estimates suggest that their contributions to GDP are 27 $\%$ for the modern agriculture sub-sector and $13 \%$ for the traditional agriculture subsector (World Bank, 2003). However, it is important to note that the modern sector is not fully mechanized as there are still some tasks that require manual labour, for example weeding, cotton picking, chopping of sugar cane, cutting and threshing of dura $^{13}$ (Sorghum). The modern sector also has an effect on the traditional subsector by drawing its labour force from this sub-sector. This has implications for the energy available from human capital ${ }^{14}$, particularly when able-bodied men migrate seasonally to the modern sub-sector. The groups who cannot migrate (women, children and the elderly) become responsible for the provision of energy services (drawing water, collecting cooking fuel and farm operations) using their own energy or animal power.

The expansion of the modern sub-sector with the aim of replacing the traditional one can be traced back to the colonial period from 1898 to 1956. After independence, in 1956, the same mode of modernization continued under successive national governments. The creation of the modern sub-sector is widely supported by international development agencies for its potential to improving the country's economic performance through increasing exports and, hence, increasing the hard currency earnings, improve the balance of payments and generating employment opportunities. It is apparent that national and international actors have wanted an end to traditional agriculture over a considerable period of time. For example, the World Bank stated in one of its reports to the Sudan government that:

"Argument as whether or not in national planning 'priority should be given to traditional agriculture' is perhaps sterile” (World Bank, 1979: 14).

This report of the World Bank further argued that traditional agriculture had no contribution to make to the country's export commodities and hence it had no role in solving problems linked to low hard currency earnings, the huge deficit in the balance of payments, and had no potential to generate waged employment which is a necessity for a market economy. Thus, the inclusion of traditional agriculture in national planning could not be justified in economic terms. Therefore, Sudan's agricultural development objective has been to favour export-oriented large-scale agriculture to replace the subsistence small-scale traditional agriculture (Gore, 1984: 431).

These views were largely shared by national government officials. Alier ${ }^{15}$, the vicepresident from 1973 to 1984, addressing local people in the Sud Areas, stated that:

\footnotetext{
${ }^{13}$ The dura crop is harvested manually due to the irregularity in height of the common and also the preferred dura varieties in Sudan. This irregularity makes combine harvesters unsuitable, and thus ears of the dura crop are cut, collected, and threshed manually.

${ }^{14}$ Human capital refers to skills, knowledge, ability to work and good health (see footnote 4 and Chapter 2).

${ }^{15}$ Abiel Alier made the statement quoted to reduce the tension aroused after starting the excavation of the Jungli canal in the swamp area along the White Nile. The Jungli canal was expected to provide large quantities of water for irrigated agriculture through channelling all the swamp water to the canal and hence reduce losses due to evaporation. That objective was pushed against the traditional use of the swamps for rice production, grazing and fishing activities pursued by the local people in the area.
} 
"We have elected to enter into the modern economy in preference to the subsistence tribal economy” (quoted in Lako, 1988: 28).

Map 1.2

\section{Locations of villages selected for this study}

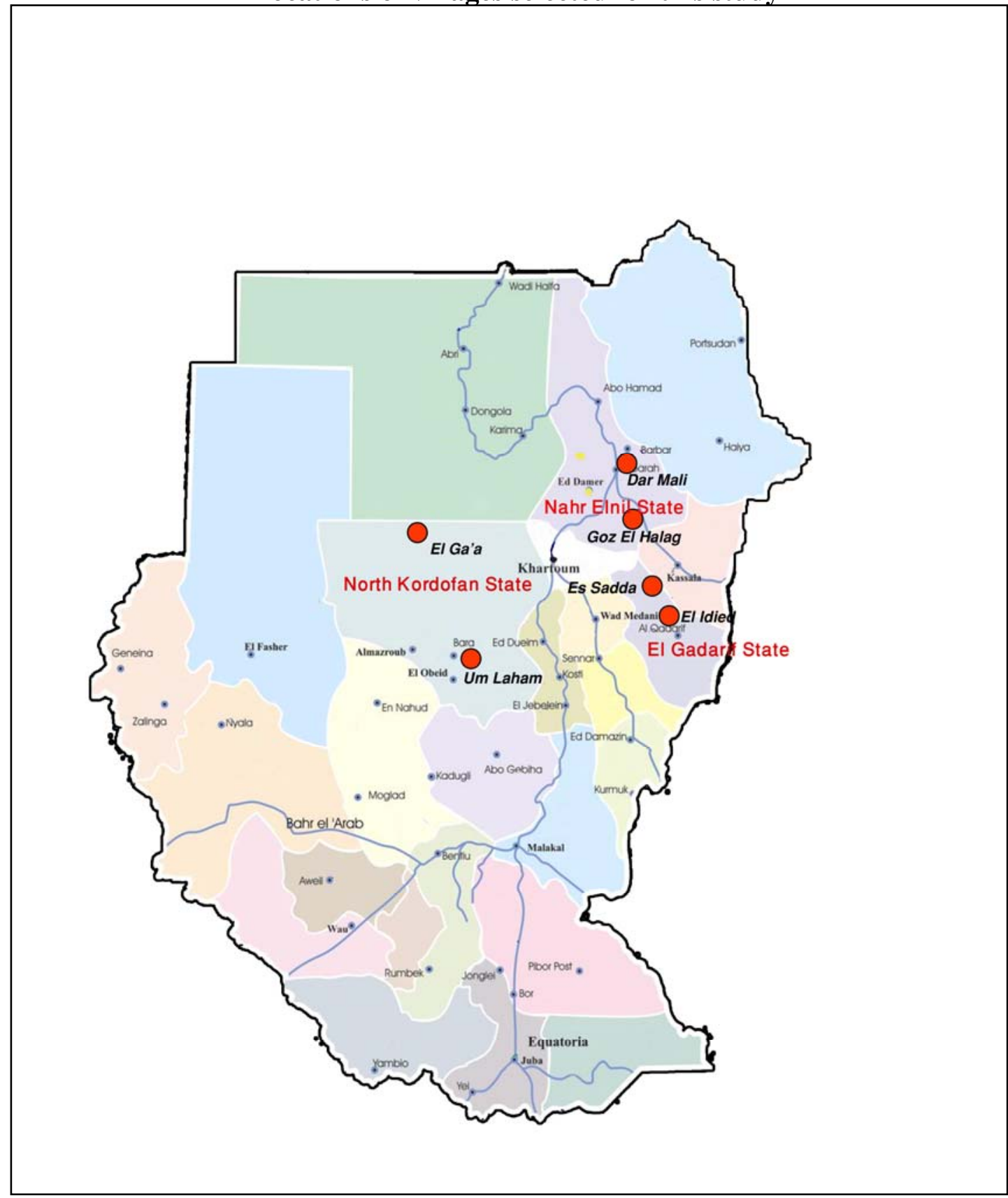

Modernization in Sudan was often accompanied by the confiscation of tribal land, and changes to the traditional land tenure systems, forcing local people into tenancy production systems and pushing the majority of them onto more marginal lands to carry out their traditional practices. This is particularly true in those areas that have been designated for mechanized agriculture where land has been allocated to agricultural investors, who are often from outside the area of the project. Two contradictory effects of the clearance of natural forest areas for mechanized farming 
on the availability of wood fuels might be expected. In the long run, the clearance of large areas for mechanized agriculture negatively affects the supply of wood fuels. However, in the short term, such clearances increase the supply of fuelwood, particularly for urban centres. The cleared wood is either directly sold by scheme owners or used to produce charcoal. This double effect illustrates well the point that without good time series data, that can explain the exact situation and its causes, energy planners might misinterpret the situation and believe that wood fuel supply is sufficient to meet needs.

Spatially, modern agriculture is confined to only a small portion of the country ${ }^{16}$ and has benefited relatively few of the population. Irrigated agriculture is estimated to provide a permanent livelihood for about 1.5 million people who also have access to some necessary services such as clean drinking water, health services, education and communications facilities (Abd Alla, 1995: 17). Given the lack of recent statistics on the movement of the population between the agriculture sectors due to war, other civil conflicts, and drought the current situation cannot be verified.

In the mid-1990s, the role of agriculture within the economy started to diminish with the start of the exploitation and export of oil, which made significant differences to the profile of export commodities and their contribution to hard currency earnings ${ }^{17}$. Since 1996, Sudan is moving from an oil importing country to one that is selfsufficient in all oil products, and then to become an oil exporting one. Significant impacts on the Sudanese economy due to the exploitation of the oil are observed. The economic growth rate, for example, increased from 3.8\% during the period 1990 to 1995 to 6.6\% during the period 1996 to 2000 (World Bank, 2003). Data from the Joint Assessment Mission (JAM, 2005: 17) estimated that the economic growth rate exceeded $8.5 \%$ in 2004. Meanwhile, the support for modern agriculture continued under the policy of increasing the contribution of non-oil export commodities by rehabilitating the existing schemes and enhancing their performance. However, the traditional sector and the traditional mode of living continue to remain outside the focus of support from national policies. A World Bank report from 2003, contrary to its earlier statement made in the late 1970s, summarized the economic situation as follows:

"The economy of Sudan continued to be characterized by large regional differences as well as differences between the modern and the traditional sectors. Investments and development efforts after Independence did not target the poorest regions. In the absence of peace, which would permit a more even-handed response to the regional inequalities, and with the severe erosion of the capability of the public sector to help the weaker regions and sectors out of their predicament these inequalities are likely to persist for some time and perhaps continue to fuel conflicts.” (World Bank, 2003: 29).

\footnotetext{
${ }^{16}$ All Sudan's large-scale irrigated sector is using water from the Blue Nile, the White Nile or the Atbara River. Thus, geographically, the modern agriculture schemes have been concentrated in central Sudan where about $96 \%$ of the total irrigated area is found and the rest is found along the northern part of the River Nile (calculated from Abu Sin, 2001:29). The mechanized rainfed agriculture which represents another form of agricultural modernization is also concentrated in central Sudan (about $70 \%$ of the area) with the remainder found in eastern and western Sudan.

${ }^{17}$ Bank of Sudan Reports 2000 to 2003.
} 
Therefore, to what extent has modernization of agriculture benefited all of the people of Sudan? Central to this thesis is the premise that modernization, as pursued in Sudan, has disadvantaged the traditional sub-sector and increased inequalities between the traditional and modern sub-sectors in access to energy services. There is no doubt in terms of contribution to GDP, there have been positive signs. Before the exploitation of oil in Sudan began in 1996, irrigated and mechanized agriculture contributed more than $40 \%$ of the GDP and about 90\% of Sudan's exported commodities, mainly cotton (World Bank, 2003). Modernization of agricultural practices is also accompanied by changes in other aspects of rural life. Modernization, particularly for people living in areas targeted for modern agriculture, brings potentially better health care, education and reduced drudgery, all of which are linked to increased inputs of modern energy sources. Increased incomes can be used to improve standards of living including the purchase of modern energy sources. But not all the changes are positive and welcomed by everyone in Sudan. There are a series of problems generated by the mode and processes of development followed so far in Sudan which continue to accumulate. Some of the unplanned consequences of modernization in rural Sudan that are closely linked to the theme of this thesis include:

A shift in the purpose of agricultural production from meeting the needs of local people (food crops and fodder) and their traditional practices, to production for export and meeting the needs of external markets (cash crops) (Ahmed, 2002). Due to the expansion of modern agricultural schemes, traditional food production and subsistence activities were forced into marginal areas. This led to a situation in which rural people practising traditional agriculture were not able to produce sufficient food and agricultural residues for use as fuels, lacked enough pasture for their animal to graze, and lacked water and fuel wood in the areas where they were forced to relocate. Thus, rural people depending for their livelihoods on traditional practises have been shifted to more marginal areas where energy services cannot easily be accessed.

The creation of landless, wage labourers when the communal land in the traditional economies is converted to private ownership with few large farms. According to Duffield (1990), this planned commercial development started in the 1960s, and led to the existence of a fragile market for both labour and commodities and a high social differentiation within Sudanese society. This lead to other consequences including the incapacity of the market to provide needed services. There is no market for services; there is no technology to harness other sources at services to compensate for the once naturally obtained ones. In particular, this lack of a market for rural energy services can be seen clearly in some of the case study villages that form part of this thesis (Annexes 1, 2 and 5). In villages like Es Sadda, El Idied and Um Laham there is no local market for energy carriers such as diesel fuel and LPG.

The creation of seasonal migration from traditional agriculture to serve the modern sector. An International Labour Organisation (ILO) labour market survey, carried out in 1982 (quoted in Abu Sin and El Samani, 1987), estimated that migrant labour accounts for $80 \%$ of total labour requirements in the modern sub-sector and only $20 \%$ is met from local family labour. The 
seasonal migrant labourers work for periods ranging from 6 to 9 months each year, resulting in an increased number of woman-headed households. Some studies estimate that 24 to $26 \%$ of rural households have women as the head (Abdel Ati ed., 2001). This can be viewed as a loss of able-bodied male family members and a reduction in the workforce needed to maintain rural life, as well as leaving responsibilities with people less able to respond due to a lack of capacity for example, no land ownership, poorer education, weak political power.

The eruption of civil unrest in many parts of the country resulting from discontent with the management of the economy and the path of development which resulted in unbalanced development between regions. The regions of unrest (the Southern region, Darfur region and Eastern region) lie far away from the centres of modern agriculture. This unrest and the increased tensions between rural societies can also be partially linked to the lack of energy services in the fragile rural environment. Displaced people find themselves in conflict with other local communities over access to water, fuel, and grazing pastures from resource-depleted areas (ed. Mustafa and Mahadi, 2004). For instance the competition over resources between nomadic animal herders and sedentary farmers triggered the conflict in Darfur (Young et al., 2005).

Modernization of the agriculture sector is based upon irrigation and mechanization. Both of these techniques need large quantities of modern energy carriers (electricity, diesel and petrol) and energy infrastructure and delivery systems (roads and railways for transportation, storage capacity and extension of the electrical grid). Providing these modern energy services for the modern agriculture sub-sector remains a major priority in all the energy sector plans of the government and the international agencies that fund development programmes and projects in Sudan (see Section 3.4.2). This in turn has led to an unequal allocation of the benefits from energy planning between areas relaying on traditional practices.

So far, the problem of development in Sudan has been presented as one of spatial exclusion whereby the regions where traditional agriculture dominates are less favoured with modern forms of energy than the regions where modern agriculture dominates. Also important, particularly for this thesis, is how energy planning in Sudan excludes specific components of the energy sector such as the supply of traditional energy sources ${ }^{18}$ and the services that these traditional energy sources provide. The consequences of this exclusion for people living in those traditional areas, who are vulnerable to changes in their fragile natural environment, involves living with uncertainty about access to energy services such as water, food, and fuel. The next section describes the energy planning process in Sudan and how it excludes those obtaining their livelihoods in the areas practicing traditional agriculture.

\subsection{Energy planning in Sudan}

The formulation of an energy plan requires several steps to be taken systematically. However, there is no standard agreed format on how to carry out energy planning but,

\footnotetext{
${ }^{18}$ Traditional energy sources are defined as biomass, human and animal muscles.
} 
by way of illustration, the following steps can be considered to be representative (Cirillo, 1982: 1):

1. define the goals and objective of the plan
2. determine the approach to be taken
3. identify the information needed for the planning process
4. chose the analysis process
5. conduct the analysis
6. present the result to decision-makers
7. prepare the energy plan

In this process of planning, the contents of the plan are formulated and are meant to inform decision-makers about the existing energy situation, as well as trends and constraints, to ensure that courses of actions that meet goals and objectives can be set in the early stages of the planning cycle (usually in response to policies (ibid.)). So, here, the notion of energy, as a derived need, involves the definition of energy goals and objectives, made in order to meet higher objectives often defined in terms of economic, social, or environmental objectives. Examples of the type of questions to be answered include: how much energy is needed to produce one ton of export commodities? How much energy is needed to achieve a certain level of welfare? Or which type of alternative energy sources are needed to preserve forests? These higher objectives are set outside the energy sector and so the energy sector has to plan to meet the energy demands of these external objectives. Thus, those who set the higher objectives determine the routes followed in the energy planning processes.

As in many other developing countries, energy planning in Sudan started in the early 1980s with assistance from the international development agencies, particularly the World Bank and the United Nations Development Program (UNDP) which carried out an assessment in a number of developing countries including Sudan. ${ }^{19}$ Sudan: Energy Assessment Report was prepared in 1982 by the joint UNDP/World Bank's energy assessment mission who visited Sudan during November and December 1982, and Sudan: Issues and Options in the Energy sector report was prepared in July 1983 by a team from the World Bank's Energy Sector Management Assistance Program (ESMAP). These two reports were taken as terms of reference in preparing the National Energy Plan 1985-2000. The World Bank and UNDP ignored the rural situation in the traditional areas which led to the formulation of a national energy plan which met only the needs of the modern sector. An objective in energy planning is to identify and quantify the linkages between macro-economic aggregates (GDP and balance of payments) and energy, as well as providing a balance for various energy supply sources (petroleum, electricity, and biomass) for different sectors (agriculture, transport, industry and household). However, in the above-mentioned reports only the

\footnotetext{
${ }^{19}$ Energy assessments for planning purposes in developing countries were initiated in the 1980s and led by joint UNDP/World Bank programmes to assist national governments in tackling energy problems. Two programmes were initiated for this purpose. The first was the Energy Sector Assessment Program which was established in 1981 to identify energy-related problems in developing countries and to formulate specific recommendations to help solving them. Accordingly, a series of country reports were published under a common title (Country: Energy Assessment Report). The second was the Energy Sector Management Assistant Program (ESMAP) which was established in 1983 to help developing countries implement the recommendations formulated in the Energy Assessment Reports. To ensure the efficient use of resources, the energy assessment reports were each complemented by another report prepared by ESMAP (Country: Issues and Options in the Energy Sector). These two types of report were prepared for many developing countries and helped set the terms of reference for energy planning in developing countries.
} 
supply data were investigated. The data were used to build an energy data system (EDS) on which energy planning was to be based. Crucially, the EDS and the derived objectives for energy planning have formed the basis from which all the succeeding energy plans to date in Sudan have been derived. One example is the five-year plan for energy investment (1985 to 1990) which was derived from the National Energy Plan (1985-2000). This five-year plan was halted in 1989 when the government was overthrown in a military coup and there was an immediate halt to finance from the international community (see also Section 3.3.1). Following the change in government, the overall National Energy Plan was then replaced by the Comprehensive National Strategy (CNS)(1992 to 2002) which was divided into three energy investment programmes: the First Salvation Programme (1992 to 1995), the Second Salvation Programme (1995 to 1998), and the Third Salvation Programme 1998 to 2001). The Second Salvation Programme was also accompanied by liberalization policies which changed the channels of delivery of energy services from those of the government (direct allocation through quotas and public corporations) to the private sector (market mechanisms). The CNS was followed by the Quartercentury Strategy (2003 to 2027) to lead investment and activities in the energy sector from which a three year programme (2003 to 2005) was first formulated and then followed by a five year plan (2006 to 2011) which continues to date. Despite all these changes in the formulation of different energy plans and programs their objectives remained the same and there was still no clear involvement of traditional rural areas in the contents of the plans.

The approach used to build up the EDS was not explicitly mentioned in any stage of the CNS, but elements of the data presented closely resemble that of the approach contained in the rural energy planning manual of the Asian and Pacific Development Centre (APDC). In this manual, the identified and collected data are analyzed and presented in certain tabulations and diagrammatic forms. Three ways are used in analysing and presenting data to form the national energy accounts: Reference Energy System (RES), the Energy Commodity Account (ECA) and the Overall Energy Balance (OEB). The data are presented disaggregated by economic sectors (EAC and OEB) or by energy source (RES). These frameworks present energy data on an annual basis to reflect any changes in supply and end uses. The impacts of these changes on the economy can be estimated, and ways to respond to these changes can then be identified and acted upon. What is important to note is that the authors of the APDC manual clearly recommended the exclusion of traditional energy data from the national accounts used in building the EDS:

"Even though traditional and animate energy sources are of very great importance in all developing countries (and estimated to account for 50 percent or more of total use in many countries) it is recommended that such energy supply and use should be excluded from the main tabulations of data in the EDS." (Codoni, Park and Ramani, 1985: 41)

The main argument for this exclusion is that data for traditional economies is unreliable. Data on biomass energy, for example, suffers from many factors of unreliability. These include a lack of standard measures to quantify the amounts of energy supplied. Traditional sources are often measured in terms of a "bundle" or "donkey load" and converting these into standard measures is an approximation with a significant degree of inaccuracy. Another point the above authors make is that most 
of the energy used has no agreed procedures for quantification, including animate energy. Therefore, inclusion of traditional energy sources, it was argued, would lead to distortions in the energy data system and hence would not serve the main purposes of the EDS which is to clearly reflect a country's energy situation to policymakers and planners. The authors continued their arguments against the inclusion of traditional energy as follows:

This is because information on traditional and animate energy is very much less reliable than that on the so called 'commercial' sources ${ }^{20}$. The effect of including all sources of energy as integral part of the EDS would be to superimpose a huge magnitude of uncertain size on better documented figures thereby reducing the apparent significance of levels, trends and changes in commercial energy supplies, transformation and uses." (ibid.: 41).

However, the UNDP presents another type of rural energy model in which different energy resources are grouped under a supply sub-system which includes traditional energy sources (cow dung, crop residues and fuelwood), commercial energy resources (charcoal, coal/coke, kerosene, electricity and diesel), animate energy resources (animal power) and renewable energy (wind and solar) (ibid.: Table 6.1 Energy supply subsystem: 125). The first observation on the model is that although it includes one of the traditional sources, rejected by APDC, it does not account for energy provided by human labour. Exclusion of human labour in rural areas effectively omits various essential tasks performed by manual labour in agricultural operations and so opportunities for substitution are missed and energy demand is under-estimated.

The UNDP rural energy model tries to overcome the problems of calculating the traditional energy sources by converting them into a secondary energy source (electricity) through conversion technologies such as biogas plants, wood gasifier plants and electricity generator sets. Finally, the primary energy from all the supply sources is converted into energy services ${ }^{21}$ (defined as cooking, water heating, lighting, pumping, land preparation, threshing and transportation) (ibid.: 131). The application of the UNDP model produces an RES at the village level which provides a potential way of reflecting rural energy data at village level which is an advantage over the APDC model. However, the UNDP model has three weaknesses in providing data for rural energy planning. Firstly, it does not account for energy provided by human labour which is an important energy source, particularly in agricultural operations. Secondly the UNDP model assumes that the conversion technologies are readily available for use in rural areas which is largely not true, at least not in Sudan. Thirdly, not all tasks in rural areas can be carried out by electrically-powered devices. Moreover, in rural villages, including those in Sudan, there are considerable energy services provided by human labour (water drawing, fetching and carrying of fuel wood) which are highly differentiated by gender and age. These important inputs of human labour and their gender and age differentiations are not reflected in the UNDP

\footnotetext{
${ }^{20}$ Commercial energy sources is a term often used to denote sources of energy that are purchased in the market and have monetary value such as petroleum products, electricity and some forms of biomass sources such as charcoal and fuelwood. The balance to commercial energy sources is traditional energy sources which are sources of energy that are freely collected, often in rural areas, such as fuelwood, dung and crop residues.

${ }^{21}$ UNDP uses the term "useful energy demand."
} 
model. These weaknesses make the UNDP model incapable of fully reflecting the energy situation in a Sudanese rural village. Therefore, the UNDP model will not be sufficient in providing a holistic approach to energy planning to ensure that rural and traditional areas in Sudan also benefit from national energy plans.

The application of what can be described as the "APDC approach", in developing the EDS for energy planning in Sudan, distracted the attention of planners and policy makers away from rural energy needs and priorities. Some of the reasons for this can be attributed to firstly, the fact that energy planning derives its overall objective from national and macro-indicators (for example GDP, hard currency earning and balance of payments) which are not sensitive to traditional and subsistence modes of livelihoods pursued in many parts of Sudan. Secondly, the identified parameters used as indicators for the energy sector performance (per capita energy consumption, energy sector efficiency and effectiveness) are all aggregates of national energy figures and thus do not reflect local rural specificity. Thirdly, the data were collected without any direct contact with the rural community. Without such contact there cannot be a complete understanding of rural livelihoods and their needs. Fourthly, the data themselves suffered from inaccuracies and were generally gathered for purposes other than energy planning. Fifthly, data were presented in a way (as aggregate sector and national energy balances) that disguised much of the specificity and diversity of rural life in Sudan. The result was that rural energy needs that are crucial for rural livelihoods were not made visible to planners and decision makers responsible for planning in the energy sector. The following extract from the National Energy Plan (1985 to 2000) shows that rural energy problems were reduced to only the shortage of fuelwood for cooking services and ignored other important energy services in rural areas such as providing for water.

"As a result of shortage, drivers of cars and lorries waste hours queuing for benzene and gasoline; businessmen see machines and workers idle when electricity is shut off; farmers watch crops dry up when there is no electricity or gas oil for irrigation pumps; consumers' appliances are damaged by erratic electricity; rural poor spent more and more time looking for wood; and urban dwellers spent more and more of their income on buying charcoal” (National Energy Plan, 1985: 2).

The choices of objectives and the prioritization of plans have continued to lead planning and investment in the energy sector. The Quarter-century Strategy (2003 to 2027) prepared by the National Council for Strategic Planning in 2002 also put a clear emphasis on the role of the modern energy sector. It stated as a policy for the electricity sub-sector: "to direct what is available from the electrical supply to the productive sectors: agriculture and industry" (The National Council for Strategic Planning, 2002).

What then about other rural services, such as water pumping, lighting, transportation, and productive operations? They are simply ignored and missed. Ignorance about these services can be partially attributed to the way the units of observation and analysis are chosen for energy investigations which are dominated by households and the specific fuel types used by households. The following definition of a household, when used as the unit of observation, clearly shows how problems of rural energy are easily reduced to a single focus.

The FAO defines “a household” in this respect as: 
"A household may be considered as a group of people who share the same cooking facilities.” (FAO, 1983: 92).

Accordingly, a FAO household energy survey includes five subheadings: (a) background (b) cooking (c) stoves (d) fuel and (e) local material and technology. The focus on the household alone detaches the rural energy problem from its whole context of complex interrelationships between the ecological, the social and the economic settings. Such a limited focus is also to be found in the African Development Bank's report on 'Household energy consumption pattern in Africa' which presents a modified form of the FAO definition. This report also failed to see any energy problems beyond the kitchen:

"The household is here defined as a group of individuals with or without family ties, living under the same roof, taking their meals together, pooling their financial resources for the welfare of the whole group and generally acting under the same authority. With this understanding one-person households are excluded and collective households are retained.” (African Development Bank, 1996: 11).

When rural energy problems are identified solely on the basis of the household as a holistic entity, a number of issues and factors will be overlooked. Such an approach misses social differentiations, particularly those based on gender and age, in the provision and use of fuel for cooking in the household. It does not reflect any differential role of men and women, or old and young groups, in the provision of fuel or the processes of cooking both within and between households. Issues such as who answers the questionnaires used for data gathering and what language is used present other problems. Household energy survey questionnaires are often completed based on interviews with only the male heads of households. Such interviews about household energy services, activities and practices, which are generally the responsibility of women, calls into question the reliability of the data (Moser and Kalton, 1979).

When the rural household is the only unit of observation, only data about the fuel types used for cooking, cooking stoves and cooking processes will be collected. However, even though cooking is an essential service, rural households require other energy services. Reducing rural energy problems to one of fuel wood simply misses the full range of problems in rural areas. Barnett has made a similar criticism that rural energy projects tend to focus on cooking and lighting rather than on providing energy for productive uses which would enable households to generate income and hence break out of their "vicious circle of energy poverty" by being able to buy needed energy services (Barnett, 2000). This is particularly true in rural Sudan where people are vulnerable to natural disasters and the production of food in itself is a problem, not only the need of energy to cook it.

One way to move beyond this reductionism is for rural energy investigators to walk out of the kitchen and observe other rural activities that require an energy input such as farms, local industries and social services. Such a shift to a broader unit of observation would allow the capture of the full range of desired energy services by extending the boundaries for where observations are to be made. After determining where observations are to be made the question becomes: what should be observed? 
This crucial question can be addressed again by broadening the unit of analysis to one of 'energy services' rather than fuel sources or types. An 'energy service' is defined as:

"The desired and useful products, processes or services that result from the use of energy; for example, illumination, comfortable indoor climate, refrigerated storage, transportation, appropriate heat for cooking" (Clancy, Skutsch and Batchelor, 2003:3).

What is important to end-users is the obtained energy service, according to own criteria, regardless of the fuel or processes used. Identifying energy services provides a bottom-up analysis instead of the top-down approach applied in developing the EDS as described above. This alternative approach provides a way to consider the specificities of different services, in different locations, for different groups of users and for the different processes employed in producing these services. In situations like rural Sudan, where people are subject to frequent natural disasters (such as droughts and their consequence) it is important to know how rural energy services are affected by, or provide relief from, such situations.

Another important issue in the analysis of rural energy is the apparent confusion with the terminology, for example the distinction between energy sources and fuels types. In this research, the term 'energy carrier' is used since it is considered to be more inclusive than the term 'fuel' which is generally taken to mean a substance which burns to release energy. An energy carrier is defined as:

" The form in which energy is delivered to the end user, for example, fuels (biomass and fossil fuels), batteries and electricity (grid). The end-user has to make an additional transformation of the energy into a useful form, for example, switching the radio on which converts electricity into sound." (ibid).

Energy carriers can be classified as traditional energy carriers (derived from traditional energy sources such as biomass, animal or human muscles) or modern energy carriers (oil derivatives, natural gas, biogas, electricity and batteries). Central to this thesis (see Chapters 4 and 5 and Annexes 1 to 6 ) is relating the quality of the energy services to the energy carriers used to produce the service, and the resultant livelihoods outcomes (see Section 1.4 below and Section 2.4.1).

There is therefore a need for a framework that is capable of linking the lack of energy services with the vulnerability of rural livelihoods in Sudan which avoids the methodological bias in planning the energy sector, which leads to exclusion, and so create a methodology of inclusion to extend benefits to all Sudanese people. One of the frameworks able to serve this need is the livelihoods framework. The following section describes the main components of the livelihoods framework.

\subsection{Introduction to the livelihoods framework}

The livelihoods framework is a holistic approach used by a number of development agencies (such as DFID, CARE, and OXFAM) as well as a number of academic researchers to integrate all the factors that influence development in one 
comprehensive framework (Carney et al., 1999). The livelihoods framework provides an adaptive and integrative approach and is used as a heuristic tool to understand the links between the various factors that affect the livelihoods of the poor. It starts from the standpoint that the livelihoods of the poor can be threatened by different unfavourable external factors such as shocks (droughts, floods, earthquakes, wars, social unrest, seasonality, which includes seasonal changes in prices, services, climate conditions and diseases) and trends (population, climate and policies) collectively called the vulnerability context, leading to negative livelihood outcomes (displacement, civil unrest and war).

The capacity to cope with, and recover from, these types of situations which increase vulnerability is based upon the interaction of five types of capital assets. These are referred to as human capital, natural capital, physical capital, social capital and financial capital. These assets interact, substitute or supplement each other in various ways to strengthen the capabilities of people to cope with, and recover from, external stresses and shocks. In the livelihoods framework, policies, programmes and plans are termed the transforming structures and processes, which can facilitate or retard the capabilities of livelihoods to cope with and recover from these stresses and shocks. In order to cope with and recover from stresses, poor people follow various strategies combining all the above components together and achieve different outcomes. When the outcomes enable communities to cope and absorb stresses and shocks the livelihoods in that community are said to be constructed on a sustainable basis. The reverse holds true: when the outcomes are the greater disabling of communities coping with and absorbing stresses, that community is said to be vulnerable and constructed on an unsustainable basis (more details of the framework are given in Chapter 2).

\subsection{Research problem}

To transform rural energy services from those based on traditional energy sources to those based on commercial energy sources is hindered by exclusion at two levels. First, there is the spatial exclusion in which rural areas are not targeted for the benefits of national energy planning. Macro-energy policy has a tendency to build a delivery system that ensures the flow of modern energy services to only the modern sector of the economy. Second, there is exclusion during the energy planning exercise. Elements and components of rural energy problems are not included in the conceptual development of the energy data system and hence no data on these aspects are collected. As a result of both levels of exclusion, the energy problems in the rural and traditional sectors are largely ignored and solutions are not sought when energy plans are set up and formulated.

This is shown by the fact that, despite the coincidence of the drought that hit Sudan between 1983 an 1985 and created huge problems in many rural areas, including the disruption of energy services, and the formulation of the national energy plan, the latter made no reference at all to energy supply problems in the rural areas and specifically those affecting the traditional sector. This lack of coverage was caused simply because planners plan to solve the problem they know about and can see based on the available data, and hence can justify including in their plans. The energyrelated problems of rural people in the traditional sector are not identified for planning 
purposes because data are not available. Hence, the plan made no reference to addressing the energy issues of the majority of the rural population. The causes and consequences of this neglect can be illustrated by the truism:

"No data, no visibility; no visibility no interest"

(Huyer and Westholm, 2001, quoted in Clancy, Skutsch and Batchelor, 2003: 6)

Consequently, rural people face a situation in which they lack support from their natural environment (with frequent droughts degrading the basis of their services) and lack support from their national government in terms of planned and built services. Their livelihoods remain vulnerable to natural disasters. Energy-related problems of traditional rural Sudan are not identified as they are not covered by the diagnosis for energy planning. Given this situation, the problem addressed in this thesis is: can the adoption of a holistic view in energy planning ensure the participation of Sudanese society in energy services in a more equitable way?

Four assumptions are made to direct this research as follows:

The negative outcomes in traditional rural livelihoods in Sudan can be linked to disruptions in the flow of energy services caused by factors of vulnerability in those rural areas.

This implicitly leads to the next assumption:

Securing energy services will contribute to ensuring that rural people in Sudan are better able to withstand their vulnerability context.

However, securing rural energy services will not take place under the current energy planning model in Sudan. The current approach excludes not only data on the traditional energy sources but also the energy services these traditional energy sources provide to the rural population. Hence the needs of the majority of the rural population are invisible to energy planners and decision makers. In order to reflect the needs of rural Sudan for energy services in the national energy plans, policies and strategies, a third assumption is that:

The inclusion of rural problems in energy planning can lead to the expansion of modern energy services to rural areas. There is a need to reduce the dependence of rural people, for their energy services, on an unpredictable environment and shift their reliance to more stable and controllable modern energy services.

Finally the fourth assumption made in this thesis is:

This shift can only be attained if both planners and policymakers are convinced of the role of energy services in securing rural livelihoods." 


\subsection{Research questions and objective}

Based on the above-defined problem of the neglect of the traditional rural sector of Sudan in energy planning, and the perceived consequences of that exclusion: the main research question becomes:

"How can energy planning be made more equitable and responsive to energy problems as they relate to rural livelihoods in Sudan?"

With the current exclusion of rural livelihoods from energy sector planning, secure energy services for all of rural Sudan will not happen. The first step towards ending this exclusion is identifying the energy issues of concern to rural people and their livelihoods. This identification can be informative to policymakers and planners in the energy sector in addressing energy services problems in rural areas. Hence, the objective of this research is:

"To identify possible linkages between the rural energy problems and the prevalent rural livelihoods in Sudan in order to contribute to a policy that will potentially be inclusive of rural populations and reduce rural vulnerability".

To answer the main research question, six sub-questions have been formulated to frame the investigation for this research. These sub-questions also form the structure of the chapters in this thesis.

1. "How can problems related to energy services in rural Sudan be investigated such that rural objectives and priorities for energy planning are identified?" (Chapter 2: Research methodology)

2. "How do factors of the vulnerability context disturb the flow of energy services and how does this disturbance affect rural livelihoods outcomes?" (Chapter 3, Section 3.2 The vulnerability context).

3. "Why were energy problems related to traditional rural livelihoods not addressed in national energy planning processes in Sudan?"(Chapter Three, Section 3.3 Transforming structures and processes).

4. "How do local differences affect access to, and priorities for, energy services in rural areas?” (Chapter Four: Access to energy services in rural Sudan).

5. "How can the expansion of modern energy carriers secure the flow of energy services and alleviate negative livelihoods outcomes in rural Sudan?" (Chapter Five: Analytical comparisons of data from the case studies).

6. "How can problems related to rural energy services be included in energy planning processes in Sudan?” (Chapter Six: Conclusion and recommendations). 


\section{Chapter Two: Research methodology}

\subsection{Introduction}

In Chapter 1, it was shown that the traditional rural sector in Sudan is excluded from the national energy planning and remains unserved by modern energy services. Section 1.3 showed that the exclusion of rural energy services stems from the way energy planning exercises are carried out. The methods used in building the energy data system fail to represent the traditional energy sources, which are commonly used in rural areas, and hence the rural energy services provided by these traditional energy sources. Therefore, the contents of the energy plan in Sudan, so far, lack any explicit objectives to serve the traditional way of life in rural areas. This chapter intends to answer Research Question 1, namely:

"How can problems related to energy services in rural Sudan be investigated such that rural objectives and priorities for energy planning are identified?"

To end the state of ignorance about rural energy issues in rural energy planning, rural problems have to become visible to planners in a more convincing way, that is by generating data that can provide a rationale for energy planning to serve the rural areas. This research proposes the use of the livelihoods framework and participatory approaches to capture facts about rural energy and its links to rural livelihoods. The two tools are used in a complementary way, the livelihoods framework enables the identification of energy problems related to rural livelihoods and linkages to other factors, both internal and external to the community, while the participatory approach allows one to represent the diversity of rural livelihoods and the priorities of rural people in terms of energy services. The order of the discussion in this chapter does not follow the historical development of these tools. Historically, the livelihoods framework came after participatory approaches in rural development practice; however, in this thesis, the livelihoods framework is described before the participatory approach. The reason for this lies in the way participation is used in this thesis: participation here is part of the research methodology strategy rather than a development goal. Participation then, in the context of this thesis, is an approach which uses a broad spectrum of tools, applied in a variety of contexts, to meet various purposes. So, practically, the context of its application is defined before choosing suitable tools that enable participation by the identified target group or groups. In this research, the livelihoods framework provides the context in which participation will be applied as a tool for gathering the data identified by the livelihoods framework. Section 2.2 describes the livelihoods framework while section 2.3 reviews some of the criticisms. Section 2.4 discusses the relevance of the livelihoods framework as a heuristic tool for identifying problems and objectives for energy planning that are conducive to supporting rural livelihoods. Section 2.5 elaborates on the link between the stock of energy services and the pentagon of capitals. Section 2.6 outlines the participation paradigm with emphasis on its use as a method for data collection and section 2.7 describes how participatory methods are used in this study. Section 2.8 reviews criticisms of participatory techniques as a data gathering method and how these criticisms are addressed in this study. Section 2.9 discusses the relevance of the livelihoods framework and participatory approaches for use in rural energy planning in Sudan. Section 2.10 examines the complementarity between sustainable 
livelihoods, participatory approaches and energy planning. Section 2.11 explains the rationale for the choice of the unit of observation and the unit of analysis while section 2.12 gives the rationale for the selection of case studies. Sine the research uses qualitative data, the measures taken to ensure the reliability and validity of the data are discussed in Section 2.13. Finally, Section 2.14 concludes the chapter with an answer to the first research question.

\subsection{The livelihoods framework}

The livelihoods framework is primarily used as an analytical tool to improve the understanding of factors affecting poor people living under the stresses of unfavourable natural, social and political conditions or, in other words, those living in vulnerable communities. The significance of such an analytical framework is its capacity to derive objectives for any planned intervention, including those from the energy sector, to secure rural livelihoods, particularly food security, against their vulnerability to changes in their environment and free the rural population from dependence on unpredictable natural resources as the basis for their services. The third underlying assumption in Section 1.3 was the proposition that taking all the factors that influence livelihoods into account would give planners and decisionmakers a more holistic view of the problems facing a group of people living under conditions of vulnerability who, in this thesis, are identified as those people following traditional rural livelihoods in Sudan. As a consequence, decision-makers would be better equipped to identify solutions to these problems and to set priorities which would improve security for rural livelihoods. At the same time, the use of the livelihoods framework in planning can lead to a more equitable distribution of energy sources, and the benefits that arise from them in rural areas.

Deriving objectives for rural energy planning based on a rural livelihoods analysis has the potential to identify the range of rural energy problems which can be addressed through energy planning, and also avoids the existing situation of the reduction of rural energy problems to that of wood fuel for cooking as explained in Section 1.3. The remainder of this section defines the main components of the framework.

\subsubsection{Definitions}

As noted in Section 1.4, there is a common definition of livelihoods provided by Chambers and Conway which is widely used in the literature:

"A livelihood comprises the capabilities, assets (including both material and social resources) and activities required for a means of living." (Quoted in DFID, 1999: Section 2.1)

The major components of the livelihoods framework (Figure 2.1) include: the vulnerability context (which includes all the negative factors threatening the sustainability of livelihoods), livelihood assets (the five capitals represented by the pentagon of capitals in Figure 2.1), transforming structures and processes (the institutions, organizations, policies and legislation that shape livelihoods) and finally the livelihoods outcome (the achievements). Thus, the framework's emphasis is on the causes of possible stresses on livelihoods (vulnerability context) and the factors 
that could possibly contribute to alleviating these stresses using people's own capabilities (stock of capitals and activities).

\section{Figure 2.1: Livelihood Framework}

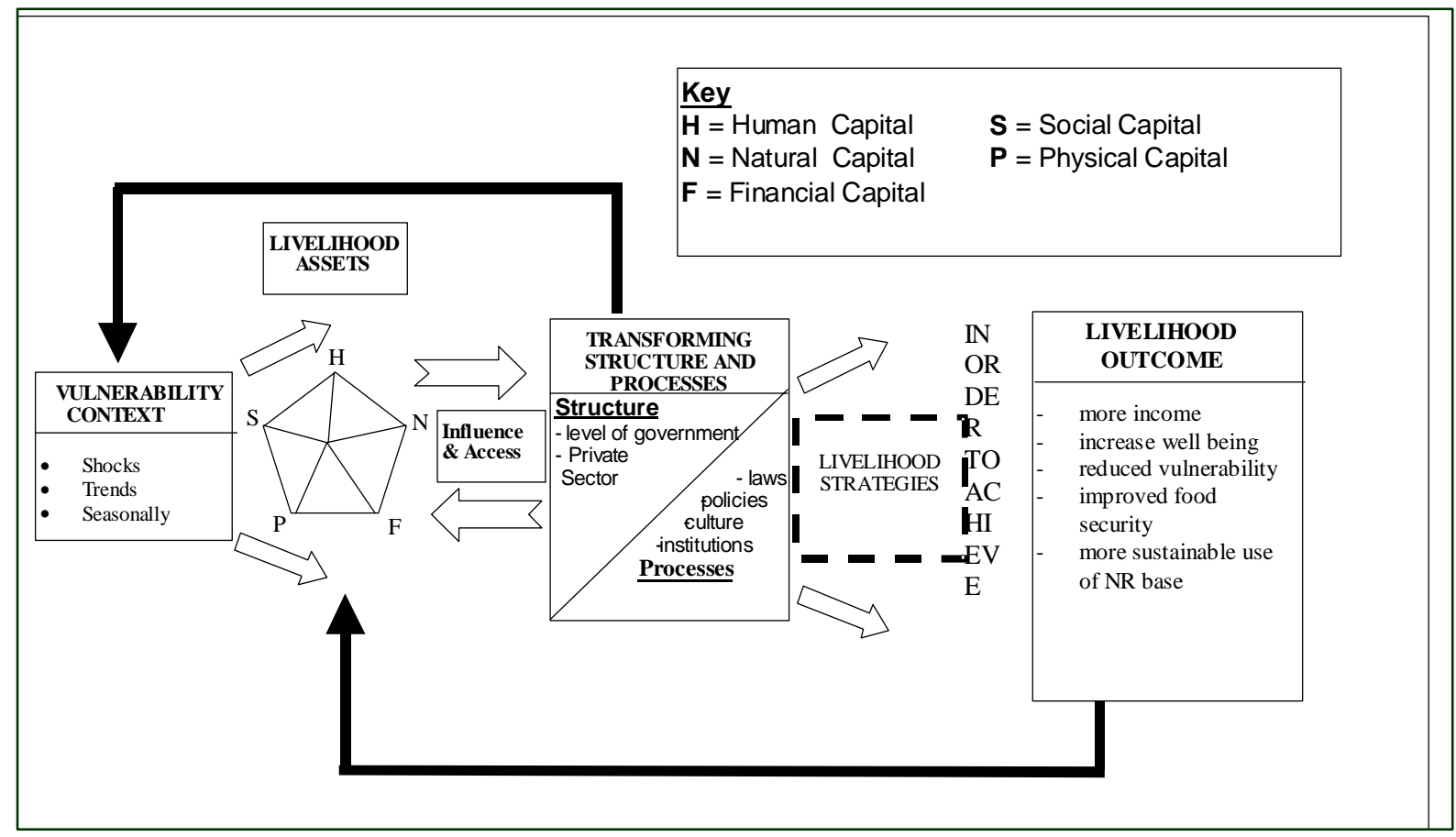

Source: Department For International Development (DFID), livelihood guidance sheet in:

http://www.livelihoods.org/info/guidance_sheets_pdfs/section1.pdf (last reviewed July 2005)

\subsubsection{Vulnerability context}

The vulnerability context refers to the ecological, social, economic and political environments which frame people's livelihoods. The vulnerability context can be defined as: "the part of the framework that lies furthest outside people's control. In the short to medium term and on an individual or small group basis there is little that can be done to alter it directly (though there are exceptions: for example, direct intervention to diffuse conflict)" (DFID, 1999: Section 2.1).

This implies that the causes of vulnerability are beyond people's capabilities to deal with. Factors causing vulnerability are classified into three categories: shocks, trends and seasonality. Shocks occur as a result of disruptive events such as droughts, floods, civil wars and outbreaks of diseases. Trends are derived from population growth, climatic changes and macro-policies. Seasonality refers to variations in availability and access to capital assets in different seasons. The severity of vulnerability and its impacts on access to capitals determine the level of coping and resilience by people to the stresses brought about these externally induced changes. Since both the severity in the degree of vulnerability and access to capitals vary, different people are impacted differently, and follow different coping strategies in response to changing circumstances which in turn result in different livelihood outcomes. Thus, analyzing vulnerability and its context is an important dimension of the livelihoods framework, and one which enables responses that reflect the diversity in access to capitals and 
hence contribute effectively to more sustainable livelihoods outcomes (Chapters 4, 5 and 6).

\subsubsection{Capital assets}

People make their living based on their use of five sets of capitals, namely human capital, physical capital, social capital, financial capital and natural capital. Human capital refers to skills, knowledge, ability to work and good health, which are important in pursuing various livelihood strategies. Physical capital refers to the basic infrastructure (transport, shelter, water, energy and communications) and the production equipment and means that enable people to pursue livelihoods. Social capital refers to the social resources upon which people draw in pursuit of livelihoods (family and kinship, networks, membership of groups, reciprocity relationships of trust, access to wider institutions of society). Financial capital includes the financial resources which are available to people both through formal mechanisms, such as loans and credits, and informal means (such as savings, credit, regular remittances and pensions) which allow a diversification in livelihood options. Natural capital refers to the stock of resources derived from the natural environment, including land, forests, pasture, rivers, stream, seas and minerals, which people rely on in deriving their needed services.

With an increased availability of and access to capitals, livelihood outcomes are improved in terms of greater income, increased well-being, improved food security and more sustainable use of natural resources, and hence the capabilities of livelihoods to cope with and recover from shocks and stresses are ensured and vulnerability is reduced. Development can aim to build rural peoples' capabilities to withstand such shocks and stress. So, planning interventions, including energy planning, should have this objective built into the planning process since, otherwise, this will provide little to those living in a vulnerable context who will benefit little from the processes of the state (Chapters 3 and 6).

People can combine the capitals in various ways to secure their livelihood outcomes. Three possible combinations of the capitals are often envisaged: sequencing, clustering and substitution (DIFID, 1999). Sequencing occurs when capitals best support livelihoods if they are available in a certain sequence. For example, the provision of financial capital needs to precede the building of physical capital. Clustering is the simultaneous combination of capitals. For example, natural capital (water) and physical capital (energy to pump water) are combined to provide irrigated agriculture. Lacking any one of the capitals will mean that the service cannot be provided; in the previous example irrigated agriculture cannot be established if there is insufficient water or no energy carrier to drive the pump. Substitution is when capitals replace one another such as the substitution of natural capital by physical capital. This substitution can be as a response to the need to enhance natural capital or for the accumulation of derived services by rural people such as increasing food production by substituting rainfed agriculture by irrigation, or reducing the drudgery of time spent on fuelwood collection by substituting wood with kerosene or LPG.

The combination of capitals can also be stimulated by policy instruments such as taxes, subsidies and direct investment by governments in capitals building. Substitution can also result in negative outcomes if vulnerability factors create a shift to lower grade energy sources which is likely to happen during vulnerability events. 
So, the ways in which capitals combine can be either chosen by rural people or imposed by external factors (Chapters 3 and 4).

The five capitals can be represented by a pentagon (Figure 2.1) to show the interlinkages among them and to emphasise the proposition that a change in one or more of these capitals will have an effect on the other capitals. The pentagon is an abstract representation of livelihood realities. The idea behind representing the five capitals in the form of a pentagon is to stimulate holistic thinking about the interrelations among the capitals rather than an attempt at proportional quantification (Carney, 1998). In fact, there is no common measuring unit for the capitals. Some, like social capital and human capital, do not easily lend themselves to quantification. Since there is a diversity of livelihoods, people will have different access to capitals and hence their livelihoods will be reflected in different pentagon sizes and shapes. Similarly, one can expect the sizes and shapes of pentagons to be differentiated by factors such as gender, age, ethnicity, and wealth since these factors govern relative access to capitals. Moreover, the size and shape of the pentagon will also be affected by the seasonality of access to certain capitals. The pentagon in Figure 2.1, as a regular shape with all points equilateral from the centre, represents an idealised form. In reality some points may be nearer to and some further from the centre, representing decreased and increased assets respectively.

As a holistic approach, the livelihoods framework offers an alternative to single sector approaches. With a better understanding of the interlinkages between the capitals that different groups may have access to, the energy planner can better understand the strategies adopted by rural people to cope with their vulnerability. Planners can design plans and policies which reflect the diversity of rural livelihoods and so support a multiplicity of strategies.

\subsubsection{Transforming structures and processes}

Transforming structures and processes cover institutions, organizations, policies and legislation, which determine access to capitals, the terms of exchange between capitals and, finally, determine the livelihoods strategies that are pursued by different groups, families or individuals (Carney, 1998). In the livelihoods framework, 'transforming structures' is the term applied to both public and private organizations that perform functions that enable people to pursue their livelihoods. They set and implement policies and legislation, they deliver services, they purchase goods and they trade. Transforming structures exist at the micro-, meso- and micro-levels. Government structures design, formulate and implement policies and legislation that determine access to services; while non-governmental structures determine the level and functioning of the market which is important for the exchange of services.

Processes encompass policies, legislation and institutions. Institutions here include customs, norms and routines: in other words, the 'way things are done' or 'the rule of the game' (North, 1990: 3). Processes include tasks performed by structures, such as policies, plans, and legislation. The processes are important because of the influence they have on the decisions rural people make about their livelihoods. Legislation, the rule of law, incentives and penal systems are important determinants of how people access and combine assets to pursue their livelihoods (Newell, 2000). Both transforming structures and processes play important roles in determining how public 
goods and services (including energy services) are allocated between different economic sectors, programmes and groups.

\subsubsection{Livelihoods strategies}

Livelihoods strategies refer to the various choices and opportunities open for people in pursuing their livelihoods. They are the combination of activities and choices selected by people to support their livelihood. The levels of access to capital assets will determine opportunities for and constraints on pursuing specific, sustainable strategies. Different groups of people face various constraints and have different opportunities which lead to a diversification of strategies. Thus, the term livelihood diversification reflects on the fact that people will follow different strategies to support their livelihood (Ellis, 2002). Livelihoods can also change in response to changes in surrounding circumstances in terms of the opening up of new opportunities and/or the imposition of new constraints that result from transforming structures and processes and from the vulnerability context.

\subsubsection{Livelihoods outcomes}

Livelihoods outcomes are defined as the achievements or outputs of livelihoods strategies. These outcomes can be, but are not limited to, the achievement of higher income, increased wellbeing, improved food security and more sustainable use of resources or, in other words, reduced vulnerability. However, the list of outcomes in the pentagon, as presented by DFID, sees only the positive outcomes that reduce vulnerability. However, livelihoods can also run into a negative situation as responses to changing circumstances (for example, declining rainfall, reduced soil fertility) are not always positive and increase vulnerability.

A new outcome may result from a deliberate act that takes advantage of new opportunities that arise and improve the outcome (i.e. a positive outcome) or may result from risks imposed by external factors (a negative outcome). Since livelihood strategies are diverse and changing, the outcomes are diverse and changing.

\subsection{Criticisms of the livelihoods framework}

The livelihoods framework is presented as a holistic approach that analyzes important factors affecting the livelihoods of groups of people. It is seen as a non-sectoral approach that considers and emphasizes the multiple influences, multiple actors and multiple strategies which, as a result, produce multiple outcomes. However, viewing the determinants of livelihood outcomes as based solely on the defined components of the livelihoods framework (vulnerability, livelihoods assets, transforming structures and processes and livelihoods strategies), makes the livelihoods framework liable to potential reductionism by ignoring other determinants of livelihoods, such as social and political powers, which are insufficiently tackled in the framework (see, for example, Hoon and Hyden, undated: 9-10). The framework fails to consider the impacts of many social and political differentiations, such as those related to gender, age and ethnicity, in the access to capital assets. Hoon and Hyden (undated) emphasized the point that development cannot be achieved without giving attention to the political dimension: to benefit the poor it is important to see how power is structured and used throughout society to determine the distribution of resources. 
Unfortunately, the framework does not offer a way of analyzing how power is exercised at various levels (from the micro-, including within households, to macrolevels) and how power determines livelihoods. Hoon and Hyden distinguish two sides of politics: distributive and constitutive. The former deals with questions such as: who gets what, when and how; the latter with questions such as who sets what rules, when, and how. The structures and processes included in the livelihoods framework, as part of politics, address only the distributive side of politics. So, the framework includes a political dimension in the processes, but not in the pentagon. Nevertheless, the framework does refer to 'conflict' under the shock factors of the vulnerability context, but it does not explain how access to capital assets and livelihood outcomes are affected by power relations, nor does it specify at what levels conflicts operate. It is understandable that the most frequent users of the livelihoods framework (NGOs and international organizations) need to avoid open disagreement with governments since this might result in outcomes more detrimental for the rural people intended to be helped (Chapters 3 and 4). However, ignoring political factors in the analysis of rural problems disguises major influences on livelihoods (Baumann, 2000). Baumann suggested incorporating an additional capital in the livelihoods analysis: political capital. By adding this capital, politics gains equal weight with other capitals in the analysis of livelihoods. However, Baumann does not specifically identify the components of political capital, or explain how to analyze them or how to link them to the other capitals. For example, democracy and governance dimensions, as constitutive parts of politics, are not as simple to analyse as economic, technological or environmental dimensions, for as easily operationalised in projects or programme that seek to provide immediate benefits for the poor. In this research, the analysis puts greater emphasis on the distributive side of politics, under the transforming structures and processes, than on the constitutive side. This is because the political dimension, so far, is not well developed as a capital, and there are no specific ways provided for analyzing the political factors in a compatible way to the five original capitals included in the livelihoods framework.

Although the framework includes social capital, only the positive components of social factors are given emphasis (such as trust, reciprocity, belonging to an organization). The negative factors, such as conflicts, struggle and suppression between and within groups are undervalued or ignored. Although multiple actors are acknowledged within the framework, the social divisions within specific groups of actors, most notably the intended beneficiaries, are not specified as part of the analysis. Gender, for example, is not explicitly mentioned in the analysis of livelihoods although its role is important in the analysis of rural livelihoods. Moreover, even though gender issues cross-cut all components of livelihoods, they are not well integrated within them (Chapters 4 and 5). The framework fails to emphasize the particular role women play in the construction of livelihoods and how women can be involved in planning development interventions.

Thus, the livelihoods framework can be seen as a technocratic approach which addresses those issues linked to livelihoods that lie outside political and social forces. However, political and social forces also shape livelihoods. So, by considering only those factors presented in the framework in an analysis potentially leads to an underestimate of the social and political implications of access to assets and their role in achieving desired outcomes by various groups. 
In this research, the transforming structures and processes used in the analysis will only deal with the distributive side of politics. This distributive side in the energy sector in Sudan is addressed through planning processes which not only define who will benefit but also who will not benefit as was illustrated by the World Bank statement (quoted in Section 1.2.2) against the inclusion of the traditional sector in national planning in Sudan. The distributive role of the transforming structures and processes within the energy sector will be addressed in Chapter 3 of this thesis.

\subsection{The Livelihoods framework as a tool in planning energy services}

In Section 1.3, failures in conventional energy planning's ability to capture and identify rural energy problems were identified. Conventional frameworks cannot determine whether a deficit of energy services 'might' or 'might not' free rural people from their vulnerability context. The main reason for this failure is that there is no direct link developed between people's livelihoods in a specific context and the aggregated energy data obtained and used for energy planning at the central state level. In this section, the livelihoods framework is presented as an integrative approach that can shed light on any links between the availability of energy services and the quality of rural livelihoods. The intention is to provide a holistic view of how energy services are linked to the other components of livelihoods: that is, defining the internal links between the functioning of livelihood capital assets and access to energy services (Section 2.7). However, external factors such as the transforming structures and processes are also important determinants of livelihood diversification and sustainability through their impacts on the capital assets involved in access to energy services.

The strategies rural people adopt are determined and shaped by the available components of the livelihood framework and thus leads to a range of livelihood outcomes. Hence, the framework provides potential ways to view the role of energy in reducing rural people's vulnerability, supporting their strategies and improving their livelihoods outcomes if the supply of energy is planned in such a way that it provides sustainable options to solve the problems of rural energy services. In this thesis, the emphasis will be on the relationship of energy to the various components of the livelihoods framework and how energy planners can be better informed in planning rural energy interventions to improve rural livelihood outcomes. This proposition underlines the second assumption in Section 1.5. Energy planners are envisaged acting as distributive agents for energy carriers and this enables rural people to build up capital assets that can be used to improve the flow of rural energy services. It is taken as a given that positive impacts on the five capitals can combine to have positive impacts on livelihood strategies and, eventually, on livelihood outcomes.

\subsubsection{Energy services and capital assets}

Capital assets are at the centre of livelihoods analysis. Energy sources and carriers are components under both physical and natural capitals, while energy conversion technologies are parts of physical capital. Energy services are the desired products from the transformation of the energy components of the two capitals. In relation to the analysis in this research, the concept of a ' is used. A stock of energy carriers is defined here as all accessible types of energy carriers used in the village to generate different types of energy services (see table 4.7). This concept is more relevant for the 
rest of the analysis because both natural and physical capitals include different types of energy carriers that can release energy to be used in the transformation of other components into a desired energy service. For example, natural capital contains various types of energy carriers, such as wood, which can be transformed into energy for cooking, heating and lighting services; animal traction which can provide energy for land preparation and transportation services; and human muscles which can release energy for a range of manually-transformed services such as the hand drawing of water and the preparation of land. Likewise, physical capital also contains different types of energy carriers such as diesel fuel which can provide energy for the transportation of people and goods, for water pumping and for land preparation; electricity for lighting, heating and cooling services; and LPG for cooking. A variety of energy carriers may be available at anyone time in a village. However, energy carriers do not produce the same quality of energy services: the quality of cooking, lighting, heating, cooling and transportation can differ. In particular, the quality of energy service is likely to be poorer when the energy carrier is drawn from natural capital. Both natural and physical capital components can be affected by the factors of vulnerability, and energy carriers are no exception. It is therefore possible to trace the effects of the factors of vulnerability on energy carriers, which in turn affect the flow of energy services, and these effects are reflected in livelihood outcomes.

Components of the other three capitals, human, social and financial, are also important in terms of which components of these natural and physical capitals will be available and accessible and influence the distribution of the transformed energy services among different groups of users of energy services (Chapter 4). As will be shown in the following paragraphs, the five capitals can be linked in different ways to energy carriers that produce desired energy services (see also Annexes 1 to 6).

\section{- Energy services and natural capital}

The relationship between energy services and natural capital is an extremely complex one. Natural capital acts as the basis for all the services used by most people in rural communities such as water, pasture, wood and food production. However, natural capital also contributes to the stock of energy carriers currently used in rural Sudan in the form of biomass and animate energy ${ }^{1}$. In this sense, natural capital can be considered as acting as a store of energy carriers. In such a relationship, a change in the natural capital will cause a change in the availability of energy carriers and hence energy services. The relationship is not one way; a change in the stock of energy carriers will also change both the quality and quantity of energy services derived from natural capital. In traditional livelihoods where the production of food (through rainfed agriculture) and the fuel to cook it (fuelwood) are both provided from natural capital that relationship is obvious.

Another example of natural capital is animate energy, as a linked provider and product of energy services, which is directly a product of services (food derived from natural capital) and a provider of energy services. Animals are important energy carriers which, through work, provide energy services such as drawing water, transport (humans, goods and services) and operating agricultural implements. Their dung can also be burnt as a fuel. The availability of this important energy carrier in

\footnotetext{
${ }^{1}$ Animate energy is a collective term used to cover the metabolic energy of humans and animals converted into work.
} 
some places depends largely on the availability and accessibility of other naturally available components. Availability of pastures and water are necessary conditions for the animals to be present, and their muscle energy available for use. When either pasture or water is depleted, animals move out and an important energy carrier is lost thereby degrading the energy stock. Similarly, human muscles provide an important energy carrier for using hand tools in agricultural operations, to draw and carry water, to collect and transport fuelwood and to build necessary physical capital energy convertors to provide energy services. This important energy carrier can be affected by outward migration, particularly of able-bodied men, which reduces the stock of energy and also shifts responsibility for providing energy services to women. However, outward migration can lead to increased financial capital and social capital which can lead to increases and improvements in the energy stock. Further, the quality and quantity of animate energy is also dependent on the natural capital since it provides the food eaten by both humans and animals.

Agriculture not only affects the demand for energy services but also supplies energy carriers such as crop residues for energy services such as cooking and lighting. The demand by large land owners for energy services is larger than the demand by small landowners and the landless.

\section{- Energy services and physical capital}

In the literature on livelihoods, energy is seen as a component of physical capital (Ellis, 2000). However, energy plays an instrumental role in accessing services from all the other capitals and from components of physical capital. Its presence is directly or indirectly essential for most other components and capitals to function. For example, production equipments, tools and machinery lie idle without energy. Other infrastructure, such as roads, railways and canals require energy inputs for both construction and for running transport on the infrastructure. However, the relationship between energy and the other components of physical capital can be viewed from the other side. An energy carrier has no value if there is no capacity (that is no other physical components) to use it for generating services that people require, for example a tank of diesel fuel has no value without a diesel engine to provide transport or pump water.

Energy services are the product of combining an energy carrier and a hardware component (technology or device) to transform natural capital into desired energy services. Nearly all energy services are made possible through the use of hardware, which can be primitive (for example the three-stone stove) or advanced (such as gas cookers). Even the simplest form of services, such as using water from running streams, need man-made components to carry it (have a bucket and rope), to store it (jar or bottles) and to be able to use it (cups and pans). From the other side, the making of the hardware itself needs energy which can also be simple (energy from firewood for making hand tools) or more complex (electrical furnaces for melting iron core). 
Moreover, the transformation of primary energy ${ }^{2}$ from one form to another to deliver particular services requires physical capital (electricity from hydropower or shaft power from diesel).

Putting energy under physical capital defines energy in terms of fuel type and technology mix. However, fuel types can also be components of the natural capital. It is the combination of these two capitals that produces the desired energy services, which cannot be classified under either physical capital or natural capital. Therefore, energy services are analysed in this thesis in a separate section, and not under capital assets. This point will be extended in the later discussion on developing a circle of stock of energy services (Section 2.5).

Development objectives within the energy sector include the reduction of drudgery. This reduction can be achieved by the replacement of human muscle energy, particularly by technology and commercial energy forms, and is an example of the substitution of natural capital by physical capital.

\section{- Energy services and human capital}

Energy services have direct and indirect links to the human capital. Direct links can be found in the use of human muscles to deliver energy services through manual work such as the drawing of water, carrying firewood and carrying out manual agricultural operations (e.g. land preparation, weeding and harvesting). Indirect links can be found through the role of energy in all factors that affect human well-being such as education, health, and nutrition. Again there is a two-way relationship between energy services and human capital. Building human capital through education and awareness raising can increase the demand for energy services based on modern energy carriers.

\section{- Energy services and social capital}

Energy is linked to social capital in various ways. Social capital can play the role of a distributive agent for most energy services to a community. Distribution takes the form of reciprocity between individuals and groups, social organizations (formal and informal) and family linkages in securing some level of energy services. Farmers help each other in manual farm operations and distribute benefits between relatives, kin, lineage and other forms of social groupings. Social capital can also play a role in building energy services through the use of social networks to raise funds for building community energy services such as water boreholes, or through cooperation in providing labour to dig, for example, a well. Energy services that promote communication and transport can develop social capital by enabling contact and interaction. So, two-way relationships between energy services and social capital can be developed. However, unlike natural and physical capitals, the relationship is a distributive one rather than one that produces an energy service itself. However, distribution is not necessarily transacted with equality since the social capital of the various actors varies, and inequalities may deprive some groups while supporting others. As Long (2001) noted, women with less time to participate in voluntarily work acquire less benefits from social capital because they are not able to build and maintain social networks.

\footnotetext{
${ }^{2}$ Primary energy is energy sources that have not been subject to any conversion or transformation processes and which, by extraction, refining (secondary energy), and delivery (energy carrier), can become useful energy which delivers energy services. This multi-step process from primary energy to energy services is known as the energy chain and is used as a tool in energy planning.
} 
- Energy services and financial capital

Energy services are linked to financial capital through the latter's double role as a necessary input for building a stock of energy services ${ }^{3}$ and as a product of the use of energy services and can be seen as an investment that generates financial capital in the future (through increased production). Financial capital is needed to purchase energy carriers, equipment and machinery, and for building other physical capital components necessary to generate energy services. At the same time, financial capital can be a product of energy services in the form of income generated from production processes that utilise energy carriers. Therefore, the assets reinforce each others' impacts to the extent that a change in financial capital, for example due to changes in price, investment levels, rules of lending or the establishment of a local saving scheme, can affect the quantity and quality of energy carriers and services.

\subsubsection{Energy services and the other livelihoods components}

In Section 2.4.1 links were identified between energy services and capital assets. All assets affect, and are affected by, access to energy services. However, the links also show the internal relationships between the capital assets and the energy services which are also part of the components of these assets.

Other components in the livelihoods framework which have an affect on capital assets can also clearly have an affect on access to energy services. These components are defined in the livelihoods framework as the vulnerability context, the transforming structures and processes, and the livelihoods shortages outcomes. This section will show how energy services are affected by these three components.

\section{- Energy services and the vulnerability context}

The effects of vulnerability factors include the destruction of capital assets and the consequent reduction in the stock of energy services. Energy services, as shown above, are linked to all capital assets. Thus, any negative effect on capital assets can be expected to have a corresponding negative impact on energy services available to any group of people. Conversely, a 'good' stock of energy services can help overcome vulnerability. As an example, transportation services can help to move goods and services to an area where there are shortages due to vulnerability factors (such as water during droughts). Energy services also help develop markets for the exchange of goods and services. Cold stores able to keep perishable food items (such as fruit and vegetables) for long periods might help to reduce the impacts of the seasonal availability of foodstuffs.

\section{- Energy services and transforming structures and processes}

The stock of energy services is bounded by the structures and processes which are part of the energy sector. Structures and processes define the context in which all the above relationships between energy services and the various capitals are increased or degraded. Policies and programmes at national and/or regional levels for energy, and in other sectors, affect the availability of the stock of energy services. Pricing policies, taxation, subsidies and legislation are instruments within the processes that are used by governments to influence the access to energy carriers as well as influencing the level of access to energy services that are provided by these carriers. For example,

\footnotetext{
${ }^{3}$ A stock of energy services is defined here as the sum of all types of energy services accessible to users in the village.
} 
increasing the price of diesel fuel may well affect the level of services such as water pumping provided by using this energy carrier. Public response may be to pump less water or to substitute the energy carrier by a cheaper alternative, for example handdrawing water.

Components at the local level, which are also determinants of the accessibility to capitals and energy services, and which are not necessarily explicitly mentioned in the livelihoods framework, include gender, age and ethnicity, culture and norms. Accessibility of energy services is in particular affected by gender roles and relations. Gender roles and responsibilities allocate different tasks to women and to men, and these require the use of different tools/machinery, different energy types and different energy services. Gender relations affect who owns and controls specific household resources. In the context of rural Sudan, men are usually the main decision-makers in the household, particularly where financial assets are to be used, even for purchases related to what has been allocated as a woman's role, e.g. cooking. This requires a consideration of gender in the analysis of energy services, since otherwise there will be an incomplete picture of needs. The same can be said for different age groups which also have different responsibilities, and hence requirements for energy services. Ethnicity can also determine rights to energy services, particularly for those who are displaced or dislocated from their areas of origin to new areas where rights to access services such as land to produce food and forest to collect fuel are claimed by original inhabitants. Moreover culture and norms can also determine access to energy services by certain groups, particularly when services are culturally prohibited. This means that wide variations in the types of energy services required can be expected. Even within a single family, gender and age create variations in the demand for energy services (see Sections 4.1.2, 4.2.2, 4.3.2, 4.4.2, 4.5.2 and 4.6.2). In Chapter 4, it is shown that access to evening education in school is prohibited for girls but not boys in all the villages studied except Dar Mali. Women working in agriculture is culturally unacceptable in Dar Mali and Goz El Halag, whereas it is allowed in Es Sadda, El Idied and Um Laham. Also entertainment shown in village clubs is exclusive to men.

\section{- Energy services and livelihoods strategies and outcomes}

Energy services, livelihoods strategies and livelihood outcomes can be linked through asking two questions. First, how can securing the flow of energy services promote livelihood choices and opportunities that improve rural people's livelihood outcomes? This question can be linked to the assumption made in Chapter 1 that securing the flow of energy services will contribute to the ability of communities in rural Sudan to respond to vulnerability events (Annexes 1 to 6). There are certain energy services whose improvement can clearly make a positive contribution, such as water pumping, cooking, refrigeration, transportation and communication. Water pumping can secure drinking water and the irrigation of food and cash crops which opens up opportunities for both food security and increased income. Shifting the cooking service from biomass to modern energy carriers can improve wellbeing through improving cooking conditions by reducing indoor air pollution and removing the drudgery of fetching fuel wood, thus improving health conditions. Refrigeration can improve the storage of medicine and vaccines within a reachable distance of the people, and can also improve storage conditions for food and perishable crops to avoid seasonal fluctuations in food availability. Transportation can enable access to distant capitals, move people, goods and services between urban markets and rural areas and can also help in the transfer of information and money. Communication can help in 
maintaining ties with family members and in the transfer of information about markets and prices for goods and services. In other words, the availability of energy services can help rural people reduce their vulnerability and improve their livelihoods outcomes.

The second question concerns the strategies people follow to secure the flow of their energy services. These strategies can involve the diversification of fuel types (use of different fuel types according to seasonal availability), diversification of sources of services (change from surface water to underground water), the substitution of natural capital-based services for physical capital-based services (such as substituting kerosene and LPG for firewood in cooking), or combining other capitals to ensure the flow of energy services (such as social, human and financial capital to purchase energy services). In other words, the strategies are varied and depend upon context.

Answering both questions directs attention to the various strategies that might be followed by different groups (based on wealth, gender, age, ethnicity and other attributes) to produce different livelihood outcomes, and how those outcomes vary with changes in the flow of energy services. What is important for an energy planner is to consider each group's strategy so that the formulated energy plans and policies help all groups, or at least that no group is disadvantaged (Chapter 6).

\subsection{The links between the stock of energy services and the pentagon of capitals}

In Section 2.4.1 above, an energy service is shown as the product of transforming natural capital components using physical capital components. Thus, an energy service is neither a component of physical capital alone nor a natural capital one, but the result of combining components from both. Energy services also directly influence the building of other capitals and, conversely, other capitals (social, human and financial) can also help in delivering energy services for securing livelihoods. In addition, political power imbalances, due to economic, gender, age and ethnic differentiation, present important factors that can facilitate or hinder the delivery of energy services, and their equitable distribution among the various groups. Including of all these dimensions of energy services shifts the analysis away from the current narrow focus of energy planning on fuel types and technology (physical capital components) to its wider connections (Chapters 4 and 5, and Annexes 1 to 6). Therefore, in order to represent the strong interconnectedness between energy services and other capitals, and the farmer's role in the substitutions among capitals (visualized as increasing the size of the pentagon), it is proposed to represent the stock of energy services by a circle at the centre of the pentagon, called here the energy circle (Figure 2.2). The energy circle can be defined for the purpose of this research as a visual representation of the size of the stock and quality of energy services available to a specific community at a particular time. The circle is not fixed and can change over time with respect to changing capital assets and the energy circle can also reinforce changes in capital assets. To explain how the energy circle is interlinked to the livelihood capitals, an existing stock of energy services is represented within the pentagon by position (A). Viewing the relationship in a more dynamic way, increasing the energy stock will push the pentagon capitals outwards to position (C) and, likewise, a degraded energy stock will pull the pentagon inwards to position (B). Such changes in stocks of energy services can result from responses to the various 
components of the livelihood framework. It should also be recognised, that in practice, the push/pull effect on the different assets by the energy cycle may not be equal and, possibly, some assets may be 'pushed out' and others 'pulled in'.

Although Figure 2.2 contains only the pentagon, and not the other external components of the framework, these external components are important influencing factors (both positive and negative) on energy stocks. Energy planning, for example, is a transforming process which influences the energy circle.

It is taken as a given in this thesis that an expansion of the energy circle leads to an expanded pentagon, enabling rural people to be better equipped to respond positively in overcoming factors of vulnerability and that this results in improved livelihood outcomes. However, the energy stock will not be the same for all groups since social factors create different levels of access to the various capitals. As there are different shapes to this pentagon of capitals for the various groups, there will be different energy circles for the various groups.

In order to avoid both exclusion and reductionism of traditional rural energy services, the livelihoods framework is proposed as a holistic framework that can identify and place rural energy services problems in wider contexts. However, within the rural context, there are various groups which can be identified according to age, gender, wealth and ethnicity whose needs for energy services can differ. Identification and representation of all these groups, and mapping their needs for energy services, remains a problem to be addressed in energy data gathering. It is therefore proposed that participatory approaches be employed as a tool in data collection to potentially provide a more equitable representation of all the groups' needs for energy services. The following section discusses how participatory approaches can help solve the problem of representing all groups in the data collection processes.

Figure 2.2

Stock and quality of energy services at the centre of the pentagon

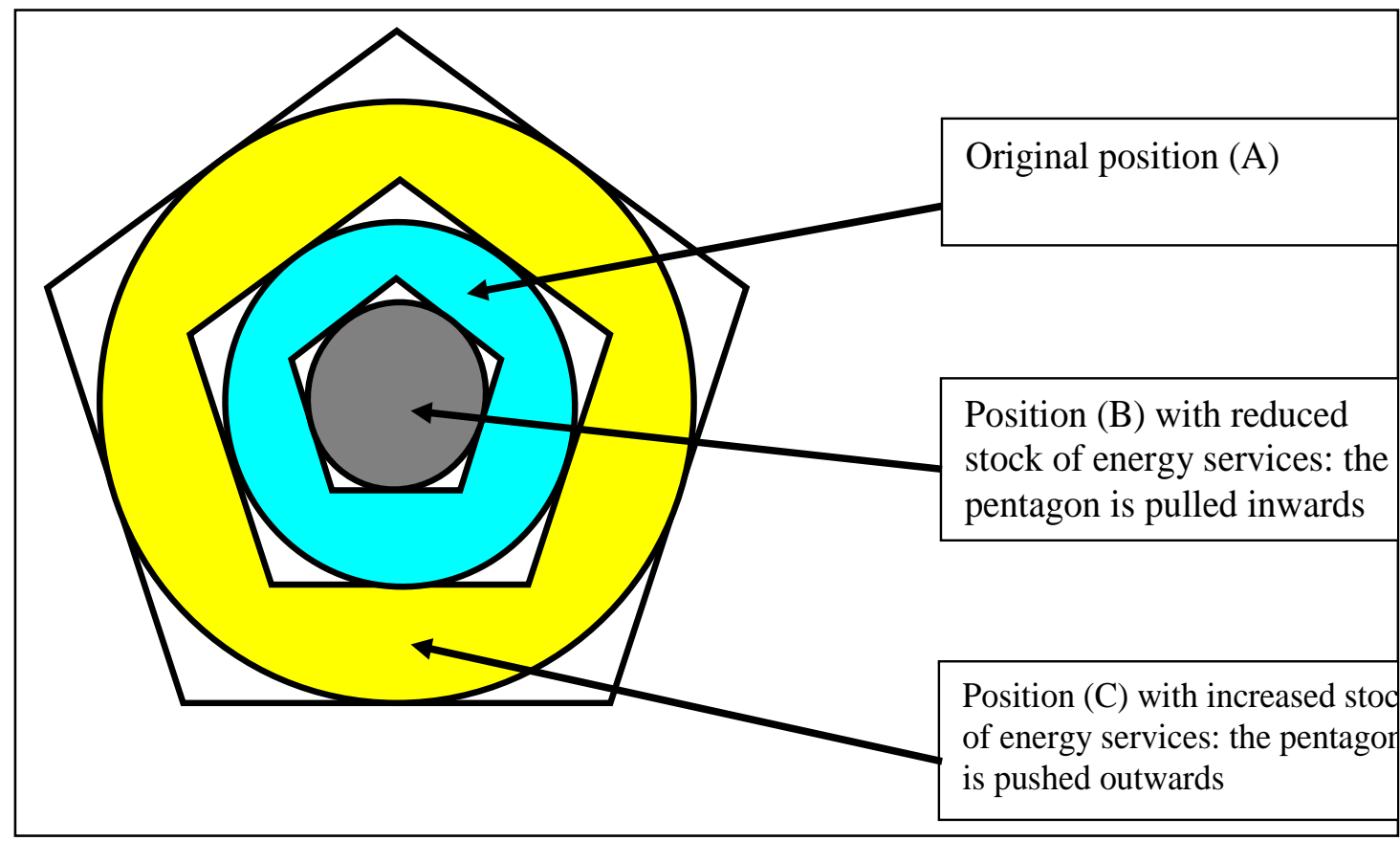




\subsection{Participation as a tool for energy data gathering}

In this thesis, it is postulated that the use of participation in investigating the demand for rural energy services to promote rural livelihoods can ensure the representation of rural groups' needs and priorities in energy planning. So, participation here is offered as a solution to the problems of reductionism and misrepresentation inherent in conventional energy data surveys (see Section 1.3). As was shown in the previous chapter, in Sudan, the rural population practising traditional agriculture has, so far, been excluded from making any input to energy sector planning that would provide planners and decision-makers with the necessary data so that their goals and needs could be included when setting objectives for energy plans and developing the EDS. Section 2.4.2 further suggests that, even at the village or community level, the demand for energy services can be differentiated for sub-groups such as women, youth and landless people. Such differentiation is missed in traditional planning approaches which rely on data gathered by questionnaires and aggregated at the national level. For this reason, there is a need to adopt approaches that ensure that the energy service demands of all groups are visible at the national level.

Traditionally, energy planning can be regarded as top-down ${ }^{4}$. Chambers (1983) argued that with bottom-up planning a different set of needs and priorities would emerge that is more representative of the different groups in society. A key tool in bottom-up ${ }^{5}$ planning is data collection through participatory methods that consult the target beneficiary groups. The participatory approach can tackle weaknesses in past development experiences (social exclusion, inequity and environmental degradation).

Participatory approaches are to be more commonly found in planning non-energy sectors such as forestry and agriculture. In this thesis, participation is used as research method to collect data on energy services in rural Sudan. Through this innovative approach, the aim is to show that participation in energy planning will produce different results to conventional top-down processes. The following section presents the participatory research methods applied in this research.

\subsection{Participatory research method as applied in this study}

Section 2.2 presented the livelihoods framework as a useful approach for the planner in terms of the identification, diagnosis and analysis of problems. Questionnaire-based household energy surveys are commonly used for gathering energy data. Limitations of these household energy surveys include their unresolved bias, nonrepresentativeness and the predetermined selection of data to be gathered, which are

\footnotetext{
${ }^{4}$ The top-down approach in planning denotes planning processes that are led by expert knowledge and perceptions of what people need. Experts determine the contents of the planning processes, including setting the objectives and priorities, determine the contents and levels of information needed and, finally, manage the implementation of the formulated plans. In top-down planning, the people intended to be served have no role in the planning processes and are usually viewed as passive beneficiaries, or receivers, of the benefits of the plans.

${ }^{5}$ The bottom-up approach in planning is the reverse of the top-down approach. In the bottom-up approach, people have control over the planning processes and are consulted by planners to define their perceived objectives and priorities in the planning processes and hence determine the contents of the data that informs policy-makers and planners of the problems to be solved by plans and the necessary actions to achieve this.
} 
often irrelevant (Section 1.3). In terms of data collection, participatory techniques are said to offer a way of involving and representing all local views and perceptions (Chambers, Pacey and Thrupp, 1989; Brown et al., 2002). Thus, a better understanding of local realities, living conditions, constraints and opportunities is reached. Capturing local realities will show that society is heterogeneous, and varies according to a number of social and economic characteristics, such as wealth, gender, power, age and level of literacy. Between and within such defined groups there will be wide differences with respect to world views, resources, interests and priorities, and particularly for poor people who will follow different livelihoods strategies (Chambers, 1991: 142-143).

Representation of the range of different realities in conventional formal questionnaires for data collection is rather difficult due to the inherent biases as discussed in Section 1.3 (outsider biases, methodological biases, respondent biases). Officials who gather such data generally meet the wealthy and powerful segments of society and not the poor and powerless. Questionnaires tend to be answered by older married men, by those who are literate, and not by women, the illiterate or the young. Thus, the realities of large segments of society are not represented, and the realities are reduced to those that belong to a small proportion of society, namely older married men. The views of this latter group are thus reflected in the results presented to decisionmakers. This data bias results in an incomplete data set (see Section 1.3). The consequences of this are that what is excluded during the process of needs identification will be also excluded from the formulation and adoption of solutions. Participation methods, as postulated in this thesis, enable the identification and categorization of rural communities as diverse groups, and this is a necessary condition for capturing all the realities within those communities. Chambers further indicates how these diverse realities can be captured by: "inferring their priorities from what they do as much as, or even more than, from what they say" (Chambers, 1991: 142). In other words, direct contact has to be made by data gatherers with all the groups of people targeted for planning services, and observing of what they do is just as important as asking what they want.

Participatory methods also have the potential to offer improved ways to promote mutual understanding and learning between rural people and those officials who seek to understand their realities. Dialogues and open discussions facilitate the exchange of views and mutual understanding between rural people and officials. So, realities are much improved by merging the indigenous knowledge that rural people hold with the formal knowledge that the officials hold or, in other words, merging the indigenous knowledge (acquired by the community through experiences in pursuing their livelihoods) with academic knowledge (acquired by formal education and training) to understand realities in a better way than the conventional methodologies achieve (Jason et al., 2002). However, it should not be assumed that any data collected are without bias since cultural factors can influence the freedom with which community members are able to describe their realties in public. Such cultural limitations are often linked to gender and age, where women must not talk to male interviewers and young people must not contradict what their elders say. It is important to deal with each of these situations in their context. The separation of groups prior to interviewing, and employing a female facilitator to collect women's views, can help to reduce errors in data representation. 
Answers to Research Question are sought through complementary participatory methodologies and livelihoods approaches in data gathering and analysis. The gathering of data was facilitated by three assistants (two female and one male) using a range of participation tools. The assistants themselves came from different educational backgrounds and had different work experiences ${ }^{6}$. To prepare the assistants to work as a team, and to introduce them to the topic to be investigated, a five-day training course was held. This five-day training concentrated on identifying and explaining rural energy issues, the data to be gathered and the tools to be employed. After this training period the team conducted fieldwork in three villages as part of the Swedish Free Mission activities.

For the purposes of this study the first fieldwork was conducted in the village of Es Sadda in May 2002. This was followed by fieldwork in the villages of Dar Mali (August 2002), Goz El Halag (February 2003), El Idied (May 2003), Um Laham (May 2004) and El Ga'a (June 2004). The assistants were involved in facilitating the participatory process of data collection in the villages, and other stakeholders and key respondents located outside the village (State and province officials) were interviewed by the researcher separately. However, their views were shared with the community during the presentation of findings to the community.

In this research, participatory techniques (focus groups, ranking, mapping, observing, drawing, interviewing and discussing with key informants) are used to collect qualitative data on current use of and demand for energy services relevant to the livelihoods of rural communities. At the start of the data collection process, differences within each village are mapped. First, wealth ranking is used to categorise households in terms of assets. Wealth can be defined in non-monetary terms, such as the state of food security (as a measure of vulnerability), health, education and skills (human capital). The indicators used to define the categories are developed with the communities; households in the village are then placed in wealth categories according to their possession of the identified components. Further sub-grouping by gender, age and ethnicity is also carried out. Thus, wealth ranking is intended to ensure that all groups are identified and have their realities and needs represented in the investigation (Chapter 4). Where data gathering in a mixed group is not possible due to social or cultural barriers each sub-group is approached separately. For example, separate subgroups of women and men were formed in some cases, in other cases where there is a sub-group with its own identity, for example a recently settled nomad group (in Dar Mali), the sub-group was also approached separately. Besides participation in focus discussion groups, each sub-group was observed in different settings. Discussions were held with people in their homes, at school, the club, the mosque, on their farms and in service centres, including clinics. In this way, these different data gathering approaches allow for triangulation to cross check the data and hence ensure their reliability.

\footnotetext{
${ }^{6}$ Their names are Omaima M. Obied, Fatma Husien and Faroum Germaia. Omaima graduated from the University of Ahfad for girls. She majored in Development Studies and then worked in a private consultancy company (Development Initiative Group, DIG) conducting participatory training and studies. In 2000, she joined the House of Learning Project (HoL) of the Swedish Free Mission (SFM). Fatma graduated from the University of Nilien, majoring in Geography. She has worked for the Energy Research Institute (ERI) since 1994 in the Department of Technology Development and Dissemination. Faroum graduated from the University of Khartoum as a Civil Engineer and joined SFM in 2001 as one of the staff of the Solar School in Sudan (SSS) Project.
} 
When all the groups present had been identified and the ways to reach them determined, a range of participatory techniques were used to gather more-detailed data. Time series analysis and mapping techniques have been used to draw the spatial and time boundaries of each village. Time series analysis identifies major events in the history of the community including events of vulnerability and the resulting impacts on their livelihoods (vulnerability context). Mapping identifies the spatial boundaries of natural resources (natural capital) and the presence of buildings, infrastructure and services (physical capital). Social relations were mapped using Venn diagrams to show the interrelations between and within local organizations and with outside organizations (financial and social capitals) that have a link with energy services (Pretty, et al., 1995). These exercises are followed by ranking processes to identify the importance of each component in livelihoods.

Application of the above methods and techniques enable the identification of subgroups, mapping their resources, identifying their livelihood outcomes and whether or not they are able to realize these outcomes under any prevailing shocks and stresses, as well as the linkages to the flow and stock of energy services. Obtaining this general information can then be used to facilitate the collection of data on energy services. Having obtained all these data, the next step is to investigate access to energy services by different sub-groups in the village. First each energy service used in the village is identified, and then all the energy carriers, sources and processes employed to make the service. For example, for cooking, the identified carriers might be wood and crop residues, the sources for these may be forests and farms, and they may require processing (chopping, transporting and drying). The capital assets and activities necessary for the flow of each service are identified in each village for the various sub-groups. Following this step, the vulnerability factors and their impacts on the flow and stock of energy services are traced from the time series data. The result of the analysis is the identification of the kind of intervention that could possibly lessen the consequences of vulnerability events on energy services and so create moresustainable livelihood outcomes.

The data obtained in communities were complemented by interviews with key informants, such as government officials, community leaders, those in charge of services in schools, health centres, water, flour mills, local electrical generators, transport drivers (merchants and traders who own cars and tractors), and providers of other consumer services. These key informants are often from the powerful groups in Sudanese society. They have links and direct contacts with government offices that control or deliver energy services (located in the transforming structures and processes). Such key informants can provide important information about how structures and processes work, and whether they have an effect on the flow of energy services in villages.

\subsection{Criticisms of participatory techniques as a data gathering method}

Participatory techniques have been criticised in the literature for a number of shortcomings. For example, Brown et al. (2002) refer to a criticism of participatory techniques and methods as the researcher becoming 'sympathetic' to the perspective of the rural community rather than maintaining a position of scientific objectivity. 
This section reviews some of the criticisms and explains how they are addressed in this research.

First, there are considerations of equity in, exclusion from and inclusion in participation by the various groups, as well as access by researchers to particular subgroups. These problems are addressed in this research by first identifying cultural barriers to specific groups and subgroups and their power relations. When there are cultural barriers to having focus and discussion groups containing participants from all groups in a community, the "excluded" sub-groups are contacted separately about their views. In this way all the social categories in a particular community are reached and they have the opportunity for their views to be recorded. The involvement of female research assistants in the data collection helps in accessing and talking to women. The female research assistants are able to participate in women's activities and make observations, which would be difficult for a male researcher (such as the author of this thesis).

A second criticism of participatory techniques is the potential reductionism as a result of preferring visual tools over verbal ones. There is scepticism about the ability of visual methods to go beyond simplification and reflect the complexities of real life. Such reductionism is a risk if only visual tools are applied. By combining both verbal and visual techniques, reductionism can be avoided. In this research, as a measure against possible reductionism, for example, maps and diagrams were created together with participants from the community not only for gathering information but also as a means to stimulate discussion. Drawing maps, assigning relationships and defining the extent of these relationships verbally with respondents, explores the complexity of real life rather than hides it. In this way, the tools complement each other to verify and cross check the data gathered using each method. Thus complexity rather than reductionism is provided by combining visual and verbal tools in the fieldwork part of this investigation.

A third criticism of participatory techniques is the lack of standards to assess and judge the quality of techniques and methods. In particular, Chambers' requirement for flexibility and suggestion of 'using your own best judgment' when applying these techniques and methods is criticised. As techniques and methods can continuously be changed and modified to fit different contexts there is no standard to judge quality and compare participatory techniques with other conventional techniques and methods. However, Brown et al. (2002) noted that there is evidence of the superiority of participatory techniques over conventional ones in empirical research due to measures taken to ensure representation of all groups. Techniques are modified to fit local conditions and hence include the different realities that standard techniques and methods might miss. It becomes clear from the application of participatory techniques in the fieldwork of this research that standardization could not be maintained without the risk of losing local specificity and conditions, particularly in exploring different livelihood strategies where differences exist in quality as well as quantity, and in the capacity to respond to vulnerability events. For example, in the villages close to the modern agricultural schemes greater diversification in non-farm livelihoods can be found than in villages where all livelihoods are based on traditional agriculture. Data on energy carriers and services linked to these differences have to be sought through various methods of data collection. An additional value of using a variety of methods in data collection is that this helps ensure reliability. The conventional, questionnaire- 
based, surveys have their own measures of reliability such as stratified sampling and statistical tests of significance. However, such methods of data collection remain a one-way flow of information in which there is only a limited possibility that respondents will be representative of all groups and that these groups will be able to raise their own issues and give their views and perceptions. Discussion groups enable a two-way flow of information in which the aim is to more accurately present all groups' perceptions and views by the respondents moderating the researcher's observations (Sapsford and Jupp, 2006) and each others statements. So, the use of a range of techniques and methods for gathering data in this research should enable the representation of different realities, which will increase the reliability of the data collected, against the exclusion of some realities, as well as a guarding against the potential data gathering errors referred to in Section 1.3.

\subsection{Relevance of livelihoods framework and participatory approaches for investigating problems related to energy services in Sudan}

Section 1.3 presented the difficulties in identifying rural energy problems and their inclusion in energy plans with the conventional methods used in energy planning. This section shows how participatory approaches can be used to overcome these problems. The first problem in identification is related to the use of language. The questionnaire-based surveys commonly used in energy data collection assume that researchers have prior knowledge of what is going to be investigated. That is, the kinds of issues to be investigated, their relevance to the already diagnosed problems and the expected output are readily known by the investigator (etic approach) (Moser and Kalton 1979). In the case of rural Sudan, it was shown in Section 1.4 that such prior knowledge about what constitutes rural energy problems is largely lacking, with the result of a reductionism of complex problems to one of 'fuelwood for cooking'. Thus, while the livelihoods framework meets with some of the same logic of the emic approach by prior identification of the five capitals, the links between energy and livelihoods in rural Sudan have never been explored. In this respect, local meaning, classifications and interpretations are used. For example, the local classification of soil types into karo which means the fertile soil close to the river bank and karad meaning the less fertile soil away from the river bank was uncovered. However simple this local soil classification, it can provide energy planners with useful information. Each of these soil types differs in the way it is cultivated and hence in the energy services required (for land preparation, irrigation, and other agricultural practices) and in the relations governing the production processes (see Chapter 4 - Dar Mali). Moreover, this classification is particular to the areas along the Nile. Moving beyond this geographical location there are other local soil classifications and farm practices, each with their own required energy services. In the context of rural Sudan, participatory approaches enable one to identify and define rural energy problems embedded within the specificities of their various locations.

In conventional approaches, sampling bias can limit data reliability. The problem of response error or of non-respondents ${ }^{7}$ in conventional approaches raises another

\footnotetext{
${ }^{7}$ Moser and Kalton (1972: 390-396) listed ten sorts of response errors, two of which are relevant for this research: a) the response error which can arise from the way in which questions are asked or answers are rephrased to serve the interviewer's opinion or expectations; b) the response error which
} 
question concerning the validity of questionnaire-base surveys for identifying rural energy problems in Sudan. Although this is more of a problem for the later stages of energy planning, when there is the need for extrapolation to the national level and aggregation of data for quantifying of energy demand, it is worth mentioning here as it forms the basis for excluding of the views and energy needs of many groups. The identification of groups and defining their relevance to the energy investigation is crucial for the later stages of quantification. This is because the need for energy services that support livelihood strategies can differ both in kind and quantity for different groups. For example, in Es Sadda, categorising the community in terms of gender and age shows clear differences in energy needs and priorities. Telecommunication is a strategic need for women's livelihood strategies in order to access financial capital, and the satellite TV is a strategic need for the youth in the village in terms of entertainment and to reduce the cost of travelling to other villages. These are different to the needs of the men, where the mechanization of farm operations is a strategic need to increase their financial capital through increasing the farmed area to produce cash crops (Annex 1). Wealth is also an important determinant of the kind and quantity of energy services demanded by different groups. For example, in Dar Mali, farm owners demand electrical pumps to increase their benefits and, by maximising output, reduce risks (see Annex 3). However, these demands run counter to those of the poor tenants whose livelihood strategy for employment is based on operating and maintaining diesel pumps for the large farmers, and whose livelihood strategies would be threatened by electric pumps. Spatial distances, even within the same village, can be a factor of differentiation in access to energy services such as the location of settlements relative to the school and the water haffir in Es Sadda, or the location of a house relative to the electricity grid in Dar Mali. Without considering and representing all these groups' differences in access to energy services, quantification of energy demand will likely focus on the needs of only the group of wealthy, older men who live in the centre of the village (who are often the respondents to questionnaires) and exclude the needs of other groups such as women, the young, the poor and those located on the periphery (who are frequently excluded from questionnaire surveys). Such a situation renders the data gathering process biased and imprecise, and any action taken on the basis of this data will not be equitable. Participatory approaches in the initial stages of data collection allow one to identify groups with different levels of access, needs and priorities for energy services, and hence to ensure their inclusion in later surveys. So, participatory approaches can be used as a means of ensuring stratified sampling and reducing nonrespondent biases through identifying and reaching all sub-groups in a village and reflecting their access, provision or use of energy services. Another important consideration is the exclusion of traditional energy sources in the quantification of national energy demand on the grounds of methodological challenges. However, since the livelihoods framework links energy services to rural livelihood outcomes regardless the types of energy carriers used, it ensures that traditional energy sources will be acknowledged.

So, for the identification of rural energy problems, participatory processes are supported for the reasons mentioned above. However, once the data have been

can arise from the respondent's misunderstanding of the question (asked using technical or vague words), or when one member of a household is asked to provide information about another member's tasks, views or roles such as asking a man in a rural area: how is the family meal cooked or which fuel type does your wife like to use for cooking purposes? 
collected, the question becomes: how can these data on rural energy be organised to provide a meaningful analysis? As an answer to this question, this thesis proposes using the livelihoods framework. The following section presents the framework, and shows how its components are linked to rural problems.

\subsection{Points of juncture between the livelihoods framework and participation methods}

Participatory approaches, sustainable livelihoods and energy planning are three distinct concepts, each with their own characteristics and logic. This research argues that they are in fact complementary, and when used together, they provide for more equitable outcomes in terms of the benefits of energy planning for rural areas. This research is exploratory in nature since it tests a hypothesis by adopting a wider scope to capture, analyse and represent the realities and dynamics of energy services in rural Sudan (Chapter 6). What is the rationale and justification for this proposition?

The first consideration is that the majority of the population in rural Sudan has largely been excluded in energy planning to date as was shown in Chapter 1. Section 2.9 showed the benefits of using participatory approaches in energy data gathering as a means of capturing a more holistic picture of rural energy needs. The relevance is based on the historic exclusion of the traditional sector and the lack of data on rural energy services in energy plans.

The second consideration is related to the data on which energy planning is based. As shown in Section 1.3, the processes used in building the energy data system do not identify, analyse or reflect, to planners and policymakers, problems linked to traditional rural livelihoods (Section 1.2.2 and Section 1.4). This ignorance of rural livelihoods in energy planning, and the unmet needs for energy services, contributes to the rural disintegration of communities (leading to both temporary and permanent internal displacements) and rural conflicts (civil wars such as in Darfur). So, for the energy planner, the livelihoods framework can help in identifying the problems of rural livelihoods and their linkages to the stock of energy services. In addition, the use of the livelihoods framework can draw attention to the kinds of problems that can be addressed in energy planning and to the consequences if these problems are not solved.

If current planning approaches continue, traditional rural societies will remain, dependent on their traditional sources and living with the threat of vulnerability, and planners will continue to ignore their energy needs and respond only to issues based on their conventional ways of deriving objectives, and identifying and presenting problems. This divergence between rural needs and planners views and ways will continue unless planners become aware of the need to be more inclusive and present the rural problems in their plans. A starting point in changing to more equitable outcomes of energy planning is to have tools that make this possible. The livelihoods framework, as used in this research, provides a way to identify, analyse and present rural energy problems to decision-makers. The framework's particular strength is that it derives the planning objectives and proposed interventions to support rural livelihoods from the perspective of the rural communities and the real needs of rural livelihoods. 
A third advantage of the livelihoods approach is that it identifies the vulnerability context as a major determinant of livelihood strategies and actions. Priorities of people in such circumstances are towards ending the situations which makes them feel vulnerable and insecure. Planning should aim to support people so that they are able to respond when vulnerability events threaten their livelihoods.

A fourth consideration is that communities in rural Sudan are heterogeneous with multiple ethnicities, family and kinship groups, and with diverse livelihoods. In terms of equity, all groups should benefit from state planning. As shown in Section 2.6, applying participatory tools in data gathering offers ways of obtaining an equitable representation of all rural groups and overcoming the weaknesses of conventional questionnaire-based approaches.

In conclusion, both the livelihoods framework and participation have the potential to contribute to exploring the rural energy problems of those stakeholders usually excluded. The livelihoods framework provides a way to identify rural energy problems, relating them to, and analyzing them within, the context of rural livelihoods. Thus, the livelihoods framework can facilitate the derivation of rural needs for energy services, which are embedded in rural livelihoods, and hence enable the inclusion of the objectives of both the traditional and modern rural sectors in energy planning. The participatory approach provides a set of tools for use in the process of identifying problems, and prioritizing them from the perspectives of the rural population. The livelihoods framework is a heuristic framework which enables one to identify the links between the vulnerability context and people's assets, and the role of energy in building assets and reducing vulnerability. Although the livelihoods framework is a qualitative approach, objectives can be quantified for planners at a later stage of the planning process. Hence the methodological argument advanced by energy planners in Sudan against the inclusion of rural livelihoods can be overcome (Section 1.3). Using this approach, the energy planners would be able to focus on the core issues: what are the real problems in rural areas of Sudan that need to be identified and made visible to decision-makers so that they take the needed courses of action? (Chapter 5).

\subsection{Unit of observation and unit of analysis}

In Section 1.3 it was shown that the current approach to the selection of the unit of observation and the unit of analysis in energy investigations favours the household and the energy carrier type respectively. Reducing energy investigations to the household as the unit of observation and the energy carrier as the unit of analysis obscures other important rural energy problem, and leads to the misrepresentation of rural energy problems in national energy planning. In this thesis, broader units of observation, the village, and as unit of analysis, energy services, are used. The selection of the village as the unit of observation, instead of the household, is based on a number of reasons. First, the village represents an arena for rural people to interact socially, economically, culturally and politically, and is an important arena for decisions affecting the village community. In the Sudanese rural context, village institutions such as committees, leaders and organizations are important in organizing and mobilizing communities to undertake the provision of common services such as drinking water facilities, education and health. Second, a village represents a structure 
that facilitates the delivery and allocation of energy services and organizes the use of the different capitals among the village community. Third, a village, as the unit of observation, provides the necessary conditions for investigating the links to other structures within government institutions, since these links fall within the domain of the village organizations rather than within individual households. This is particularly relevant in the case of traditional livelihood modes where most resources and services are subject to community ownership rather than owned at the individual level. In addition, the village organizations play an important facilitating role in negotiating the village needs with providers of energy services (government, NGOs, the private sector) and mobilize the community to participate in village affairs.

The selection of energy services as the unit of analysis, rather than energy carriers, is based on two arguments: First, it avoids reducing rural energy problems to one of cooking fuels as happens with the conventional approach of household energy surveys. Secondly, energy services, as defined in Chapter 1, represent what actually matters to the people: the generated services rather than the energy carrier. What is important is the level and quality of the services that directly affect livelihoods and the capacity to respond to vulnerability events, and not specifically the energy carrier/technology mix (physical capital components) used to provide the services. The energy carrier/technology mixes are important but not necessarily determinants. So, using energy services as the unit of analysis in this thesis enables one to consider the interrelations among all capitals in transforming sources into energy services as shown in Section 2.5.

Thus selecting the village as the unit of observation and energy services as the unit analysis allows one to move out of the rural kitchen and investigate rural energy in its broader links to rural livelihoods. Rural energy services such as water, agricultural production, income generation, transportation and communication are important services for rural livelihoods but are not visible in the Energy Data System and consequently neither in the developed energy plans. Such kinds of rural energy services will not be identified when the household, as defined by FAO and the ADB, is the unit of observation (see Section 1.3). So, the use of broader units of observation and analysis, linked to the use of livelihoods as a heuristic framework enabling the identification of rural energy problems, and the participatory approach are elements of bottom-up planning which allows for a wider, more inclusive, representation of all societal groups. As was argued in Section 2.6, bottom-up planning will provide decision-makers and energy planners with a different set of needs, services and priorities for energy, which can be included as objectives in energy planning, and hence result in more equitable outcomes.

\subsection{Selection of case studies}

Based on the research objective, the selected case studies are drawn from areas dominated by the traditional agriculture sector and outside the modern large-scale agriculture sector. The selected areas are characterized by frequent occurrences of vulnerability events (drought in some, floods in others). Spatially, the case studies are located in the northern part of Sudan made up of the semi-desert grassland and shrubland, desert dunes without perennial biomass cover and the absolute desert ecological zones (see Map 1.1). These zones together cover about $47 \%$ of the total 
area of Sudan (Mustafa and Ahmed, 2005) and are inhabited by $34.6 \%{ }^{8}$ of the country's population (Central Bureau of Statistics, 2002). Having set the general spatial characteristics, a screening process based on specific criteria was used to systematically select individual villages as case studies. The criteria for village selection were set to ensure representation of different contexts and conditions. These differences include variations in the kinds of natural capital on which livelihoods are constructed. The screening process was eased by the author's accumulated lengthy experience in the area, gained when participating in a number of energy projects executed by the Energy Research Institute ${ }^{9}$.

Table 2.1

The main spatial and economic characteristics of the selected villages

\begin{tabular}{|l|l|l|l|l|l|}
\hline Villages & $\begin{array}{l}\text { Administrative } \\
\text { affiliation }\end{array}$ & $\begin{array}{l}\text { Nearest } \\
\text { town }\end{array}$ & $\begin{array}{l}\text { Type of } \\
\text { roads to } \\
\text { nearest } \\
\text { city }\end{array}$ & $\begin{array}{l}\text { Source of } \\
\text { water }\end{array}$ & $\begin{array}{l}\text { Main economic } \\
\text { activity }\end{array}$ \\
\hline $\begin{array}{l}\text { Es } \\
\text { Sadda }\end{array}$ & El Gedarif & $50 \mathrm{~km}$ & Earth & $\begin{array}{l}\text { Surface, rain } \\
\text { water } \\
\text { harvesting }\end{array}$ & $\begin{array}{l}\text { Livestock } \\
\text { Agriculture }\end{array}$ \\
\hline El Ideid & El Gedarif & $100 \mathrm{~km}$ & Earth & $\begin{array}{l}\text { Surface, rain } \\
\text { water } \\
\text { harvesting } \\
\text { /underground }\end{array}$ & $\begin{array}{l}\text { Livestock } \\
\text { Agriculture }\end{array}$ \\
\hline $\begin{array}{l}\text { Dar } \\
\text { Mali }\end{array}$ & Nahr Alnil & $16 \mathrm{~km}$ & Paved & $\begin{array}{l}\text { Permanent } \\
\text { running river } \\
\text { /underground }\end{array}$ & Agriculture \\
\hline $\begin{array}{l}\text { Goz El } \\
\text { Halag }\end{array}$ & Nahr Alnil & $32 \mathrm{~km}$ & Earth & $\begin{array}{l}\text { Seasonal } \\
\text { running river } \\
\text { /underground }\end{array}$ & Agriculture \\
\hline $\begin{array}{l}\text { Um } \\
\text { Laham }\end{array}$ & North Kordofan & $17 \mathrm{~km}$ & Earth & $\begin{array}{l}\text { Rain/ } \\
\text { Underground }\end{array}$ & $\begin{array}{l}\text { Livestock } \\
\text { Agriculture }\end{array}$ \\
\hline El Ga'a & North Kordofan & $160 \mathrm{~km}$ & Earth & Underground & Salt extraction \\
\hline
\end{tabular}

The criteria of village selection are set to represent different contexts and conditions. These differences primarily include spatial location relative to urban centres, types of roads, sources of water and main economic activities. Table 2.1 summarises these main differences between the selected villages (See also Chapter 4 and Annexes 1 to 6).

\subsection{Data reliability and validity in this research}

Reliability and validity are two important aspects to be considered in qualitative research (Yin, 1994). Reliability refers to the likelihood that the study could be

\footnotetext{
${ }^{8}$ This excludes the population of the metropolitan area of Khartoum.

${ }^{9}$ I participated in the following research projects located in the case study areas: North Kordofan State (1993-1997) - the implementation of the UNDP funded Rural Solar Energy Development project (RSED); Nahr Elnil State (1988-1992) - implementation of the Sudan Renewable Energy Programme (SREP); and El Gedarif State (1999 - 2004) - implementation of the Solar School in Sudan project (SSS).
} 
replicated with the same results. This is provided through the description of the methodology applied in conducting the fieldwork. The triangulation of both methods and sources of data ensures the quality and reliability of the data.

Validity refers to both internal and external validity. Internal validity is provided here by developing possible relationships between the energy services and the various components in the livelihoods framework. However, the causal linkages identified in Dar Mali highlight a limitation in the livelihoods framework, where some factors which affect livelihoods are clearly embedded in the specific political dimension and the history of the village. The concept of the energy circle, to reflect the relationship between capitals and energy services, adds to the internal validity by proposing casual links between livelihood outcomes and the stock of energy services. Multiple case studies involving six villages can increase the external validity of the research findings by providing comparisons between different situations and accumulating evidence that allows one to generalize the findings.

The case studies undertaken in this research are, however, only applicable to certain contexts within rural Sudan. All the cases are confined to areas where there are no direct conflicts between the different groups in the area, or with the government. However, there are some geographical areas, such as Darfur, where there is civil instability and war due to various vulnerability contexts. These contexts can present different realities to the case study area of this thesis and so might not fit a generalization inferred from the villages in this study. Also, any generalization in this research will be specific to the time of this study as Sudan, since 1992 has witnessed considerable economic and political liberalization. The move towards political liberalization is not taking place at the same pace as that of economic liberalization, although, two important events are likely to take place in 2008. The first is a change to a multiparty democratic system, and the second will be a vote for selfdetermination for Southern Sudan. Both political events are expected to make considerable differences to the current management of economic and political affairs in Sudan ${ }^{10}$, which could potentially change the planning approaches currently used in the energy sector and the wider economy.

Participatory data methods, with their built-in cross-checks and allowing all groups in a village to be reflected in the participant sample, enable the gathering of reliable data. For example, the availability and location of fuelwood, as indicated in the resource map, is checked against the ranking of fuel types used in providing energy services, the seasonal calendar of fuel availability and the focus group discussion. The findings are moderated and confirmed by transect walks in which the data gathering group walks across the village following different routes. Conclusions drawn from applying all these techniques increase the reliability of the data gathered. The reliability of the data is also increased by including the views obtained from the different groups in the

\footnotetext{
${ }^{10}$ Marginalization is a hot issue in Sudanese discussions and media. A Sudanese website (http://sudaneseonline.com) allows an open and wide discussion on what people consider to be the issues causing of dissatisfaction with the way political and economic affairs are managed. A Google search on this website for the Arabic word 'Tahmiesh' (which means marginalization) showed that, up to June 2007, there had been 4670 issues discussed on the state of marginalization in Sudan. Cultural, social, economic and spatial dimensions are some of the topics along which marginalization in Sudan is discussed and analysed.
} 
community and cross-checking the data gathered from the community with that obtained from key informants.

Finally, it is important to consider those who participated in the collection of data for this research since this is important in limiting observer and provisional biases and ensuring that all important issues linked to energy services and rural livelihoods are raised for discussion and analysis. Three research assistants participated in the collection of data for this research, one trained in development studies, one a geographer and the third an engineer (see footnote 16).

\subsection{Conclusion}

This chapter has provided an answer to the first research question, i.e. "How can problems related to energy services in rural Sudan be investigated such that rural objectives and priorities for energy planning are identified?" That is, firstly, by the use of the livelihoods framework to identify those energy services that are a priority for the rural population and can secure rural livelihoods. The livelihoods framework also provides a justification for the inclusion of traditional energy services, on which rural livelihoods are based, by analysing the links between the vulnerability contexts of rural Sudan and their impacts on the flow of energy services which have led to the destruction of rural livelihoods and displaced the rural populations in the past (Annexes 1 to 6). Second, complementing the livelihoods framework with the participatory approach to data collection ensures the representation of all rural groups' priorities and objectives for energy services in the energy data system and in the subsequent contents of energy plans. So, the use of the livelihoods framework and participatory approaches at lower planning levels (i.e. state, province) in the investigation has the potential to expose energy planners and decision-makers to the real problems of rural energy services and their importance in securing rural livelihoods in Sudan.

However, the inclusion of rural energy services in the energy policies and plans requires both existing and functioning of capable transforming structures and processes, specifically the energy structures and processes on which rest the use of this methodology which incorporated analytical framework with an approach for data collection. The methodology will hopefully identify and provide sufficient justification to include, within energy planning processes, the objective of solving the energy problems of rural livelihoods. The next chapter will describe the vulnerability contexts, as disturbance factors in rural livelihoods, in Sudan, and present the transforming structures and processes, as possible channels for inclusion and solving the energy problems of rural livelihoods. 


\section{Chapter Three: Vulnerability and transforming structures and processes}

\subsection{Introduction}

Chapters 1 and 2 presented the research problems and the research methodology to be used. Chapter 1 presented the research problem in terms of the exclusion of traditional rural areas from the benefits of energy planning. This exclusion is shown to result from the disinterest of planners in the rural areas and traditional livelihoods. Energy planning aims to meet the national economic objectives of increasing export commodities in order to increase hard currency earnings, improve the balance of payments and generate employment opportunities. Economic sectors which are considered important in solving the related problems are in the modern agricultural sector and the industrial sector. The former is limited to certain geographical areas with irrigated and mechanized agriculture. These areas are targeted by the government for transport and financial support. Activities outside these two sectors are defined as traditional, which are viewed by both national planners and their international sponsors, as having no contribution to make to national economic objectives, and are thus excluded from the processes of energy planning (Section 1.2.2). The energy planning processes (identification of problems, thus diagnosis and setting objectives) institutionalise this state of exclusion (Section 1.3). The energy needs of the traditional sector are, therefore, not reflected in the energy data system. Accordingly, energy planning, so far, in Sudan fails to address issues of concern to the majority of the rural people who are involved in the traditional sector and hence it does not identify their problems or propose solutions.

Chapter 2 proposes some ways that could be employed in energy planning processes to end this state of exclusion and present to decision makers and planners the problems related to rural energy services in the traditional sector. Section 2.2 discusses the livelihoods framework, as a possible approach for identifying and analyzing energy problems related to, and derived from, the needs of rural livelihoods. Section 2.6 discusses participation as a possible methodology for inclusion and representation of different local groups' energy services needs, identify problems related to access of these groups' to energy services and the groups' perceptions of possible solutions for their problems of access to energy services. Section 2.9 links the livelihoods framework with participatory approaches in the context of energy planning. It is argued that such an approach will lead to the identification of problems related to rural energy services and further provides sufficient justification for planners and decision makers to include them in energy sector plans.

The inclusion of the traditional energy sources used to provide the energy services required for rural livelihoods in energy planning does face some methodological difficulties in terms of quantification, which has been used to justify ignoring their contribution to economic development (See the World Bank quotation in Section 1.2.2). However, the exclusion of traditional energy sources from the national energy plan resulted, in rural Sudan, in negative livelihoods outcomes, the consequences of which include widespread rural displacement and social unrest due to competition over scarce natural resources. So, it can be argued that the social and political costs of excluding traditional energy sources from the EDS are far greater than the saved cost 
of not developing a data collection approach that estimates the quantity of traditional energy sources used to provide rural energy services. So, securing rural livelihoods, to which energy planning can make a significant contribution, against vulnerability can contribute solving socioeconomic problems and political instability in Sudan. To include the rural energy services necessary for rural livelihoods in national energy planning, the distributive and constitutive roles of the transforming structures and processes must be widened to include rural livelihoods.

In this chapter, two sides of the problem of ensuring a stock of rural energy services are investigated. The first side is the vulnerability context which can disturb the flow of energy services to the rural population and threaten the whole rural livelihoods system. Investigating on this side of the problem tackles the second research question:

"How do factors of the vulnerability context disturb the flow of energy services and how does this disturbance affect rural livelihood outcomes?"

The other side of the problem is the functioning of the transforming structures and processes which can offer possible solutions for the rural vulnerability context. Looking into this side of the problem involves the third research question:

"Why were energy problems related to traditional rural livelihoods not addressed in national energy planning processes in Sudan?”

To answer the above research questions, this chapter first investigates the vulnerability context and exposes the types of vulnerability common in Sudan, and how they affect the flow of energy services linked to rural livelihoods. Second, it investigates the transforming structures and processes in order to explain why the needs for energy services (traditional rural livelihoods) are missing from the objectives set for national energy planning in the past. Further, it indicates opportunities for transforming structures and processes that would provide solutions and secure the flow of energy services to support rural livelihoods.

The chapter is organized as five sections. After this introduction (Section 3.1), Section 3.2 discusses those factors that have wide vulnerability consequences for rural livelihoods in Sudan. Section 3.3 discusses the general transforming structures and processes, Section 3.4 outlines the energy sector structures and processes and, finally, Section 3.5, based on the findings of the chapter, answers the questions posed in this chapter.

\subsection{The vulnerability context}

This section describes the general vulnerability contexts that have wide negative impacts on Sudanese society. According to Carney, these contexts can be classified into three categories: shocks, trends and seasonality (DFID, 1999: Section 4.8). As shown in Section 2.12, the selection of villages for this study is based on some of the vulnerability factors such as droughts that disrupt rural livelihoods. However, not all vulnerability factors such as civil conflicts and war can be directly applied to the selected villages in this thesis (see Annexes 1 to 6). Despite the fact that civil unrest 
and war affects all parts of Sudan to some extent, in the case study areas the effects of these factors were not significant.

\subsubsection{Shocks}

In the Sudanese context, the most important types of shocks that have wide impacts are war and droughts (Eltigani, 1995). Both have the common features of destroying the assets on which people construct their livelihoods and resulting in a displacement of rural people in Sudan (Bekker, 2002; Assal, 2004). Some shock factors are specific to certain areas such as flooding along the Nile and its tributaries. Other shock factors are also local in their occurrence and impacts, such as fire outbreaks in pasture areas, and outbreaks of human and animal diseases.

Civil conflicts and war: generally there are two types of conflict in Sudan. One in which the government is part of the conflict, such as armed opposition which often arises following the seizure of political power in a military coup (where groups have political demands such as a share of the wealth and power, or for democracy, as was seen in the conflict between the Government in Khartoum and the opposition in South Sudan). The second type of conflict is that which often occurs between tribes and within local groups over the use of natural resources.

In terms of the first type of conflict, Sudan has the longest running civil war in Africa, with more than 50 years of civil war in its southern region. The conflict started as far back as 1953, three years before the independence of Sudan. Besides this prolonged war, in recent decades (since 1990) other wars have erupted in several parts of the country such as those in the eastern part, the Nuba Mountains in the south-east, and in the Darfur region in Western Sudan.

Different reasons have been cited for eruption of civil war in the various regions of Sudan. In southern Sudan, war is explained in terms of ethnic, economic and religious factors. In Darfur, war is rooted in tribalism, ecological degradation, trade and politics (Young et al., 2005: 12) ${ }^{1}$. In the eastern region, conflict is based on development and trade factors. The widespread conflicts within Sudan have also been related to economic factors and unbalanced development, where some regions were developed while others were marginalized and ignored (Duffield, 1990).

The discovery of commercial deposits of oil in the southern and western parts of Sudan in the 1980s added to the ongoing conflicts (Newell, 2000). People in the areas where oil was discovered suspected that the exploitation of oil would not benefit their regions. These views were based on suggestions made in 1983 by the government of Sudan, the World Bank/UNDP mission and the Chevron Oil Company, which was then active in oil exploration in Sudan, namely the idea to establish oil refineries outside the regions of oil discovery ${ }^{2}$ (UNDP/Word Bank, 1983). So, throughout the period of conflict the oil fields were targeted by the militants forcing the exploration company to cease operations and evacuate the area.

\footnotetext{
${ }^{1}$ Available at : http://nutrition.tufts.edu/pdf/research/famine/darfur_livelihoods_under_seige.pdf ${ }^{2}$ UNDP/World Bank mission suggested the establishment of two refineries to be located in Kosti and Port Sudan which were to be connected through pipelines to the oilfields. The two suggested cites are about $700 \mathrm{~km}$ and $1600 \mathrm{~km}$ respectively from the oilfields. Today, refineries are located in Abu Gabra (western Sudan), El Obied (western Sudan), Kartoum (northern Sudan) and Portsudan (eastern Sudan). All these refineries are connected by $1610 \mathrm{~km}$ of pipeline.
} 
The second type of conflict, involving more localized fighting, is often explained in terms of ecological factors where natural degradation has resulted in a scarcity of resources (land, pasture or water) (Eltigani 1995). Conflicts arise over the control of these resources by different users, defined by mode of livelihood such as sedentary/nomadic or agriculturalist/pastoralist or by identity, such as tribe or religion.

Regardless of the reasons for conflicts and their spread, their impact on livelihoods is dramatic, including the destruction of assets from which people draw their livelihoods. The loss of assets can lead to the displacement of people from their original areas to other places searching for security and assets to sustain their livelihoods. Examples from the recent conflict in Darfur show that there were a large number of villages destroyed including assets such as houses, water sources, schools, health centres and farms, and the looting of personal assets and animals (Young et al., 2005: 43).

This reflects the fact that an immediate outcome of such conflicts can be the destruction of components of physical and natural capitals. The ownership of the affected capital can be at various levels: national, as with the oil constructions and the Jungli canal; community, as with schools and water wells; or individual, such as houses. The destruction of natural capital results in the loss of farms, pasture and forests. The other capitals (social, human and financial) can also be affected: loss of family members, who die in conflict, the displacement of families members to other areas where their social and kinship networks are weak (social capital), separation of people from their money earning activities (financial capital) and the lack of health and educational opportunities (human capital). A study of internally displaced people (Assal, 2004), shows that people in the displaced camps around Khartoum lack water, health facilities and have no jobs (energy is not explicitly mentioned). This state of insecurity and destruction of assets leads to the total failure of local livelihoods forcing people to search for refuge and security in other areas, increasing their vulnerability and creating further conflicts between newcomers and the original inhabitants of these areas.

Drought: Drought events are a devastating factor for both the natural resource base and the livelihoods of rural people. Sudan has witnessed frequent lengthy droughts since the 1980s. The drought which happened in 1983/1985 was the worst. The most severely affected people were those who lived in areas north of latitude $13^{\circ} \mathrm{N}$ (Bailey, Buchanan-Smith and Maxwell, 1990). The drought resulted in the spread of famine across the country causing a massive displacement of people from rural areas. The UN Department of Humanitarian Affairs, on January $4^{\text {th }} 1985$, estimated that around 4.5 million people were severely affected by drought. About $25 \%$ of these had been displaced. Food and water were the most important services lacking during the droughts. During the 1983/85 drought, the UN estimated that in western Sudan alone there was an urgent need for 70,000 tonnes of food items, the digging of 800 shallow wells to supply drinking water and housing materials to accommodate 300,000 affected families.

The problems resulting from the drought were aggravated by the fact that the people affected were dispersed over vast areas where there was no suitable infrastructure or 
fast and reliable means of transportation to reach the affected areas. Although there was plenty of food provided by the international community, as observed by the Sudan Now magazine (quotation at the beginning of Chapter1), getting these food items to the affected areas was not possible due to the lack of an effective transportation system. So, rural people in affected areas faced a severely limited access to locally provided services from natural capital, and outside support due to non-existent physical capital to facilitate the transport of food available elsewhere in Sudan.

Floods: floods generally occur along the River Nile and its tributaries (the Blue Nile, the White Nile, Atbara River, and Gash River) and other seasonal streams and valleys. The months of July to September are the usual flooding periods for these rivers. However, in some years (e.g. 1946 and 1988) the flood level exceeds typical values which lead to wide destruction of livelihood assets (houses, services, buildings, farms, crops and orchards) along the river banks.

To sum up this section on shocks, the factors of conflict, drought and flood have had (and continue to have) major impacts through the destruction of people's capital assets. As was seen in the above, conflicts lead to the destruction of most capital components and drought leads mainly to the destruction of natural capital components. Thus, it is reasonable to conclude that these shocks have negative impacts on the stock of rural energy services. The destruction of assets, in particular the biomass energy carriers, on which energy services are based, leads to a reduction in the stock of energy services and hence causes the energy circle to contract. Also, vulnerability is increased by the failure to deliver energy services based on modern energy carriers to overcome these shock factors.

\subsubsection{Seasonality}

The seasonal availability of some components of livelihood assets and services also has an impact on livelihoods outcomes. The most significant is the seasonality of rainfall which occurs during the months of July to October in most of Sudan's regions. Rural people heavily depend on the rainy season for water: to provide pasture for their animals and to grow their food, and for the growth of natural biomass that provides fuelwood. Most of these services start to decline after the rainy season ends. Harvested water in natural depressions or manmade reservoirs is available for only a few months after the end of the rainy season, pasture begins to become scarce, and food is no longer produced. Not only the rains, but also the shift between cool and hot weather affects the need for energy services to provide heating or cooling. At the same time, the seasonal fluctuation in prices for animals and crops, which are important sources of financial capital in rural areas, affects rural people's ability to buy energy services. As shown in the Es Sadda case study, the higher price levels for water services can coincide with the minimum prices for livestock (the main source of financial capital) which reduces the financial capital of families (Figure 1.1 in Annex 1).

From the above description of the vulnerability context in Sudan, it is clear that there are various factors that currently degrade the capital assets of the rural communities and consequently the stock of energy services is reduced. Evidence for the impacts of these vulnerability factors on rural energy services is found in all the villages in the work reported here (Tables 4.7.1, 5.1 and 5.2). Nevertheless, there are some 
differences between the studied villages due to spatial location, economic activities, wealth of the people and other attributes which result in the stock of energy services varying from one village to another (Annexes 1 to 6). These differences, between and within the six villages, result in differentiation of access to energy services and lead to variations livelihoods outcomes for different groups (Chapter 4).

\subsubsection{Trends}

Here, for Sudan, we consider macro-economic trends, population growth and climatic trends.

Macroeconomic trends: the main economic trend in Sudan is a move towards full liberalization of the economy, which started in the early 1970s and continues to date. The externally driven liberalization policies were partially initiated in the 1970s with the World Bank/IFM led stabilization and structural adjustment programme (Brown, 1986: 125-162). However, a complete liberalization of the economy (removing subsidies, cutting back the public sector, full cost recovery of services, and removing constraints on the private sector) was not announced until 1992. The announcement of the liberalization policy placed Sudan under a new economic order. In the liberalization of the economy, most of the public sector corporations were privatised and its services were commercialized (Osman, 2000). The only exemption is the national electricity corporation which is still, at the time of writing, a public sector company and its tariffs are subsidized by the federal government. In the provision of all other services the government is not directly involved. All the public services which were previously provided by the public sector were either handed over to the private sector or are now run on a cost recovery basis. For example, the National Rural Water Corporation (NRWC), which is responsible for digging boreholes and operating water pumps, was restructured to operate on a commercial basis. Another example is the abolishment of the payment of boarding schools fees by the government, resulting in students' families having to pay for their stay. Those families who could not afford to pay the fees were forced to withdraw their children from school. Children from the more remote regions were particularly affected.

The negative consequences of these liberalisation policies especially intensified the hardships felt by the majority of the rural population where traditional practices do not operate according to market mechanisms. Exchange of goods for money is not common in traditional societies. Because of this, the overall result has been the transformation of the subsistence economy, which provides some sort of social and economic security, into a fragile market economy. This fragile market neither provides sufficiency in remunerative employment or in available goods and services to buy. As a consequence, the rural population, lacking the support of their old subsistence economy, has been forced to encourage young male family members to migrate within and beyond the country to seek alternative sources of income to support the remaining family members (females, children and elders) who are left behind to face unfavourable ecological factors and, sometimes, social unrest. The effects of the trends observed in the six case study villages clearly show the vulnerability of the rural population caused by the failure of the local production systems and an inefficient market mechanism (linked to a lack of energy services). As will be shown in Chapter 4, in Dar Mali, Goz El Halag and El Ga'a villages, where production is aimed at the market, energy services can be secured from the market. In $\mathrm{El} \mathrm{Ga'a,} \mathrm{there} \mathrm{is} \mathrm{a} \mathrm{well-developed} \mathrm{market} \mathrm{for} \mathrm{the} \mathrm{extracted} \mathrm{salt,} \mathrm{as} \mathrm{there} \mathrm{is} \mathrm{for} \mathrm{the} \mathrm{farm}$ products from Dar Mali and Goz El Halag where the cash income is used to obtain 
energy services. (Chapter 4 and Annexes 3, 4 and 6). In the other three villages (Es Sadda, El Idied and Um Laham), although there are some differences among them, production is predominantly at the subsistence level and energy services are largely obtained from natural capital. There is only a limited role for the market in providing energy services in these villages from physical capital. The problem of a high dependence on natural capital stems from its erratic and fluctuating nature that quite often makes rural livelihood into vulnerable due to a lack of energy services (see Chapter 5, Tables 5.1 and 5.2). This relationship between natural capital, physical capital and the vulnerability of livelihoods is illustrated in Figure 5.1. Migration to earn cash is one of the few options open to people in these villages to obtain energy services. However, this comes at the expense of a loss of available labour from which to extract energy services such as the manual drawing of water and manual farm operations (Chapter 4 and Annexes 1, 2 and 5).

Population growth: On the eve of independence, in 1956, Sudan's population was estimated at approximately 10 million and, in 2005, the estimates were of a figure of 38 million, with an annual growth rate of $2.6 \%$ (based on an extrapolation of figures from the 1993 census). In the six villages that are part of the study reported here, the population increase results not only from natural growth but also in the villages of Es Sadda, Dar Mali and El Ga'a due to the arrival of people displaced due to the factors of vulnerability (Annexes 1 to 6). In order to sustain livelihoods, this increase in population requires a corresponding increase in capitals. However, the national economic resources and assets that can provide employment and sustain livelihoods remain unchanged in most rural areas. This increases pressure on the available capitals. This pressure was further intensified by the adopted economic policy of liberalization and commercialization of all services. The liberalization policies, accompanied by the decentralisation of services such as water, education and health, have made these services unaffordable to many people. In Um Laham, for example, the water pump remained unfixed for the three years leading up to this study because the people of the village were unable to pay for its maintenance. Likewise, the abolishment of boarding schools, in 1996, has meant that people in many rural areas are now unable to send their children to school or pay associated living costs. Medicine and medical services are also no longer provided free at government hospitals. In many rural areas, there is still a subsistence economy and hence there is no locally generated cash income that would enable people to pay for such services (World Bank 2003). This leads to men migrating from the traditional rural sector to the urban and modern sectors in order to be able to finance their families' needs for services (Chapter 4 and Annexes 1 to 6). Although the financial capital may be increased by this strategy, both social and human capitals decline for those left behind (women, children and elders).

Climatic trends: This refers to those climatic conditions that affect livelihood assets. Metrological observations show a decline in the mean annual rainfall since the early 1960s. The levels of rainfall declined by $6.7 \%$ over the period from the 1960 s to the 1980s. Due to this decline in rainfall and pressures on natural vegetation, most of the semi-desert and acacia lands have become desert (Khalid, 1996). The recent studies as part of a climate change project in some parts of Sudan (e.g. the Kordofan area) show that the trend in average rainfall is one of decline (Higher Council for Environment and Natural Resources, 2003). These trends have led to a decline in other components of natural capital such as soil fertility, from erosion and desertification, which in turn 
can lead to a decline in all materials drawn from natural capital such as food, water, fodder and fuel. In the studied villages, the reported increased frequency of drought has led to displacements from some of the villages (Annexes 1, 2, 4 and 5), and increased settlement in others (Annexes 3 and 6). This provides empirical evidence on how these climatic trends lead to negative livelihoods outcomes in rural areas.

\subsection{General structures and processes}

Structures and processes in the livelihoods framework play a mediating role by influencing access to capitals through defining rights of access. Structures and processes include policies, programmes, laws and legislation, and the level of the market, which all shape the ways capitals are combined, clustered, substituted or sequenced to help a particular group's strategy. Subsection 3.3.1 describes the general structures through which Sudan is administered. A brief description of the political make-up of the different governments that have ruled in Sudan, and their impacts on the administrative structures, is given. Subsection 3.3.2 describes the general processes through which Sudan is ruled, and what rights are granted by laws and legislation for access to capitals and for participation in political power and economic wealth.

\subsubsection{General Structures}

Structures refer to the organizations and institutions that set and implement macro economic policies and legislation, deliver services, purchase trade or perform other functions that affect livelihoods (DFID, 1999: Section 2.4.1). This subsection describes the development of the general structures since Sudan gained its independence until the time of writing.

Sudan gained its independence from the British in 1956, since when it has witnessed six major changes in government structures, and two transitional governments which lasted for one year each. However, a distinction can be made between three forms of structures created by these changes: those structures of government which are based on democratic parliamentary ruling systems, those which are based on socialist ruling systems and, finally, those which are based on Islamic ruling systems. The changes in the ruling system since independence are listed in Table 3.1. After each major change in political power, a complete change in the political structures took place. These were parliamentary in the first democratic regime, technocratic ruling during the Aboud military regime, parliamentary in the second democratic regime, socialist in the Mayo military regime, parliamentary in the third democratic regime and, later, an Islamic system under the National Salvation military regime. However, no fixed structure was followed by any regime throughout its entire lifetime: they all made changes to their structures during their periods in power. The regime in power at the time of writing gained power in 1989 and has passed through different phases in its structures. In 2005, after the peace agreement with the Southern Popular Liberation Movement (SPLM) and the agreement with northern oppositions represented by the National Democratic Alliances-Sudan (NDA), the government system changed from the military Revolutionary Command Council for National Salvation (RCC-NS) to a multiparty parliamentary system providing freedom to political parties to prepare for a general election in 2011 (the CPA). Three parties make up the government at the time 
of writing, sharing the executive and legislative bodies of the government according to the 2005 Peace Agreement which determined the levels of representation.

Administratively, Sudan adopted a federal system in 1996 which provides two levels of authority within the government system. The political power and economic resources are shared between government at the federal and state levels.

Table 3.1

Types of ruling systems in Sudan since independence

\begin{tabular}{|l|l|l|l|}
\hline No. & \multicolumn{1}{|c|}{ Type of Government } & System of government & \multicolumn{1}{|c|}{$\begin{array}{c}\text { Period in } \\
\text { Power }\end{array}$} \\
\hline 1 & The first democracy & $\begin{array}{l}\text { Multi-party } \\
\text { Parliamentary }\end{array}$ & 1956 to 1958 \\
\hline 2 & Aboud military regime & Technocratic & 1958 to 1964 \\
\hline 3 & The second democracy & $\begin{array}{l}\text { Multi-party } \\
\text { Parliamentary }\end{array}$ & 1964 to 1969 \\
\hline 4 & Mayo military regime & Single party (socialist) & 1969 to 1985 \\
\hline 5 & The third democracy & $\begin{array}{l}\text { Multi-party } \\
\text { Parliamentary }\end{array}$ & 1985 to 1989 \\
\hline 6 & $\begin{array}{l}\text { National Salvation military } \\
\text { regime }\end{array}$ & Single party (Islamic) & 1989 to present \\
\hline
\end{tabular}

The federal structure is composed of the President, two vice-presidents, and the cabinet of ministers, the national assembly and the constitutional court. The first vicePresident is also the President of the southern government formed after the 2005 peace agreement.

Nationally, Sudan is divided into 26 states (Map 3.1). Each state is further divided into provinces based on certain criteria such as homogeneity of population and level of resources (See Section One of Part One of the Constitution). The number of provinces within each state varies. When the federal system was first adopted smaller units known as localities were formed within provinces but, in 2004, some localities were abolished (particularly those which failed to generate revenues to meet some of their expenses) and the rest amalgamated into provinces to reduce state administrative costs. Therefore, as of early 2008, there is no administrative structure between the provincial level and local levels. This has had an enormous impact on the (lack of) planning capacity, including energy planning, as will be further elaborated in Chapter 6 (see also Section 3.5). At the local village level, the government structure is represented by the Village Popular Committee (VPC). The people of the village elect the 12 members of the VPC. The VPC chooses its officers and establishes subcommittees to run village affairs and communicate with officials at provincial and state levels. Relations among the upper levels of the administrative system (federal, state and provincial) are well defined by the constitution (Boxes 3.1 and 3.2 below). However, political power is only defined at these levels: power relations between the provincial and village levels are not stipulated in the constitution. However, with 
respect to financial resources, the constitution did define the resources of the localities, before their abolishment, and afterwards the shifting of the localities' financial resources to the provinces (see Section 3.3.3 for further detail). At the village level, however, the division of power and financial resources are not stipulated in the constitution. This means that, at the village level, there are no stipulated rights with regards to political power and financial resources that can be demanded and, hence, villagers' participation in these affairs is not supported by the constitution. However, one of the constitution's objectives is to ensure popular participation as will be described in Section 3.3.3 
Map 3.1: The administrative map of Sudan

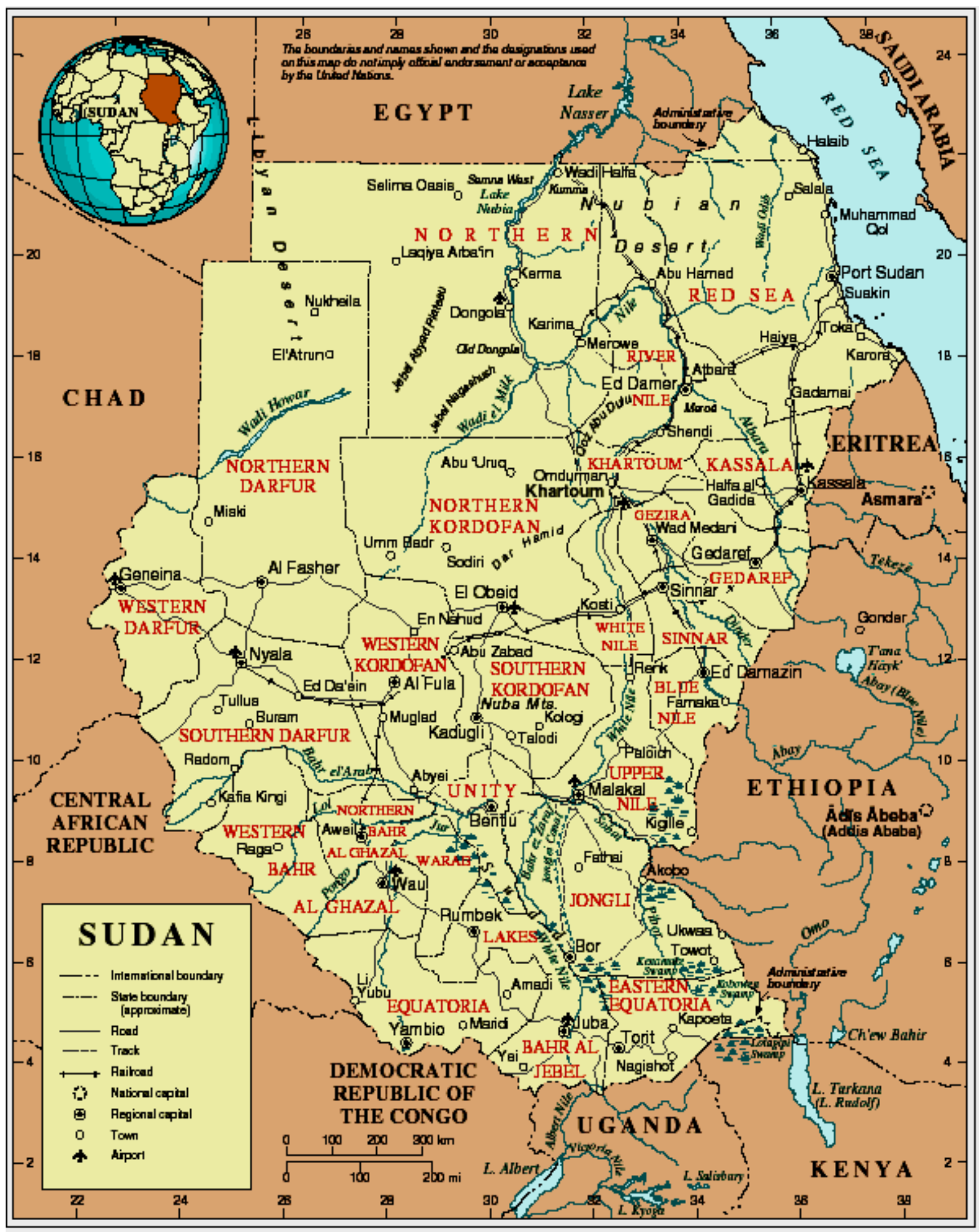

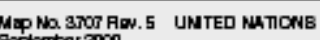

Dqparmantor Putes rfomatom Cortograpto Sarion 


\subsubsection{General Processes}

Due to frequent changes in government structures, as shown above, policies, legislation and the administrative system have witnessed changes after each successive government took power. The change of government systems between multi-party democratic and single-party ones often results in a shift of policies, legislation and administrative systems. Since the end of colonialism, two major shifts have occurred: the adoption of socialism in early 1969, and Islamism in 1989. It is important to note here that the paradigm shift was done by the same regime (the Mayo regime). The period between 1984 and 1989, in which a democratic system took over, was marked by the processes of rebuilding the components of democracy (political parties, the election of a constituent assembly and drafting the constitution) and negotiations to end the southern Sudan conflict. However, the building of a democratic system was halted by a military coup in 1989, led by Mayo, which resulted in the introduction of an Islamic system. After each of the military coups, armed opposition groups were formed and were based in the neighbouring countries to fight the central government. Conflicts over political power have created in Sudan, a very long period of political instability. In addition, the shift in ideologies by the same regime is symptomatic of politics in Sudan, in which ideologies are used for sloganising without real political commitment. Ideology is a tool to serve the interests of the ruling elite without serving the interests of the population.

The regionalization process of the 1970s and 1980s had limited success in achieving the development of the regions and meeting the aspirations of the people. Three important reasons can be cited here as the main causes of the failure of regionalization to meet its set objectives.

Firstly, the regional system was introduced by a single party regime (Sudanese Socialist Union, SSU) which dominated the whole political life of the country and often interfered in regional policies and decisions. Despite a policy of regionalization and administrative decentralization, the central authority held the final say in regional affairs and imposed the central government's views and wishes regardless of the demands of the regions. However, this is not surprising when one sees how the SSU interprets regionalisation, as can be seen from this quotation taken from an SSU document: "regional government is a government in the region but not selfgovernment” (Moharir, 1986: 262).

Secondly, the regions failed to generate enough locally-based financial resources. This was particularly the case in those regions where traditional agriculture dominated and, hence, where money exchange in the market is limited. As a consequence, taxes bring only limited revenue for investment in infrastructure and services. This created a situation in which the regions were totally dependent on the central grant which was, quite often, not transferred fully or at the right time (Faddlalla, 1986: 187-229).

Thirdly, the resistance of senior civil servants to working in the remote regions added another difficulty in the form of a lack of experienced staff to properly run and plan development in the regions. In some cases, administrative officers came into direct confrontation with the central government when they refused to move outside Khartoum (Moharir, 1984: 261). In spite of all these problems, the regional system continued, in name, until 1991 when it was officially replaced by the federal system. 
In 1989, a new regime took power and started a new system of administration. The new regime discussed federal system for the entire country during a conference on "National Dialogue on Peace Issues", which recommended the creation of a federal system for Sudan. Accordingly, in 1991, the government officially announced a federal system for the administration of the country. Following this, the 12th and 14th Constitutional Directives, issued in 1994 and 1997 respectively, set the basis for the shift to the federal system. These directives established the conditions for the formation of state and lower level administrative bodies and outlined their relationship to the federal government. The year 1998 witnessed the approval by parliament of the Constitution of the Republic of Sudan which established the federal system. In the early adoption of the federal system, each state was divided into a number of localities. However, in 2003, some localities were abolished and the rest amalgamated into a number of provinces to reduce their administrative cost to the States. Instead, local councils were formed which now levy the financial revenues granted by the constitution for the former localities. Accordingly, four levels of administration now exist. These are: the Federal level, the State level, Provincial level and Local Councils level (ESRSC 2004). Section 2 of Part 1of the constitution states that:

"Sudan is a federal republic, the supreme authority thereof is based on the federal system drawn by the Constitution as a national centre and States, and administered at the base by local governments in accordance with the law, to ensure popular participation, consultation and mobilization, and to provide justice in the distribution of power and wealth".

The constitution also defines the rules governing the division of power and the sharing of financial resources between state governments and the federal government. (Part VI of the constitution on the federal system). The federal system created the basis for dividing the whole country into 26 states. Each state has some autonomy to form its own government. For each established state, there is an elected legislative council which, in turn, participates in the election of a governor. The elected governor then appoints the state cabinet of ministers and other executive bodies.

Three-quarters of the state council are directly elected. The remaining $25 \%$ are appointments to represent groups such as women, youth and professionals who are unlikely to be elected. The governor in each state is elected from a short list of three candidates chosen by the state council and approved by the President. At provincial level, the provincial commissioners are directly appointed by the President. The commissioner is assisted by a Provincial Council formed by chairmen of the Village Popular Committees (VPCs). While the formulation of the Provincial Council contains an element of participatory decentralised democracy, the way the commissioner is appointed has a centralistic character. At the lower levels, $25 \%$ of the seats are left for women to choose their representatives in the VPCs and in the Provincial Councils.

The $12^{\text {th }}$ and the $14^{\text {th }}$ Constitutional Directives established the conditions governing the formation of the states and their administrative bodies, and outline their interrelations with the federal government. At the same time, the Local Government Law of 1995 was formulated to govern the division of the state into provinces and the native administration (specifically the role of tribal leaders). Localities which were 
formed in accordance with the Local Government Law were later merged to form provinces which inherited all the previous authorities and financial resources of the localities stipulated in the constitution.

Part II of the 1998 Constitution, entitled the Federal System, defines the relationships between the different bodies of the federal government and of the state government. It outlines the division of power into federal power, state power and concurrent power as shown in Box 3.1.

The 1998 Constitution of the Republic of Sudan, which established the federal system, was replaced in 2005 the Interim Constitution of the Republic of Sudan ${ }^{3}$ and was approved, by Parliament, on June 7th, 2005. The interim constitution is composed of the 1998 constitution plus the Comprehensive Peace Agreement (CPA). The interim constitution states that:

"Guided by the Comprehensive Peace Agreement of January 2005, the 1998 Constitution, erstwhile Sudanese constitutional experiences and other relevant experiences” (The 2005 Interim Constitution: 2).

The 1998 Constitution and the Interim Constitution of 2005 define sources of revenues for: the national government, the government of Southern Sudan, the State governments and the local council revenues as shown in Box 3.2 below.

\footnotetext{
${ }^{3}$ The 1998 constitution can be found on www.sudan.net/governmnet/constitution/english.html and the 2005 Interim Constitution of Sudan can be found on: http://www.sudantribune.com/IMG/pdf/20050316_Sudan_Draft_Concstitutional_text.pdf (February 2008)
} 
Box 3.1

Division of political power and financial resources as stipulated in the 1998 constitution

\section{Article 1 10: Federal powers}

The federal power shall practise the power for planning, legislation and execution in the following affairs:

a. defence, armed forces, police, security and disciplined people's forces;

b. the Sudan international boarders and settlement of border dispute between States;

c. nationality, passports, immigration and aliens' affairs;

d. foreign relations;

e. rules of general elections for constitutional, federal, state and local institutions;

f. advocacy ;

g. general professions organized by federal law;

h. currency, financial fiscal and credit policies;

i. $\quad$ specifications, weights, measures and dates and times;

j. federal financial resources;

k. foreign trade;

l. national projects, corporations and companies;

m. federal lands and natural resources, minerals and subterranean wealth;

n. inter States water;

o. national electricity projects;

p. federal air transport, inter States land and sea routes and inter States federal transport and communication;

q. epidemics and general disasters;

r. archaeology and archaeological sites

Article 111: State Powers

The States shall exercise jurisdiction within their boundaries over the following matters by planning, legislation and administration:

a. Administration of the State and its proper functioning, including the promotion of the public interest, public security and public order.

b. State taxation and fees.

c. State trade, supply, cooperation and industry.

d. State land and the State's natural resources and animals wealth.

e. Utilize state water and electric power.

f. Maintain roads, transport and communication.

g. Missionary teaching or other non-profit activities that benefit the community.

h. Registration of births, death and marriages.

i. Questions of law that are particular to the state, including custom and its codification.

Article 112: Concurrent Powers

1. The federal government shall exercise its power over the whole of the Sudan, and the states' governments shall exercise the powers granted them by federal law, and both shall exercise power over:

a. Civil Service.

b. Public Legal Advisors and Attorneys.

c. Organizing Interstate Information, Culture and Publishing.

d. Local Government.

e. Media, Culture and Publication.

f. Education and Scientific Research.

g. Health.

h. Social Welfare.

i. Economic Policies.

j. Cooperation.

k. Industry.

l. Quarries.

m. Border Trade.

n. Urban Planning and Population Policy.

o. Surveys

p. Censuses.

q. Environment.

r. Tourism.

s. Meteorology.

2. Councils shall be established by state and federal law to divide, plan and maintain inter-state forests.

3. Any powers not allocated to the federal or state authorities shall be their common responsibility. 
Box 3.2

Division of financial resources as stipulated in the Constitution 1998 and Interim Constitution of Sudan 2005

\section{Sources of National Revenue (I nterim constitution 2005)}

193. The National Government may raise revenue, legislate for and collect taxes listed taxes from these sources:
(a) national personal income tax;
(b) corporate or business profit tax;
(c) custom duties and import taxes;
(d) sea-ports and airports revenue;
(e) service charges;
(f) oil revenues;
(g) national government enterprises and projects;
(h) value added tax or general sales tax or other retail taxes on goods and services;
(i) excise tax;
(j) loans, including borrowing from the Central Bank of the Sudan and the public;
(k) any other tax as determined by law;

\section{Sources of Southern Sudan Revenue (I nterim constitution 2005)}

194. The Government of Southern Sudan may raise revenue, legislate for and collect taxes from the following sources:

(a) the national revenue allocation to the Government of Southern Sudan and states from the National Revenue Fund as set out in Article 197 of this Constitution;

(b) revenue from any of the sources listed as state revenue sources referred to in Article 195 of this Constitution;

(c) Southern Sudan Reconstruction and Development Fund (SSRDF);

(d) oil revenues as set out in Article 192 of this Constitution,

(e) Southern Sudan Government taxes, which do not encroach on the exclusive National Government taxing powers;

(f) Service charges of Government of Southern Sudan;

(g) Government of Southern Sudan enterprises and projects,

(h) grants-in-aid and foreign financial flows,

(i) taxes and levies on small and medium businesses;

(j) excise taxes on goods within Southern Sudan deemed to be luxury consumables;

(k) Southern Sudan personal income tax;

(I) Loans and borrowing in accordance with Article 203 of this Constitution;

(m) Any other taxes as may be determined by law;

\section{Sources of State Revenue (I nterim constitution 2005)}

195. The states may raise revenue, legislate for and collect taxes as set out below :
(a) State land and property tax and royalties;
(b) service charges for state services;
(c) licenses;
(d) State personal income tax;
(e) levies on tourism;
(f) state share of oil revenue as is set out in Article 192 (4) of this Constitution;
(g) state government projects and national parks;
(h) stamp duties;
(i) agricultural Taxes;
(j) grants-in-aid and foreign aid
(k) excise taxes;
(I) border trade charges or levies in accordance with national legislation;
(m) other state taxes, which do not encroach on National or Southern Sudan Government taxes;
(n) loans and borrowing in accordance with Article 203of this Constitution;
(o) any other tax as may be determined by law:

Article 115 (Constitution 1998)

Local Councils Financial Resources

The Local Councils shall have the following revenues:

a. Real Estate taxes.

b. Sales taxes.

c. Agriculture and animal production taxes, with the percentage determined by federal law being allocated to the state.

d. Fees for local land and water transport

e. Excise duties form local industrial and handcraft production.

f. Any other revenue generated locally. 
Although the constitution allocates local financial resources and revenues to states and local councils (now replaced by the provinces), in reality these revenue sources are subject to frequent amendments from the federal government through issuing constitutional directives to appropriate or ban the levying of some sources of state revenue. Examples of major amendments that have had significant impacts on state revenues are the liberalization of sugar in 1995, and of petroleum fuels in 1996, the centralization of value added tax (VAT) and, finally in 2001, the abolishment of all taxes on agricultural production ${ }^{4}$. Further, any decisions to raise state revenues from any other local resources are in the hands of the federal government and not the states. The state revenues steadily declined from $2.7 \%$ of GDP in 1998 to $1.7 \%$ of GDP in 2001 (World Bank, 2003). Therefore, despite the claimed national advantages of these changes, they have had negative consequences for the revenues of the states and provinces by depriving them of their main sources of revenue. That, in turn, resulted in the states' failures to provide the needed services for their populations. These financial difficulties led, in 2004, to the abolition of localities that failed to generate sufficient local financial resources to meet their administration costs and the formation of provinces to reduce state government expenditures. Moreover, the states' financial situation is becoming more difficult due to the de-concentration of services. This has meant that the running and development of all pubic services (education, health, water and development of infrastructure [energy is not specified]) have to be met from each state's own financial resources. Although it is stated in Chapter Three, Section 112 (a, e, f, g and m) of the 2005 Interim Constitution that the public services of education, health, social welfare, building development planning and housing are joint responsibilities, they are, in practice, left to the states. The development tasks and obligations put on the states, accompanied by their reduced revenues from taxes, have increased the dependence of states on financial support from the centre through the National States Support Fund (NSSF) ${ }^{5}$. The budget transferred through NSSF to the states is much less than the revenues forgone as indicated by the revenue percentage of GDP shown above. The World Bank report of 2003 stated, that in most states, revenues are low and declining and do not allow the states to deliver services to their communities.

An important addition to the interim constitution with respect to the theme of this research is the formation of the National Petroleum Commission (NPC). The NPC allowed oil producing states to participate in the management of the petroleum sector and a share of oil revenues. The National Petroleum Commission (NPC) has the following members (the Interim Constitution Chapter III: 77).

a) The President of the Republic and the President of the Government of Southern Sudan (GOSS) as co-chairs,

b) Four permanent members representing the National Government,

c) Four permanent members representing the GOSS,

d) Not more than three non-permanent members representing an oil producing state in which petroleum development is being considered;

\footnotetext{
${ }^{4}$ The abolition of taxes on agriculture was demanded by the Sudanese Farmers Union to reduce the cost of production and to increase the competitiveness of locally-produced farm products with imported ones.

${ }^{5}$ The National States Support Fund is a central body to help states with financial deficits. This support can be either in the form of direct transfers or supporting services.
} 
With respect to oil revenues, the Interim Constitution set up the following criteria for the sharing of oil revenues between the oil producing states, the Government of Southern Sudan and the national government as follows (the Interim Constitution Chapter III: 80):

$\rightarrow \quad$ At least two per cent (2\%) of oil revenue shall be allocated to the oil producing states in proportion to output produced in the state.

$\rightarrow \quad$ After the payments to the Oil Revenue Stabilization Account (ORSA) ${ }^{6}$ and to the oil producing states, fifty per cent (50\%) of net oil revenue derived from oil producing wells in Southern Sudan shall be allocated to the Government of Southern Sudan (GOSS) as of the beginning of the pre-interim period and the remaining fifty percent to the National Government and states in Northern Sudan.

$\rightarrow \quad$ A Future Generations Fund shall be established once national oil production reaches two million barrels per day. This production criterion may, as part of the National Government's normal budgetary process, be reduced down to one million barrels per day.

This federal administration of political and economic affairs is extended across all physical (including energy) and natural resources. The right to use and the right to generate revenues from these resources are defined for each federal body by the constitution. The following section outlines the development of the structures and processes within the energy sector.

\subsection{Structures and processes of the energy sector}

Within the general structures and processes, specific transforming structures and processes for the energy sector have been established and developed. With changes to the general structures and processes, the energy sector is also subject to consequent restructuring. Under the socialist economy, where public corporations dominated, the role of the energy sector was extended to include the formulation of policies, planning, and the provision and distribution of all energy sources (in particular oil fuels and electricity). Under the liberal economy, the role of the sector was restated to include the formulation of policies and planning, leaving the provision and distribution of energy sources to the private sector. Subsection 3.4.1 describes the evolution of energy sector structures in Sudan. The way in which energy sector policies and planning have been formulated, leading to the exclusion of traditional rural livelihoods from the benefits of access to energy, are analysed in Subsection 3.4.2. Subsection 3.4.3 highlights how the Non-Governmental Organisations (NGOs) and the international agencies have tried to fill the gaps created by the energy sector structures and processes to meet the needs of traditional rural livelihoods. The linkages between the various energy institutions are described in Subsection 3.4.4.

\footnotetext{
${ }^{6}$ The Oil Revenues Stabilization Account is an account in the Bank of Sudan in which all proceeds from exported oil and amounts that exceed the ceiling for the budget from oil exports are deposited.
} 


\subsubsection{Structures in the energy sector}

The Government's involvement in organising the energy sector started in 1969. Before that, the functioning of the energy sector was characterized by the little interference by the government. The private sector was the major player in the provision and distribution of oil products. Four private, foreign firms shared the supply and distribution of oil products. These firms were the Shell Oil Company, which started refining and distributing oil fuels in 1928, followed by Mobil Oil in 1953, Total in 1954 and then Agip in 1959. They all set up their own refining facilities, their channels of distribution and commercial facilities (Ali and Ismail, 1995). In 1969, all private enterprises, foreign or local, operating in the energy sector were either nationalized or confiscated ${ }^{7}$. Thus, the role of the public sector in the energy provision and distribution was strengthened at the expense of the private sector. Structures for the production and distribution of modern fuels were developed in the 1970s, and were organised according to the type of energy source. There are separate, and different, structures for oil products, electricity, fuelwood and for renewable energy sources (see Annex 8: Development of energy institutions and their defined roles and objectives in Sudan).

However, until 1976, the provision and distribution of oil products was the responsibility of small and fragmented departments within various ministries. After 1976, all oil product offices were unified under the National Petroleum Corporation (GPC) (El Gizouli, 1982: 287-288). In 1977, the Ministry of Energy and Mining (MEM) was formed, to which the GPC was affiliated. The GPC was replaced by the Sudan Petroleum Corporation (SPC) which was created under the 1998 Oil Resource Act. Responsibilities and mandates of the two bodies are given in Annex 8. As shown, there are some differences in responsibilities between the GPC and SPC in terms of both exploitation of local oil resources and liberalization of oil products. SPC's main responsibilities are management and exploration activities while the refining of crude oil and distribution, which were major responsibilities of the former GPC, are now left to private companies.

The structures for electrical power passed through similar phases as those for oil products. A private British firm, the Light Company, started power generation in 1908 with diesel generators in the three largest cities in Sudan: Khartoum, Wad Madani and Port Sudan (Abdeen, 1997). This company was later confiscated and replaced by the publicly owned National Electrical Corporation (NEC) in 1969. After the establishment of hydropower plants in the Roseires and Khashim El Girba dams, and the extension of the inter-state grids, the NEC held responsibility for both the supply and distribution of electricity. Two major interconnected grids were established: the Blue Nile Grid from the Roseires dam which extends to Khartoum, Geziera, Sinnar and the White Nile states; and the Eastern Grid from the Khashim El Girba dam which extends to El Gedarif state. The NEC is responsible for other isolated thermal power generation plants that service major cities not on the above grids (see Map 3.2). As can be seen on Map 3.2, with the exception of Dar Mali, none of the studied villages lie close to grids and neither are they close to any of the large thermal power plants.

\footnotetext{
${ }^{7}$ A distinction here is made between nationalization and confiscation when used as instruments in Sudan. The former is used to identify the process when private assets are taken into state ownership accompanied by compensation to the owners whereas the latter is when private assets are taken into state ownership without compensation to the owners.
} 
Map 3.2: Locations of National Grid and large thermal power plants in the Sudan

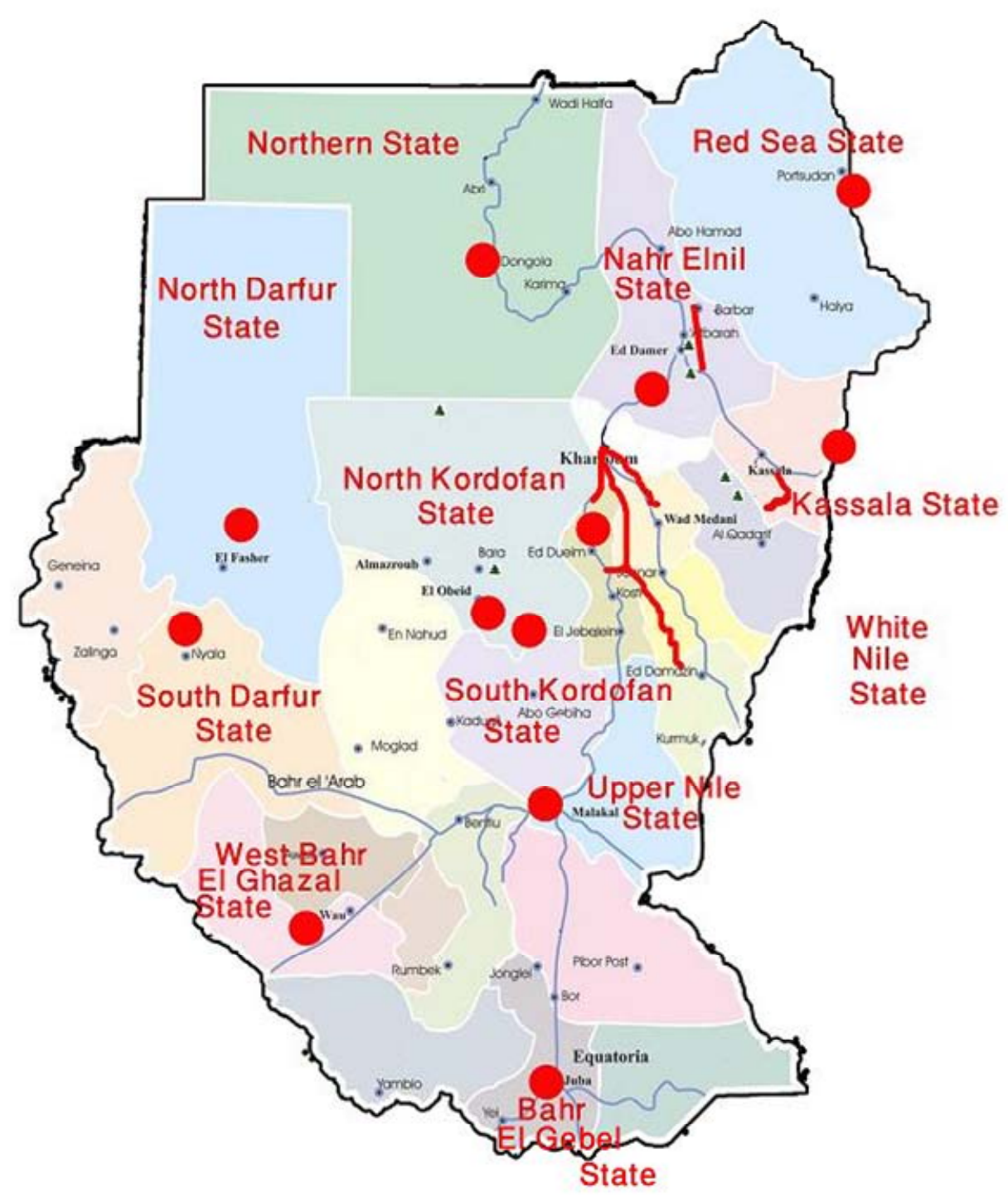


Renewable sources of energy come under two separate structures. Renewable sources such as solar, wind and mini-hydro, agricultural waste and agro-industrial waste are the responsibility of the Energy Research Institute (ERI) which was established in 1972 under the umbrella of the National Council for Research (NCR). Woody biomass sources (from natural forests) are the responsibility of the National Forestry Administration (NFC) which is affiliated to the Ministry of Agriculture.

During the 1980s, when planning the energy sector attracted wide attention from international organizations such as the World Bank and UNDP, a new structure, the National Energy Administration (NEA), was formed within MEM to coordinate energy structures and develop a national plan for the energy sector. NEA as a coordination body includes, within its structure, departments for all the energy sources.

The development of energy structures (represented by ERC, GPC, NEA, ERI, NFA and SPC) responsible for energy sector planning and management, together with their defined roles and objectives, are summarized in Annex 8 which lists energy institutions and their roles as defined in the laws that led to their formation.

The energy organisation structures developed during the 1980s continued to operate until 1992, when the GPC and the NEA were dissolved and the MEM was restructured to act as a coordinator with the private sector which now had full responsibility for petroleum products. The current energy sector structures, which were formed in 1992, are dominated by the Ministry of Energy and Mining which supervises local and international companies involved in the exploration, production, export and local distribution of oil products. Other organisations, including NEC, ERI and NFC, remain relatively autonomous from the authority of MEM and outside its structures. Unlike with the oil resources, all attempts to involve the private sector in electrical power generation and distribution have failed, and the NEC remains the main actor in electrical power generation and distribution. The main reasons for the lack of private sector investment in electrical power are summarised in the following two points.

First, the high cost of establishing both power generation and distribution systems discourages the involvement of the private sector (Abdeen, 1997). Table 3.2 provides estimates of the cost (in 1997 prices) of establishing and operating the different types of power plants operating in Sudan.

Table 3.2

Establishment and operation costs (in 1997 prices) for different types of power generation in Sudan

\begin{tabular}{|l|c|c|}
\hline \multicolumn{1}{|c|}{ Type of generation } & $\begin{array}{c}\text { Cost of establishment (in } \\
\text { Million US Dollars per } \\
\text { Megawatt) }\end{array}$ & $\begin{array}{c}\text { Operational costs (in Million } \\
\text { US Dollars per Megawatt) }\end{array}$ \\
\hline Hydro & 2.383 & 1.67 \\
\hline Steam & 1.333 & 20.67 \\
\hline Diesel & 1.2 & 30.00 \\
\hline Gas & 0.60 & 66.67 \\
\hline
\end{tabular}

Source: Abdeen, 1997: 7 
The concessions provided by the Investment Act 2000 gave a five-year exemption from taxes and duties for power plants with generation capacities of 15 Megawatts and above. However, at least at the time of writing, these concessions have failed to attract any private investors. Decentralised systems based on renewable energy have also seen little involvement from the private sector.

Not all organisations with energy mandates are under the authority of the MEM. The Energy Research Institute (ERI) belongs to the Ministry of Science and Technologies (MOST), and the National Forestry Corporation belongs to the Ministry of Agriculture and Forestry (MAF). However, the responsibilities and mandates from the 1980s remain.

The structures described above all operate at the federal level while, at the state level, energy affairs are divided among the state Ministry of Physical Affairs and the state offices of the National Forestry Corporation, plus branches of the National Electrical Corporation in the eleven states with large thermal power generators (Map 3.2). Further, there are branches of private petroleum companies operating in each state. At the state level, ERI has rural offices in two states: North Kordofan and South Darfur.

No energy structures exist at provincial or lower administrative levels. This lack of energy structures is one of the main reasons for the ignorance surrounding the energy needs of traditional livelihoods in the NEP in Sudan. This issue will be further discussed in Chapter 6.

The above section has presented the energy structures at the federal and state levels. How these structures perform, and their governing processes, are discussed in the following section.

\subsubsection{Processes relevant to the energy sector}

Processes particular to the energy sector in Sudan include: the nationalization of energy operations, setting objectives for the energy sector, formulating a plan of activities, privatization and supporting policies. The processes for the energy sector in Sudan can be divided into three periods depending on the level of government intervention in energy operations.

The first period, 1956 to 1969, was characterized by the maintenance of the inherited colonial system of energy operations. This period involved little government intervention. As stated in Section 3.4.1, during this period the private sector ran all operations related to both oil products and electrical power. Out of the six villages included in this study, Dar Mali is the only village that had an electricity connection to the grid initiated during the Aboud regime (1958-1964) (Annex 3).

The second period, 1969 to 1985, is characterized by the strengthening of the public sector and central planning of the energy sector. Specific processes can be dated to 1983 with the setting of energy sector objectives and the formulation of the first national energy plan. These planning efforts were mainly based on the findings of the UNDP/World Bank mission which had visited Sudan in 1982 to identify issues and options for the country's energy sector. The mission proposed energy objectives related to the broad economic problems of external debts and deteriorating balance of payments resulting from decreasing exports and increasing imports. These problems 
were thought to occur primarily because of a shortage of supply in the modern energy sector (oil and electricity) to key economic sectors producing for export (UNDP/World Bank, 1983: 8 - 9). In July 1983, the findings and recommendations were forwarded to the Government of Sudan in the UNDP/World Bank report entitled Sudan: Energy Assessment Report (joint UNDP/World Bank report, 1983, see also Section 1.3).

The mission identified several issues of top priority in the energy sector that contributed to the stagnation of the Sudan economy which are summarized below:

1. Supply disruption of petroleum products, mainly due to financial constraints.

2. The urgent need for policy decisions on a number of options for the development and utilization of indigenous crude oil resources.

3. Low efficiency in the utilization of petroleum products and wood fuels.

4. Serious over-cutting of Sudan's fuelwood resources

5. Inadequate reliability and shortage of power supply as well as high system losses.

6. Shortcomings in petroleum product prices and power tariffs.

7. The need to develop renewable energy sources other than fuelwood.

8. Lack of sector-wide planning and coordination. (ibid.)

According to the mission, the resolution of these issues would help the development of the energy sector and fuel the recovery of the whole economy. Specific recommendations were given to tackle the issues listed. The issues included the lack of a broad sector-wide planning framework, for which specific recommendations were made:

a) Establish an energy planning team of technical experts from various sectors.

b) Improve the energy data collection process to facilitate coordinated energy planning.

c) Seek technical assistance to enable the Ministry of Energy and Mining (MEM) to evaluate, monitor and coordinate foreign donor assistance.

d) Establish a mechanism for routinely coordinating the different groups with MEM and for coordinatngn the activities of MEM with other ministries and external agencies related to the energy sector. Also establish followup procedures for ministerial decisions.

e) Strengthen the staffing and expertise of the Geology and Mineral Resources Directorate.

f) Define the extent of the General Petroleum Corporation's (GPC) authority in contract awarding, management and monitoring.

g) Strengthen the Central Forest Administration (CFA) by: (i) creating a body in CFA to plan, review and monitor forestry projects and (ii) providing technical assistance and training to CFA to help implement these projects and to recommend revisions in forest policy, legislation and administrative procedures.

In May 1983, the Ministry of Energy and Mining issued a decree to create a committee representing all ministries in addition to representatives from all energy institutions or bodies (including the NEA, GPC, NEC, ERI and NFC) to formulate a national plan for the energy sector (NEA, 1985: 131-158). The committee started by 
gathering information on the energy needs of the key economic sectors (modern agriculture, industry and transport) based on the assumption that if their energy problems were properly addressed by identifying the modern energy sources that meet their specific needs, the solutions would contribute to the recovery of the economy. The information was supplemented with urban household energy needs data (fuelwood, kerosene and LPG) to create the overall energy data system. The plan was finished in January 1985, and top priority projects were identified for each energy subsector. Ten projects were identified in petroleum, seven in electricity, four in fuelwood and two in renewable energy sources. The total required investment was estimated at US\$ 5,531 million. Table 3.3 presents a breakdown of the proposed investment programme for each energy subsector as part of the national energy plan. It should be noted that the fuelwood and renewable energy projects that were included in the national energy plan were not directly linked to rural energy services as might be expected. The wood fuel projects involved improving the efficiency of kilns for charcoal production. Renewable energy projects were intended to create a market for solar, wind and biogas through testing and demonstration projects leading to the commercialization of renewable energy technologies. So, for both groups of projects, rural populations were not directly the targets of these project activities. The plan concentrated on improving the efficiency of charcoal production (improved kilns) and use (improved charcoal stove), an energy carrier which is used mainly in cities and not in rural areas. Thus, there are no direct benefits to rural energy services that can be linked to these fuelwood projects (National Energy Plan 1985-2000). Renewable energy projects also concentrated in areas where there could be potential markets, especially the modern agriculture sector. For example biogas, cotton stalk carbonization and briquetting were planned in Geziera, Rahad and the new Halfa irrigation schemes. These seem suitable projects for these areas because there are plenty of cotton stalks burnt ${ }^{8}$ in the field as waste, and there is also sufficient animal waste and water to produce biogas. What is not reasonable in the plan is the complete lack of suitable projects for traditional rural areas.

Table 3.3, below, shows the emphasis on the physical supply of energy sources to solve problems that were identified as causing the stagnation of the economy. The classification of investments was based on energy supply subsectors. Key sectors of the economy, for which the energy plan was formulated to supply, were already identified as the modern sectors (irrigated and mechanized agriculture, transportation and industry). A a consequence, petroleum and electrical power supply received $84.32 \%$ of the total planned investment. The rest (15.68\%) was devoted to improving the supply of wood fuels and to developing renewable energy sources to fill a gap in the supply of energy sources for the household sector. However, it was not defined whether it was urban or rural households which would benefit from the investment. Rural households generally collect their fuelwood from surrounding forests, and when there are shortages they have to use other biomass alternatives such as dung and crop residues. Using the term 'wood fuel' (fuelwood and charcoal) rather than fuelwood (firewood) can be interpreted to mean that the intended households to be served were in urban centres since these tend to use charcoal rather than fuelwood.

\footnotetext{
${ }^{8}$ Cotton stalks are usually burned in the field to limit transmission of crop diseases. It is mandatory, that all cotton stalks left after harvesting are burnt during the period April (end of crop season) to June (beginning of new cropping season).
} 
Table 3.3

National Energy Plan Proposed Investment Programme (1985-2000) in Million US Dollars

\begin{tabular}{|l|r|r|r|r|r|}
\hline Subsector & $\begin{array}{l}\text { Number of } \\
\text { Projects }\end{array}$ & $\begin{array}{l}\text { Short-term } \\
\text { Investment } \\
\mathbf{( 1 9 8 5 - 1 9 9 0 )}\end{array}$ & $\begin{array}{l}\text { Long-term } \\
\text { Investment } \\
\text { (1991-2000) }\end{array}$ & $\begin{array}{l}\text { Total Planned } \\
\text { Investment }\end{array}$ & $\begin{array}{l}\text { \% of total } \\
\text { investment }\end{array}$ \\
\hline Petroleum & 149 & 683 & 832 & $15.0 \%$ \\
\hline $\begin{array}{l}\text { Electrical Power } \\
\text { Generation }\end{array}$ & 7 & 1548 & 2284 & 3832 & $69.3 \%$ \\
\hline Wood fuels & 4 & 281 & 563 & 844 & $15.3 \%$ \\
\hline Renewable & 2 & 10 & 3543 & 5531 & $0.4 \%$ \\
\hline Total & 23 & 1988 & 13 & $100.0 \%$ \\
\hline
\end{tabular}

Source: NEA: the National Energy Plan (1985: 122)

Rural and traditional economies, with no direct contribution to export products, fell almost completely outside the plan's objectives even though the plan coincided with the heavy drought of 1983/1985 and the mass displacement of rural people due to the failure of their livelihoods systems. Despite the identified and urgent need of large parts of rural communities for water and food, the supply of energy to meet their energy services were not part of the planning objectives. Although the plan mentioned the signs of the energy problems of different groups (Section 1.3), the destruction of rural livelihoods, the spread of famine and the displacement of communities were not viewed as problems to which energy could contribute a solution.

The concentration on the energy supply side led to the marginalization of rural energy needs and priorities. Problems linked to water, food and fuel that surfaced in the drought stricken areas were totally ignored in the 1985-2000 National Energy Plan.

During the third period, 1992 to present, the energy policy is designed to be consistent with the general economic liberalization and encourage private investment in the energy sector development. The policies aiming to support energy sector development include:

1. Ending state control over energy supply. The privatisation of oil products and gas was adopted in 1996.

2. Encouraging the private sector through concessions including tax exemptions for periods ranging from 5 to 10 years, depending on the size and type of energy investment.

3. Exemptions for oil companies from taxes and duties on the import of equipment.

4. Removal of subsidies on all types of hydrocarbon fuels.

5. Ending the monopoly of the NEC on electricity generation, transmission and distribution beyond the national grid.

6. Priorities in electricity supply are for the productive export sectors of agriculture and industry.

7. Encouraging the use of renewable energy through the exemption from taxes and duties of all renewable energy equipment.

These are therefore the proposed policies by the Ministry of Energy and Mining to support its plan for the development of the energy sector. The objective of this plan is 
stated in the Four-Year Program (1999 - 2003), entitled Energy Sector Development and the plan includes specific activities for oil, electricity and renewables.

The oil sector's objectives include:

- Completion of the pipeline from the oil fields to Bashier's harbour on the Red Sea. (Completed in 1999).

- Construction of a refinery in Khartoum (completed in 2000).

- Construction of thermal power generation units at oil production sites (some completed by early 2008).

- Construction of a National Laboratory for petroleum products (completed in 2000).

The electricity sector:

- Start construction on three dams along the Nile (Merowe dam, Shriek dam and Kagabar dam): construction work started on the Merowe dam in 2004.

- Extension of the grid to cover other parts of Sudan.

- Increased efficiency of transmission and distribution by rehabilitation of the national grid (ongoing).

- Establishment of large thermal power units to power states that lie beyond the reach of the national grid. Newly added thermal power plants have been established in Gare in Khartoum and in Atbara, in addition to the rehabilitation and upgrading of the existing thermal power plants shown on Map 3.2. However, not all states are yet served by large thermal plants. States such as Northern and Eastern Darfur cannot be reached due to the civil conflict in the region.

The renewable energy sector:

- Installation of 500 solar units in the rural areas. (Not yet installed).

- Construction of 130 biogas household units in rural areas. At the time of writing, this work has not started.

- Making reservations of more natural forests. The reserved forest in Sudan makes about $25 \%$ of the total natural forest with about $5 \%$ reserved for irrigated area schemes and $10 \%$ of rainfed schemes for wood lots.

The investment in the energy sector for this programme amounts to SDG 7280 million (€ 2,912 million). Of this sum, 73.9\% was invested by international companies in the petroleum sector and the remainder, 26.1\%, was invested by the government of Sudan $^{9}$. All the investment is aimed at increasing the physical supply of energy. These investments would favour those for whom the basic infrastructure (paved roads, grids and supply channels) are well developed, that is the modern economic sectors and urban dwellers. Meeting the energy needs of rural communities, whose economy is based on traditional practices, remains outside the processes of all the modern energy subsectors. The following points explain how processes in energy subsectors are unfavourable to rural people.

Petroleum products: Since the liberalization of petroleum fuels and the abolishment of the GPC in 1996, the state governments have no direct relationship with MEM over

\footnotetext{
${ }^{9}$ These figures were compiled from a mid-term evaluation report in 2001 of the performance of the energy sector carried out by the MEM for the Fourth Year programme.
} 
providing for their needs from petroleum fuels. More than 30 private companies are now involved in the distribution of all types of oil fuel and its refined products to meet the demands across the whole county. States are only responsible for issuing licenses to private companies willing to operate at the state level. The base price for oil fuels is generally determined by MEM, and the companies add the transportation costs for the different areas. Then prices for the consumers in different states are agreed upon between the state petroleum directorates and the supplying companies. Given the difficulties of transportation, long distances and unfavourable road networks in rural areas, the expectation that most rural areas will not be served by the privately operating companies is realistic. Even those areas served have to pay high prices as companies are allowed to add their transportation costs to the base prices. Thus prices vary from one place to another depending on the distance the petroleum products are transported. For example, in May 2006, the price of diesel fuel per litre in Khartoum was SDG 1 ( $€$ 0.50), in El Gedarif SDG 1.25 (€ 0.65), and in El Obied SDG 1.5 (€ $0.75)$.

Electric power generation: The electricity sector is the responsibility of the National Electricity Corporation (NEC). The NEC, which is a federal public sector body, is responsible for the National Grid. The NEC is also responsible for large thermal power generation plants in the states with a capacity of more than 2 MW (Map 3.2). Thermal generation less than $2 \mathrm{MW}$ is the responsibility of the state level bodies, or private individuals or NGOs who have established their own facilities. This regulation of the electricity sector began in 1995 with ministerial decree No. 519, which defines the boundaries between the state and NEC responsibilities (as the federal body) concerning the administration of the electric power sector. The 1998 constitution defines the responsibilities between the state and the federal agencies in all energy affairs as shown in Boxes 3.1 and 3.2.

In 1996, the responsibilities for state electrical power plants were handed over to the state level Ministry of Physical Affairs. This was in response to demands from the state governments. However, the state Ministries of Physical Affairs failed to keep them running and failed to provide the needed electrical services (Abdeen, 1997). One of the problems is price subsidies for electricity which are determined by the federal government but which states have to fund cost from their own resources. The federal NEC sets prices for the whole country which do not take into consideration the different costs of system construction and operation. For example, all the thermal power generation plants (Map 3.2), run on steam and diesel engines. The high operation costs should be reflected in the prices charged to consumers, but this is not possible with a nationally unified price and subsidies which are difficult to remove. The state governments are expected to meet the difference between the actual cost of supply and consumer prices but this does not happen. Having these financial difficulties in supplying electricity, and dwindling states revenues, the states have neither the capabilities nor the incentive to develop electrical power in the remote areas.

Sudan's main electrical power policies favour large hydropower generation. There are four large dams operating in Sudan which both generate electrical power and store water for irrigation. These are the Rosaries dam (500 km south of Khartoum) and Sinar dam (300km south of Khartoum) on the Blue Nile, the Jabal Awlia dam (40 km south of Khartoum) on the White Nile, and Khashm Al-Girba on the Atbara River. 
Dams that are currently under construction include the Merowe dam on the River Nile (350 km north of the capital Khartoum) and initiated dam projects include Kajabar (North of Dongla City) and Al-Sheraik (north of Atbara city) on the River Nile, and the Saiteet dam on the Atbara River. Construction of the Merowe dam began in 2004 and is planned to be completed in mid-2008, while construction of the other three is expected to begin in 2009. The building of these hydro power dams will not serve, at least in the short term, remote and rural areas. Thermal power plants continue to be built in urban centres away from the grid (see Map 3.2).

The NEC, being responsible for serving all of Sudan, has certain criteria for areas to qualify for its support in extending the grid. This support includes the provision of equipment, recruitment of staff, provision of spare parts, and supervision, operation and maintenance of generators. States, on the other hand, are responsible for the provision of fuel and lubricants. Areas fall into three categories (Table 3.4). Based on this categorization most villages with a population less than 10,000 inhabitants will not qualify for an installation by NEC since the criteria are designed to only supply towns and cities in rural areas with a minimum population of 10,000 inhabitants. Five of the six villages in this thesis are too small to qualify for services by NEC. The sixth, Dar Mali, was electrified long before these conditions were set. If rural communities want to set up their own local generation units they can do so, but at a relatively high cost compared to those served by the NEC. The NEC provides a cross subsidy for the household sector whereby, for the first $200 \mathrm{kWh}$ of electricity used per month consumers pay a rate of SDG 0.2 per $\mathrm{kWh}(€ 0.08)$, for any additional consumption the charged rate is SDG 0.26 (€ 0.10). Estimates in 2003, show that rural households who had built and used their own generators, or use mini-grids, pay roughly a rate of SDG 14 per $\mathrm{kWh}(€ 5.60)$ (Annexes 2, 4, 5 and 6). Moreover, the Investment Act 2000, which was designed to attract investment by private enterprises, and particularly foreign investment, stated that the minimum size of a power generation plant for which private investors could receive concessions was $15 \mathrm{MW}$.

Table 3.4

Characteristics and Categories for areas qualifying for NEC Support

\begin{tabular}{|l|l|l|l|}
\hline \multicolumn{1}{|c|}{ Categories } & \multicolumn{1}{|c|}{ Population } & Maximum Demand & \multicolumn{1}{c|}{$\begin{array}{c}\text { Total cost } \\
\text { Estimate US\$ }\end{array}$} \\
\hline Category A & $>30,000$ inhabitants & $1000-3000 \mathrm{~kW}$ & $4,120,000$ \\
\hline Category B & $\begin{array}{l}20,000-30,000 \\
\text { inhabitants }\end{array}$ & $500-1000 \mathrm{~kW}$ & $2,005,000$ \\
\hline Category C & $\begin{array}{l}10,000-20,000 \\
\text { inhabitants }\end{array}$ & $250-500 \mathrm{~kW}$ & 93,000 \\
\hline
\end{tabular}

Source: NEC Power Plan 1990-2005 (NEC, 1990).

The conditions set for extending electrical services as shown in Table 3.4 are not conducive to rural conditions. Neither the required size of the plant for receiving the concessions by the private sector nor the population necessary for NEC support can be found in rural villages. Therefore the policies for encouraging the development of the electrical power sector are indirectly biased against rural communities. 


\subsubsection{The role of NGOs and international agencies in energy services in Sudan} In 1979, the Sudan Council of Voluntary Organizations (SCOVA) was formed to organize and coordinate the activities of NGOs in Sudan. However, the formation of many local NGOs, and the entry of many international NGOs into Sudan, date from the drought of 1983/85 and the Sudan Call campaign in 1984 to help the droughtaffected areas. About 80\% of both types of NGO were registered after 1983 (SCOVA, 1997). Although they started in small numbers, NGOs in Sudan have increased significantly. In 1997, the number of national and international NGOs listed in the directory of the Sudan Council of Voluntary Organizations (SCOCA) were 101 and 72 respectively (SCOVA, 1997), by 2006 the number had reached 500 for national NGOs and 83 for international NGOs as listed in the Directory of Development Organizations ${ }^{10}$. Geographically, NGOs (national and international) cover all of Sudan: $31 \%$ of all NGOs are found in the Central part, $22 \%$ in the Southern part, $21.5 \%$ in the Eastern part, $20 \%$ in the Western part, and 5.5\% in the Northern part (Bakhiet and Dawelbiet, 2003). The major fields of activities for NGOs are community development, social services, health education and gender. However, all these activities cut across each other, for example the activities of NGOs that come under the heading "gender" include activities related to health, education and other services.

United Nations agencies, such as UNDP, FAO, UNICEF, UNHCR, WFP and WHO, work in the fields of relief and development. The activities of UN agencies target those who are affected by drought and those who are affected by conflicts (UN, 1993). One of the major development programmes launched by the UNDP during the period 1986-2002 was the Area Development Scheme (ADS). The ADS programme was composed of five projects implemented in five different geographical areas: North Darfur State, South Darfur State, North Kordofan State, El Gedarif State (Annexes 1 and 2: Es Sadda and El Idied) and Nile state (Annex 4: Goz El Halag). ADS included in its programme activities to address social services, environment, and gender issues. Other UN agency activities in rural areas include UNICEF's village hand pump programme and WHO's Basic Needs support activities (Annex 3: Dar Mali).

Both the international development agencies and the NGOs have been active in specifically implementing energy projects and projects with energy components. For example, the Rural Solar Energy Development project (RSED) was funded by UNDP and implemented by the Energy Research Institute to disseminate solar energy technologies in North Kordofan State from 1991 to 1998. RSED was involved in the dissemination of solar lighting, solar pumps and solar cookers, as well as solar evaporators for salt extraction which were specifically designed for El Ga'a (Annex 6). The RSED also coordinated with other UN agencies in installing other solar technologies, for example with UNICEF, through the Extended Programme of Immunization (EPI), to install vaccine fridges in selected villages in North Kordofan State.

International NGOs active in energy include Practical Action ${ }^{11}$ which has had a number of technical projects including the dissemination of improved charcoal stoves

\footnotetext{
${ }^{10}$ The Directory of Development Organizations www.devdir.org/files/Sudan.pdf ,July 2006.

${ }^{11}$ Formerly ITDG.
} 
and wood stoves during the 1990s and, in 2004, was involved with micro-finance to assist families in rural Kassala State in purchasing LPG stoves.

The Swedish Sudanese Friendship Association (SSA) provided solar pumps for five villages in Bara area (North Kordofan State) to cultivate vegetables on small farms. The Swedish Free Mission implemented, from 1999 to 2004, the Solar School in Sudan project (SSS) (Annex 1), disseminating solar lighting systems, solar pumps and solar cookers.

Local NGOs have also been involved in some energy activities. The Sudanese Environmental Conservation Society (SECS), disseminated improved charcoal stoves and solar cookers. The Bawadina Rural Women Development Society (BRWDS) disseminated improved wood and charcoal stoves and solar cookers.

A framework for sustained peace, development and poverty eradication was prepared in 2005 by the Joint Assessment Mission (JAM Sudan) of the UNDP and World Bank (JAM Sudan, 2005). The framework followed the signing of the Comprehensive Peace Agreement (CPA) which includes some development programmes to be implemented in the northern states, and others to be implanted in the southern states as follows:

I - Programmes under the National Government and the northern states

1. Enabling consolidation of the peace, including implementing the range of measures outlined in the CPA, from the national level down to local peace building and reconciliation;

2. Improving governance, especially institutional capacity and public accountability;

3. Broad-based growth of income-earning opportunities, with a focus on smallholders, pastoralists and private sector development.

4. Expanding access to basic services in the northern states-in particular access to basic health care, primary education, and safe water and sanitation-to put progress on track for meeting the MDGs. (JAM Sudan, 2005: 28)

II - Programmes under the Government of Southern Sudan

1. Developing physical infrastructure;

2. Prioritizing agriculture, and promoting private sector development;

3. Restoring peace and harmony (including through access to basic services);

4. Regenerating social capital (including safe return and reintegration of IDPs and refugees); and

5. Developing institutional infrastructure for better governance. (JAM Sudan, 2005: 40)

The JAM framework provides an opportunity to benefit those areas disadvantaged by conflicts in the southern states and drought affected areas in the northern states. However, these programmes, as of early 2008, had not been transformed into specific projects. Energy in the JAM programmes is only described in a broad sense. 
"JAM will support the extension of the national grid, rural electrification, promotion of renewable energy options and the development of a national electrification master plan." (JAM Sudan, 2005: 34).

Nearly all areas in Sudan are covered by at least one of the NGOs and international agencies or agreements referred to above that play important roles in initiating several energy services in rural areas. They provide their services directly to the rural community as can be seen in the six villages studied (Annexes 1 to 6).

However, there are problems of ownership of services provided by these NGOs which affects their sustainability. For example, in El Ga'a, vaccines have not regularly been provided since the end of the UNICEF project to provide immunization, although the vaccine fridge is still functioning. In Um Laham, the water service stopped a short time after its establishment, and the Popular Committee of the village failed to fix the broken pumping system (Annex 5). Also in Um Laham, the villagers cannot use the well dug by the UNDP Drought Mitigation Project, because ownership of the well was not formally handed over to them after the project ended. While it is understandable that NGOs and international organizations cannot continue to support services in rural villages forever, continuity of the services could be planned for by defining roles in advance for the village community and the government offices, and clarifying at which stage responsibilities for a particular service will be transferred.

\subsubsection{Links between energy institutions in Sudan}

Having been created independently from each other, the relationships and linkages between the energy institutions were not clearly defined in their decrees or acts of their establishment. In fact, they tended to perform their functions as isolated islands with no official direct links between them. For instance, separate Boards of Directors managed both the NEC and the GPC, autonomously and independent of the MEM. This situation arose because these boards were formed before the establishment of the MEM and they were able to keep their authority even after the MEM was established in 1977 (Dr. Shuli ${ }^{12}$ interviewed on 7 July 2002). Even though they were formally under the MEM structure, the MEM had no direct control over their plans, operations and financial decisions. The autonomy of the GPC and the NEC was actually strengthened by a 1972 decree by the Cabinet of Ministers which authorized all ministers and heads of corporations to seek external finance for their projects and activities independently. When the MEM and the NEA were established they found that both the GPC and the NEC already had their own external financial relationships. They did not need to refer to either the MEM or the NEA for their financial support as the structures of the energy sector imply. So the NEA, as a planning arm of the MEM, found itself confined to areas outside the spheres of the GPC and the NEC (as stipulated in Point b in Annex 8 under NEA) in terms of its roles and objectives. Practically, this means that planning for the petroleum and electricity subsectors is done outside the authority of the MEM and its planning arm (the NEA). Similarly, all the other energy institutions have some degree of autonomy from the MEM and the NEA. This has negatively affected the ability of the NEA to get sufficient information

\footnotetext{
${ }^{12}$ Dr. Abd Elrahman Shuli is former director of National Energy Administration (NEA), the planning arm of the Ministry of Energy and Mining. He chaired the planning committee that formulated the National energy Plan (1985-2000). Currently he runs a private consultancy company: African Management System Company Ltd. (AF-MS)
} 
to plan and coordinate activities in the energy sector. Dr. Shuli, the former NEA director, commented that:

'We found little cooperation in getting information from these institutions. They thought that the NEA was closer to the minister who should not know everything. It was a struggle for power not finance. In terms of finance, each institution was implementing more than one externally financed projec, at that time, which put quite a lot of money, training and logistic facilities at their disposal'. (Dr. Shuli interviewed on 7 July 2002).

So, with energy institutions retaining their autonomy and reluctant to share their power with others institutions, there was a problem for the NEA in accessing the information needed to formulate the energy plan.

Dr. Shuli also described the difficulties that the NEA faced in formulating the national energy plan (1985-2000):

'There was no tradition of comprehensive or strategic national energy planning. Tto all the directors of these institutions, planning simply means someone else will take decisions in your field of work, and this was the real problem of planning and coordinating activities within these different institutions'.

However, it was not only on the vertical and horizontal levels where coordination was lacking among the different institutions of the energy sector: cross-sectoral coordination was also totally lacking in the National Energy Plan 1985-2000. The plan provides no avenues for linkages with other sectors. This can be attributed, besides the general unwillingness to share information, to planning concentrating on the supply side. The delivery of energy services was seen as the responsibility of other sectors, which would have to work out their own plans. This situation existed in the period prior to 1992, when both the NEA and the GPC were dissolved and the provision of energy supplies was privatized. However, the NEC which manages electricity generation and distribution remains a public corporation and still carries out its duties and responsibilities as previously defined.

\subsection{Conclusion}

This chapter set out to answer the second and third research questions. Research Question 2 concerns the impacts of the vulnerability context on the flow of energy services in rural areas:

"How do factors of the vulnerability context disturb the flow of energy services and how does this disturbance affect rural livelihoods outcomes?"

Research Question 3 sought an explanation for the absence of rural energy services in national energy planning processes:

"Why were energy problems related to traditional rural livelihoods not addressed in national energy planning processes in Sudan?” 
In responding the second question, Section 3.2 shows that there are a number of vulnerability factors that contribute to the disturbance of energy services and consequently affect the outcomes of rural livelihoods in Sudan. The most significant vulnerability factors in Sudan are drought, civil wars, floods, seasonality and trends. In the case study villages, drought, seasonality, floods and trends can be linked to negative livelihoods outcomes (Annexes 1 to 6). A major consequence of vulnerability on rural livelihoods is the failure of the rural population to obtain energy services such as water pumping, food production and cooking, necessary to maintain rural livelihoods. Livelihoods are particularly threatened in rural areas where most of the energy carriers used to produce the energy services are obtained from natural capital. All the vulnerability factors identified in the case study villages lead to the destruction of natural capital which in turn reduces the availability of traditional energy carriers (both in terms of quantity and quality, and hence the stock of energy carriers is diminished), the consequence of which is a disturbance in the flow of energy services. This disturbance in the flow of energy services generally results in negative livelihoods outcomes which, in the extreme, leads to the displacement of the rural population. Alternative energy carriers, from physical capital, were not available to substitute for natural capital and so maintain the stock of energy carriers. Further insights based on empirical evidence about energy services and rural livelihoods are provided in Chapter 5 by tracing vulnerability factors in each of the six studied villages and showing their affect on the flow of energy services.

The answer to Research Question 3 is found in Section 3.3, the general structures and processes, and Section 3.4, structures and processes in the energy sector. Section 3.3 shows there has been general instability in the political system since Sudan gained its independence. This instability has dominated the formulation of political and economic macro-policies. Changes in political structures between multiparty democracy and single party military regimes, and from centralized to decentralized administrations, has hindered the development of peaceful channels for participation in political life. The involvement of the military in government, or in opposition, has led to insecurity in many rural areas. Neither the socialist centrally-planned economy nor the liberal market economy have made traditional agriculture a priority. In the centrally planned eras, traditional rural areas were excluded from the economic objectives which were focussed on developing and expanding the modern sector. In the liberal market-led economy, the fragile market for labour and commodities has discouraged investment by private services providers that would serve the traditional rural areas (see also Section 1.2.2).

The macro-level political and economic systems adopted in Sudan shape the planning processes of the energy sector, and as a consequence, the traditional rural areas have been excluded from the energy planning processes. The existing energy structures have no specific departments for providing the majority of the rural people with modern energy services. The policies formulated for petroleum products and electricity supply are biased against remote areas (petroleum pricing) with low population densities (criteria for electrical supply). Energy policies and plans do not provide incentives for a growth in the supply of modern energy carriers which would secure the flow of energy services to rural areas or, in other words, they form disincentives for the enlargement of the energy circle. Identification of the kind of problems related to traditional rural livelihood activities, strategies, and outcomes are lacking in energy planning processes. There is no data at any level (federal, state, 
province or local council) linking the disturbances in energy services to negative livelihood outcomes in traditional rural areas. The lack of data is a failure of the transforming structures and processes within the energy sector. The lack of data leads to a second failure: a lack of equitable access to modern energy carriers.

The decentralized structures supported by the Interim Constitution, as presented in the federal system adopted in 1991 and the Comprehensive Peace Agreement of 2005, provide (at least theoretically) the prospect of rural areas being served. The constitution allows for a decentralised administrative system with broad-based participation at the local level. The representation of women, youth and professional groups in local structures potentially provides a platform for tackling wider issues. However, people do not participate in the election of representatives to the higher structures (governors and provincial commissioners). Overall, the practices present a rather gloomy picture.

What does it mean to be represented in an incapable and ineffective structure? The gap that exists between the State and its lower level structures, operating under strict control from the centre, removes any opportunities for wider participation. Indirect control from the centre is also imposed through financial control of the budget and investments. Centralised control can occur because there are insufficient locallygenerated revenues by the states, provinces and local councils. The lower administrative levels, therefore, in order to function depend on financial transfers from the centre. In addition to low revenues, the lack of technical capacity and the lack of real political will make the formulation and implementation of state plans for development, including energy services, rather unlikely. However, the movement towards democratization of political life following the Comprehensive Peace Agreement (CPA), offers some hope. The CPA has opened the political arena for all parties to prepare for a general election in 2011, with the potential for a more equitable share of wealth and political power between the states and the existing federal agencies. Finances combined with political will can be used more effectively to deliver services.

The transfer of the delivery of services to lower-level structures (states and provinces) without ensuring the transfer of the needed finance, or ensuring that these lower levels are capable of generating sufficient revenues, will only transfer the problems to lower levels of the state bureaucracy, not help to solve them.

The prevailing vulnerability factors and the poor functioning of the transforming structures and processes that could serve the traditional rural areas have led NGOs and international agencies to step in and provide the lacking energy services in some traditional rural areas. However, the organisations do not have the resources to replace the government. Without lower-level planning of energy services, to provide modern energy carriers and to enable the shift of rural energy services from the dependence on erratic natural capital to the use of well-planned physical capital, traditional rural livelihood outcomes will remain subject to the vulnerabilities present in Sudan. Lower-level planning requires acknowledging local differences and variations in rural livelihoods. The next chapter shows the local differences that are to be found in rural areas and how these affect access to, and priorities for, energy services. These variations and differences need to be taken into account in energy planning to ensure a more inclusive and more equitable distribution of benefits from energy planning. 


\section{Chapter Four: Variation in access to energy services in rural Sudan}

\section{Introduction}

The previous chapter shows, at a general level, that the disruption of the flow of energy services to rural areas can be attributed to the prevailing vulnerability context in rural areas which destroys the natural basis of energy services (Section 3.2) and to the failure of the distributive and constitutive roles of transforming structures and processes to compensate for the loss of these energy services (Section 3.3). However, for an effective and equitable distribution of energy services (who gets what, when and how), differences within rural populations need to be considered. Rural populations are not homogenous entities, nor are their livelihoods based on the same assets. As noted in Section 2.4.2, access to energy services varies with local differences such as geographical location, wealth, gender, age and ethnicity. Therefore to ensure effective and equitable distribution of benefits from energy planning, and at the same time to avoid exclusion, the energy service needs of these different groups have to be identified and accommodated in energy planning processes. Therefore, the focus in this chapter is in showing how the differences in livelihoods affect the needs and priorities for energy services, which are important considerations for an energy plan or policy. So, this chapter sets out to answer Research Question 4:

“How do local differences affect access to, and priorities for, energy services in rural areas?”

This question will be answered through investigating the differences in access to energy services in six villages representing different rural contexts in Sudan (see, for the rationale of village selection, Section 2.12) and the differences between groups within each village. Differences in access to energy services between these villages were sought by selecting villages with different geographic and spatial characteristics located within three different States (Map 1.2). The villages of Es Sadda and El Idied, located within El Gedarif State, represent an area where the level of dependence on the natural capital for energy services is relatively high, and where the natural capital in itself is erratic with large seasonal variations. However, El Idied is much closer to an urban centre and modern agricultural schemes than Es Sada which means it is relatively well served with energy services (Annexes 1 and 2). The villages of Dar Mali and Goz El Halag are located within Nile State (Annexes 3 and 4). Dar Mali is located along the banks of the River Nile, close to urban centres (Atbara, Ed Damar and Barabar), and the villagers have relatively easy access to modern energy services in these urban centres through a paved road and the railway line. Goz El Halag, on the other hand, lies along the banks of the Atbara River and is only connected to Ed Damar, the nearest urban centre, by a difficult earth road which makes access to energy services rather more difficult than from Dar Mali. Also, Goz El Halag lies downstream of a dam that controls the flow of the Atbara River and this affects access to water services and agricultural production. The villages of Um Laham and El Ga'a are located within North Kordofan State. Although both villages share the characteristic of being located in similar sand dune areas, there are large differences in economic activities and the basis of livelihoods in the two villages. Salt forms the basis of livelihoods within El Ga'a, allowing the accumulation of financial capital 
which allows access to modern energy carriers to secure energy services. In contrast, the basis of livelihoods in Um Laham is subsistence agriculture and livestock raising. Traditional energy carriers provide energy services but these are subject to disruption by prevailing factors of vulnerability (Annexes 5 and 6). Despite their common ecological characteristics, i.e. the semi-desert region, the differences in spatial location and natural capital of these villages significantly affect access to energy services.

Within the various villages, differences in energy service needs, and access to these services, between different groups were investigated.. Groups can be constituted based on socioeconomic indicators such as wealth, gender and age. In terms of wealth, families can typically be ranked as wealthy, middle income, poor or very poor. However, there were differences between the villages in the way villagers identified the components of wealth that define membership of wealthy and middle income groups, but all the villages share a common definition of poor and very poor, membership being defined on the basis of a family's food security. Islamic definitions of poor (fageer) and very poor (miskeen) were used in making a distinction. A poor family is defined as one which is not able to secure their food over the whole year, whereas the very poor are those families who are not able to secure their daily needs for food. Groups constituted by gender and age were used due to their role in the provision of energy services. Other groups which were also identified included the newly settled nomads (Es Sadda, El Idied, Um Laham and El Ga'a), a displaced group (Dar Mali) and seasonal visiting nomads (Goz El Halag). In this research, classification is based on the village people's own classification system, in which children are aged 10 to 15 years old (who are often active in the provision of energy services such as collecting wood and water), youth who are normally between 15 and 40 years old (whose needs for energy are rather different to other age groups), old between 40 and 60 years old, and elders being those aged over 60 years old (who are not active in the manual provision of energy services). It is important to note that the term "youth" is used here only to refer to younger males who attend the clubs ${ }^{1}$ which have satellite TVs and videos and who can also migrate and work outside the village. Women as a group are not sub-divided in terms of age since women, irrespective of their age, perform similar activities within a specific village, in terms of access, provision and use of energy services. This classification is at variance with the official classification system which divides the population into an economically active group (15 to 75 years old) and a non-active economic group which includes children younger than 15 years old and elders above 75 years old (Central Bureau of Statistics, 2002).

This chapter is organized into seven sections. Sections 4.1 through 4.6 present descriptive analyses of access to and priorities of energy services in the six villages as are perceived by the different groups. The section for each village is subdivided into four parts. The first subsection describes the geographical location and the population's livelihoods and wealth. The second subsection analyzes access to energy services and identifies different groups' access to energy services. The third subsection identifies the different groups' priorities when it comes to energy services

\footnotetext{
${ }^{1}$ There are two types of clubs found in villages which provide entertainment: Nadi Mushahada which can be a private business and Nadi El Shabab (youth club) is always a community centre
} 
in each village. The fourth subsection summarizes the main findings from each village.

In this chapter, only the main characteristics of the above aspects are presented. In Annexes 1-6, more detailed data for the six villages are presented.

Section 4.7 provides the answer to the Research Question 4. It shows how access to energy services varies between the six village locations and for the different groups within each village.

\subsection{Es Sadda}

\subsubsection{Background}

Es Sadda lies in the Central Butana area of El Gedarif State. The village lies about $100 \mathrm{~km}$ north of El Gedarif city, the state capital. The other nearby urban centres are Es Subagh and New Halfa which are about $30 \mathrm{~km}$ and $50 \mathrm{~km}$ respectively from the village. The village is made up of four small groups of settlements (there are 92 families in total with 20 to 25 families per settlement). Es Sadda is the name given to the village centre, which is the oldest established part of the settlement and where social services (basic school, shops, and health centre) are located. The other three settlements are: Wad El Bahi, El Saadonab and Wad Rahama. They are located west, south-east and north-east and lie about $5 \mathrm{~km}, 3 \mathrm{~km}$ and $2 \mathrm{~km}$ respectively from the village centre. When "Es Sadda" is used in the following text it should be taken to mean all four settlements unless otherwise specified.

The oldest part of the village (Es Sadda) was established in 1918 but, until 1986, there were only 15 families, totalling less than 100 persons, settled permanently in the village. $^{2}$ After the drought of $1983 / 85$ more families started to settle and the population had increased to 1,328 in 1995 (UNDP 1995 - $\mathrm{ADS}^{3}$ Villages Profile Report). In May 2002, during data collection for this thesis, the participants gave the number of families as 92 making about 1,500 people inhabiting the village. However, the number is continuously increasing not only due to natural population increase but also due to more people settling in the village. The village residents belong to the Shukria, which is the largest tribe dominating most of Central Butana. The village population is made up of four Shukria lineage groups, which form an extended kinship network. It was noted that the inhabitants in each settlement descend from a single lineage group which had moved around together during their nomadic life. The reason for the settlements being away from each other is to have enough space to keep the animals of each settlement separate from those of the others. Within the village, there are no boundaries between these groups in terms of social relations, in rights to access resources and services, or any other social benefits.

\footnotetext{
${ }^{2}$ Interview with Mohamed El Awad, the village leader, May 2002.

${ }^{3}$ ADS stands for the Area Development Scheme Project, which was a UNDP-funded project implemented in five areas of Sudan. The ADS was set up to rebuild drought-stricken areas in Sudan through the provision of adequate water supply, credit and seeds to farmers, extension services, storage, marketing and transportation facilities. Central Butana was one of the five areas in rural Sudan selected by UNDP to receive this assistance. In Central Butana, the ADS extended it services to 23 villages with a total population estimated at 60,000 (UNDP 1988).
} 
The people of Es Sadda are by tradition nomadic, but the successive losses of their animals due to drought has forced them to settle in a village. Previously, they moved with their animals following the availability of water and pasture. Generally, their movement was fixed along certain routes (locally called marahil) from north to south during October to March, remaining until the beginning of the rainy season in June, when they moved back north. In the north, they stayed in one place (locally called Damar) until the available pastures and water were finished when they moved southwards again. By moving along these routes, the nomads were able to meet their needs for water, pasture, and fuels which were all naturally available. Food items and other necessities could be bought from surrounding markets where they were also able to sell their animals. All these services would become scarce in drought events and animals died of hunger and thirst, or were sold cheaply. Over time, the number of animals owned by an individual family (which is a reflection of their wealth and status) decreased from several hundreds (generally 500 to 1000 heads) to less than 200. This decline in assets is the main reason behind their permanent settlement in the village. Settling in the village does bring benefits in that it allows education for children and involvement in new economic activities, such as mechanized farming.

Depending on the type and magnitude of income sources, families in the village vary in their possession of wealth and this leads to differences in access to energy services between the different wealth groups in the village. Based on wealth ranking, as defined by the village participants in this study, the population is grouped into four categories. The criteria of wealth and the ranking of families into different categories are shown in Table 4.1.1. The main source of wealth is animals and families are consequently ranked according to the number of animals they $\mathrm{own}^{4}$. It was noted that animals move along the same routes followed by a single member of the family and sometimes by hired labour.

\footnotetext{
${ }^{4}$ It should be noted that families are allocated to a particular category based on the perceptions of those villagers participating in the data gathering exercise. A family may own some or all of the wealth assets of the category to which they are assigned. In the case of Es Sadda the number of animals is the key defining criterion for membership of a particular category.
} 
Table 4.1.1

Wealth criteria and wealth categories in Es Sadda

\begin{tabular}{|c|c|c|c|}
\hline Categories & Wealth criteria & $\begin{array}{c}\text { Number of } \\
\text { families }\end{array}$ & Percentage of total \\
\hline Wealthy families & $\begin{array}{l}\text { - } \text { own large herds } 100-150 \\
\text { animals } \\
\text { - } \quad \text { own large mechanised rain-fed } \\
\text { agriculture farm (more than } \\
1000 \text { fedans) } \\
\text { - } \quad \text { own private car } \\
\text { - } \text { own tractor } \\
\end{array}$ & 13 & $14.13 \%$ \\
\hline Medium wealth & $\begin{array}{l}\text { own medium-sized herd } 50 \text { - } \\
100 \text { animals } \\
\text { own medium size mechanised } \\
\text { farm ( } 10-50 \text { fedans) } \\
\text { - have a migrant family member } \\
\text { (remittances) }\end{array}$ & 33 & $35.87 \%$ \\
\hline Poor families & 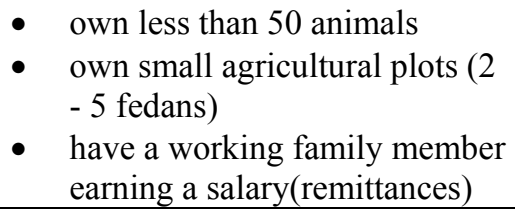 & 32 & $34.78 \%$ \\
\hline Very poor families & $\begin{array}{l}\text { - } \quad \text { own small agricultural plots } \\
\text { - } \quad \text { have no family members with } \\
\text { other income sources }\end{array}$ & 14 & $15.22 \%$ \\
\hline Total & & 92 & $100 \%$ \\
\hline
\end{tabular}

The village can also be analysed in terms of gender since the ratio of women to men in the village varies by season. When men migrate to work in cities or in irrigated schemes, the percentage of women in the population increases to $60 \%$. This means the position of women as heads of household changes seasonally. The village inhabitants can also be categorized into different age groups.

\subsubsection{Access to energy services in Es Sadda}

Energy services used in Es Sadda are analysed into household, agriculture, nonagriculture, water, education, social centres and transportation and communication applications. Different energy carriers are used to obtain these services dominated by the use of traditional sources (Annex 1: Section 1.3). The level of wealth has a clear affect on access to energy services, allowing a transition from low quality energy carriers drawn from natural capital to those obtained from physical capital. However, both types are vulnerable to disruption by the factors of vulnerability and women may have to shift from LPG back to fuelwood with the negative health implications. Water can be obtained from natural capital components, free of any monetary cost during some months of the year, and can bought from physical capital components in other months (Annex 1: Table 1.6). Wealthier families can afford to buy water from private tankers at a higher price (SDG 2.5 (Euro 1) per barrel) than from the UNDPADS tankers (SDG 1 per barrel). They can also store water in large tanks or barrels to secure their water needs for several days if tankers do not come to the village. Being able to pay for water allows them to build their houses from bricks and hence have a 
better quality house. So, financial capital is an important determinant factor in the flow of energy services. Conversely, poor families depend on their own labour to get the water service directly from the haffir or they can get it from the canals for free but they then need to travel longer distances which takes more time, and represents an opportunity cost. Their houses are built from grasses and wood materials because they are unable to buy the large amount of water needed to make bricks and other building materials. Sometimes, during a poor rainy season, some families move and resettle close to the irrigation canals and wait until the next season to return to the village provided there are sufficient rains. So, water in this village plays an important role in securing the flow of energy services for those who have access to it, particularly during times of vulnerability (shocks and seasonal stresses). Access to financial capital allows the purchase and use of energy services made available through physical capital components which smoothes the flow of energy and removes the burden accompanying the provision of energy services from the natural capital components.

Gender affects access to energy services in the following manner. Women shoulder the burden for providing water and fuel for cooking when the inputs are obtained from natural capital components. This burden is removed when financial capital components are used to provide the energy service from physical capital. The provision of water from tankers and the use of LPG needs little muscle effort from women to meet their family's water needs or to cook their family's meals. Gender also affects the accessibility and use of some energy services available in the village such as attending evening studies held in the school. Girls are not allowed to go and study in the school during the evening. As a consequence, they miss the opportunity to do their homework under good light and miss out on the evening classes provided by teachers to the final-year class. Further, final-year boys are allowed to stay fulltime in the school in the two months prior to taking the final examination. The boys lodge in one of the classes equipped with the lighting system and study in the other. So boys get longer hours of study, close to their teacher, and get their support, while this is not an option for the girls. Girls also do not attend the khalwa education classes which are usually held at inappropriate times for girls to attend due to social customs. Women and girls do not move about when it is dark (early morning and late evening). This shows that, besides wealth, gender is also an important factor in determining the burden of providing energy services (such as water and firewood) and in determining access to some energy services (such as school lighting).

Age groups in the village also have different roles in access to energy services. Children are responsible, together with women, for the provision of water and fuel. When fuels are not locally available, children fetch water from the canals and fuelwood from afar using donkeys. The younger men may migrate seasonally to the irrigated schemes and cities in search of paid work. The elders usually stay in the village to look after the family which lets younger male family members leave. The migrants contribute financially to their families' energy services by sending money to finance the purchase of water from tankers and sometimes LPG (Annex1: Section $1.2)$.

Distances between the houses and the location of the service also affect accessibility to energy services. For example, khalwa education is only possible for boys having their house close to the school. The time set for khalwa lessons is also not appropriate 
for boys from the outlaying settlements which are located 2 to 5 kilometre away from the village centre where the khalwa is located (Wad Ebahi, El Saadonab and Wad Rahama). Also the boys from these outlying settlements do not come to study during the evenings because of the long walk to the school in the dark when the risk of being bitten by poisonous creatures (snakes and scorpions) is considered high. As shown in Annex 1, social capital components such as kinship, membership of unions and informal organizations, as well as spatial factors, have an influence on access to energy services by the different groups in the village.

The stock of energy services available in the village is insufficient to support livelihoods. The availability and accessibility of energy services is subject to the prevailing factors of vulnerability, the level of wealth, gender, age and spatial proximity to services. The insufficient stock of energy services is caused by three factors. First, the occurrence of vulnerability factors that weakens the natural capital on which most of the villagers rely for energy services. Second, the limited financial capital to build energy services based on physical capital components which would improve the flow of energy services. Third, the lack of any role for the transforming structures and processes of the government in planning for an uninterrupted flow of energy services to the village. Instead, as shown in Annex 1.4, there is a noticeable role for non-government authorities in developing energy services in the village, including international organizations (UNDP-ADS) which provide water tankers, charity organizations (Zakat chamber) which dug the haffir and NGOs (Swedish Free Mission) which installed a solar lighting system in the school.

\subsubsection{Energy services priorities ${ }^{5}$ in Es Sadda village}

The highest priority for the villagers is accessibility to more reliable drinking water all year round. They need more reservoirs to be excavated closer to the village to be able to store sufficient water for the whole year. Other development priorities in Es Sadda were found and these varied with gender and age, but not with wealth.

Men, for example, perceived an immediate need to increase food production by increasing the cultivated area through mechanisation. Tractors and combines can put more land under cultivation, increasing production and making farm labour much easier. They also want electricity in the village community centres: in the mosque, the khalwa, the school and the dispensary.

Women, on the other hand, put a cellular telephone as their top priority. They want to be able to communicate with their husbands, sons and relatives working most of the year in the cities or in irrigated schemes outside the village area, or with those who have migrated outside Sudan and return only once every year or several years. They need to be able to encourage them to send money to be able to meet the family's expenditure in the village, as shown in the following quotes ${ }^{6}$ :

\footnotetext{
${ }^{5}$ Data gathering on energy service priorities in Es Sadda involved two separate groups of women and men. Each was then subdivided into two groups according to age. Each subgroup was asked to list their energy service priorities. A list of energy service priorities from each subgroup was presented to the whole group, which discussed and ranked the services

${ }^{6}$ These statements are from an exercise in which five women were asked to imagine that they had a telephone in their hands and their husband, son or other relative was on the other end: what would they say to them?
} 
- If I had a telephone, I would call my husband and tell him that we have little grain left from the season and we need to buy more from the market.

- Our daughter is sick I want to take her to Halfa or Gadarif Hospital. Would you come to accompany us?

- My uncle's daughter will get married next month; I need new clothes and need a gift for her wedding.

- The school will open soon and we need the kids' school uniform and school fees.

Because there is no telephone in the village, residents with urgent needs, go to New Halfa or El Gedarif to communicate with their relatives, which costs a lot of money and time. They try to keep migrant family members in touch with village events and maintain ties with them. In other words, Es Sadda residents need to maintain and build social capital to enable them to deal with the factors of vulnerability.

Both women and men put having a fridge in the village dispensary within their priorities in order to keep antidotes for scorpion and snake bites to treat their children for that eventuality in the rainy season or when they are collecting fuelwood. The fridge could also store vaccines and provide regular vaccinations for infants and children besides keeping life saving medicines such as insulin. Other priorities for women include the provision of bottled gas for cooking and for lighting, so that they do not have to go out every morning to collect fuelwood and crop residues to cook their meals.

A third group that mentioned distinct needs were the young men who prioritise the building of a club with a TV and satellite dish. It is very common in villages in Sudan for the young men to join together to build a club and install such equipment as a place for recreation. Such a club also provides a place where social occasions, adult education, and training programmes can be held. In Es Sadda such a club has not yet been established due to objections by the sheiek and elders in the village who have a veto on all village affairs. A group of young men had already bought the satellite dish, the diesel generator, the TV and all the accessories. They had collected money from all the young men in the village and got additional financial support from El Gedarif State's Ministry of Culture. However, the elders think that it is morally dangerous to let the young people and children watch programmes broadcast by satellite TV stations, even though there are two families in the village who own and use satellite dishes. The youth bought the equipment just before the Football World Cup in 2002, with the intention of watching the competition in the village. Because they were not allowed to install their system, they went daily to a nearby village to watch some of the matches. One of the participants mentioned that: "We hired a car to take us to watch some of the matches, particularly the Brazilian ones. The village club there is equipped with generator sets and dishes. Audiences were allowed to attend at a rate of SDG 0.5 (Euro 0.20) for one match in the early stages, and SDG 0.75(Euro 0.30) in the final stages". 
As outlined above, there are differences in the village in terms of accessibility and priority of energy services determined by both gender and age. However, although wealth affects access to energy services in the village, wealth has no direct influence on energy service priorities. The different priorities for energy services are important for supporting different livelihoods strategies that would improve livelihoods outcomes. Women's need for telecommunications is to get timely remittances to secure the flow of water services and maintain their social ties. Young men's need for satellite TV is to reduce the cost of entertainment. The common priority of all groups is to secure the flow of water services.

\subsubsection{Findings from Es Sadda}

Four significant findings emerge from the analysis of the Es Sadda data. The first significant finding in this case is the use of a wide range of energy carriers and exploitation of a wide range of mechanisms, to access different energy services (Annex 1: Section 1.2). This diversification in sources of service can be seen as a strategy to reduce the negative impacts of vulnerability on access to energy services. However, this diversification is a coping strategy that people resort to under difficult conditions such as having to travel long distances to get water during shortages in the haffirs or shifting to low quality fuel types during a scarcity of good quality fuel types from the forest. The coping strategies are only viable options against certain vulnerability factors such as seasonality and trends, but not for shock factors. For example, although the diversification of processes to extend the flow of water services to the village (Annex 1: Section 1.3) helps during normal rainfall years, as a measure against seasonal changes in the availability of water, such diversification does not help during the years of severe drought (shock) when these sources are totally lacking for extended periods as in 1983/85 drought. As shown in Annexes 1 to 6 and Chapter 5 (Table 5.2), seasonality causes scarcity in energy services for different periods in different villages which can be endured by diversification of sources for energy services such as water (digging inside the haffir, buying water from tankers or transporting water from the canal on camels and donkeys). When this scarcity extends to longer periods, as in the case of drought, people lack camels and donkeys for water transportation due to a lack of pasture on which animals could graze and also gradually lose their financial capital to pay the price of water from tankers. However, the capacity to diversify is not equal for all groups. The form of diversification is linked to household wealth. Poor families have limited access to financial capital to buy water, and their access to physical capital and human capital to transport and store water is also limited. Diversification of energy sources under vulnerability conditions can amount to increased use of poor quality fuels which has negative consequences on the health of women due to exposure to high levels of indoor air pollution. In terms of water provision, the lack of financial capital in poor households means that the poor are unable to buy water, and they also lack the physical and human capitals to transport and store water. Instead, they shift to the more difficult or more costly (in terms of time and effort) options for obtaining water such as hauling surface water, hand dug wells, and travelling long distances to find water or, as a final resort, moving to places with rich water sources such as an irrigation canal or the river. The wealthy households, on the other hand, buy water from tankers and store it in large tanks for several days.

The second significant finding is the strong link between natural capital and the energy carriers used to draw energy services such as the provision of water, the 
production of food, the cooking of meals and the transportation of people and services (Annex 1). The existence of this link can be seen by the fact that a shortage in the natural capital due to seasonality factors leads to seasonal shortages in the flow of energy services. Also, when degradation of natural capital occurs due to shock factors, this leads to complete disruption of the flow of energy services and ultimately leads to negative livelihoods outcomes (displacement). In other words, the sources of services, the energy carrier required to deliver the services and the mechanism to obtain the energy carrier are mainly drawn from natural capital. Thus, the vulnerability factors that affect natural capital also affect the flow of energy services. In periods of drought, the basics inputs of ordinary energy services are lacking: there is no water, no shrubs and grasses, no crop residues and no animal dung (Annex 1: Sections 1.2 and 1.3). This leads to the movement of animals and men beyond the village in search of water and fodder. Both animals and men are important energy carriers themselves by providing energy services such as transporting water. However, seasonal and shock factors make services, particularly water and fuelwood, only available at considerable distances from the village, such that transport other than head loading is needed. The responsibility for transporting water and fuel then shifts from women to men. At the same time many able-bodied young male members of families migrate to work in towns or in irrigation schemes, which in turn degrades the village stock of energy carriers available from human sources to collect and transport water and fuels. On the other hand, this migration increases the household's financial capital and allows families to purchase some energy services (LPG and water). However, the overall impact of vulnerability on the natural capital reduces the stock of energy services and consequently decreases the energy circle of the village. As a consequence, people implement different coping strategies which, in extreme situations, involves relocation to places closer to sources where they can obtain the desired energy services (Annex 1: Sections: 1.1 and 1.3). The people of Es Sadda dig shallow wells inside the haffir and then transport water from the irrigation canal to smooth out supply during seasonal shortages and during short droughts (one year). Overall, their energy services have been developed on the basis of their human and physical assets: existing skills, manual tools and metabolic energy. The problem emerges when the capacity of these assets is outstripped by the demand for energy services as has emerged due to the trends towards more settled livelihoods and more frequent periods of drought. The increased demand for water could be met by building more and larger haffirs, which requires mechanical equipment. The level of human assets (skills) and financial assets to use such equipment are beyond the capabilities of those currently living in Es Sadda.

The third significant finding is that the links between the factors of vulnerability, the capitals for transforming the energy services and livelihood outcomes vary with wealth, age and gender, and the type of service mostly affected. The wealthy group has better access to energy services than the poor because of a farmer's ability to pay for and to transport and store services such as drinking water and LPG for cooking. Income level does not automatically guarantee a transition from reliance on natural capital for energy carriers. The newly-settled nomadic families, despite having sufficient financial assets, do not buy LPG for reasons related to cultural practices in food preparation and also uncertainty about the safety of LPG use. The wealthy are the last to be displaced during times of vulnerability. The impacts of the factors of vulnerability were also found to vary with gender and age. Women and children, being responsible for the provision of energy services such as water and cooking, 
suffered the most negative impacts such as having to walk long distances to obtain these services and being exposed to health risks linked to the provision of these services. This means there are different energy service circles for each of the identified groups. Wealthier households have a larger energy circle than the poor, men have a larger energy circle than women, and elders have a larger energy circle than children.

A fourth significant finding in this village is the lack of any role of governmental energy transforming structures and processes at all levels in the development of energy services. The existing modern energy sector structures and processes do not reach Es Sadda other than limited access to kerosene and LPG. The lack of transforming structures and processes in developing energy services in the village can be seen as decreasing opportunities for the energy service circles to expand. For instance, building large haffirs could reduce seasonal fluctuations in water flow and improving roads for transportation could reduce the seasonal scarcity of LPG, kerosene and diesel fuel for cooking and lighting services. Such examples could possibly expand the circles of energy services for the whole village. The role of supplying energy services cannot be fully compensated by other parties such as international organizations, NGOs or by the people themselves. The role of the first two is important, but governed by their fields of activities, their limited finance and the relatively short span and coverage of projects such as the SFM's Solar School Project which only provided lighting in the school. The capacity of the village people is also limited by their financial assets and often even the delivery of the priority service, water, is beyond their means. The private sector is also unlikely to see Es Sadda as a lucrative market. However, the community has demonstrated a willingness to cooperate in managing essential services when support is given, as can be seen in the VDCs taking over responsibility for managing the water tankers (Annex 1, Section 1.2.4). This suggests that the flow of energy services could be secured by the inclusion and involvement of lower level institutions.

Possible intervention options that are most likely to deal with the shocks can be found in the provision of water by pumping water to the village, either through pipes from the irrigation canal or directly from the River Atbara. Both options are expensive for an individual village. However, the costs could be reduced if all 23 villages in the Butana area with similar situations of water scarcity were included. Another option is providing a water tanker to link to the village which could secure the water during times of scarcity. Either option for securing water requires a well coordinated effort involving all the concerned authorities such as NRWC, State Ministry of Physical Affairs, State Ministry of Finance, NGOs and financial institutions. Special consideration in such an option should be given to the poor families who might not be able to pay the water fees. Special low fee rates could be charged, or the poor could even be exempt from water fees, similar to the considerations and exemptions granted to the poor in terms of education fees.

Similarly, an intervention to make available LPG devices (cylinders and stoves) for cooking, and electrical generators or solar home systems for lighting is needed. This intervention could be in the form of providing loans or delayed payment by instalments as with the Teacher Union. The Teacher Union scheme has been a factor in enabling access to and use of LPG for cooking and the use of electricity for lighting by some households. For LPG, such an intervention could increase the number of 
users and lead to the establishment of private gas dealers in the village with enough cylinders to exchange empty ones for full ones, saving an expensive trip to town. However, it is important to consider those who are going to be negatively affected by such an intervention with physical capital. These are the poor who depend on providing traditional fuels to wealthier households for their livelihoods, and the generation of financial capital. It is also important to note that disaggregated data gathering helps in identifying the need for diversified strategies in promoting a transition to modern energy services. For example, the families who are not using LPG despite having the financial ability to do so (bounded by their cultural traditions require approaches that change their attitudes to LPG such as training on the use of the gas and safety measures.

In conclusion, the village, in general, has an unstable energy circle. The flow of energy services is interrupted by various factors of vulnerability and, as a result, the energy circle changes frequently in size due to shocks and trend factors, and annually due to seasonality factors. It is also possible to draw different circles for different groups based on wealth, gender, age and spatial distances to the centre of energy services. These differences between groups in the village also result in different priorities for energy services. As shown in Section 4.1.3 above, men's priority is the use of tractors for farm operations to be able to extract greater financial capital by farming cash crops. Women's priorities are to have access to communication facilities which can be linked to their need to secure financial capital from their migrant family members and to access purchased energy services. Communication is important to women as they seasonally become heads of households, due to the seasonal migration of men, responsible for the provision of energy services but without direct access and control over financial assets. Young men, on the other hand, want TV satellite facilities which can be seen as a strategy to reduce the cost spent on travelling to other villages to use their facilities.

\subsection{El Idied}

\subsubsection{Background}

The village of El Idied lies in the southern part of the central Butana area at coordinates $14^{\circ} 38^{\prime} 13.5^{\prime \prime} \mathrm{N}$ and $34^{\circ} 48^{\prime} 0.3^{\prime \prime} \mathrm{E}$. The nearest urban centres are El Gedarif, about 50 kilometres to the south of the village, and New Halfa, about 150 kilometres to the east. The village is located at the foot of two hills (El Rudiem and El Ghubiesha) and, on its eastern side, the village faces a forest area which separates it from large mechanised agriculture schemes.

The inhabitants of the village were previously nomads who moved along fixed routes with their animals from one place to another following the availability of water and pasture. However, they would settle in the village area from December to July (this period is locally called the damar ${ }^{7}$ time) each year, after which they would move

\footnotetext{
${ }^{7}$ When nomads stay in one place for a significant time that place is called dammar, a place along the nomads' migration route, and the period they stay there is called the damar time. El Idied had been a damar location before people permanently settled there. Damars have the characteristics of good pasture and sources of water that remain for two to three months after the rainy season is over. Not all places are suitable as damars, for example, Es Sadda was not a damar because of its poor water
} 
southwards for the rest of the year. The permanent settlement in El Idied started in 1964 with six families, and since, then the number of settled families continues to grow. In 2004, at the time of the fieldwork for this study, the village was inhabited by 251 families with a population estimated at $1800 .^{8}$ As part of the Butana area the village population descends from the Shukria tribe who form $90 \%$ of the population. The other $10 \%$ came from various tribal groups.

The people in the village depend on animal grazing and agriculture as their main source of livelihood. Although the people of El Idied were traditionally nomadic herdsmen, after they permanently settled in the village they started to practise certain agricultural activities. The proximity of the village to mechanized schemes allows the use of mechanized equipment for producing cash crops by the villagers. The mechanized schemes also provide employment for manual farm operations such as weeding, harvesting and threshing.

The basic indicators of wealth, as identified by the villagers, are the number of animals, type of agricultural practices, trade, and remittance from migrant family members. Based on the level of wealth ownership, the village inhabitants could be divided into four groups: high income, above moderate, moderate, and low income. Table 4.2.1 below shows the types of wealth by which families are classified, the number of families in each group, and the percentage of each group in the population.

availability. The other villages in this study are not located along nomad migration routes and so cannot be damars.

${ }^{8}$ These figures were obtained from the records of the VDC in 2003. The reasons mentioned by the committee for gathering and keeping a record for the village are to decide the share of families in the village agricultural cooperative, for collecting fees for an electricity connection to local generators, and for maintaining a record of infant vaccinations. 
Table 4.2.1

Wealth criteria and wealth categories in El Idied

\begin{tabular}{|c|c|c|c|c|}
\hline No. & Categories & Wealth criteria & $\begin{array}{l}\text { Number of } \\
\text { families }\end{array}$ & $\begin{array}{l}\text { Percentage of } \\
\text { total }\end{array}$ \\
\hline 1 & $\begin{array}{l}\text { High income } \\
\text { group }\end{array}$ & $\begin{array}{l}\text { - Own more than } 100 \text { animals } \\
\text { (camels, cows and sheep) } \\
\text { - mechanized agriculture (more } 200 \\
\text { feddans) } \\
\text { - wholesale trade in towns and } \\
\text { markets } \\
\text { - migrants }\end{array}$ & 23 & $9 \%$ \\
\hline 2 & $\begin{array}{l}\text { Above } \\
\text { moderate }\end{array}$ & $\begin{array}{l}\text { - Own about } 100 \text { head (camels, sheep } \\
\text { and goats) } \\
\text { - } \text { mechanized agriculture } \\
\text { - } \quad \text { professionals, eg teachers } \\
\text { - } \text { migrants }\end{array}$ & 48 & $19 \%$ \\
\hline 3 & Moderate & $\begin{array}{l}\text { - Own about } 50 \text { head( sheep and } \\
\text { goats) } \\
\text { - } \quad \text { Migrants }\end{array}$ & 53 & $21 \%$ \\
\hline 4 & $\begin{array}{l}\text { Low income } \\
\text { group }\end{array}$ & $\begin{array}{ll}\text { - } & \text { Own less than } 20 \text { head (sheep and } \\
\text { goats) } \\
\text { - } \quad \text { Wage labourers } \\
\text { - } \quad \text { Migrants } \\
\text { - } \quad \text { Seasonal labour in mechanized } \\
\text { farming }\end{array}$ & 127 & $51 \%$ \\
\hline & Total & & 251 & $100 \%$ \\
\hline
\end{tabular}

Source: Developed during the PRA sessions, based on the VDC records, by the participants.

The terms wealthy and poor are not used by the people of El Idied to classify themselves. A poor family, for example, was previously defined as one that could not secure its food for a whole year. During the fieldwork period, not a single household was found to fall within this category. That is, every household can produce enough food, or can earn enough money to buy it.

The main reason for the comparative wealth of this village is its closeness to the mechanized agriculture schemes, which provide some waged employment even after the rainy season is over. Thus, all families can secure their food over the whole year, at least during typical seasons with adequate rainfall for food production and animal survival. However, during times of vulnerability, such as heavy droughts, many families would fit the poor category, being unable to produce their own food or find sources of income to buy their food (Annex 2, Section 2.1). The village inhabitants can also be classified in terms of gender and age, which form important groups in terms of variation in access to energy services. El Idied has no significant seasonal migration outside the village and, therefore, the ratio of women to men is not affected significantly by seasonal migration.

\subsubsection{Access to energy services in El Idied}

As in Es Sadda, the energy services used in El Idied are analysed into household, agriculture, non-agriculture, water, education, health, social centres, transportation and communication categories. Inhabitants in El Idied also combine different energy 
types and practices to obtain their energy services. However, unlike in Es Sadda, El Idied has a relatively larger circle of energy services since there is a greater stock of energy services such as a mini-grid and agricultural mechanization (Annex 2, Section 2.2). All the villagers have the customary right to participate in all services. The village has three water sources which are available for all to use. The village land belongs to the whole community ${ }^{9}$ and is sufficiently abundant that each family can cultivate as much land as they have the capacity to farm. The allocation of services is controlled by village organizations (Annex 2: Section 2.1.2.4). However, a family's financial capital does create some differentiation in access to and use of energy services. High income families, for example, use more electrical appliances than the other groups. In their houses they have satellite TVs and more electrical lamps. They can draw more benefits by using mechanization to cultivate more land and generate more profits. Although other groups can access machinery and can grow cash crops, the area they can cultivate is limited by their ability to finance land preparation. This differentiation is also governed by the risk of unpredictable rainfall. High income families can bear some risk without significantly affecting their level of livelihoods whereas low income families cannot.

The village cooperative provides some energy services in the village. It allows cultivators of small plots to access mechanization services in preparing their land and so increase their level of production with only a low level of labour input. Also, electricity from the mini-grid is accessed by all houses and has been extended to the village club. All families in the village are members of the cooperative that owns the tractor and the mini-grid generator, and runs the club. Membership of the cooperative builds social capital and as such, facilitates access by all families to the available village services (Annex 2: Sections 2.2 and 2.3).

Gender also lends to differentiation in access to some energy services. Women are not allowed to attend the club where the TV set is, and hence do not participate in this energy service for entertainment. Girls do not attend evening classes held in the school although they at least have electric light at home enabling them to do some extra study. Further, it was also found that women do not use machinery in cultivating and processing the subsistence crop Dura. Since the Dura is only for meeting the families' food needs, investment in the substitution of labour by technology is not considered necessary. Again women and children are responsible for the provision of cooking fuel, such as wood, crop residues and animal dung, and so shoulder a greater burden in cooking. However, women who are members of families belonging to the high income, above moderate and moderate income groups do use LPG and kerosene for cooking.

The data presented in Annex 2 show that energy services in El Idied are affected by the factors of vulnerability prevailing in the area, mainly drought and seasonality. However, compared to Es Sadda, El Idied has a larger stock of energy services. This additional stock of energy services includes shallow water wells and a large forest area (additional natural capital components), and mechanical farm equipment and the mini-grid (additional physical capital components) (Annex 2: Sections 2.2 and 2.3).

\footnotetext{
${ }^{9}$ The community owns the right to allocate land for small farms, up to 20 feddan in size, but not for the large mechanized schemes which are the responsibility of the State Ministry of Agriculture.
} 
Generally, all groups can access and use the energy services available in the village, with the exception of some gender differentiation (women cannot go to the youth centre and girls cannot go to the school after dark. However, access to energy services varies significantly among the wealth groups during times of vulnerability when the ability to purchase energy services, such as water, determines whether or not a family is forced to move to another area (Annex 2: Section 2.1.1). As with Es Sadda, there is a lack of government involvement in enabling access to energy services. In El Idied, the gap left by the government is partially filled by a development agency, UNDPADS, which has played a significant role in improving access to some services including water.

\subsubsection{Energy services priorities in El Idied}

Amongst the energy service priorities in El Idied, the provision of drinking water is the first for all groups. As a first step, the village people propose improving the water services by building a dike across the seasonal stream that passes close to the village to increase the water storage capacity and secure water services the whole year round. The next step would be to pump water to a service unit inside the village to reduce time, effort, and cost spent on water transportation.

Another common priority is equipping both the health centre and the proposed veterinary unit ${ }^{10}$ with refrigerators to store drugs and vaccines. A refrigerator in the health centre would enable medicines and vaccines to be kept, which would reduce the need to travel to a town. Such a local service would avoid the high cost of travelling to town. It is not only the cost of transportation that matters but also the time cost of losing another family member, who has to accompany the patient, from farm work during the rainy season. A refrigerator in the veterinary unit would help to maintain animal health and reduce animal losses through disease. It could also reduce the cost of obtaining veterinary services from town. The refrigerator could be used to store sufficient animal drugs in the village, particularly for the rainy season when transportation to town is blocked.

There are no priorities clearly differentiated based on wealth, gender or age as are found in the other five case study villages. One reason is that, in El Idied, wealth differentiation is too diffuse to be able to make sharp differences in needs and priorities. All households can earn enough to pay for the services, either by working in mechanized schemes or by producing cash crops. An indication of the wealth of El Idied can be seen by the fact that all families are able to pay for the costs of installing and operating an electrical mini-grid. Since all the households are electrified, both men and women have access to electricity. Also, a youth club has already been established and equipped with a satellite TV set and is available for men in all age groups. Women have access to satellite TV at home.

\subsubsection{Findings from El Idied}

The findings from El Idied show that there are some similarities and some differences to the findings from Es Sadda. First, there is a use of wide range of energy carriers (Annex 2: Section 2.3). For example, the water service is obtained by using the haffir,

\footnotetext{
${ }^{10}$ During this study an application for a veterinary unit in the village was forwarded to the State government. Approval was not received at that time, but promises were made by the state government to provide staff if a building for the unit is established by the village.
} 
shallow wells and water tankers. When the easily accessible sources of energy services run short, families move to lower grade, more expensive options to obtain the needed services. Also, the division in use of the sources of water (haffir and shallow wells) between human use and animal use helps to ensure the flow of water beyond the rainy season. It is the variation in the availability of good quality energy services during the rainy and off-rainy seasons which enforces the return to lower grade, more expensive energy services. The use of a wide range of energy sources also helps as a coping strategy during seasonal changes but not during periods of increased vulnerability brought about by the shock factor of drought. A smaller number of families, than in El Sadda, had to displace during the drought periods due to the presence of more financial and physical capital components in El Idied that could replace natural capital in the provision of energy services (Annex 2: Section 2.3).

The second finding is, as in Es Sadda, that there is a close link between the natural capital and the energy carriers used to draw the required energy service (Annex 2: Sections 2.1 and 2.2). Therefore, the provision and flow of energy services is subject to disruption due to the same factors of vulnerability as in Es Sadda: primarily drought and seasonality. However, the disruption in El Idied is less than in Es Sadda, since the financial and physical assets of the villagers are greater and can be converted into energy services to absorb the shock factors. In El Idied the level of natural capital is greater than in of Es Sadda. There are underground sources of water (easily tapped by shallow wells) which make water services more easily accessible and available for a longer period of time compared to Es Sadda. As a consequence, the villagers of El Idied are better placed than those of Es Sadda to survive the seasonal fluctuations in surface water availability. The presence of the forest area close to El Idied provides a source of fuelwood for cooking. The forest may also be a contributory factor to the better water availability by protecting the watershed.

Linked to this finding, is the way different capitals are combined in developing and accessing energy services in the village. The presence of mechanized schemes (components of physical capital) is due to the relatively high rainfall, creating natural capital that contributes to increasing physical, financial and human capitals. The village also benefits from the little forced migration of strong male household members beyond the village together with their animals. Households thus suffer less temporary reductions in components of physical and human capitals than in Es Sadda. The reason for this can partially be found in the relatively better water and pasture sources which allow animals to stay longer around the village area and partially in the presence of mechanized schemes close to the village which provide not only job opportunities but also crop residues for supplementary animal feed. Thus, for the people in the village there are more capitals that can be transferred into energy services. Different combinations of capitals are found in accessing the energy services. In the provision of a water service, for example, there is the combination of natural capital (rain water) and physical capital (haffir) combined with human capital (labour) in some seasons of the year. At other times, there is a combination of physical capital (means of transportation) and financial capital (money spent on buying water). In some cases, physical capital (mechanized farms) joins with human capital (labour) and is transferred into financial capital (wages from labour) and then into energy services (purchase prices). All these opportunities lead to a significant shift towards LPG for cooking. Also, there is a shift to electricity for lighting. These shifts towards getting energy services from a new energy technology and carrier can 
be attributed to the availability of paid work. That is, cash incomes enable families to pay the initial costs of obtaining the equipment (gas cylinder and stoves, and lamps and wiring) besides being able to pay the regular costs required for refilling the gas cylinder and the regular fees for electricity usage. The availability of transportation (trucks, lorries, and tractors) facilitates the refilling of LPG gas cylinders in El Gedarif. Also, the significant human capital in the skills gained from the operation and maintenance of mechanical equipment facilitates the installation, operation and maintenance of the electrical equipment (generator and the electrical connections). All these factors play an important role in the shift from traditional to modern energy services and provide additional options for accessing energy services which enable the villagers of El Idied to cope with vulnerability. This is in contrast to Es Sadda. It also leads to less forced displacement and less seasonal migration of able-bodied men to outside the village. So, unlike in Es Sadda, women in El Idied do not seasonally shoulder the responsibility of providing energy services.

The third finding is the relationship between the vulnerability factors, livelihood disturbances due to lack of energy services, on one side, and the factors of wealth status, gender and age in the village on the other (Annex 2: Sections 2.1 and 2.2). High income families have a relatively larger circle of energy services in the village. The use of LPG for cooking, the use of their own cars for transport services, and tractors for agricultural production shows some differentiation in energy services by economic status. High income families were able to use their financial and physical capitals to purchase and transport energy services, when they became unavailable from local natural capital during drought events. In El Idied, the inhabitants' coping strategy against vulnerability and the lack of energy services is to sell their animals. They do so until there are no animals left to sell, then they move to areas where services can be obtained. The low-income families started to leave the village after the first year of the drought. Those who are relatively better off stay longer because they are able to transport water services and pay for it by the sale of animals. Thus, the group with better financial capital has better coping strategies for getting their energy services than those with less financial capital. Access to financial capital determines to some extent which families will cope and how long they can withstand a drought situation. When there is drought, all forms of income from the mechanized farms cease because mechanized farms are not cultivated when there is no rain to support the crops.

Gender and age are more important differential factors in access to energy services in the village. Women and children are primarily responsible for the provision of water and fuel to meet household needs. Women also do the manual agricultural tasks (sowing and weeding) and grow subsistence crops, whereas men grow cash crops and carry out the agricultural operations that involve tractors. Other services that are differentiated by gender are the club and evening study in the school. Thus, the drudgery involved in the provision of water and cooking services by these groups, and the health impacts women face during cooking with low grade fuels, have negative consequences on the human capital of women and children. In particular, these negative consequences increase during times of vulnerability when the work involved in accessing energy services increases and exposure to pollutants also increases due to the use of traditional lower quality fuel types. Thus women and children have a smaller energy service circle in the village than the men. 
The fourth finding, from El Idied, which is different to Es Sadda, is the use of social capital (the village cooperative) to buy a tractor for agricultural land preparation and a mini-grid to supply electricity to households. Social capital has also built a payment system for using of the tractor, which allows farmers to rent it and pay after they harvest their crops. In this village, it is the social capital that mobilizes the financial capital to build physical capital for an energy service. So, it is a sequencing of these capitals that allow the provision of these energy services in the village and has increased its energy circle compared to the time before the cooperative was established.

The fifth finding is, as in El Sadda, the modest role of energy transforming structures and processes in the development of the needed energy services. However, there is no doubt that the people of El Idied benefit from the proximity of the large scale private mechanized agriculture in being able to use more modern energy services from the physical capital components in agricultural operations. Such a facility ensures a continuous supply of modern fuels, particularly diesel. Also the people of El Idied used their agency to begin the transforming processes by the installation of a minigrid for electricity generation which provides lighting and other services (satellite TV for entertainment). An international development agency (UNDP-ADS) plays a role in providing energy services, including financing the cooperative to purchase a tractor and agricultural implements.

Interventions that can help people achieve better livelihood outcomes than in the current situation is required to smooth the flow of energy services during vulnerability periods. For El Idied, the shift in energy services from dependence on natural capital to dependence on physical capital components is highly beneficial. By smoothing the flow of water services by building a dike along the seasonal stream, sufficient water can be stored for the whole year. There is a further need for refrigerators to provide cooling services to smooth the flow of vaccines and store medicines and antidotes to poisonous bites and stings for both human and animal applications. This intervention needs not only the building of physical capital in the form of energy services but also coordinating with other sectors such as the water authority and the Ministries of Health, Agriculture and Livestock. As reflected in the identified priorities in Section 4.2.3 above, energy interventions can improve the water supply (building dikes), human health (refrigerators) and can provide veterinary services (refrigerator) which together can lead to better and more sustainable livelihood outcomes.

In conclusion, this village also has an unstable energy circle. The flow of energy services is interrupted by factors of vulnerability making the energy circle change frequently by shock factors and annually by seasonality. All these factors reduce the circle of energy services in El Idied although to a lesser extent than in Es Sadda.. The energy circle in El Idied is relatively more stable than in Es Sadda because of the presence of more physical and natural capital components. The village is able to absorb short-duration changes in the flow of energy services such as seasonal change and short drought periods. For example, the income generated in mechanized agriculture enables the use of LPG for cooking (improves human capital through reducing drudgery and exposure to pollutants from burning biomass) and the use of electricity in both households and community services centres which improves health services, improves both human and social capitals through a good environment for education, and allows gatherings for entertainment (social capital). So, livelihoods 
outcomes in the village are improved by the increased stock of energy services which reduces vulnerability and increases access to more capitals. However, it is also possible to draw different circles for various groups based on wealth, gender and age. Wealth has clear impacts on securing the flow of energy services during severe drought events. As noticed, even during extended drought events, wealthy families are able to use their financial capital to draw more energy services and avoid displacement as is the case with poor families. Women and children as responsible for the provision of traditional energy carriers and have to shoulder both drudgery and health risks (exposure to poisonous stings and bites). However, there are no differences in energy service priorities across the social categories.

\subsection{Dar Mali}

\subsubsection{Background}

Dar Mali is part of the Barbar Province of the Nile State and lies along the eastern bank of the River Nile. The nearest urban centres are Atbara (13 km to the south), Ed Damar (26 km to the south) and Barbar (27 km to the north). Dar Mali is connected to these cities by a railway line (no longer in common use) and by a paved road that connects the northern part of Sudan to Khartoum.

The exact date of the establishment of the village is not known, but it is believed that pilgrims from the Mali area of West Africa used to come on camels and cross the Nile at the point where the village is now established. Upon arrival at the place of the village, the pilgrims camped for several months before continuing their journey to the port of Sawakin along the Red Sea to cross to Mecca, and hence the name Dar Mali which means the place where Mali people camped. The village records show that the number of families inhabiting the village is 354 , with a total population of $2,102^{11}$. The main tribes inhabiting the village are the Galyeen and the Rubatab which constitute about 42\% (149 families) and 44\% (157 families) respectively, the remaining 14\% (48 families) are mixed nomadic tribes, mainly Hadandawa, who settled in the village in 1984 after the severe drought during the period 1983/1985. The village is divided into seven blocks: Western Block, Central Block, Eastern Block, Ansar Block, Ghubush Block, Wagielab Block, and the Ruhal Block (the last of these being occupied by the Hadandawa tribe).

The village inhabitants are predominantly farmers practising irrigated agriculture by pumping water from the River Nile. Farms are generally small in size, ranging from less than a quarter of a feddan to 20 feddans. There are two seasons of cultivation: the winter season in which cash crops are grown such as faba beans, fasulus, chickpeas, alfa alfa, vegetables, onions, and spices; and the summer season in which crops such as sorghum (dura), vegetables, and fodder (Abu70, legumes and corn) are grown.

\footnotetext{
${ }^{11}$ These records were first collected and compiled in 1999 for the Basic Development Needs Project (BDN) which was implemented by the WHO. The records have been annually updated through family representatives. Each representative is responsible for about 20 families and provides data on births and deaths within their group of families.
} 
Besides agriculture, non-farm occupations are also practised including the following:

- Wholesale trade: mostly in Atbara, Ed Damar and Barbar town centres.

Major activities are the marketing of crops, spare parts, and clothes.

- Petty trade: this includes small shops (retailers) selling food items and family needs located inside the village.

- Carpentry: there are two types of carpenters. One uses manual tools, and does small jobs in the village such as repairing broken windows, doors, tables, cupboards, etc. The other is a larger organisation that uses electrical machines and makes furniture, doors and windows, and other large wood items.

- Mechanics: fix and repair diesel engines, pump sets and similar equipment such as diesel generators and electrical motors.

- Tailors: generally women doing small jobs in the village.

- Other small businesses including ice cream making and food selling to pupils during school times.

- Income from pensions, from retired workers

- Income from remittance of relatives, mainly those who work abroad.

Families tend to depend on one or more activities besides farming.

Based on these activities, wealth criteria were defined by the participants during the data gathering and, accordingly, the village inhabitants were divided into four income groups as shown in Table 4.3.1 below. These groups are termed wealthy, medium, poor and very poor. Wealth is generally defined as a relative combination of different sources of income/assets and their magnitude. Poor (fageer) and very poor families (miskeen) are defined in terms of relatively lacking stable sources of income for all family members. All the displaced families are classified within the latter two groups since have the financial capital to place them in the first two wealth groups. Table 4.3.1 shows the number and percentage of families in the different income groups in the village, and their relative wealth in terms of assets as classified by participants in a focus group discussion.

Table 4.3.1

Wealth criteria and wealth categories in Dar Mali 


\begin{tabular}{|c|c|c|c|}
\hline Categories & Wealth criteria & Number of families & $\begin{array}{c}\text { Percentage of } \\
\text { total }\end{array}$ \\
\hline Wealthy & $\begin{array}{ll}\text { - } & \text { Large vegetable land } \\
\text { - } & \text { Date palm garden } \\
\text { - } & \text { Wholesale activities } \\
\text { - } & \text { Remittance from expatriates } \\
\text { - } & \text { Railway employees } \\
\text { - } & \text { Skilled labourers (carpenters } \\
& \text { using modern tools) } \\
\text { - } & \text { Laboratory technician } \\
\end{array}$ & 77 & $22 \%$ \\
\hline Moderate & $\begin{array}{ll}\text { - } & \text { Daily waged labourers } \\
\text { - } & \text { Government employee } \\
\text { - } & \text { Agricultural labour } \\
\text { - } & \text { Small farmers } \\
\text { - } & \text { Petty trade } \\
\text { - } & \text { Pension } \\
\text { - } & \text { Remittance from expatriates } \\
\end{array}$ & 122 & $34 \%$ \\
\hline Poor & $\begin{array}{ll}\text { - } & \text { No stable source of income } \\
\text { - } & \text { Unemployed } \\
\text { - } & \text { Large families } \\
\text { - } & \text { Day-to-day income } \\
\text { - } & \text { Labour } \\
\end{array}$ & 106 & $30 \%$ \\
\hline Very Poor & $\begin{array}{l}\text { - No source of income for any } \\
\text { family member } \\
\text { - Depend on aid from others }\end{array}$ & 49 & $14 \%$ \\
\hline Total & & 354 & $100 \%$ \\
\hline
\end{tabular}

Besides categorising the village population in terms of wealth, gender and age, the village population can also be classified by residence: the original village inhabitants, the nomadic people who settled in the village after the 1984 drought, and the group displaced after the 1988 flooding destroyed their house were destroyed. The latter two groups differ from the original inhabitants in terms of energy services. Their households are located away from the electricity grid which passes through the village and so these families do not benefit from access to electricity. The nomadic group also differ from the other families in terms of their financial capital which is not sufficient to pay the cost of an electricity connection. Their accommodation (small tents made of grasses) are also not suitable for wiring.

\subsubsection{Access to energy services in Dar Mali}

The village has relatively well established energy services compared to the previous two villages. The use of electricity from the grid and local generators, irrigated farm production, piped water and a well-developed transportation and communication systems are some of the additional energy services present in Dar Mali village (Annex 3: Section 3.2). These are available to all groups, and there are no clear wealth, gender and age barriers to accessing and using the available energy services. However, access to energy services for agriculture depends on land ownership, and land is privately owned and usually inherited. Renting of land, sharecropping and hired labour agreements are arranged between people in the village, which widens access to energy services developed or produced in agriculture.

Gender and age have little impact on access to energy services. Women by virtue of having had the opportunity to receive education since 1938 (the date of the 
establishment of the basic school for girls) are able to earn their own income. Further, in addition to those who have formal employment, such as engineers, teachers and secretaries, there are also small enterprises such as tailoring, using manual and electrical sewing machines, and the making and selling of ice cream and other food items. Women, by having their own incomes, are able to finance the purchase of LPG devices, sewing machines and refrigerators which benefit the family both directly and indirectly through increased household income. The only service that is differentiated by gender is the community club where attendance is restricted (culturally and customarily) to men (Annex 3: Section 3.1.2.4). Age also shows little differentiation in access to energy services in this village. One reason is that the energy service needs of the younger generation in the village are already met in the youth club or in their households through the grid and local electricity generators.

The location of some households in the village presents a difficulty in gaining access to electricity from the grid. Two groups of households in the village are not connected to the grid. The first is the group whose original family homes were destroyed by the Nile flooding in 1988. This group was forced to relocate away from the flooded area, but this also meant away from the grid line and hence they lost their connections (Annex 3: Section 3.1.1.3). The second group is the one that settled in the village in the 1980s. Overall, with the exception of connection to the grid, there is an equitable distribution of services which can be seen as contributing to the cohesion of the community. Even the incoming groups are regarded as part of the community and share the available energy services, such as water, with the original inhabitants. This equitable participation has its roots in the mutual benefits of relationships between the immigrants and the original inhabitants with the former providing labour on the latter's farms or tending their animals. This has arisen because there is a shortage of family labour in the village since educated men work outside the village and it is culturally unacceptable for women to work on farms. However, families do benefit from the education of their sons through paid employment and access to needed energy services. Thus a win-win relation has developed, even resulting in intermarriage between the two groups. Hence social capital is built.

\subsubsection{Energy services priorities in Dar Mali}

Dar Mali is a village in which energy services are well developed. However, there are some energy services that need to be improved, others need to be further developed and new energy services need to be introduced. The participants from Dar Mali who took part in the data gathering exercises identified four types of energy service priorities:

1. Improve the working environment in schools by providing energy services such as ventilation and cooling in addition to lighting.

2. Improve accessibility to medicines through the provision of refrigeration to keep life-saving medicines, such as insulin, and provide regular vaccination services for the children.

3. Move towards greater mechanization in agricultural operations, as well as running the irrigation equipment on electricity rather than diesel.

4. Change from diesel pumps to electric pumps for the drinking water supply. 
The prioritised energy services are centred on the provision of a larger electricity supply. However, there are differences between women and men in the purpose for which electricity is needed.

Women want electricity for the following purposes:

- Improving educational performance.

- Food preservation by refrigeration.

- Allowing children to follow TV programmes directed at them.

- Improving informal education and study.

- Usage of electrical equipment (fans, coolers, fruit and vegetables mixers, refrigerators, sewing machines, washing machines and ovens)

Men want electricity for the following purposes:

- Increasing agricultural production areas and reducing the cost of irrigation by using electrical pump sets instead of diesel ones.

- Building cold stores to preserve vegetables and fruit for export.

- Improving educational performance.

- Improving security through the provision of street lighting.

- Spread of awareness through media (satellite TVs).

This gender differentiation reflects the distinct interests and responsibilities. Women are responsible for running the household and need electricity to make their tasks less arduous. Men, on the other hand, need electricity for tasks primarily related to agricultural production. However, improved educational performance is a common interest of both groups.

\subsection{4 - Findings from Dar Mali}

The first significant finding in Dar Mali is the lower diversification of sources of energy carriers than in the first two case villages (Annex 3: Section 3.2). For cooking, LPG is commonly used, for lighting electricity, and for water pumping diesel and electricity. This reflects a close relationship between the quality of services and the source of the energy carrier. The energy delivering the services is drawn from physical capital rather than natural capital, as was the case in the previous villages. All the energy services, including pumping irrigation water for food and cash crop production, the piped drinking water system, cooking and lighting, are not subject to interruption by vulnerability factors. Also, the availability of telecommunication facilities in the village provides information from different market places and the paved road passing through the village allows the transport of people and products to different market places. Both facilities (telecommunications and the paved road) allow farmers to get better prices for their products and hence increase their financial capital and improve secure livelihood outcomes.

The second significant finding is the weak link between energy carriers and the natural capital. Instead, there are more links between carriers and physical capital. This use of energy carriers (physical capital components) has allowed the extension of the water network to all households, and ensures no disparities in the provision of services between the different social and economic groups in the village. Also, modern energy carriers remove the responsibilities of specific gender or age groups in the provision of water services and free these groups from the drudgery seen in the 
previous two villages. Various factors have contributed to the development of physical capital:

a) Historical factors such as the colonial campaigns passing through the village and building the railway line have played an important role in the development of the village. The railway line facilitated the transportation of diesel fuel and hence the easy shift of irrigation technology from the shadouf and sagia to diesel pumps (Annex 3). The presence of the railway also provided work opportunities for people in the village (financial capital) and helped in developing mechanical skills (human capital). Both components were invested in financing the mechanization of agricultural operations leading to increased agricultural production. Therefore, an important finding is that not all factors which produce positive energy transitions can be reproduced.

b) The location of the village, between the urban centres of Atbara and Barbar, has been fortuitous in enabling access to grid electricity because the power line between the two cities passes through Dar Mali.

c) The strong social capital of networks and contacts in the village has contributed significantly to the development of energy services. For example, a social network had a major role in extending the water pipes to households. The necessary SDG 90,000 (Euro 36,000) was made available through contacts with village members working abroad and elsewhere in Sudan.

d) Access to financial services from banks had a significant role in the development of energy services. The purchase of agricultural machinery can be financed through the Agricultural Bank of Sudan (ABS). Finance is also available from other banks such as the Nilein Industrial Development Bank (NIDB) and the Saving and Social Development Bank (SSDB) for other services such as small enterprises, electrical generators and even LPG cylinders (Annex 3: Section 3.1.2.5).

The third significant finding is the limited occurrence of vulnerability factors and their low impacts on the flow of energy services in the village. Families have never been forced to move beyond the village boundaries, although some families had to be relocated within the village due to flooding in 1988. Although the social capital of the displaced families has not been reduced, there has been a reduction in their physical capital and a serious reduction in their energy circles since they have lost their connection to the electrical grid. Given the large dependence on physical capital, the vulnerability factors that affect the natural capital of the village have few negative impacts on the flow of energy services to the village. The case of Dar Mali also shows that when people are not under frequent stresses, they can build good quality energy services, gains can be maintained and built up on progressively, and there are positive livelihood outcomes. Building a stock of good quality energy services amounts to building a circle of energy services that is large enough to stabilize and smooth the flow of services that are vulnerable to seasonality factors. In part, this can also be attributed to the level of peoples' financial capitals, since these can be transferred into energy services, and to the paved road which provides a good transport system allowing access to distant energy services. Noticeable in all these services is the 
strong relationship between the quality of energy services and the use of physical capital components, such as the higher quality water service and the use of a piped water system. However, there are still some agricultural tasks performed manually on some farms (Annex 3: Table 3.3). This is because the right type of physical capital component, such as buffalo tractors which are highly manoeuvrable on small areas of land, is not available to them.

The above mentioned four factors contribute to the transition from traditional energy services, such as the shadouf and sagia, to modern energy services such as diesel and electrical pumps for irrigation, and from firewood to LPG for cooking.

The fourth significant finding is that, in Dar Mali, the development of energy services is aided by several parties (stakeholders) who have an interest in the development of energy services in the village. However, this development would have not been possible without direct government intervention to build physical assets beyond the local people's capabilities (electrical grid, the paved road and the railway). Such government interventions (through its structures and processes) were found in the extension of the electrical grid, which put electricity services from the national grid within people's grasp, and the establishment of the paved road linking Dar Mali to urban centres (Barbar, Atbara, Dammar and Khartoum) which opened up new marketing opportunities for vegetables, fruit and other farm products. These government interventions created a basis for the move towards a more marketoriented economy and attracted other service providers, such as banks to provide loans and a communication company to provide its services. Further, an important party in this development was the World Health Organization (WHO) which not only put efforts into the provision of certain energy services but also contributed to the fair distribution of energy services by ensuring the participation of all groups (immigrants, women, and others) in the VDC, through which WHO services are channelled. WHO's role in building up the local capacity to monitor and follow up village activities is also a new form of input for rural areas. The recruitment of family representatives, by WHO, to regularly report on their families' health and wellbeing allows the VDC to know about village problems and to look for its own solutions.

In conclusion, Dar Mali is a village with a relatively larger and more stable energy circle than the previous two case villages, with several energy services that are constructed in the village and with a flow of energy services that are not interrupted by factors of vulnerability The flood in 1988 caused the displacement of some families and, as a result, those families lost their connection to the grid, therefore these households now have a smaller energy circle. The immigrant households' energy circle is even smaller due to their lack of land requiring additional energy services (land preparation and irrigation).

However, due to the low capacity of the grid, electricity is not continuously available and the full potential of electricity is not realised (for example a shift to electrical water pumping). In terms of electricity, there are some differentiations in priorities between the groups not connected and the rest of the village groups. Those who are not connected want to be connected. Stated priorities also show some differences between small farmers and large farmers. Small farm owners want arrangements so that they can use electricity for irrigation whereas large farmers want a secure supply of electricity so that they can switch from diesel pumps to electrical pumps. 


\subsection{Goz El Halag}

\subsubsection{Background}

Goz El Halag is located along the southern bank of the River Atbara and separated from this river by village farms. The village boundaries are marked by the village farms to the north and by a desert and hilly area to the south. The east and west sides the village are bordered by two neighbouring villages. The nearest urban centre is the city of Ed Damar, the capital of the Nile state, which is located about 32 kilometres to the west. The village is positioned at coordinates $17^{\circ} 23^{\prime} 04^{\prime \prime} \mathrm{N}$ and $34^{\circ} 16^{\prime}$ 0.6 "E.

The villagers believe that Goz El Halag was first inhabited in the $17^{\text {th }}$ century. Goz El Halag is now inhabited by 84 families with a population estimated at $1500^{12}$. All the people are descended from the Ababda tribe, which dominates most of the area along the River Atbara. Nomads visit the area during the winter season and stay for about three months before they move southwards. During the period they stay, they rent fallow farms on which to keep their animals, and graze the grasses and crop residues left after harvesting. Goz El Halag also lies within a UNDP-ADS project area: the Lower Atbara ADS. The project covers an area north to the Khashim El Girba Dam.

The villagers practise irrigated agriculture as their main occupation. They grow vegetables and legumes as cash crops, and dura for their own use. Animals (cattle, sheep and goats) are also kept in small numbers (generally 3 to 5) for their milk and other products. The agricultural land within the entire village is generally estimated at 500 feddan, of which approximately 450 feddan is owned by the village agricultural cooperative and only eight farmers own private land. Farmers can be distinguished into three groups as follows:

- Farmers who are landowners.

- Farmers who rent land from the co-operative society.

- Daily agricultural waged labourers

The main criteria used for defining wealth is ownership of irrigated land close to the riverbank followed by ownership of cattle, cars and shops. Based on the ownership and sources of wealth, people in the village were divided by the participants in the data gathering exercises into four groups as shown in Table 4.4.1.

Since opportunities for earning income are available on the irrigated land of the village (both private and cooperative land), and in the New Halfa Scheme, male family members can earn an income throughout the year which can be sufficient to buy the family's food and other life necessities. There are no families which lack their daily food needs and hence could be considered "very poor".

\footnotetext{
${ }^{12}$ The last official population data for Goz El Halag were collected in 1992 during a time when a quota system for the distribution of sugar was in place. Under this system, every family had a card listing its family members and the Village Popular Committee kept a copy of the cards in the village. In 2000, the VPC updated the figures and this estimate is based on those figures.
} 
Table 4.4.1

Wealth criteria and wealth categories in Goz El Halag

\begin{tabular}{|c|c|c|c|}
\hline $\begin{array}{c}\text { Wealth } \\
\text { categories }\end{array}$ & Wealth criteria & $\begin{array}{l}\text { Number of } \\
\text { families }\end{array}$ & $\begin{array}{c}\% \text { of total number } \\
\text { of families }\end{array}$ \\
\hline Wealthy & $\begin{array}{ll}\text { - } & \text { Own irrigated land } \\
\text { - } & \text { Own cattle } \\
\text { - } & \text { Own cars (cars/lorry) } \\
\text { - } & \text { Fund/Rent farms }\end{array}$ & 10 & $12 \%$ \\
\hline Middle & $\begin{array}{ll}\text { - } & \text { Own shops } \\
\text { - } & \text { Animals traders } \\
\text { - } & \text { Rent agricultural land } \\
\text { - } & \text { Remittance from migrants and } \\
\text { expatriates }\end{array}$ & 15 & $18 \%$ \\
\hline Poor & $\begin{array}{ll}\text { - } & \text { Sharecroppers with other land } \\
\text { owners or with the cooperative } \\
\text { - } & \text { Have one or two goats for milking. } \\
\text { - } & \text { Daily waged labourers. } \\
\text { - } & \text { Remittance from migrants and } \\
\text { expatriates }\end{array}$ & 59 & $70 \%$ \\
\hline \multicolumn{2}{|l|}{ Total } & 84 & $100 \%$ \\
\hline
\end{tabular}

Wealth, gender and age were identified in the village as factors leading to different levels of access to energy services. The seasonal visits by nomads from March to July also affect the need for energy services. The numbers of families visiting the village seasonally varies between 15 and 20 families. So, the burden on the circle of energy services increases by about $25 \%$, mainly for water. A distinction in residence status (permanent or temporary) adds another factor in influencing access to energy services.

\subsubsection{Access to energy services in Goz El Halag}

The energy services available in Goz El Halag are analysed, as in the other villages, using the categories of household, agricultural, non-agriculture, water, education, health, social centre, and transportation and communication. Again various energy carriers are used to meet these services (Annex 4: Section 4.2). Access to these energy services varies according to social and economic factors of which wealth, gender, age and residence status are the most important. There are common services 'such as water from hand pumps and lighting systems in the school and the mosque that are used with no clear exclusion. However, there are clearly wealth, gender and age differentiations in access to energy services.

Wealthy families, since they own farms, have better access to finance which enables them to increase their energy services. Owning private land has the same importance as in Dar Mali, as collateral for getting loans from banks (mainly the Agricultural Bank of Sudan). As reflected in the table above, those who have private land also own irrigation equipment, farm machinery, cars for transportation, and they have modern energy carriers in their household (LPG and electricity). So, land as natural capital increases access to financial capital and access to better energy services than available to those who have no land. Thus, the wealthy group can be said to have the largest circle of energy services in the village. The middle income households are less privileged than the wealthy group in terms of built capitals, but they still share the characteristic of having some modern energy carrier services (LPG and electricity). 
Although they do not have their own land, they are able to build businesses that bring them greater financial capital (animal trading and shops). This allows them to finance their access to energy carriers such as LPG and electricity. The main difference is that they do not own cars. At the bottom of the wealth ranking are the poor who use fewer energy services than the other groups. Overall, wealth plays an important role in the expanding of the energy circle.

Gender and age differentiations are also significant in access to energy services. Women and children are involved in the provision of energy services more than men such as in using hand pumps, rather than diesel or electric pumping, for water services. Thus, in this village, different size energy circles can be anticipated based on gender and age. Very clearly, the women's circles are smaller than those of their male partners. Women do not participate in the social club, and women shoulder the burden of water provision which reduces their human capital (more drudgery and poorer health). There is a desire by women to generate income through an energy service that could change their roles and status in the household. The village women identified the electrical sewing machine as a source that could build their financial capital. In Goz El Halag, women have no sources of their own income unlike in the other case study villages (such as milk products in Es Sadda (Annex 1 Section 1.3.6) and El Idied (Annex 2 Section 2.3.6, and ice-cream making and operating telephones in Dar Mali (Annex 3 Section 3.3.6)). It should be noted that sewing machines might not resolve women's lack of financial capital since other inputs, such as market development, may also be needed.

\subsubsection{Energy services priorities in Goz El Halag}

Although Goz El Halag is close to the River Atbara, the villagers still make the provision of a reliable water service their top priority. This was a common priority, listed by both women and men, during the focus group discussions. They agreed that what was needed was the establishment of a water distribution system based on good water quality, stored close to the riverbank and piped to the households. This priority, if met, will free women from the tedious and time consuming daily work of lifting and transporting water from the hand pumps to the households. Since women are not allowed to work in agriculture, their saved time would provide them with opportunities for more education or developing other income-generating opportunities.

Also, as in the other three villages, the priorities for energy services in Goz El Halag vary depending on gender and age. Women's priorities, besides water, are linked to generating their own income from the available electricity. Electrical sewing machines, women think, will enable them to exploit their free time in a productive way and earn income. Making and selling school uniforms and other clothing would enable women to increase their financial capital. However, women's present lack of financial means prevents them taking such initiatives. They do not have collateral to offer to banks, and there are no opportunities to gain income from agricultural work as this is exclusive to men. Outside intervention and support is needed to develop their ideas further. Further, women also need training in various newly-introduced technologies, such as electrical appliances and safety aspects of using LPG, to avoid the risk of electrical shocks or burns, not only for themselves but also for their children. 
Men's priorities, on the other hand, focus on the exploitation of more agricultural land. They need finance and equipment to drill wells in the karo land which lies away from the village to increase the area under irrigated agriculture and this would also provide protection to the village from the shifting sand. Meeting this priority, would it make possible for landless families to have their own lands. Moreover, cultivating irrigated land provides a valuable asset that banks will accept as collateral. So, irrigating the karo land is key factor in accessing more physical and financial capitals which can then be used to build up more energy services in line with those of the wealthy families.

In Goz El Halag, the young male group did not seem to have specific priorities, unlike in other case villages, which could be said to be different from those mentioned by the male adults. This is probably because the male youth club is already equipped with an electrical service to run TV/satellite dish sets and lighting.

\subsubsection{Findings from Goz El Halag}

The first significant finding in this village is the lower level of enforced diversification in the sources of energy services (Annex 4.3). The energy services here are derived from the use of physical and relatively stable natural capital, with fw seasonal fluctuations such as in water depths. Despite this, there is some diversification in energy carriers for cooking, to an extent due to the high cost of the preferred fuel type (LPG), which prevents some families using LPG, and partially due to the unavailability of devices that satisfactorily cook certain types of food such as kissra, which is more suited to a three-stone stove. Diversification in lighting is due to the limited availability of electricity $(6 \mathrm{pm}$ to $12 \mathrm{pm})$. The need for lighting beyond this time is met from other sources. There is also a need for a lighting device to carry out irrigation tasks at night. In other words, there is a need for flexible lighting when electricity is not available or when certain devices are more suitable for doing specific tasks such as the need for torches to irrigate at night.

The second significant finding is the weak link between energy carriers and natural capital. As in Dar Mali, there is a link between energy carriers and physical capital, albeit to a lesser extent. This use of energy carriers derived from physical capital is aided by the financial capital available from the banks to purchase pumps for irrigation and diesel generators. However, this does not remove the responsibilities of gender or age groups in the provision of water services as was the case in Dar Mali. Drawing water using hand pumps is still a manual effort for women and children.

The third significant finding is that there is no direct relationship between the vulnerability factors most common in the village and the flow of energy services. There are no natural shocks that have serious impacts to the extent that they force the displacement of people from the village. The greatest impact on the flow of energy services was the construction of the Khashim El Girba Dam in 1961 across the River Atbara, a man-made rather than a natural source of vulnerability. This permanently changed the natural flow of the river, reducing the flow of water for the village. The water level dropped and the time of flooding changed. These changes have forced a shift to larger diesel pump sets (Annex 4: Sections 4.2.5 and 4.1.1.2). This was accompanied by an increase in the use of diesel fuel to irrigate the same land, which means an increase in the cost of production. So, this man-made vulnerability factor enforced changes in the way people use their capitals, such as the change in natural 
capital (pumping underground water instead of river water), in physical capital (digging matarat and changing to larger pumps and increased diesel fuel consumption for irrigation), and in financial capital (added cost of digging matarat, added cost of larger pump sets and more fuel). These increases in the cost of production for the same outputs of farm products have negative impacts on the financial capital of all households including the landless. This is due to the fact that even the income of the landless households comes from sharecropping with landowners or with the cooperative society after deducting some of the costs of production. Thus, landless inhabitants in the village also share the costs of production and the negative impacts of increases on their financial capital.

The shift to a larger size pump set, and the use of more diesel fuel, for irrigation has not been accompanied by an increase in the village's stock of energy services. This increase in the amount of fuel used adds no new services and makes no improvements to the quality of the energy services already provided. Thus, this shift in the use of capitals has resulted only in the same level of production as before the dam was constructed.

The fourth significant finding is that interventions of the government through its structures and processes are largely absent in terms of the energy sector (Annex 4: Section 4.4.5). The village can be seen as a victim of a government intervention which led to the building of the dam which contributed to a decrease in the village energy circle. However, the government contributed to the building of the school, the health centre and an overhead water storage tank. All the other energy services in the village, such as the hand pumps and the cooperative's electricity generator, were built with the support of the UNDP-ADS project. However, the village does benefit from the policies and agricultural loans available from the Agricultural Bank of Sudan in building physical capital for agricultural production (loans to buy irrigation pump sets and farm machinery) for both the cooperative and the private land owners. However, this financial capital available from the ABS has not been used to finance other energy services or modern energy carriers such as piped water, LPG or the mini-grid as was the case in Dar Mali. The extent of the market in the provision of energy services in the village is very limited. Also, compared to Dar Mali, there is a lack of social capital which could facilitate the build up of physical capital for energy services. However, the market has made transportation available, which is now provided by a private telephone company (Sudatel Company). So, the market can have a role in building energy services in the village as a result of income generated from agriculture.

In Goz El Halag there is a need to remove seasonal water stresses created by the Khasm El Giba Dam (Annex 4: Section 4.1.1.2). Possible intervention options that could deal with these seasonal water stresses could be secured through establishing a water pumping system closer to the River Atbara, where water is suitable for drinking, and piping the water to the village. Similarly, an intervention enabling access to LPG for cooking could increase the number of users and lead to the establishment of private gas dealers in the village.

In conclusion, for this village, it is possible to conclude that the energy circle is not affected by seasonal changes in the level of the water table or the unpredictable timing of the flood of the River Atbara. However, the village energy circle is seasonally 
affected by the incoming nomads who compete for the existing services and therefore reduce the energy circle. It is again possible to draw different energy circles for the various groups in the village, particularly those based on wealth, gender and age. Wealthy families, through having private farms, have access to loans from the bank and can then have their own irrigation pumps, tractors and electrical generators. Wealthy families have a larger energy circle than farmers who rent land or are hired as daily waged labourers. Women's and children's energy circles are smaller than men's due to their involvement in manual drawing of water in which they exert work. Women also cannot attend the social clubs, a service which is exclusive to men.

\subsection{Um Laham}

\subsubsection{Background}

The village of Um Laham is located within Bara Province in North Kordofan State, at coordinates 13०39'24.2"N longitude and 30 $39^{\prime} 24.2^{\prime \prime} \mathrm{E}$ latitude. The nearest urban centres are Bara and El Obied. It is about $13 \mathrm{~km}$ from Bara, the capital of the province, and $60 \mathrm{~km}$ from El Obied, the capital of the state. The village is made up of two settlements less than one kilometre apart. The first settlement has the name of the village, Um Laham, and the second settlement is called El Rukab.

The exact date of the establishment of the village is not known but some events mentioned by the people would indicate its establishment around the 1880s when some groups from the Juwma'a tribe moved to the area from the southern part of the North Kordofan State during the Mahadia revolution in Sudan $(1882$ - 1895). The village is inhabited by 271 families and its estimated population is 1500 people divided between the two settlements. Um Laham is the largest settlement and has 149 families and El Rukab is slightly smaller with 122 families. Despite belonging to one tribe (the Juwma'a), the two settlements consider themselves to be separate villages each having its own village shiekh and village committees.

The people in the village depend on animal raising and rainfed agriculture as their main livelihood occupations. Animals (sheep, goats and camels) often graze on natural pasture around the village. However, during drought periods, animals are moved beyond the village to the southern part of the State. Agriculture is practised on small plots in which the main crops grown are millet and Dura, usually for a family's own consumption. In a good rainy season, sesame and watermelon are also grown. The sesame oil is also extracted in the village using traditional oil mills made from wood and powered by a camel. In addition, people also collect Gum Arabic from the Hashab trees (Acacia Senegal) which often grown naturally on fallow lands. Land ownership is not restricted in size, so each family can have as much land as it can cultivate; cultivated land is only limited by the availability of family labour and rainfall. As such, land ownership is not seen as a wealth criterion since everyone can cultivate as much land as they want.

In the village, land is commonly owned, and there is no private land registered under individual names. Each household can cultivate any size of land provided it has approval from the sheikh of the village. In 1992, a small farm irrigated using solar pumping was established in the Um Laham settlement by an NGO, the Sudanese Swedish Friendship Association (SSA). The project aimed to produce vegetables and 
some fruits for the villagers own consumption and generate income when a surplus was produced.

Wealth in the village is mainly perceived based on animal ownership, small trading, sesame oil extraction, other small businesses and remittances. Table 4.5.1 shows the wealth ranking of families in the village. They are divided into four groups; wealthy, moderate, poor and very poor groups.

There are no landless families, but the cultivated plots can vary according to the number of family labourers present during the cultivation period. Usually, women do all the agricultural tasks linked to the production of sorghum and millet for family consumption. Men usually cultivate sorghum, millet, sesame, groundnut and water melon as cash crops. So women are responsible for the production of the family's food, and men are responsible for the generation of financial capital, either from work outside the village or by growing cash crops.

Table 4.5.1

Wealth criteria and wealth categories in Um Laham (including El Rukab)

\begin{tabular}{|c|c|c|c|}
\hline Category & Wealth criterion & $\begin{array}{c}\text { Number of } \\
\text { families }\end{array}$ & $\begin{array}{c}\text { Percentage of } \\
\text { total }\end{array}$ \\
\hline Wealthy & $\begin{array}{l}\text { Large herds (100-150 } \\
\text { animals) }\end{array}$ & 39 & $14 \%$ \\
\hline Moderate & $\begin{array}{l}\text { Medium sized herds (50 to } \\
100 \text { animals) } \\
\text { Expatriate family } \\
\text { members } \\
\text { - Family working in other } \\
\text { cities inside Sudan }\end{array}$ & 70 & $26 \%$ \\
\hline Poor & $\begin{array}{l}\text { Some goats ( } 2 \text { to } 5 \\
\text { animals) and camels ( } 1 \text { to } \\
3 \text { animals). }\end{array}$ & 119 & $44 \%$ \\
\hline Very Poor & 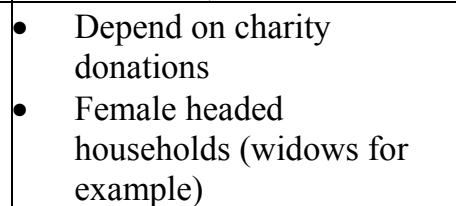 & 43 & $16 \%$ \\
\hline Total & & 271 & 100 \\
\hline
\end{tabular}

As with the other villages, gender and age were identified as important variables in access to energy services. But, unlike in the previous villages, women, besides their traditional role in the provision of water and fuelwood, are responsible for cultivating the farm land to produce their families' subsistence needs. Children's role is to help women in their tasks and activities. So, both gender and age groups are important in identifying and investigating their different links to desired energy services. 


\subsubsection{Access to energy services in Um Laham}

In Um Laham, there is also a wide range of energy carriers used to access energy services. For example, for cooking use is made of firewood and LPG, for water pumping the villagers use a diesel pump, solar pumps, animal and human power and, for transportation, animals and lorries are used (Annex 5: Section 5.2). In Um Laham access to energy services is again found to be based on wealth, gender and age. Access varies significantly from complete exclusion of a group, such as the population of El Rukab from the management and revenues of the solar-irrigated farm (although they can buy its products), to unconditional access to some energy services such as the use of fuelwood from the forest and water from the shallow wells.

The wealthy group has higher quality energy services such as electricity in their households. Wealth affects access to energy services because it represents better access to physical capital. The wealthy group own and draw more energy services from physical capital. This is because this group invests in energy services such as private generators, telephone units and oil mills. For example, out of the 39 wealthy families, 22 own sesame oil mills. Moreover, eight wealthy families have electrical services in their household. The two telephone units are both owned by families belonging to the wealthy group. Some wealthy families sell these energy services to the rest of the village. So, the wealthy group, by virtue of their financial and social capital, is able to build private physical capital and to draw more energy services. In their households, there are satellites TV sets, electrical lamps and other electrical appliances.

Gender is an important variable in access to energy services in Um Laham. Women are responsible for the cultivation of the family farm in which all operations are carried out manually. Women are also responsible for the provision of water which is drawn by hand from shallow wells and carried on their heads home (when the water system is not functioning). Women collect fuelwood to cook family meals. Due to the close proximity of the forest to the village, the provision of wood is not a time consuming task and firewood is collected from distances of not more than 200 metres from the house. However, the use of wood has negative effects since it comes at the expense of women's health due to exposure to smoke and other pollutants from burning fuelwood. In other words human capital is reduced.

Age also presents some differentiation in access to energy services. It is primarily children who share with women the responsibility of providing water, fuelwood and cultivating the family farm. Youth and able-bodied family members often migrate outside the village to find paid work. The remittances from these groups increase access to modern energy services such as through the purchase of the generator and telephone units (Annex 5).

In this village, access to energy services also varies between the two settlements. This, in particularly can be noticed in the vegetable farm irrigated by the solar pump. People in the El Rukab settlement are excluded from both the operation and a share in the revenues from the sale of vegetable crops. So here it can be said that the El Rukab settlement has a smaller energy circle than the Um Laham settlement because of the the solar pump in the latter settlement. The solar pump not only adds an additional energy service (water pumping) but also has positive effects on financial capital 
(revenues from the sale of vegetables) and human capital (removing the drudgery of manually drawing of water).

\subsubsection{Energy service priorities in Um Laham}

The energy service priorities identified by the people who participated in this study are centred on the provision of sufficient water for household consumption, animal watering and vegetable growing. Water availability is the most important single factor that threatens livelihoods in the village. Three energy services were identified as the main priorities for ensuring positive livelihood outcomes by the people in the village.

The first priority is improving the delivery of water services which would include the accomplishment of three tasks. (1) Rehabilitation of the diesel water pump as a first priority mentioned by both women and men. Bringing the pump back into operation will ensure a continuous flow of water which will reduce women's burden and time spent drawing water manually from the shallow wells. The shallow wells are also not clean and are subject to contamination when animals are watered at the well sites. So, the rehabilitation of the pump would provide a better quality water service than currently obtained. The rehabilitation of the pump will also allow the water obtained from the solar pump to be used for irrigation rather than for building or household uses. The pump rehabilitation needs a level of finance that is beyond the villagers' financial capacities (Annex 5, Section 5.1.2.2). (2) Equipping the bore hole dug by the UNDP funded Drought Mitigation Project with a solar pump and purchasing the other irrigation equipment required. The villagers believe that this will enable production of vegetables and fruits. This will ensure that, even in times of drought, villagers can secure their needs for food and water. Further, it would provide work for some villagers during the non-rainy season. (3) Rehabilitation of the solar pump linked to the irrigated farm by clearing the sand that has accumulated inside the well.

The second priority is staffing and equipping the Health Centre. The newly built Health Centre, at the time of this study, was not functioning because staff have not been appointed by the State Health Authority, which has also not procured the necessary equipment. Operation of the Health Centre would provide health services in the village, reducing the need to travel to Bara or El Obied. This will save a lot of the time and money spent on travelling to get basic health services, such as child vaccinations and treatment for other minor health problems, that could be dealt with at the village level.

The third priority, for the youth, is establishing a youth club equipped with a satellite dish and a TV. As in all the other villages in this study, the youth want entertainment and communication with the outside world. A youth club is considered as a place where males in the village can gather and have a pleasant time watching TV for news, sport and general information.

The energy services priorities, as conceived by the participants in the data gathering exercise, are centred on the provision of sufficient water to meet the needs of households, the needs of animals and irrigating vegetable farms. Water is the single main factor that threatens livelihoods in the village. So, both women and men put the rehabilitation of the broken water system first. They differ, however, in their second and third priorities. Women put the rehabilitation of the borehole second, followed by the rehabilitation of the solar pump. Men reverse the order. The youth, on the other 
hand, put a club first (not a priority for women or men) followed by equipping the borehole.

\subsubsection{Findings from Um Laham}

The first significant finding is that there is a diversification of energy carriers and exploitation of various mechanisms to obtain the energy services required to cope with the vulnerability context. Water in the village is obtained from both shallow wells and boreholes, using different types of energy carriers. From the shallow wells water is drawn manually while, from the borehole, a diesel pump is used. However, although the diesel pump reduces the drudgery of work exerted in drawing water, any breakdown of the diesel pump, as was observed during the period of data collection for this study, forces the people back to using shallow wells. The lack of both financial capital and skills (human capital) to maintain the pump had kept the diesel pump out of service for at least three years. For cooking, fuelwood, charcoal, kerosene and LPG are used in the village with firewood being the most common fuel. Fuelwood for cooking has never been scarce. Even in the successive droughts of 1983/85 there were still dry branches that people could collect and use. The use of fuelwood at no financial cost reduces financial expenditure on energy carriers, however, its use has other opportunity costs on women's time and health (reducing their human capital). The available but scarce financial resources of families are essential for supporting family livelihoods when naturally obtained services such as water and food are in short supply due to any of the factors of vulnerability. The two factors of the good availability of fuelwood and the limited financial assets of many households block the transition to LPG, despite the availability of LPG in Bara which is only 13 kilometres away.

The second significant finding is that in Um Laham, as in Es Sadda, there are strong links between the natural capital and the energy carriers used to draw the required energy services such as water and food production. Disturbances in natural capital lead to disturbances in the flow of the energy services. Drought is the main vulnerability factor, interrupting the flow of energy services such as food and water. Food is in short supply immediately there is no rain. However, water is available from the shallow wells even if there is no rain for two successive seasons. However, after two years of no rain or low rainfall, the level of water in the wells starts to drop significantly. People start to deepen the wells until they reach a level where they cannot go down further using manual digging tools. At this point, people in the village start to suffer from the lack of water services. This situation was overcome by the installation of the solar pump which secured the water supply. However, the breakdown of the water system has returned the village to an increased dependence on natural capital and manual raising of water, and increased their vulnerability.

The third significant finding is that the impact of the vulnerability factors on livelihood outcomes varies with wealth, gender and age. The wealthy group has better access to energy services than the poor because of their ability to transform part of their wealth into energy services. As in Es Sadda, the impacts of vulnerability on energy services and livelihood outcomes were also found to vary with gender and age. Women and children are responsible for the provision of energy services such as water and cooking, but they do not have to walk long distances to obtain these services. Water is accessed by manually drawing from shallow wells, or it can be brought from the solar pump. Wood is collected in the vicinity to the village. So in 
this village, compared to Es Sadda, there is relatively better natural capital which reduces the efforts expended on providing energy services.

The borehole dug as part of the UNDP- Mitigation of Drought Impacts Project had no government body ready to take it over in order to coordinate operation and maintenance services once the project phase was completed. The installed service requires technical skills, and the cost of spare parts and maintenance is high. There has been no development, by the project implementers, of the villagers' skills (building human capital) to tackle these issues; and there was also no village involvement in the initial installation and management of this service. It is clear that the project was designed to be handed over to the NRWC which was then expected to provide the maintenance service. However, the privatization policies and the decentralisation of services and the restructuring of the NRWC to work on a commercial basis has halted the project in this village. The villagers face a situation in which project support has ceased, the NRWC is no longer responsible for the water services, and the villagers themselves lack financial assets to buy the spare parts. The fourth significant finding is that in Um Laham, as in the other villages, there is a lack of government structures and processes to develop energy services. The case of the broken borehole reflects the lack of government involvement in planning and implementing energy services. Without any structures and processes to coordinate non-state actors, such as the international and national agencies and NGOs, no longterm strategy was developed for operation and maintenance. This reveals one of the problems with energy services: who should take the responsibility for providing postinstallation services.

In Um Laham, there is a link between the disruption of the flow of energy services and the seasonality and shock factors. Energy planners can intervene and plan for securing the flow of energy services in order to prevent their disturbances resulting in negative livelihood outcomes in the village. Intervention to secure the flow of water is a high priority for the villagers. Likewise, an intervention (as has been done by the Teacher Union) to make LPG devices (cylinders and stoves) for cooking, and electrical generators, available is also needed. The provision of loans or delayed payments through instalments schemes are also required. Assisting in the provision of LPG will lead to an increase in the number of users which in turn will help to establish private gas dealers in the village to refill the gas cylinders. Also, training to change women's attitudes towards the safety of LPG devices could encourage more women to use LPG.

In conclusion, this village has an unstable energy circle. Vulnerability factors frequently lead to a disruption in the flow of energy services. It is also possible to draw different circles for the two settlements in the village. The Um Laham settlement has a larger energy circle than the El Rukab settlement due to the use of a solar pump in the former. Within these settlements, different energy circles can also be drawn for the various groups based on wealth, gender, and age (Section 4.5.2). However, these differences among the groups in the villages do not result in different priorities for energy services. As noted in Section 4.5.3, all the groups agree on the priorities that they believe could secure livelihoods in the village. 


\subsection{El Ga’a}

\subsubsection{Background}

The village of El Ga'a lies in Bara Province of North Kordofan State. It is located at $14^{\circ} 14^{\prime} 43.1^{\prime \prime} \mathrm{N}$ latitude and $29^{\circ} 59^{\prime} 35.4^{\prime \prime} \mathrm{E}$ longitude. The nearest urban centres are Bara $(50 \mathrm{~km})$, which is the capital of the province, and El Obied $(160 \mathrm{~km})$, which is the capital of the state. The village is made up of two separate settlements El Riwais and Um Safari. So, compared to the previous village, Um Laham, this village is further away from any urban centres.

The village was established by a small number of families in the early $17^{\text {th }}$ century (UNDESD and ERI 1992: 3). Then, gradually, the village grew as more families settled in the village. The total number of families in El Ga'a was estimated during this study at 1060 , with an estimated total population of 5000 people. The dominant tribe is the Dar Hamid to which more than $90 \%$ of the villagers belong. The other $10 \%$ belongs to various tribal groups, including the Ja'alin, Hawazma, Shewayhat, Nuba and Rikabiya.

The village is famous in Western Sudan for the extraction of salt used for animal fattening ${ }^{13}$. The extraction of salt is the main source of wealth for the village inhabitants and the main economic activity practised by all the people in the village. Traditionally, salt used to be extracted by boiling the brine in pans cut from oil drums heated using fuelwood. The traditional process of boiling the brine was replaced by solar evaporators in 1994. The brine from which the salt is obtained comes from underground water sources accessed by digging wells. The process of salt extraction involves seven steps. At each step there are opportunities for income earning. These tasks are listed below:

1. Well digging: the brine wells are dug manually by well diggers who also deepen and rehabilitate old brine wells.

2. Water drawing and transporting: transportation of the brine from the well sites to the evaporators sites is carried out by children who use barrels (200 litres) mounted on donkey carts.

3. Water string: this task is required to break up the salt layer formed on top of the evaporator. The purpose is to speed up the evaporation process.

4. Collection of salt: the salt has to be removed from the evaporator and packed into plastic sacks. The evaporator owners either do the job themselves or hire in labour when there are a large number of evaporators (usually more than 20).

5. Transportation of salt: transporting the salt to market is by hired donkey carts.

\footnotetext{
${ }^{13}$ The salt extracted in El Ga'a is known to be an important supplement for animal feed. The constituents of this salt include; Chlorine, Sulphate, Sodium, Potassium, Calcium, Magnesium, and Phosphorus. All these minerals are seen as essential minerals (McDonald, Edward and Greenhalgh 1981, P 85). Animals fed on fodder lacking one or more of these minerals suffer from various deficiencies. This salt is not used in human food; it tastes bitter because of its magnesium content.
} 
6. Weighing the salt: the salt is weighed when it is brought by village merchants from the village extractors and when it is sold to outside distributors of salt. Each merchant has two hired labourers to weigh the salt.

7. Loading of salt sacks: the salt sacks are loaded onto lorries by hired labourers (who are known as salt loaders).

Other people earn an income from making the tools used in salt extraction. Providing food, tea and coffee in the market provides an additional income generation source for women.

However, ownership of a brine well represents the main source of wealth in the village. A well, on average, can provide a daily income of SD 5000 (Euro 25) from selling the brine. So, owning a brine well means a good income. Table 4.6.1 shows that the village is economically divided into three main groups. These are the wealthy, middle and poor income groups. The majority of the village population belong to the middle income group $(75 \%)$, followed by the poor $(19 \%)$, and the wealthy group makes up the remaining $6 \%$.

Table 4.6.1

Wealth criteria and wealth categories in El Ga'a

\begin{tabular}{|c|c|c|c|}
\hline \multirow[b]{2}{*}{ Category } & \multirow[b]{2}{*}{ Wealth criterion } & \multicolumn{2}{|c|}{ Ranking of families in El Ga'a } \\
\hline & & $\begin{array}{c}\text { Number of } \\
\text { families }\end{array}$ & $\begin{array}{l}\text { \% from the } \\
\text { village total }\end{array}$ \\
\hline Wealthy & $\begin{array}{l}\text { - Own more than } 3 \text { wells } \\
\text { - Lorries } \\
\text { - Private cars } \\
\text { - Water tankers } \\
\text { - Shops in the village market } \\
\text { - Shops in city markets } \\
\text { - Large number of evaporators (more than 100) }\end{array}$ & 60 & $6 \%$ \\
\hline Middle & $\begin{array}{l}\text { - Own } 1 \text { to } 2 \text { wells } \\
\text { - Have } 10 \text { to } 20 \text { evaporators } \\
\text { - Small shops } \\
\end{array}$ & 800 & $75 \%$ \\
\hline Poor & $\begin{array}{l}\text { - Have no wells } \\
\text { - Have } 5 \text { to } 7 \text { evaporators } \\
\text { - Waged workers in well digging and other salt } \\
\text { extraction processes }\end{array}$ & 200 & $19 \%$ \\
\hline Total & & 1060 & $100 \%$ \\
\hline
\end{tabular}

The middle income group is made up largely of descendants of the original inhabitants of the village who settled in the Um Safari and El Riwais settlements. The poor settled in the village after the $1980 \mathrm{~s}$, coming from the surrounding areas. They occupy the area between the two old settlements. The wealthy group is composed of the merchants and traders in the village, and they are found in the Um Safari settlement.

Due to the availability of paid work in the salt extraction processes, all families can earn enough income to pay for their necessities and there is no very poor category (that is those who cannot afford their daily food necessities) in the village. Everyone 
can obtain sufficient income to pay for his/her food and water supply by working in the salt extraction processes as producers or waged labourers.

\subsubsection{Access to energy services in El Ga'a}

As before, in El Ga'a energy services are analysed in terms of the following categories: household, agricultural, non-agriculture, water, education, health, social centre and transportation and communication (Annex 5: Section 5.2). In El Ga'a, important energy services such as pumping water, producing food and cooking meals are brought in from outside the village (Annex 6: Sections 6.1 and 6.2). The basis of livelihoods in the village (salt extraction) is different to the other five villages in the study and requires different energy carriers to perform the various processes (Annex 6: Table 6.2). At the same time, energy services for agricultural operations are quite limited. Unlike in the other villages, access to energy services is clearly differentiated by wealth rather than by attributes of gender and age. This is particularly evident in the participation in the benefits from salt extraction and the use of evaporators. The wealthy families have more evaporators than the other groups. The wealthy group uses large numbers of evaporators (more than 100) per family and they also own more than three brine wells. The middle income group uses between 10 and 20 evaporators and own one or two brine wells. The poor families use between five and seven evaporators but do not own brine wells. Thus, the level of energy services in the salt extraction processes are highly differentiated by wealth. Wealthy families use their financial capital to dig brine wells, to use large numbers of evaporators, to deal in the marketing of salt, and to be involved in the provision and selling of other energy services such as drinking water and other goods and services.

There is no clear differentiation in access to the other energy services (cooking, lighting, water, education, health). Nearly all families use LPG for cooking, they are connected to mini-grids for lighting, and they buy water from tankers. Access is open to all groups for energy services (lighting) in schools and health centres. In El Ga'a, access to energy services is governed by the willingness and ability to pay their cost. As such, all have equal right to access and benefit from the available energy services in the village, whether community provided or privately provided. Similarly, there is no exclusion of any category except that women do not attend the night-time entertainment shows. For those who have their own satellite dishes, however, there is no restriction on women and children watching programmes. The two schools (for girls and for boys) are connected to the electrical mini-grid and girls as wells as boys can attend night classes.

However, it is important to note that the change of technology in the salt extraction process has been accompanied by changes in the gender roles in the processes and the benefits from salt extraction. The traditional process of salt extraction was purely a woman's business. Men were not involved, except in the provision of fuelwood and digging brine wells. Although women gained the financial benefits, they were also exposed to the negative impacts of working for long hours in unfavourable conditions $^{14}$ which had serious impacts on their health. After the introduction of solar

\footnotetext{
${ }^{14}$ The traditional process for salt extraction took about 14 hours a day. During this time, women had to go inside the Tukul every 30 to 60 minutes to manage the fire, add fuelwood and collect any crystalised salt from the pans and put more brine in the empty pans. All these tasks had been carried out in dense smoke and high ambient temperatures estimated as 45 to $55^{\circ} \mathrm{C}$ (Ahmed, 1996)
} 
evaporators, men became involved in the process of salt extraction, so they now also share in the benefits. Interestingly, every individual (young and old, woman and men) in a household has her/his own evaporator to extract salt to earn an income.

\subsubsection{Energy services priorities in El Ga'a}

The energy service priorities in the village are the same for all groups. As in all the other villages, the main priority is related to water. Drinking water, however, is available, and quantity is only limited by willingness to pay. The average consumption per family is estimated at one barrel a day (200 litres). Taking the cost of water in the village as SDG 1 (Euro 0.40) this is equivalent to a monthly cost of approximately SDG 30 (Euro 12). The villagers believe that laying pipes from the drinking water well sites to the village could make water less expensive because they would save the cost of transportation by tankers, which represents the largest share of the total cost. The difference between the price of water at the well site and that in the village is about SDG 0.75 (Euro 0.30 ), meaning that about $75 \%$ of the water cost goes on its transportation to the village (Annex 6: Section 6.2.3).

Another priority also agreed upon by all groups (based on wealth, gender and age) is the need to increase the number of wells and hence the supply of brine water. This is linked to a desire to replace the manual digging of wells with mechanical drilling techniques. Salt concentration is linked to well depth, and villagers believe that mechanical drilling would allow them to go deeper and get brine with a higher salt concentration. The area has not been subject to geological investigation to confirm this local expectation (Annex 6).

\subsubsection{Findings from El Ga'a}

The first significant finding from El Ga'a is that there is limited diversification in the sources of energy services. As in Dar Mali, diversification is linked to the high dependence on physical capital and on the market for the provision of energy services. Thus, to secure energy services, people have to possess sufficient financial capital to buy the desired services, which is made possible through the involvement of all family members in the salt extraction process and other income generation opportunities. The locally available natural capital in the village does not provide any sources for obtaining direct services, in particular there are no sources of drinking water and insufficient food is produced. Thus all energy services are brought from outside, and sold as ready for use energy services.

The second significant finding is that there are only weak links between natural capital and the energy carriers used to provide energy services in the village. Even the wood which is locally available is not collected by the villagers of El Ga'a themselves, but by people from the surrounding areas who sell the wood in the market. So, all the fuel used for cooking in El Ga'a is from commercial sources (wood, charcoal, LPG). Lighting is also a commercial service provided from private generators. This situation is largely due to the limited availability of fuelwood close to the village. Travelling to find fuelwood would take a lot of time, and this time can be more profitably spent in extracting salt. Thus collecting fuelwood for family use would represent a lost opportunity cost. So, fuelwood has been a market commodity from the time of the traditional salt extraction process. This encourages people from the other villages to collect and bring fuelwood to sell in El Ga'a, thus creating livelihood opportunities for others. Water is another service provided by the market. 
Water is pumped from stable and deep aquifers located some 30 kilometres from the village and transportation systems (tankers) and storage facilities (reservoirs) have been built to make water service accessible to users at all times. Most facilities involved in the provision of drinking water are privately owned except for one tanker that is owned by the village water committee. As with fuelwood, having family members bring water using camels or donkeys would again represent a lost opportunity cost. This has similarly led to the development of private water services pushed by the financial capital of the villagers, which is of a sufficient level that they can pay for water. Similarly, the components of providing energy services in the salt extraction processes are bought and sold in the market. The evaporators that use the free solar energy, the brine, and the other tasks required to reach the end product (salt) are all commercially available. It is important to note here that there is no one person, or even one family, that can carry out all the tasks. Labour has to be hired, at least to draw and transport the brine, or transport the packed salt to the market.

The third significant finding is that, in El Ga'a, the market provides all the energy services through establishing sufficient physical capital components to generate the energy services required in the village. Thus, the energy services are secured against the vulnerability factors through developed market mechanisms. A major factor that enables the market to serve this village is the financial capital created from the extraction of salt which is not severely affected by any factors of vulnerability. However, floods have had some damaging impacts on brine sources (wells) but they have not completely stopped the process of salt extraction (Annex 6: Section 6.1.1.3). The combination of a natural capital component (the brine) and physical capital components (extraction technologies, marketplace, transportation and communication) has generated the financial capital which smoothes the flow of energy services to the village. This smooth flow of services is also supported by an important component of human capital (skilled labour) to run and maintain services.

The fourth significant finding is on the impact of changing the salt extraction process from wood to solar evaporators. The introduction of a technology that was originally intended, by the Energy Research Institute (ERI), to benefit women (a reduction in the level of smoke exposure improving their health, i.e. building their human capital) has unintentionally changed the division of financial benefits between women and men. Responsibility for the process of salt extraction has shifted from women only to being shared by both males and females. Thus, women's control of the salt extraction process has been reduced in the move from traditional to modern technologies. This gender change in contributions to families' financial capital has the potential to reduce the status of women in the family ${ }^{15}$. Instead of being the sole income earners in the household, women are now, at best, equal participants in contributing to family income.

A possible intervention in El Ga'a, as identified by the people, is to reduce the drudgery in digging wells and drawing brine water manually. Such an intervention, with a technology that digs in stony areas, could possibly reduce the time spent in digging wells, increasing the number of wells and hence increasing salt extraction

\footnotetext{
${ }^{15}$ However, in this study no attempt was made to determine whether or not there had been a change in gender relations within households.
} 
rates. A technology that could pump water would help to reduce the drudgery of drawing the brine water manually, freeing women's and children's time which could be used for education, other productive activities or entertainment. However, any such intervention has to consider the change in women's status, as experience with the solar evaporators shows that women can be disadvantaged with respect to men who shared the economic benefits from salt after the introduction of the solar evaporator technology, reducing women's economic status. Another aspect to consider is the possible lowering of salt prices due to increases in level of salt extraction when new technology is introduced. Previous experience shows no signs of lower prices due to the introduction of the evaporators, but this should not be taken for granted. The mechanical digging of wells and the pumping of the brine together could put more salt into the market than the evaporator technology can produce on its own.

In conclusion, El Ga'a is, with respect to the stability of its energy circle, similar to Dar Mali. Factors of vulnerability rarely interrupt the flow of energy services. With the exception of flooding which occurs infrequently and which interrupts the extraction of salt, no other energy services are affected by factors of vulnerability. However, during droughts, the immigrants compete for both services and work, and this reduces the energy circle of some groups in the village. In this village there is relatively less differentiation of energy circles by gender and by age than seen elsewhere. Differences in energy circles are only due to wealth. Wealthy families, by having more financial capital, are able to use more energy services and accumulate more assets (evaporators, wells and private cars).

\subsection{Conclusion}

In conclusion, and to answer the fourth research question, this section will highlight factors that make the differences in access to energy services. Subsection 4.7.1 discusses the differences between villages in access to energy services which can be attributed to differences in geographic (location and climatic) and economic (purpose of production) factors which affect the availability of the energy carriers used to generate energy services. Subsection 4.7.2 discusses differences in access to energy services within the villages. These differences are attributed to social (gender and age), economic (wealth differentiation) and spatial (distances to point of service) factors.

\subsubsection{Differences in access to energy services between the six villages}

The previous sections have analyzed the access to and priorities of energy services in each village. This subsection shows that access to energy services varies between villages in terms of the stock of energy carriers and the origin of the carriers. Whether the origin of the energy carriers stems from a natural capital component or from a physical capital component affects the access to and the flow of energy services (see also Chapter 5 Figure 5.1). Table 4.7.1 summarises the types of energy carriers used in each village. It shows that there are large differences between the six villages in the origin and the stock of energy carriers and energy services available to each village. Based on these differences, the six villages are ordered, from left to right, representing a move from a low to a high stock of energy services. Es Sadda has the fewest energy services, only 13, and Dar Mali has the largest number of energy services. This variation in the stock of energy services is also linked to variations in the types of 
energy carriers used for generating these energy services. The ratio of physical capital components to total stock of energy carriers has the same order of villages from left to right, with Es Sadda having the smallest proportion of physical capital components in the stock of energy carriers (37\% of the energy carriers come from physical capital components and the rest from natural capital components) and Dar Mali the highest proportion ( $70 \%$ physical, $30 \%$ natural).

Factors that have led to this variation include geographical location (proximity to urban centres or the modern economic sector) components of natural capital (mainly rain, rivers and forests), presence of other physical capital components (paved roads, electrical grid, telecommunications and canals) and economic practices and activities (irrigated agriculture, rainfed agriculture, types and purpose of production - whether for market or for subsistence purposes). These factors determine whether energy carriers come from natural capital or physical capital components. The location and proximity to urban centres are important factors in access to energy services from physical capital components. Dar Mali's location between Atbara and Barbar cities (see Annex 4) enables the village to be connected to the electricity grid. The paved road allows the easy transportation of modern energy carriers to the village. In comparison, Es Sadda, a village with a lower stock of energy services, is located away from any urban centre (see Annex 1) making access to energy carriers based on physical capital components rather difficult. However, not all villages benefit from proximity to an urban centre. Um Laham, which is close to Bara city, is not well served with energy services from physical capital. Other factors, such as economic activities, play a role. This is most apparent in El Ga'a which is located far from any urban centre. Here, its unique economic activities (salt extraction) enable this village to have better energy services than Um Laham which is located in the same state. So, the combination of these three factors, proximity to urban centres, presence of other capital components, and economic activities, makes a difference in access to energy services between and in the six villages in this study. El Idied is close to mechanized agricultural schemes and has access to, and use of, mechanical equipment for land preparation and a supply of an energy carrier (diesel fuel). The spatial locations within a village can also present a barrier to access to energy services. For example, in Es Sadda, school pupils from outside the main village settlements cannot attend night classes and therefore cannot benefit from the solar lighting system in the school. 
Table 4.7.1 Energy carriers used to generate energy services in the six villages

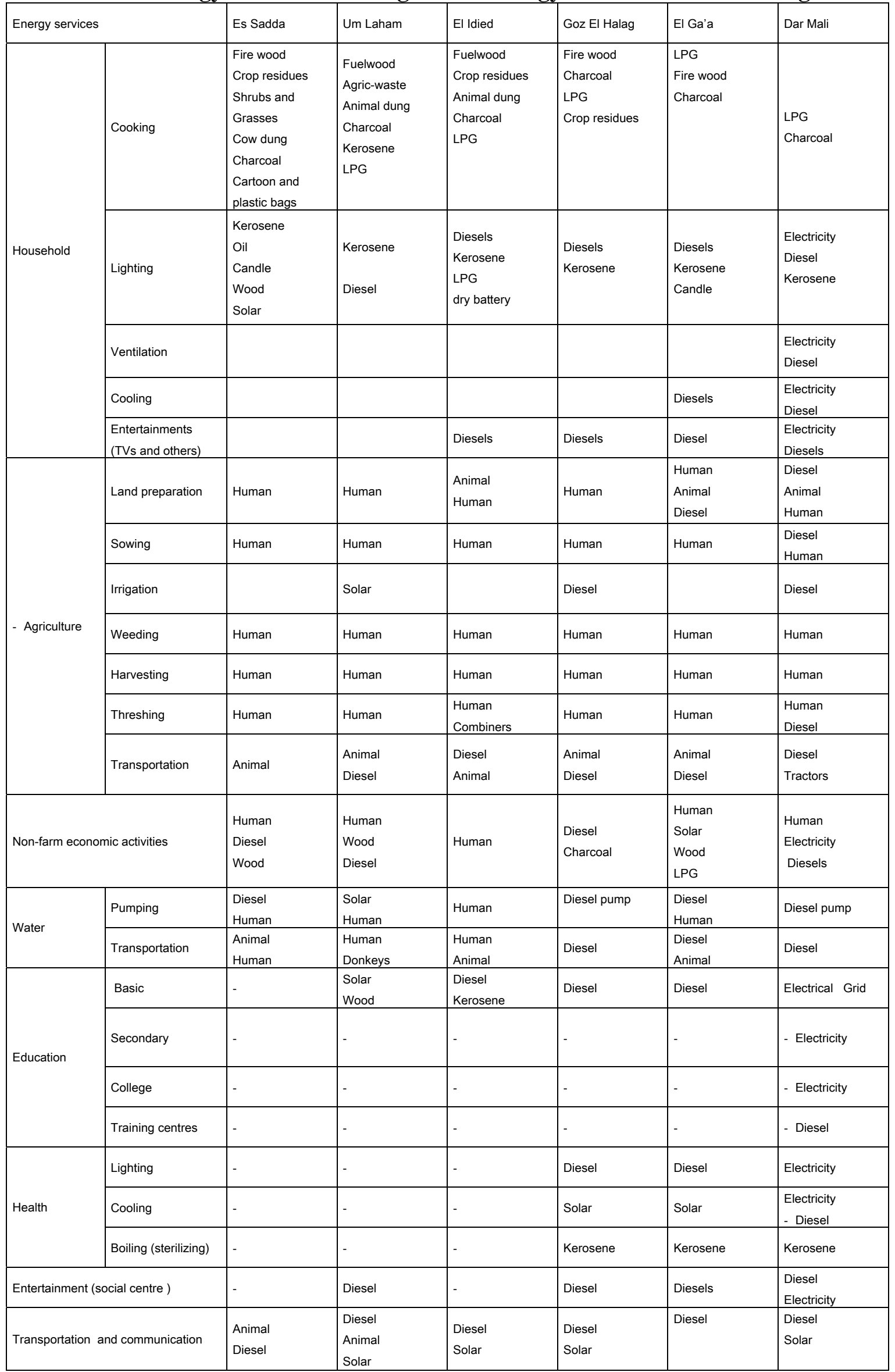




\subsubsection{Differences in access to energy services for different activities within the six villages}

Within the six case study villages there are variations in access to energy services between the different groups in each village. Groups could be constructed around different socio-economic indicators: wealth (wealthy, moderate, poor and very poor), gender (women and men), age groups (children, youth, adults and elders) and residence status (old/new inhabitants and spatial location). There is a large differentiation in access to energy services by wealth, gender age and spatial settlements. This differentiation is more noticeable in villages where energy services are generated by natural capital components than in those where energy services are generated from physical capital components. In Es Sadda, Um Laham, El Idied and Goz El Halag, access to energy services such as water is highly differentiated by wealth, gender and age.

These variations in access to energy services and in types of energy carriers employed to generate the desired energy services, result in different priorities among the energy services desired by different villages and by the various groups within each village. However, in all villages, there are some common priorities for energy services, in particular water. In some villages, such as Es Sadda, where variations in access to energy services is significantly differentiated by wealth, gender and age, each group has different priorities (telephones for women, tractors for men, and satellite TV for youth).

These findings show that local factors affect both access to and priorities in energy services in different ways. Proximity to urban centres, the presence of other physical capital components, and economic practices and activities determine to a large extent the access to energy carriers. Wealth, gender and age determine the priorities for energy services that are important in their strategies for improving livelihood outcomes for each group. So, the findings from the six villages with respect to local differences, spatial location and social differences, and their impacts on access to and priorities for energy services, provide an answer to the research question:

“How do local differences affect access to and priorities for energy services in rural villages?”

The findings show that, in the first instance, access is determined by the types of natural capital (sources of water, biomass availability, soil type, and climatic conditions) available and by the presence of other physical capital components (paved road, electrical grid, communications, transportation, economic activities) which play an important role in the building up of a stock of energy services. Access is also determined by the socioeconomic factors of wealth, gender, age and residence status. These factors also play a role in determining priorities for energy services. This finding means that an awareness of, and data on, these local differences is important for more equitable energy planning. This answer also supports the proposition in Chapter 2 for identifying these local differences through participatory data gathering methods and analysing the access to energy services by the livelihoods framework. Without such data, locational and social differentiations between Sudanese communities in accessing the benefits of energy planning will be perpetuated (see also Section 3.2). The effect of these local differences in access to energy services can be 
more acute and destructive in situations where the vulnerability factors predominate. This issue will be the theme of the next chapter, which compares the impact of the vulnerability context on the flow of energy services and on the attained livelihoods outcomes. 


\section{Chapter Five: Analytical comparison of energy services and livelihood outcomes between the six villages}

\subsection{Introduction}

Chapter 4 shows that, due to differences in access to capitals and differences in factors of vulnerability, there are wide variations in access to the use of modern energy carriers and, through that, the flow of energy services among and within the six villages in this study. The variations among the villages can be attributed to the villages' different geographical locations (proximity to urban centres or modern sector agriculture), the components of natural capital present (rains, rivers and forests), the presence of other physical capital components (paved roads, electrical grid, telecommunication and canals) and economic activities (irrigated agriculture, rainfed agriculture, types and purpose of production (whether for market or for subsistence purposes). Within villages, variations in access to energy services exist between different groups according to wealth (wealthy, moderate, poor and very poor), gender (women and men), age (children, youth, adults and elders) and the residence status within the village (old/new inhabitants and proximity to sources of services) (see Sections 4.1.2, 4.2.2, 4.3.2, 4.4.2, 4.5.2 and 4.6.2).

These factors together determine the conditions under which a village tries to maintain the flow of desired energy services. This chapter identifies the conditions which enable some villages to achieve better livelihood outcomes than others. It argues that many of the negative livelihood outcomes that occur during vulnerability events can be explained by disturbances in the flow of energy services. This confirms the assumption made in Chapter One (Section 1.5):

The negative outcomes in traditional rural livelihoods in Sudan can be linked to disruptions in the flow of energy services caused by factors of vulnerability in those rural areas.

Annexes 1 to 6 show that disturbances in the flow of energy services happen in areas where there is a greater dependency on traditional energy carriers than on modern energy carriers in the provision of energy services. The research reported in this thesis also shows that the transforming structures and processes of the energy sector in Sudan play a limited role in helping villagers to secure the flow of energy services in rural areas. The conclusion is that negative livelihood outcomes in rural areas of Sudan could be reduced by planning to increase access to modern energy carriers for the provision of energy services. The validity of the assumption provides an answer to Research Question 5 which states:

"How can the expansion of modern energy carriers secure the flow of energy services and alleviate negative livelihood outcomes in rural Sudan?”

An expansion in the availability of modern energy carriers can be fostered by activities in the transformation structures and processes through formulating energy policies and plans that are more conducive to meeting rural needs (see Section 3.4). One of the problems in planning an expansion in the availability of modern energy carriers in traditional rural areas is the lack of any justification for such a policy, due 
to the lack of appropriate data for energy planners and decision-makers (Sections 1.2.2 and 1.3). So, answering Research Question 5 provides a justification for planners and policymakers to include traditional rural area objectives in energy policies and plans. Securing energy services for rural areas can contribute to reducing the negative outcomes of rural livelihoods (displacement, social unrest and political instability) and possibly provide opportunities for economic benefits.

To answer Research Question 5, this chapter compares the levels of energy services and livelihood outcomes in the six villages. This analysis links variations in access to energy services with the differences in livelihood outcomes achieved in the villages. The remainder of this chapter is organized in four sections. Section 5.2 compares the impacts of the vulnerability contexts on energy services in the six villages. Section 5.3 links the types of energy carriers and the delivery of access to energy services to livelihood outcomes. Section 5.4 brings the findings from the above sections together and provides the main conclusions of this chapter.

\subsection{Impacts of the vulnerability context on energy services}

Section 2.2.2.1 explains that vulnerability should be seen as negative changes in the nature of or the access to capital resulting from disturbances in the ecological, social, economic or political environments. All these forms of vulnerability contexts can be found in some parts of Sudan where they result in the destruction of rural livelihoods and cause massive displacements of the population from rural areas (Section 3.2). Chapter 4 also showed that the livelihoods of the populations in the case study villages reflect, to some extent, similar impacts but to different degrees. This is taken further by analyzing occurrences of these vulnerability factors and their consequences on the flow of energy services in the six villages (Annexes 1 to 6: Sections 1.1, 2.1, 3.1, 4.1, 5.1 and 6.1). The effects of the three components of the vulnerability context on the flow of energy services, and how this impacts on livelihood outcomes, in the six villages are combined and compared in the subsections below.

\subsubsection{Impacts of shock factors on energy services}

The shock factors found to have serious impacts on the flow of energy services in the six villages are drought and floods. Table 5.1 summarises, for the six villages, the impacts of the shock factors on the flow of energy services and the resultant negative livelihood outcomes. The data are organised so that the village with the severest impacts on the flow of energy services from the shock factors (Es Sadda) is in the left-hand column and the village with the lowest impacts from the shock factors is in the right-hand column (Dar Mali). The other villages are ordered accordingly. This ordering is maintained in the subsequent analysis and discussion in the rest of this chapter. The shock factor with the greatest impact is drought which disturbs the flow of energy services such as water provision, food production and cooking. Droughts have direct impacts on those components of natural capital which provide the energy carriers used in the provision of these services in Es Sadda, El Idied and Um Laham (see Annexes 1, 2 and 5, Sections 1.3, 2.3 and 3.5). However, not all energy services are equally affected by drought as shown in Table 5.1. Drought affects both the basis of the services and the energy carriers used to harness the flow of these energy services. The effects of drought can extend over several years (for example the 1983/1985 drought) leading to a complete failure of the energy services system and 
forcing people to relocate closer to irrigation canals or rivers where energy services are obtainable using the available energy carriers (mostly drawn from human and animal muscle power).

Table 5.1

Analysis of occurrences of drought and flood events in the six villages and their impacts on energy services

\begin{tabular}{|c|c|c|c|c|c|c|}
\hline & Es Sadda & El Idied & Um Laham & Goz El Halg & El Ga’a & Dar Mali \\
\hline $\begin{array}{l}\text { Years of } \\
\text { drought } \\
\text { events }\end{array}$ & $\begin{array}{l}1983 \\
1984 \\
1985 \\
1990 \\
2000 \\
\end{array}$ & $\begin{array}{l}1983 \\
1984 \\
1985 \\
1990\end{array}$ & $\begin{array}{l}1983 \\
1984 \\
1985 \\
1992\end{array}$ & & 1983 & \\
\hline $\begin{array}{l}\text { Years of } \\
\text { flood } \\
\text { events }\end{array}$ & & & & $\begin{array}{l}1946 \\
1963 \\
1988\end{array}$ & $\begin{array}{l}1970 \\
1980 \\
1984 \\
1988\end{array}$ & $\begin{array}{c}1946 \\
1988\end{array}$ \\
\hline $\begin{array}{l}\text { Energy } \\
\text { services } \\
\text { affected }\end{array}$ & $\begin{array}{l}\text { - Provision of } \\
\text { drinking water } \\
\text { - Food } \\
\text { production } \\
\text { - Cooking fuel }\end{array}$ & $\begin{array}{l}\text { - Provision of } \\
\text { drinking water } \\
\text { - Food production }\end{array}$ & $\begin{array}{l}\text { - Provision of } \\
\text { drinking water } \\
\text { - Food production }\end{array}$ & $\begin{array}{l}\text { - Provision } \\
\text { of drinking } \\
\text { water } \\
\text { - Pumping } \\
\text { water for } \\
\text { irrigation }\end{array}$ & $\begin{array}{l}\text { - Boiling } \\
\text { brine for } \\
\text { salt } \\
\text { extraction }\end{array}$ & $\begin{array}{l}\text { - Pumping } \\
\text { water for } \\
\text { irrigation } \\
\text { - Electrical } \\
\text { supply }\end{array}$ \\
\hline $\begin{array}{l}\text { Resultant } \\
\text { livelihood } \\
\text { outcomes }\end{array}$ & $\begin{array}{l}\text { - Frequent } \\
\text { displacement of } \\
\text { population in } \\
\text { each drought } \\
\text { event }\end{array}$ & $\begin{array}{l}\text { - Displacement of } \\
\text { population only } \\
\text { during extended } \\
\text { drought }\end{array}$ & $\begin{array}{l}\text { - Displacement of } \\
\text { some families in } \\
\text { extended } \\
\text { drought }\end{array}$ & $\begin{array}{l}\text { - Drudgery } \\
\text { of work } \\
\text { - Increased } \\
\text { cost of } \\
\text { farm } \\
\text { production }\end{array}$ & $\begin{array}{l}\text { - Increased } \\
\text { cost to } \\
\text { rehabilitate } \\
\text { wells } \\
\text { - In-coming } \\
\text { displaced } \\
\text { people }\end{array}$ & $\begin{array}{l}\text { - Relocation } \\
\text { of some } \\
\text { families } \\
\text { - In-coming } \\
\text { displaced } \\
\text { people }\end{array}$ \\
\hline
\end{tabular}

Indirect effects of the shock factors can also be seen in the other three villages (Dar Mali, El Ga'a, and Goz El Halag). These villages act as receiving areas for displaced people, and their energy services are affected by having more people competing for the existing services. However, the impacts on these villages resulting from the newcomers are not always negative. In Dar Mali, the displaced people fill the gap in available labour for manual agricultural operations such as land preparation, operating and attending diesel pumps, and supervising irrigation. So, here, the immigrants improve the provision of energy services for agricultural operations. In El Ga'a, the immigrants have a dual impact. Since there is no shortage of labour for salt extraction, the newcomers create a labour surplus, enabling salt extractors to pay lower wages. So the impacts are negative on the financial capital of the waged labourers (who receive a lower wage) and positive on the financial capital of the salt extractors (lower cost of labour).

The second shock factor, flooding, affects the flow of energy services in Goz El Halag, El Ga'a and Dar Mali. In these three villages, the impact of flood events is the destruction of physical components of the services (Annexes 3, 4 and 6). Damage to diesel pumps, canals and other irrigation equipment in Dar Mali and Goz El Halag, and destruction of brine wells in El Ga'a have been consequences of flood events. The impacts do not extend for long periods (usually 1 to 2 months duration), and soon after the floods subside, the services resume. However, this comes at the expense of financial capital since large amounts of finance are needed to rehabilitate or replace the destroyed physical capital components such as irrigation equipment and rehabilitate the irrigation channels (Dar Mali and Goz El Halag) or rehabilitate brine 
wells or dig new ones (El Ga'a). In some places, floods can lead to the relocation of people within a village. In Dar Mali and Goz El Halag, some houses were destroyed and families moved away from the banks of the Nile. In Dar Mali the relocated households lost their connection to the electrical grid since the supply line does not pass by their new location.

A number of localized shock factors have variable impacts on livelihoods: fire outbreaks in Es Sadda and El Ga'a, sandstorms in Dar Mali and Goz El Halag, and water contamination in Dar Mali. The impacts of fire outbreaks vary. In Es Sadda, fire outbreaks destroyed the natural capital from which energy carriers are obtained such as trees, shrubs and crop residues. In El Ga'a, the fire outbreaks destroyed homes and places where salt was extracted. The impact is mainly on physical capital which, in turn, reduces financial capital since there is a need for financial outlay to build new households and new places for salt extraction. In both Dar Mali and Goz El Halag, the sandstorms blocked irrigation canals and affected the water flowing to crops. Here again, financial capital had to be converted to physical capital to clear sand from the canals. Sandstorms also have impacts on the operation and life time of technologies such as diesel pumps, computer and telecommunication systems. In Goz El Halag, sandstorms have the additional impact of making transportation difficult for people, goods and services to and from the city. The contamination of drinking water in Dar Mali had immediate impacts on human capital by affecting the health of the people, and particularly the children. Avoiding such health shocks requires considerable amounts of financial capital to enable a shift from natural capital components (manual drawing of water from open wells) to physical capital components (pumping water and extension of the piped water system).

As shown above, there are a range of shock factors which have different impacts on the flow of energy services in these villages. The most affected villages (where people were forced to relocate) are those with the highest dependency on traditional energy carriers. Villages with a greater stock of modern energy carriers are less affected by shock factors, which do not have long-lasting direct effects on these modern energy carriers (Annexes 1 to 6). Within the villages, the various groups experience the impacts of vulnerability in different ways since they have different levels of capitals with which to form their coping strategies for shocks. This was very clear in Es Sadda and El Idied, where wealthy groups with greater financial capital are better able to cope with drought events than poor groups since they are able to covert their financial capital into the needed energy services. Poor groups on the other hand, with limited financial capital, resort to relocation outside the village to access other sources of natural capital to provide their energy services. Also the shock factors are found to have different impacts on the different gender and age groups. Men tend to migrate beyond the village, leaving women, children and elders to struggle to provide water, food and fuel (Es Sadda, El Idied and Um Laham). However, migrants tend to send money home to help in the purchase of services, but those remaining have to wait some time before migrant members are able to find jobs and send money.

\subsubsection{Impacts of seasonality on energy services}

The availability of energy services was found to vary during the different seasons of the year including as water supply, services in the local market, transportation, employment, pasture and health services for each of the villages (Annexes 1 to 6: Sections 1.1.5, 2.1.3, 3.1.2, 4.1.4, 5.1.4 and 6.1.6). Table 5.2 summarises the number 
of months where certain energy services are unavailable in each village. It shows that changes in some services in some places are highly seasonal while in others they are not.

Table 5.2

Impacts of seasonality on the availability of energy carriers and the flow of energy services ${ }^{1}$

The figures represent number of months in typical year

\begin{tabular}{|l|c|c|c|c|c|c|}
\hline & Es Sadda & El Idied & $\begin{array}{c}\text { Um } \\
\text { Laham }\end{array}$ & $\begin{array}{c}\text { Goz El } \\
\text { Halag }\end{array}$ & $\begin{array}{c}\text { El } \\
\text { Ga'a }\end{array}$ & $\begin{array}{c}\text { Dar } \\
\text { Mali }\end{array}$ \\
\hline $\begin{array}{l}\text { Easy access to drinking } \\
\text { water supply }\end{array}$ & 8 & 6 & 4 & 4 & 0 & 0 \\
\hline $\begin{array}{l}\text { Availability of goods in } \\
\text { local market }\end{array}$ & 4 & 2 & 0 & 0 & 0 & 0 \\
\hline Transportation & 3 & 3 & 0 & 0 & 0 & 0 \\
\hline Employment & 9 & 7 & 9 & 0 & 0 & 0 \\
\hline $\begin{array}{l}\text { Pasture and availability } \\
\text { of animals to use their } \\
\text { energy for drawing and } \\
\text { transporting water }\end{array}$ & 6 & 6 & 3 & & & 0 \\
\hline Health services & 3 & 3 & 0 & 0 & 0 & 0 \\
\hline $\begin{array}{l}\text { Resultant livelihood } \\
\text { outcomes }\end{array}$ & $\begin{array}{l}\text { Drudgery } \\
\text { work }\end{array}$ & $\begin{array}{l}\text { Drudgery } \\
\text { work }\end{array}$ & $\begin{array}{l}\text { Drudgery } \\
\text { work }\end{array}$ & $\begin{array}{l}\text { Exert } \\
\text { some } \\
\text { pressures }\end{array}$ & $\begin{array}{l}\text { No } \\
\text { effects }\end{array}$ & $\begin{array}{l}\text { No } \\
\text { effects }\end{array}$ \\
\hline
\end{tabular}

When seasonality affects the availability of modern energy carriers (kerosene and LPG), as in Es Sadda and El Idied, people in those villages are forced to go back to their traditional forms of energy carriers (fuelwood, animal dung and residues). Seasonality not only affects the availability of energy services but also affects their prices. This applies to all services that are subject to seasonal fluctuations, for example water prices and the cost of transportation in Es Sadda and in El Idied increase due to the prices of modern energy carriers when roads are blocked during the rainy season. Seasonal availability of employment also affects the level of people's financial capital to buy an energy carrier or an energy service (Annexes 1, 2 and 5).

The proximity to urban centres and modern agriculture centres can offset the impacts of seasonality by reducing the periods of unavailability of energy services. Um Laham, for example, due to its closeness to an urban centre (Bara city), and El Idied due to its proximity to mechanized farming have better access to some energy services (modern energy carriers and transportation) than Es Sadda. The types of economic activity also affect the seasonality of waged employment. Generally, in rainfed agriculture areas (Es Sadda, Um Laham and El Idied), periods without paid employment are generally longer than in areas where there is irrigated agriculture

\footnotetext{
${ }^{1}$ Impacts of seasonality on availability of energy carriers are measured in months during which a specific type of energy carrier is not available for use in the village. Likewise, the flow of energy services is also measured in months during which a specific energy service is not available to people in the village.
} 
(Dar Mali and Goz El Halag). However, in El Ga'a, where economic activities are based on non-agricultural activities, seasonality has no impact on employment.

\subsubsection{Impacts of trend factors on energy services}

Trends with important impacts on the provision of energy services are those related to population, climate and the macro-economy. These trends, as vulnerability factors, disturb the flow of energy services and impose negative pressures on livelihood outcomes. Generally, population increases were found in all villages, either through natural growth or by new settlements (Annexes 1 to 6: Sections 1.1.6, 2.1.5, 3.1.5, 4.1.5, 5.1.5 and 6.1.5). However, there can also be temporary decreases in population during serious droughts (Es Sadda, El Idied and Um Laham), and immediately a drought is over the population increases due to new settlements. In terms of climate, there is a steady decline in rainfall (Section 3.2.2). The most significant macroeconomic trend that impacts on the energy services is the liberalization polices which started as early as the 1970s (see Section 3.2.3).

These vulnerability factors together affect the flow of energy services and, consequently, impact on livelihood outcomes. The flow of energy services is, in turn, is determined by whether energy carriers are derived from natural capital (traditional energy carriers) or from physical capital (modern energy carriers). Annexes 1 to 6 show that energy services are more secure when the energy carriers are based on physical capital components than when they stem from natural capital components.

\subsection{The links between access to capitals assets and energy services}

In Section 2.5, the relationship between capital assets and the stock of energy services was represented by a circle drawn inside the 'pentagon of capitals'. Energy is viewed as a dynamic element within the pentagon of capitals, representing the necessary conditions whereby capitals are transformed into energy services. The capitals can be combined as a sequence, clustered, or substituted to provide energy services. Thus, the stock of energy services (represented by the circle) and the pentagon of capitals can expand by transforming more capitals into additional energy services. However, events, such as those linked to factors of vulnerability or contextual factors, can prevent access to any of the five capitals, thereby hindering their transformation into energy services. The stock of energy services then decreases and the energy circle shrinks, which can reduce the size of the pentagon. The following subsections describe this relationship between the flow of energy services and capital assets in the six villages studied.

\subsubsection{Natural capital}

Chapter 4 showed that there were two categories of villages based on the degree of reliance on natural capital for energy carriers. In three villages (Es Sadda, El Idied and Um Laham), there is a close and direct link between the sources of energy carriers and how they are mainly drawn from natural capital to produce the needed energy services. In order to derive energy services, people use traditional energy techniques to draw water from surface sources (haffirs), where rainwater is collected and put in containers to be transported by donkeys or on women's heads to homes. Farm operations are commonly carried out using manual tools which also require only traditional sources of energy (human and animal muscles). Cooking uses biomass fuels from the forest, crop residues or animal dung. The transportation of people, 
goods and services is achieved by using animals fed on natural pasture. In such livelihoods, transforming the natural capital into energy services is highly dependent on the conditions, the quantity and the quality of the natural capital itself. This is because the types of energy used are by-products of the natural capital (Annexes 1 to 6). This high dependence on natural capital has led people in some villages to diversify the ways they obtain energy services. In Um Laham, the shift has been between using running surface water and drawing water manually from shallow wells. Transforming any of these forms of natural capital, as sources of water, into services for people in each village involves with the use of different components of natural capital. In the other three villages (Goz El Halag, El Ga'a and Dar Mali), there is a more indirect relation between natural capital, as sources of energy carriers, and the flow of energy services. In these villages, the energy carriers used to produce most energy services are not drawn from natural capital although the natural capital does provide the basis for services.

\subsubsection{Physical capital}

The level of built physical capital and the flow of energy services are linked in different ways. The level of physical capital varies between the six villages (Chapter 4, Table 4.7.1). Building physical capital improves the quantity and/or quality of the energy services and reduces vulnerability. The components of physical capital (including modern energy carriers) can combine with other capitals to produce energy services. For example:

- Physical capital can substitute for certain natural capital components in transforming other natural capital components into energy services. In Es Sadda, the physical components, although poor, improve the flow of energy services. The building of the haffir enables the storage of large quantities of rainwater and extends the flow of water services for two or three months longer than before the haffir was built. Water tankers provide a better service than using camels or donkeys since they allow the rapid transportation of large quantities of water.

- Physical capital components can substitute for other physical capital components to improve the quality of energy services such as substituting deep wells for open shallow wells to improve the quality of water services and reduce the health risks resulted from contamination of water in open wells as seen in Dar Mali. In Dar Mali, the substitution of electrical pumps for diesel pumps has also increased the area of irrigated land (Annex 3: Table 4.3.2).

- Physical capital components can bring new energy services, such as telecommunications, computers and the internet, electrical lighting in households and schools, video shows for entertainment. These new services bring the outside world closer to the villager. Social networks are more easily maintained with family members who have migrated. Commodity prices can be accessed quickly for improved income, and new knowledge and information is acquired. 
- Some physical capital components, such as the paved road and telecommunication in Dar Mali, facilitate the outcomes from energy services. The paved road provides improved transportation and enables better marketing of irrigated crops (more timely delivery of fresh produce can ensure better prices). Another example of physical capital components improving outcomes is the evaporators in El Ga'a which increase salt production, reduce the cost of extraction and reduce health hazards associated with the traditional extraction process. Physical capital components also open opportunities to diversify sources of income, as in the cases of using refrigerators to make and sell ice cream in Dar Mali and using electrical sewing machines to make clothes in Goz El Halag (Annexes 1 to 6).

However, energy services from physical capital are not always equally accessible to all groups. For example, female pupils do not benefit from the school lighting systems in Es Sadda, and women in El Ga'a lost overall control of the salt extraction process after the introduction of solar evaporators. Women are no longer the only income earners in the family which changed their status within the family. The shift to modern energy carriers meant a loss of income to the poor who had previously sold fuelwood to other villagers.

Building physical capital is related to the use of additional modern forms of energy. For example, in Es Sadda the building of the large haffir was accompanied by the use of a diesel pump for water pumping instead of the manual collection of water from a stream. Similarly, in Dar Mali, the building of a piped water system was accompanied by the use of diesel pumps instead of manually drawing water from shallow wells. An increase in the stock of energy services is obtained when the use of physical capital leads to an expansion of the energy circle. Again, transforming energy services through physical capital secures the flow of these services against the factors of vulnerability. This can be seen by comparing the effect of the vulnerability factors on the flow of services in the six villages. Livelihoods in Dar Mali and El Ga'a, where physical capital components are used to derive energy services, were not seriously affected by disturbing impacts linked to factors of vulnerability on the flow of energy services (see Tables 4.7.1, 5.1 and 5.2).

\subsubsection{Human capital}

The elements of human capital can be linked in various ways to the provision and the flow of energy services. The role of human capital differs in the provision of energy services according to the type of service. In Es Sadda, El Idied and Um Laham, human muscle power is an important source of energy for drawing water and collecting fuelwood. In Goz El Halag and Dar Mali, human capital is important for manual work on the farms. In El Ga'a, human capital is important for digging wells and for drawing and transporting the brine water. Here, human capital directly transforms natural capital into energy services. However, in other energy services, knowledge and skills are important to maintain the flow of energy services. In Dar Mali, knowledge and skills are used to operate the diesel pumps and generators, and locally maintain them, unlike in Um Laham where a water service was interrupted by an inability to maintain the broken water pumping system. In Dar Mali, the introduction of diesel pumps for irrigation has enabled the building of skills within the village to deal with operation and maintenance of diesel engines and motors. Those skills enable easy and timely maintenance and repair which reduces the time when services are not available. The skills acquired with the diesel engine can also be used 
to operate diesel generators to provide electricity for those who are not connected to the grid. Conversely, in Um Laham, an operator is hired from outside the village to maintain the electrical generators. This process takes time to organise and so the flow of the energy service is interrupted for a longer period than if the villages could do this for themselves.

Human capital can thus play a direct role in transforming natural capital into energy services, or an indirect one through the skills and knowledge necessary for the maintenance of physical capital components that transform energy services and ensure their continuity.

Energy services can have impacts (positive or negative) on human capital. Positive impacts lead to the development of human capital such as improved health conditions (piped water systems preventing water contamination, LPG reducing indoor pollution), improved education (school lighting, computer and internet), building skills (water pumping and generators), widened knowledge and contact with the world beyond the village (satellite TVs and telecommunications) and reduced drudgery in work (LPG and water pumping).

On the other hand, the provision of energy services can have negative impacts on human capital, such as the impacts on the women and children responsible for providing fuel for cooking in Es Sadda and El Idied (drudgery and the hazards of snake bites and scorpion stings), the manual drawing of water in Um Laham and Goz El Halag (drudgery) and the traditional process of salt extraction (health hazards).

Based on the links found between human capital and energy services in the villages, there is a clear link between human capital components and the circle of energy services. Factors that reduce the level of human capital, such as migration, or reduce its quality, such as illness, will definitely lead to a decrease in the stock of energy services and lead to a shrinkage of the energy circle. On the other hand, increasing the stock of energy services has been shown to increase human capital in terms of reducing muscle effort in obtaining services, and bringing in new skills and knowledge.

\subsubsection{Social capital}

Social capital can also be linked in various ways to the provision of energy services in the six villages through various organisations and networks such as: VPCs, VDCs, associations, cooperatives, kinship relations and other family networks, government authorities, NGOs and other energy service providers. Social capital often plays a liaison role in communicating the needed services to the authorities and to NGOs for providing the needed services. Examples of the first kind found include the role of village organizations in ES Sadda in excavating the haffirs, in Dar Mali in building the piped water system, in El Idied in getting a tractor and in Um Laham in installing the solar pump. The only difference is in the size of services that these organizations are able to arrange.

Examples of the distributive role of social capital in facilitating access to energy services were found in all the villages. In Es Sadda, access to LPG was facilitated through the Teachers Union for teachers, and for some poor families their kinship networks played a role. In El Idied, access to the electrical mini-grid was through the 
VDC, and the cooperative helped to ensure access to mechanization for farm operations. In Dar Mali, the VDC enabled access to LPG, and access to the water piped system was through formal and informal organizations (Table 4.3.4). In Goz El Halag, the cooperative was responsible for the installation of the diesel pumps, and the satellite TV sets were organised through the Youth Committee. Kinship networks were instrumental in Um Laham in accessing the electrical mini-grid, and the access to the solar pump was facilitated through the VDC. Access to the electrical generator in El Ga'a was through the actions of the VPC, and the women's groups enabled access to LPG (through enabling informal financial arrangements).

All these represent positive roles of social capital in relation to access to energy services. However, as mentioned in Section 2.3 social capital can also play a negative role.

Conflicts of interest and different priorities inenergy services are clear between the various social groups (see Sections 4.1.3, 4.2.3, 4.3.3, 4.4.3, 4.5.3 and 4.6.3). A conflict of interest could be seen in Dar Mali where the move to greater levels of mechanization to replace manual farm operations negatively affected the income of the poor. Differences in priorities were shown in Es Sadda where women's needs are different from those of men. Women wanted a telephone to communicate with migrant family members and so increase their financial capital through increased remittances. Men's desire for tractors was to increase their financial capital through increased production of cash crops. Youth wanted their own club, equipped with satellite TV to reduce the cost of entertainment involved in travelling to other villages.

So, in terms of the expansion of energy services by using modern energy carriers, it is important to consider the different groups' interests and priorities within any planned intervention. Underestimating these different interests may lead to conflicts and instability within the community.

\subsubsection{Financial capital}

Components of financial capital also have an important role to play in accessing energy services, in particular in enabling access to the purchased components of high quality energy services. Groups with a relatively high income have better access to energy services: they are able to convert their financial capital into energy services. For example in Es Sadda and El Idied, wealthy groups were able to buy LPG when there is a shortage of biomass fuels and to buy water during severe shortages during droughts. The availability of formal financial institutions plays an important role in building energy services in Dar Mali and Goz El Halag. For example, the provision of diesel pumps, electrical pumps, tractors and other farm implements, diesel generators, LPG devices and even the computer and internet service were financed by banks and this increased the villagers' stock of energy services.

Other forms of financial capital, such as local finance (deferred payments), local savings groups (sandug) and remittances, are important in gaining access to energy services. For example, in El Idied, poor people can use tractors to prepare their land but do defer payment for tractor use until after the harvest. A good example of local saving is in El Ga'a where women use their income generated from salt through informal financial arrangements (sandug) to buy LPG. Remittances from migrant family members were a source of finance to access energy services, as in Es Sadda where remittances were used to finance LPG and purchase water in the dry season. 
In contrast, a lack of financial capital was also found to suppress access to energy services: directly in Es Sadda and El Idied, where poor families could not buy water; and indirectly in Um Laham, where the lack of finance meant the water pumping system could not be maintained.

Another important link between financial capital and energy services found in this study concerns poor groups who sell traditional fuel (fuelwood) in order to accumulate assets. These groups will be losers in any intervention to expand modern energy carriers. Alternatives to compensate them for their lost income must be considered to ensure equity in the distribution of benefits.

\subsubsection{The energy circle and the pentagon of capitals}

The preceeding discussion demonstrates the linkage between energy services and the five capitals, and provides evidence of the relationship between the energy circle and the pentagon of capitals. If the energy circle is not tangential to a capital then this particular capital is not used to access energy services in a village. This situation can occur as result of vulnerability as shown in the previous section. Shocks, seasonality and trends mean that the levels of some capital components are insufficient or simply not available, for example when drought reduces the availability of components of natural capital (Es Sadda, El Idied and Um Laham), or the lack of physical capital in the form of a connection to the electrical grid for the relocated groups in Dar Mali after the flood. As explained in Section 2.2.2.2, capitals can be combined in various ways, which was shown in this study with people using different combinations of components to access the desired energy services. For example, for water pumping, Es Sadda sequences the use of different energy carriers in different seasons (see Annex 1, Table 1.5). Um Laham provides a case where clustering is used: water is pumped by solar and then transported by animals or carried by humans. In Dar Mali there is a substitution of energy carriers for water pumping with electrical pumps replacing diesel pumps to bring an improved outcome (see Annex 4, Table 3.1). An understanding of the links between the various capitals and the different rural contexts allows one to plan the expansion modern energy carriers in a more equitable way.

\subsection{Impacts of the vulnerability context on the flow of energy services}

This section discusses how the vulnerability context affects the flow of energy services to traditional rural populations. This can be shown by linking the flow of energy services, the types of energy carriers used and the achieved livelihood outcomes under vulnerability conditions in the six villages. By comparing the six villages in terms of the flow of the most important energy services in securing livelihoods (water, fuel and food), it becomes possible to rank the villages by the extent they use the more traditional energy carriers as against the use of more modern energy carriers to transform energy services: Es Sadda, El Ideied, Um Laham, Goz El Halag and Dar Mali. This order is comparable with the ranking of the villages in terms of vulnerability, from the most vulnerable village lacking the desired energy services (Es Sadda, where the population can be displaced due to the vulnerability factors) to the least vulnerable village with sufficient energy services (Dar Mali, where the community is able to absorb displaced people). These links between the source of energy carriers (natural or physical capital), the vulnerability context and 
livelihood outcomes are shown in Figure 5.1. In this figure, the links between vulnerability factors, type of energy carriers used to transform energy services and livelihood outcomes are schematically presented. The links drawn show how the vulnerability of rural livelihoods can be attributed to dependence on traditional energy carriers stemming from highly-fluctuating natural capital for the provision of the desired energy services.

Vulnerability factors disturb the flow of energy services as shown in Tables 5.1 and 5.2. This disturbance in the flow of energy services can be avoided if new energy services are planned based on increasing physical capital instead of drawing entirely on natural capital. Figure 5.1 shows that an increase in the use of modern energy carriers based on from physical capital brings more stable energy services and more secure livelihood outcomes than those based on the use of traditional energy carriers based on natural capital.

Figure 5.1

Schematic representation of combinations of natural and physical capitals in transforming of energy services and levels of vulnerability

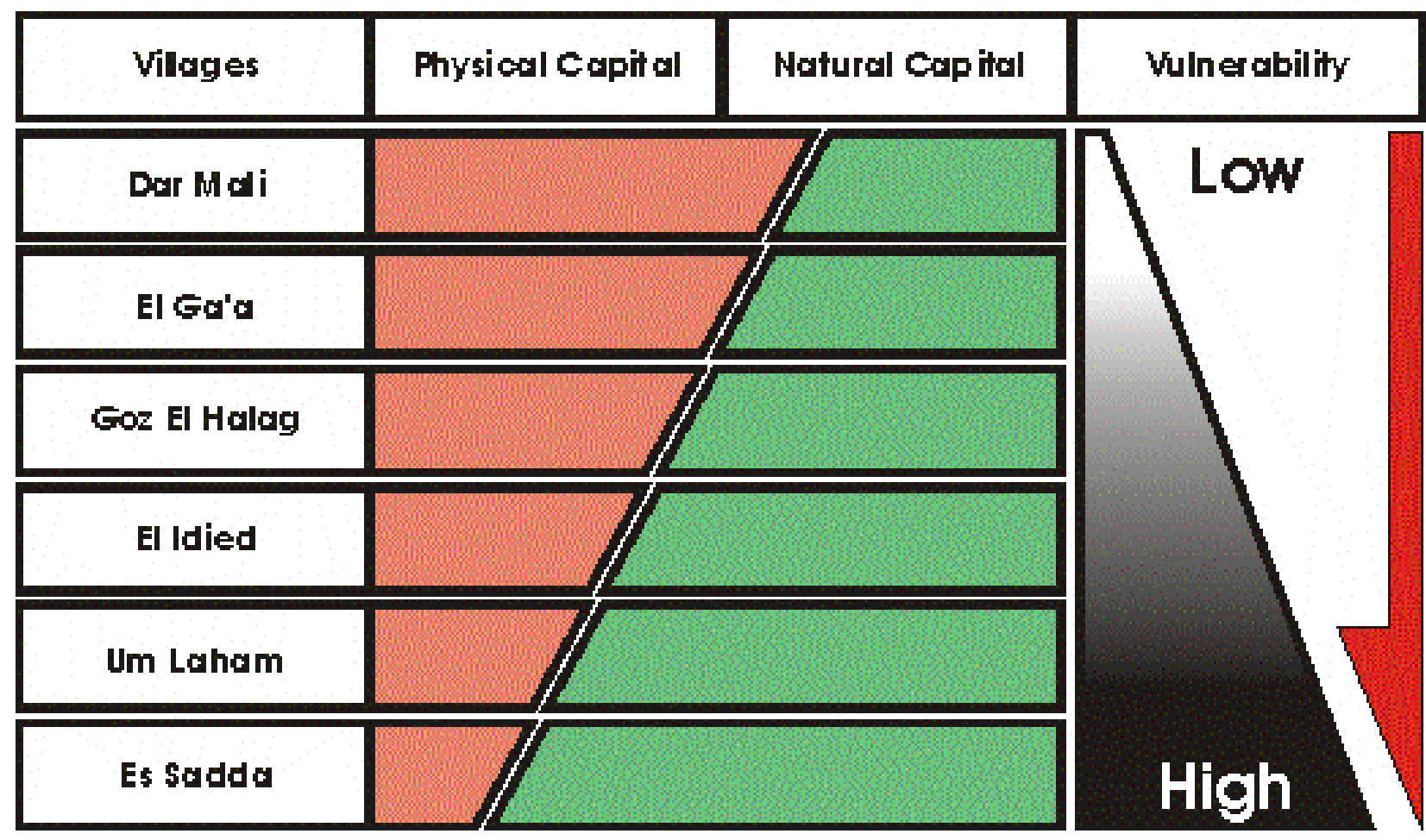

How are levels of traditional energy carriers (from natural capital), and modern energy carriers (from physical capital), and the vulnerability context linked to determine livelihood outcomes in a rural village? To illustrate this, the links between vulnerability contexts, energy carriers and livelihood outcomes are contrasted for the two extreme villages encountered (Es Sadda and Dar Mali). These extreme situations are represented in Figure 5.2 with letter A representing Dar Mali and the letter $\mathbf{B}$ representing Es Sadda. As shown in Figure 5.1, the differences between these two villages stem from the relative combinations of natural and physical capitals in transforming and accessing energy services, with the resultant livelihood outcomes, in 
each village. In the case of Dar Mali, the basis of services is a relatively stable natural capital and the transforming capital is dominated by physical capital components (the electrical grid, LPG, the paved road, telephones, diesel/electrical pumps and the railway) on which access to energy services is constructed. In this situation livelihoods are more sustainable; firstly because the natural capital is more stable than elsewhere, and, secondly, because the other components necessary to secure a stable flow of energy services are derived from physical capital which is less subject to disruption by vulnerability factors. The physical capital components are relatively independent systems in that a disturbance to one system does not significantly affect the level of the other system, neither qualitatively nor quantitatively. This means that vulnerability factors have rather limited effects on the flow of energy services and that villages with a greater reliance on physical capital components are capable of absorbing shocks and reverting to their normal conditions relatively quickly. In other words, the whole livelihood system does not collapse, and this secures people's livelihoods within their villages without the need to more elsewhere as is the case in villages which use fewer physical capital components. However, some vulnerability factors in Situation A did have negative impacts represented by the displacement of some families, but none led to the complete destruction of livelihoods or forced families to relocate beyond the village.

In Situation (B), Es Sadda, there is a close relationship between the sources of services and the energy carriers used, which mainly come from natural capital (Annex 1). The energy services are derived from unstable natural capital (uneven rainfall, seasonal streams and forests) and the transforming capital components themselves are by-products of this unstable natural capital (biomass, animal and human power). In such a situation the natural capital provides both the basis of the services and the energy carriers for transformation into services. Consequently, any disturbances in the natural capital will directly be reflected in a reduction in the stock of energy services when factors of vulnerability are evident. When there is no rain, there are no pastures or water, resulting in animals leaving the area and, as a consequence, the energy source (animal muscles) to produce energy services (drawing and transporting water) is removed. Such stresses also lead to the migration of able-bodied family members who are also an important energy carrier. Thus, this system is very vulnerable to even small changes in the natural capital. Unlike in Situation A, the village in Situation B does not have the level of other capitals required to deal with the factors of vulnerability, with the exception of being able to mobilise social networks and for the men to migrate in search of work.

As shown in Figure 5.1 the other four villages can be placed on a continuum between the extremes of Dar Mali and El Sadda, depending on the extent of substitution of physical capital components for natural capital components in the transformation of energy services. Therefore, a conclusion from comparing the energy services in the two "extreme" villages is that improving livelihood outcomes and ensuring their capacity to respond to vulnerability factors in villages such as Es Sadda requires the building and use of additional physical capital components that enable access to modern energy services. Energy planners and decision-makers need to be more aware that better rural livelihood outcomes can be expected by their inclusion in national energy planning processes, and by including, as an objective, meeting rural energy services from planned physical capital. 
Figure 5.2

Casual relation of energy services and sustainable livelihood

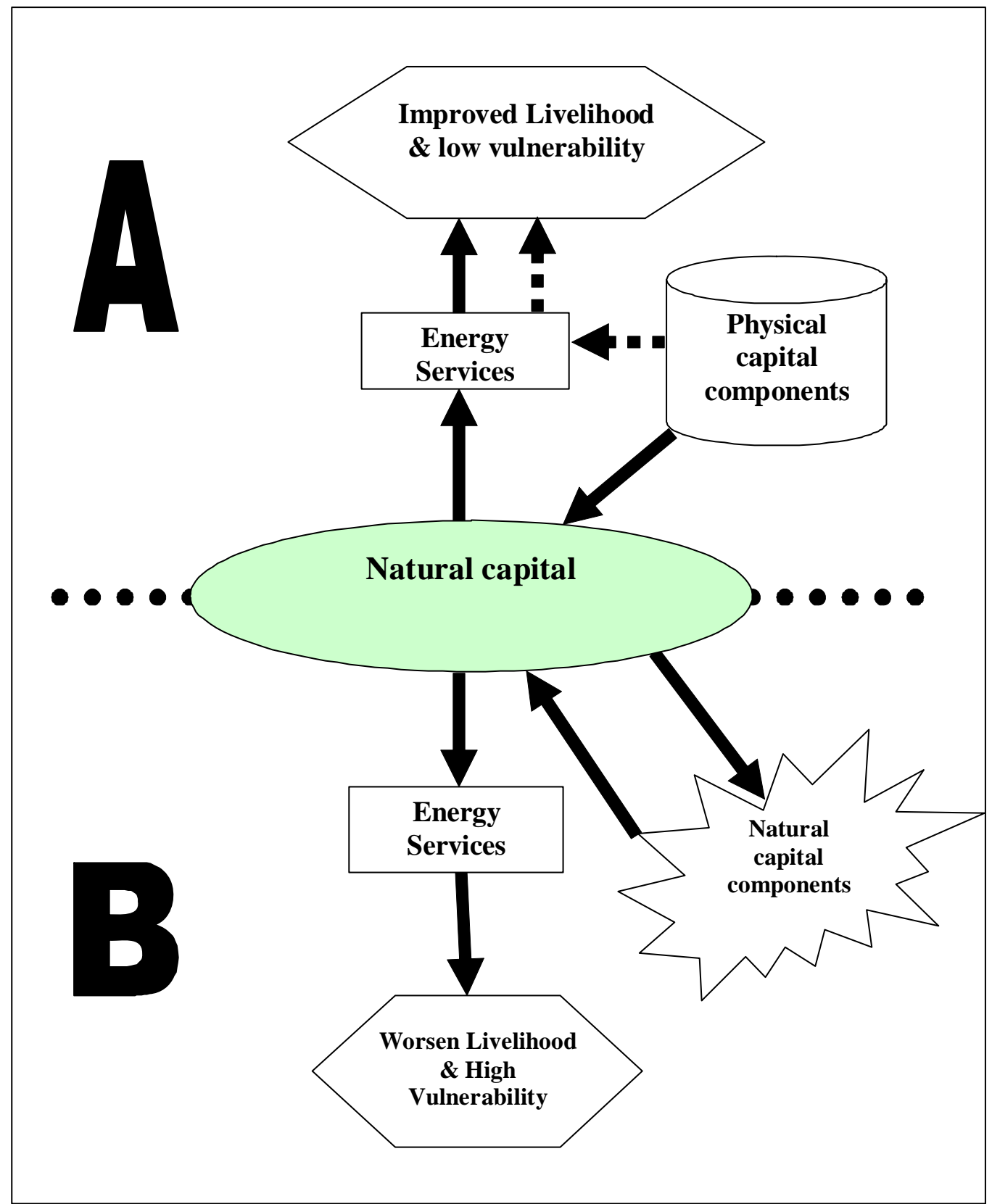

\subsection{Conclusion}

This section concludes this chapter and sets out to test whether or not the first assumption is valid:

The negative outcomes in traditional rural livelihoods in Sudan can be linked to disruptions in the flow of energy services caused by factors of vulnerability in those rural areas.

It also provides an answer to the fifth research question: 
"How can the expansion of modern energy carriers secure the flow of energy services and alleviate negative livelihoods outcomes in rural Sudan?”

The findings from the various villages show that rural livelihoods are strongly linked to natural capital. Any disruption or destruction of natural capital disrupts livelihoods and undermines the services drawn from the environment. The vulnerability factors, in particular drought, are a constant threat to rural livelihoods and in extreme situations lead to the displacement of people from their home villages. The seasonal nature of natural capital also affects the flow of energy services and causes seasonal stresses on rural livelihoods. The evidence presented in this thesis supports the validity of the first assumption.

The evidence shows that, when energy carriers are at a sufficient level. Communities are able to generate the energy services they need to maintain their livelihoods. Energy carriers are seen as components of either natural or physical capital and generally a mixture of both types is in use at any one time. The combination adopted depends on the ecological context and financial capital.

An important finding from the empirical evidence is that communities with access to energy carriers based on physical capital are less vulnerable than those that are dependent on energy carriers from natural capital. However, other components are needed to secure livelihoods. The other three types of capital, human, social and financial, play important roles in access to and distribution of energy services within a community.

With the types of vulnerability prevalent in rural areas of Sudan, the flow of energy services is conditioned by whether energy carriers used are derived from natural capital or from physical capital. The evidence from this research demonstrates that better livelihood outcomes, free from adverse responses to the vulnerability context, can be achieved by a greater use of modern energy carriers derived from physical capital, replacing traditional energy carriers from natural capital, in the provision of energy services.

The availability and use of modern energy carriers is not linked to the conditions of the natural capital so, even under severe vulnerability conditions, modern energy carriers can be obtained and used to generate needed energy services. This link shows that modern energy carriers, as they are relatively free from effects of vulnerability, can secure the flow of desired energy services and thus provides an answer to Research Question 5.

The build up of physical capital components and the use of more modern energy carriers can ensure a continuous flow of energy services and secure rural livelihoods against the prevalent vulnerabilities. Planning to expand modern energy carriers to rural areas will reduce disturbances in the flow of energy services by freeing these services from their link to erratic natural capital. Thus, by an expansion of modern energy services, many of the negative livelihood outcomes can be reduced significantly, and possibly even eliminated. Displacement of people occurs when energy services are not available, and people only return to their villages if and when these energy services become available again. Displacement is not the only negative livelihood outcome in rural Sudan, and securing energy services could possibly 
contribute to solving other negative outcomes including civil war and social instability. All the areas suffering civil war and social unrest (Darfur and the eastern states) have similar situations in terms of factors of vulnerability, dominance of the traditional subsistence economy and the use of traditional energy carriers. Expanding modern energy carriers to rural areas could also open up opportunities for involvement in the market economy. Several examples from the villages in this study demonstrate this possibility. In Dar Mali, farmers can produce for the market now that the enabling physical capital components exist (paved road, good transportation and telecommunications). In Um Laham, sesame oil-mills can switch from the traditional system using camels to ones using mechanical power and hence increase output. Women in Goz El Halag, through using electrical sewing machines, can increase the output and quality of clothes. Better livelihood outcomes, from the expansion in the use of modern energy carriers based on physical capital to replace traditional energy carriers from natural capital in rural areas, can be anticipated. This chapter presents, to both planners and decision makers, sufficient evidence to justify including the objectives and desires of traditional rural areas in planning the energy sector. The next chapter recommends some changes to the structures and processes of the energy sector that would ensure that energy policy was more inclusive in terms of the energy needs of traditional rural areas. 


\section{Chapter Six: Conclusion and recommendations}

\subsection{Introduction}

This chapter sets out to answer the main research question:

How can energy planning be made more equitable and responsive to energy problems as they relate to rural livelihoods in Sudan?

Answering this research question requires addressing problems associated with the planning processes. These will be considered in Sections 6.2 and 6.3. The first part deal with the seven steps of the planning processes listed in Section 1.3. Identification of the problems and the collection of data are related to the setting of the overall objectives which determines their relation to rural livelihoods. Crucial factors, as findings from this research substantiate are: firstly, the vulnerability context which interrupts the flow of energy services and results in most of the problems related to rural livelihood outcomes (Section 6.2.1). Secondly, the exclusion of these problems related to rural livelihoods from energy planning processes. This exclusion has its basis in the methods applied in building the energy data system (EDS) used for planning and policy formulation (Section 6.2.2). This exclusion is also linked to the poor functioning of the transforming structures and processes of the energy sector in rural areas (Section 6.2.3). The identification of rural energy problems in the traditional sector and of the reasons for their exclusion from energy planning and policies led to emergence of five groups of recommendations to overcome problems of inclusion and equity (Section 6.3). These recommendations call for: (i) broadening the unit of observation from the shared kitchen to shared livelihoods and broadening the unit of analysis from fuel types to energy services (Section 6.3.1); (ii) broadening the view taken in energy service analysis (Section 6.3.2); (iii) shifting the focus in energy planning from the supply side to the energy needs of users (Section 6.3.3); (iv) shifting from an exclusive perspective to an inclusive one (Section 6.3.4); and (v) developing a specific structure within energy institutions to plan for rural energy services (Section 6.3.5).

\subsection{Main findings}

This section highlights the main findings from the previous chapters. It brings together the answers to the research question posed at the beginning of each chapter.

\subsubsection{Vulnerability as a determinant of rural energy services in Sudan}

The second research question asked:

"How do the factors of the vulnerability context disturb the flow of energy services and how does that disturbance affect rural livelihood outcomes?"

The vulnerability factors that disturb the flow of energy services in rural Sudan are drought, floods, seasonality, health and trends in the climate, population and the economy. Impacts of these different vulnerability factors on energy services vary 
from a complete cessation of services (drought and flood) to reduced quantity (seasonality and trends) or quality (health and seasonality) of energy services.

These vulnerabilities are responsible for disturbing the flow of energy services in two ways. First, they reduce the availability of traditional energy carriers and so reduce the stock of energy services produced by these carriers. In villages where traditional energy carriers are dominant (Es Sadda, El Idied and Um Laham), disturbances in the flow of energy services occur following the occurrence of vulnerabilities (Annexes 1, 2 and 5). Second, they degrade the natural sources of energy services, resulting in people either accessing the services under less convenient circumstances or paying an increased financial cost for them. In Goz El Halag, for example, the building of the Khashim El Girba dam led to the ground water level falling after which the drawing/pumping of water required more effort and time (manual drawing of domestic water) or became more expensive (larger pump and more diesel fuel to irrigate the same area of land) (Annex 4). Barriers to, and inconvenience in, accessing energy services caused by the factors of vulnerability were found to be linked to negative livelihood outcomes in rural areas. Tables 5.1 and 5.2 (Chapter 5) link the factors of vulnerability in the six villages to disturbances in the flow of energy services and the consequent negative livelihood outcomes, thus providing an answer to Research Question 2. In rural areas, where energy carriers are predominantly obtained from natural capital components, there is a strong link between the prevailing factors of vulnerability, the degradation in energy services and negative livelihood outcomes. However, such negative livelihood outcomes can be avoided in rural areas where the energy carriers are predominantly obtained from physical capital components (Annexes 1 to 6).

Decision-makers and planners need to be aware of the links in order for energy policy to address problems related to rural energy services within the energy sector's objectives. In order to raise awareness, problems related to rural energy services must be reflected in the Energy Data System (EDS) from which the objectives of policies and plans are derived. The following section shows how problems related to rural energy services are excluded in building the EDS.

\subsubsection{Methods used in building the EDS for energy policies and planning purposes in Sudan}

This section comes as response to answer the Research Question 1:

"How can problems related to energy services in rural Sudan be investigated such that rural objectives and priorities for energy planning are identified?”

One of the reasons for the past exclusion of rural and traditional areas in energy sector planning is the lack of data on rural energy services. Rural and traditional areas have never been investigated to identify problems related to their energy services. A fundamental problem is how to investigate and collect relevant data for presentation to planners and decision-makers. Section 1.3 gave an outline of the steps that shape the processes of energy sector planning. These steps include defining the objectives, determining the approach, determining the information to be used, determining the analysis process, conducting the analysis, presenting the results and preparing the plan. The steps are important determinants of both the conceptual contents of the energy planning processes and the geographical areas to be served by the plan, that is where the contents of the plan are going to be implemented. 
Why then have decision-makers not acquired the necessary data on which to formulate more equitable energy policies and plans? The reasons for the lack of such data are found in the approach used for data identification and gathering. It was shown in Section 1.3 that there is some quantifying of traditional energy sources in developing the Energy Data System (EDS). However, instead of developing appropriate data gathering approaches, to give at least an estimate of the quantities of traditional energy sources used, energy planners take the easy route of ignoring these sources all together. So, when energy data are presented by sources and sectors (agriculture, industry, transportation and household) in the EDS, rural energy services are excluded. This is largely because of the concentration on energy sources rather than on the services they provide. Even when data for households are gathered, they insufficiently represent all the energy services present in rural areas.

In rural energy surveys, the standard approach data to gathering, as used by FAO and the African Development Bank tends to reduce the problem of energy services to that of cooking, and so collects data on energy carrier and conversion devices used only for cooking. This reduction stems from the choice of the household as the unit of observation and fuel as unit of analysis (see the definition provided for a household in Section 1.3). The focus on the household disguises the complex interrelations between the ecological, the social and the economic settings and energy services. In this research, it has been shown that there are other services that are equally as important for livelihoods as cooking. These important energy services include water pumping, farm operations, transportation, refrigeration in health centres, lighting in education and energy services in income generation activities. Energy related data on these are, so far, lacking in Sudan. These services are not covered in household energy surveys since the activities are not found within the domain of households. Thus, the limited investigations made in rural areas provide incomplete information about rural energy services. Section 3.4.2 shows that there is, to date, no explicit reference to wider problems related to rural energy services in the contents of the planning processes in Sudan (see the National Energy Plan 1985-2000, the National Comprehensive Strategy 1992-2002 and the five year-plans 2002-2006 and 2007-2011). However, all the plans do refer to the shortage of fuelwood for cooking in rural areas as one of Sudan's energy problems.

Moreover, there is a difficulty in representing, in a standard questionnaire, all the possible variations in rural areas and their distinct different energy problems and priorities. Chapter 4 provides evidence of local differences and inequalities in access to energy services between and within different rural areas. Differences between the six villages resulted from their geographical locations (proximity to urban centres or the modern agricultural sector), the components of natural capital within reach of the village (mainly rains, rivers and forests), presence of physical capital components (paved roads, electrical grid, telecommunications and canals) and economic activities (irrigated agriculture, rainfed agriculture, types and purpose of production - whether for market or for subsistence purposes). Within villages, access to energy services is found to vary by wealth, gender, age group and also by spatial distance from the location of services (settlements away from services in Es Sadda and the displacement of people away from the grid in Dar Mali). The analysis of the variations in access to energy services will help planners and decision-makers recognise and identify problems related to different groups' needs in terms of energy services, and their priorities, as well as consider how any intervention will affect the various groups. 
Such an analysis is important for energy planning and for policymakers to ensure support for all rural groups' livelihoods and an equitable distribution of benefits from energy services.

All these variations in the desired energy services, and the way they are provided in rural areas, cannot be captured in the household energy surveys or the other standard energy surveys so far used for constructing the Energy Data System (EDS). As an alternative, this research proposes, in answering Research Question 3, a methodology based on the village as the unit of observation and energy services as the unit of analysis. The livelihoods framework is proposed for problem identification and the participatory approach to ensure wider representation in energy data gathering. This should then reflect more clearly the ecological, social and economic dimensions of problems related to energy services and rural livelihoods. Such a methodology allows for a more holistic view in investigating energy problems relevant to the range of rural livelihoods found in Sudan and can ensure their inclusion in the Energy Data System (EDS). Chapter 4 has shown that the proposed methodology provides sufficient data to identify that securing the flow of energy services should be the main rural objective for energy policies and planning. In addition, it draws attention to two points which would not emerge from household surveys: the sensitivity of rural energy services to the vulnerability context, and the strong link between securing the flow of energy services and building more sustainable livelihood outcomes in rural Sudan.

This subsection argues that the exclusion of rural energy services is partially due to the approaches adopted in planning processes. These planning processes are part of a wider context of transforming structures and processes which determine how economic, social and political aspects are managed at the federal level of government. The next subsection will show how the transforming structures and processes, as currently constructed in Sudan, contribute to the exclusion of problems related to rural energy services in energy planning.

\subsubsection{The functioning of the transforming structures and processes in the energy sector.}

This section provides the answer to Research Question 3:

\section{"Why were energy problems related to traditional rural livelihoods not addressed in national energy planning processes in Sudan?”}

Chapter 3 includes an analysis of the structures and processes, and their role in the exclusion of the traditional rural sector from all development efforts including energy sector policies and plans. This was attributed to the lack of awareness by decision-makers of the complexities of rural livelihoods. Energy is viewed as a vital component in meeting the macro-policy objectives determined by the World Bank and by successive national governments, but only in the creation of a modern economic sector. The traditional rural sector is viewed as a burden on the economy and should therefore be excluded from national planning. These views, supporting the modern sector and excluding the traditional rural sector, are clearly reflected in the energy structures and processes in Sudan.

The existing energy structures are mainly located at the federal level. The only institution that has offices in all States is the National Forestry Corporation (NFC), 
and these were established to manage natural forests and collect revenues from the use of forest resources. Other than the NFC, there are no specific departments or offices for rural energy services within the various institutions. Although the decentralized structures supported by the federal system adopted in 1991, and the protocols of the Comprehensive Peace Agreement (signed in 2005), do provide mechanisms to establish structures for delivering energy services to rural areas, the lack of revenues and the lack of technical capacity has meant that the States are unable to support energy structures at the State level. As a consequence, the transfer of the delivery of services to lower-level structures (States and Provinces) brings no real development of rural energy structures.

The main reason for the failure of the energy processes can be found in the objectives set for planning in the energy sector. Planning in terms of energy is derived from the need to meet the objectives of the modern agriculture sector for its conceived benefits for the Sudanese economy. As argued by the World Bank and UNDP, the objectives and priorities of the energy sector are to serve the modern agriculture sector that produces commodities for export since this will contribute to the recovery of the Sudanese economy from its present stagnation (Section 3.4.2). Thus, the contents of the energy planning objectives were derived to meet the needs of the modern sector and include no reference to meeting the needs of rural energy services. In Chapter 3, it was shown that rural energy services are excluded from the policies and plans so far adopted in Sudan.

The policies formulated for petroleum and electricity supply are biased against the remote areas as, for example, petroleum pricing and the criteria for extending the electrical grid do not favour small remote rural villages (Table 3.2). Solving the energy problems necessary for the maintenance of rural livelihoods is simply not part of the planning processes adopted in Sudan.

Linking the lack of structures for rural energy services within energy sector institutions, to the lack of interest reflected the objectives set for energy planning and the lack of appropriate approaches to data collection, can present to decision-makers the nature of energy services in a way that demonstrates why rural energy services have not previously been addressed in national energy plans in Sudan. This provides an answer to the third research question.

\subsubsection{Differences in access to energy services in rural areas}

This section answers Research Question 4:

"How do local differences affect access to and priorities of energy services in rural areas?”

Chapter 4 provides evidence of the large differences in access to energy services between different villages and among different groups within a village. Differences between the villages are attributed to spatial location, economic activities, proximity to urban centres and differences in types of capitals. Within each village, wealth, gender, age, the spatial location of households and residence status determine the level of access to energy services and the predominant type of energy carriers employed (modern or traditional). 


\subsubsection{The need to plan additional modern energy carriers in rural areas}

This section provides the answer to Research Question 5:

"How can the expansion of modern energy carriers secure the flow of energy services and alleviate negative livelihood outcomes in rural Sudan?"

Chapter 5 provides evidence that negative livelihood outcomes are more likely in villages where there is less use of modern energy carriers and a greater use made of traditional energy carriers. It also shows that livelihoods are less subject to the factors of vulnerability in villages where modern energy carriers are used (Figure 5.1). These findings demonstrate that the expansion of modern energy services will free villagers access to energy carriers from a dependence on erratic natural capital and hence reduce the impacts of vulnerabilities on livelihood outcomes.

To sum up, this Section 6.2 draws together the main findings concerning the links between energy problems related to rural livelihoods and their main causes, and suggests how to investigate and present them more effectively to energy policymakers and planners. This contributes to answering the main research question:

"How can energy planning be made more equitable and responsive to energy problems related to rural livelihoods in Sudan?"

This section sums up the findings from the previous chapters by arguing that the negative livelihood outcomes in rural areas (displacement, civil unrest, destruction of capitals) can be reduced through expanding the use of modern energy carriers. This is seen as justifying the identification and inclusion, in energy planning, of problems related to rural energy services.

Problems related to rural energy services have so far been addressed in the conceptual content of planning process. However, in order to fully answer the main research question, mechanisms are required that will ensure that all geographical areas where rural problems are identified are included in the solutions. For this to happen, changes in the transforming structures and processes are required. The lower levels of the federal administration (the States and Provinces) currently adopted in Sudan provide for structures that could possibly address the issue of present-day rural exclusion from national energy planning objectives. The states and provinces could accept the responsibility for detailed data gathering and, based on an analysis of their findings, they could communicate the desirable rural objectives for their area to energy planners and decision-makers at the federal level. However, for this inclusive process to work, some changes in the transforming structures and processes are needed. The next section provides five recommendations that would help the transforming structures and processes become more inclusive of energy problems related to rural livelihoods. 


\subsection{Recommendations}

This section responds to Research Question 6:

"How to include problems related to rural energy services in energy planning processes in Sudan?"

As shown in Chapters 4 and 5, energy related problems are diverse, and their impacts on rural livelihoods vary with ecological locations and for groups with different wealth, gender and age attributes. All these diversities need to be represented and included in all steps of the energy planning processes if energy planning is to be more inclusive and equitable. To ensure such inclusion, and equity in energy planning processes, requires some changes in the way rural energy problems are perceived. In answer to the main research question, this research suggests that there are five areas in which changes could address rural energy problems and provide solutions:

- Change from shared kitchen to shared livelihoods as the unit of observation

- Adopt a broader view of energy services in the analysis

- Change from a fuel supply focus to a problem solving one

- Change from exclusion to inclusion of traditional economies

- Develop specific structures within energy institutions for rural energy services

\subsubsection{Change from shared kitchen to shared livelihoods as unit of observation}

This research provides rich and detailed data on rural energy services. Its important contribution is the proposed change in the focus in energy planning away, from the reductionism of rural energy to cooking to the full range of energy services required to support rural livelihoods. Broadening the unit of observation from the kitchen to the whole village enables capturing the full range of energy services needed. Data from the six villages show clearly that problems related to rural energy services are much greater than those found in the rural kitchen. The destruction of livelihoods and negative livelihood outcomes (displacement of rural populations, civil unrest and the destruction of natural capital) in rural areas are more closely related to the lack of a stock of energy services than to a scarcity of fuelwood and a lack of efficient cooking devices. In none of the villages studied was woodfuel seen as an immediate energy problem since a range of energy carriers for cooking are available; people do find ways to cook their meals. However, some of these energy carriers are of poor quality with associated indoor pollution problems (smoke and smells when they burn) which have negative consequences for the health of women and children. The main energy problems, as in the three villages of Es Sadda, Um Laham and El Idied, are related to accessing drinking water and food stuffs rather than finding fuel to cook. In these villages, problems of livelihood failure were clearly due to a lack of energy services to complete tasks that are far beyond their stock of traditional energy carriers. Water, for example, is now too far away to be transported by animals in some areas such as Es Sadda village, and too deep to manually dig wells and draw water in other areas like Um Laham village.

To focus on livelihood problems requires a perspective that relates the wider aspects of livelihood outcomes to energy services and the types of energy carriers, and that can then stimulate changes to happen. The explanatory part of this is provided by the energy circle drawn within the pentagon of capital assets as shown in Chapter 2. Chapters 4 and 5 provide the empirical evidence on how these relationships are constructed. Data from these villages demonstrate that rural energy problems have 
links to the wider livelihood settings (mainly the vulnerability context and access to the five capitals). These settings largely determine the availability and accessibility of energy services in the village. Investigating these aspects together can help in designing energy policies that directly target rural problems and, at the same time, take into account the opportunities and constraints inherent to the specificity of the location of a village and the types of livelihood to be found there.

\subsubsection{Adopt a broader view of energy services in the analysis}

A broader view of energy services is obtained by changing the unit of analysis from the narrow focus on energy carriers to one on energy services. The villages studied provide examples of rural problems and priorities which could be tackled by careful planning of energy services rather than by focussing planning on energy supply. The livelihoods analysis relates the vulnerability of rural livelihoods to natural factors such as drought, flood and fire and to health shocks. The importance of the broader view, as adopted in this research, is not in the identification of these factors per se, but the identification of links between the flow of energy services and sustainable livelihoods since energy planning can make significant contributions to a solution. Seasonality factors and the frequent occurrences of drought disrupt the flow of energy services and have negative consequences on livelihood outcomes in Es Sadda, El Idied and Um Laham. The disruption in the flow of services could be avoided by careful planning of energy services for these villages. It is impossible to completely change the natural capital, but it is feasible to upgrade or build flexible energy services based on modern energy carriers which are not disturbed by erratic natural capital. Analysis of energy services, and their natural bases, will direct attention towards possible energy interventions that can smooth the flow of energy services and support rural livelihoods. Such analysis also helps in identifying the level of intervention needed for a specific situation. Direct intervention is needed in villages where the energy circle is small, such as Es Sadda where the village does not have the capacity to mobilise resources to meet its energy service priorities, such as building a haffir sufficiently large to store a year's supply of water. Indirect interventions can be sufficient in villages where the energy circle is large, such as Dar Mali, where the village is able to mobilise resources to meet its energy priorities. In Dar Mali, increasing the capacity of the power supply would encourage people to increase their irrigated areas by switching to electrical pump sets.

\subsubsection{Change focus from supply of modern energy to problem solving}

As shown in Chapter 3, one of the main priorities in energy planning in Sudan is to supply modern forms of energy to the modern sectors of the economy. This was initiated in the 1980s by the direct allocation of energy supplies from government energy institutions to meet the needs of those sectors which were viewed as providing a significant contribution to exports. In so doing, rural and traditional economies that did not contribute to export commodities were automatically excluded from being supplied with modern energy carriers. Since liberalization in 1992, the role of supplying energy is left to the market. While this policy does not directly exclude the rural and traditional economies from access to modern energy carriers, the findings from the six villages show that the lack of access is more than a problem of improving supply. The nationwide exploitation of oil is generally perceived as having overcome supply problems, but, in rural areas, there is still only very limited use of modern energy carriers in transforming and accessing energy services and in securing their flow against disruption caused by the factors of vulnerability. Based on the findings in 
the six case study villages, five main reasons were identified that explain why there remains a problem of access and limited use of modern energy carriers.

First, there is a lack of physical support infrastructures in rural areas. There is a poor road system which hinders the transport of modern energy carriers to many rural areas (Es Sadda and El Idied). Modern energy carriers become unavailable during the rainy season. In addition, prices increase to prohibitive levels after the rains in many rural areas. Thus, energy supply alone cannot solve problems of access to modern energy carriers in rural areas.

Second, there is a lack of financial facilities in rural areas. The high prices of the technologies for use with modern energy carriers, and their unavailability in local markets, make them inaccessible to most rural people. LPG is a good example in this regard. The high costs of accessing technologies means its use is limited to only the richest families and to families for whom the purchase of the technology is facilitated by external support such as teachers association (social capital) and banks (financial capital). The unavailability of a refilling service in local markets also creates another constraint to using gas cylinders.

Third, the lack of technical know-how on using modern energy technologies acts as a barrier to access. In Um Laham, some families own LPG cylinders and stoves but do not use them because they feel they did not know how to operate the technology safely.

Fourth, an intervention with modern energy carriers is not a neutral process, and benefits can be unevenly distributed among different groups in a village, and sometimes a group can even be disadvantaged by an intervention. Examples of uneven accesses to built energy services can be found in Es Sadda where the lighting from the solar system in the school is accessed only by male pupils from the village settlements close to the school. Girls are prevented by cultural practices from attending evening classes. Hence, here an available service is unevenly accessed based on gender and spatial location criteria. A further example of groups being disadvantaged by an intervention can be found in the village of El Ga'a. The introduction of solar evaporators for salt extraction was originally intended to benefit women (to avoid their exposure to smoke, to reduce their workload, to reduce their costs and to improve their income). While three of the four benefits have been realised, the intervention has unintentionally changed the division of financial benefits between women and men. Responsibility for the process of salt extraction has changed from one exclusively benefitting women to one done by both male and female family members. Thus, the control of women over the salt extraction process has been reduced by the shift from traditional to modern technologies. This change in gender roles in contributing to a family's financial capital can be interpreted as reducing the status of women in the family. Instead of being the sole income earners in the household, women are now, at best, equal contributors to family income. Another example is the poorer families who depend on providing and selling traditional energy carriers (own labour, fuelwood, crop residues and animal dung) for their livelihoods, since they may lose their sources of income by interventions aiming to replace traditional energy carriers. For example, in Dar Mali, the use of a buffalo tractor and electrical pumps has replaced manually performed tasks and, in El Idied, LPG is replacing fuelwood. 
Fifth, there is a lack of coordination with providers of services outside the energy sector. A clear example of this was found in El Ga'a where the vaccine fridge, which was brought by Rural Solar Energy Development project (RSED) in 1994, was not used to store for quite a long period. Vaccine provision is the responsibility of another agency, the State Ministry of Health, who were not adequately consulted about providing vaccines. So, although both energy components (the technology and the energy source) were operating properly, the end service was not available. In general, the providers of other components of services are essential stakeholders in developing the energy sector in rural areas. Therefore, energy planning needs to identify other critical components without which an intended end service cannot be delivered, and involve the relevant stakeholders in the planning processes.

These five reasons highlight the reality that the supply of modern energy carriers is one thing and the accessibility to generate end-user services in rural areas is something else. Problems that arise from constraints in the use of modern energy carriers in rural areas are apparent in the findings of this research: the disruption of rural livelihoods and negative livelihood outcomes, which occur because villagers are not able to respond to the factors of vulnerability. In Dar Mali, these constraints were removed by a switch to modern energy services and improved means of service delivery. The shift was aided by the presence of appropriate physical infrastructure (the paved road and the electrical grid) and the provision of bank loans to buy technologies. Further, the availability of local technical know-how meant that the village could avoid major disruptions to its livelihood system when the vulnerability factors were prevalent. The simultaneous existence of all these components enhanced the capability of local people to access and use modern energy services. In contrast, in villages where these capabilities and components of physical, financial and human capitals are lacking, as in Es Sadda and Um Laham, the villagers are more vulnerable to disruptions in their livelihood systems because the capabilities to access and use modern energy services are quite limited.

The current approach to energy supply management can only service those people for whom access to modern energy carriers has already been largely solved. Expansion in electricity generation and supply will serve only those who are connected to the grid and the increase in the supply of oil products reaches only those who are connected through a good road network and have the local physical capacity to use modern energy services. This research draws attention to the problems associated with the capabilities to use modern energy services by those who are outside the normal energy supply considerations or the remit of energy planning institutions. These energy issues in the broadest sense necessitate a careful look by planners into solving problems of capabilities to use, rather than considering only the supply and physical allocation of modern energy carriers.

\subsubsection{Change from exclusion to inclusion of traditional economies}

The energy services needs in traditional and subsistence economies are ignored in drawing up energy policies and plans in Sudan. Due to this exclusion, several negative livelihood problems highlighted in Sections 3.2 and 5.2 remain unresolved. Inclusion of the traditional and subsistence economies in energy planning would help to avoid many of these negative livelihood outcomes. It is the lack of services that lead to the destruction of rural livelihoods and the displacement of rural populations. 
Avoiding these negative outcomes is possible by providing those services that disappear during events linked to vulnerability factors. To achieve this, requires the inclusion of the traditional rural sector in energy planning. The exclusion is largely based on socioeconomic factors, linked to wealth, gender, age, spatial location and residence status.

\subsubsection{Develop specific structures within energy institutions for rural services}

The structures and processes of centrally-located energy institutions cannot adequately identify rural energy problems. Located at the federal level, existing energy institutions have little knowledge about the needs of remote rural areas and their local specificities. It is very clear from this research that, in a country like Sudan with a wide regional diversity, it is very difficult, if not impossible, to cater for all the groups' interests and aspirations in national plans in the way they have been formulated in the past. Variations and location specificities require the decentralization of planning to the state, provincial, locality and village levels. Establishing and equipping an energy planning office at the state level is important for two reasons. First, it will create the capacity to plan energy at the state and lower levels of the administration. This is important for identifying energy problems through gathering data related to the rural areas of a particular state, and this will also lead to local training and capacity building in the energy planning processes. Second, it can form a bridge between the federal level energy offices and the rural communities. In this way, the knowledge gap between federal energy institutions and local realties can be filled and rural peoples' energy problems and needs can be channelled through an intermediate energy office to the federal energy institutions and then be incorporated in national energy planning.

\subsection{Concluding remarks}

To summarise, this research has drawn attention to the importance of considering different modes of livelihoods in energy planning, particularly in traditional rural areas. The thesis proposes a solution to the problem of how to identify the needs for rural energy services by the adoption of the livelihoods framework, and problems related to the representation of traditional livelihoods in data collection by the adoption of participatory methods. This research also shows that energy planning can contribute, through securing the flow of critical energy services, to reducing negative livelihood outcomes in traditional rural areas. The potential contribution that energy planning can make to reducing these negative livelihood outcomes in rural areas can be used as a justification for formulating more-inclusive energy policies and plans for Sudan. The costs of not securing the flow of energy services in rural areas, although beyond this investigation, are tremendous (the destruction of rural livelihoods, the displacement of communities which is often accompanied by civil unrest and insecurity). Carefully targeted energy planning can at least bring food and water to the hungry and the homeless and, by so doing avoid further displacements from traditional rural areas. 


\section{References}

Abdel Ati, Hassan A. (ed.) (2001) "Sustainable Development in Sudan: ten Years after Rio Summit, A civil society perspective" Solo for press and print, Khartoum.

Abu Sin, M. E. and M. O. El Sammani (1987) "Population and environment in Sudan" in Atif A Saghayroun Etal (ed.) “Population and development in Sudan: the quest for a national policy” proceedings of the third national population conference October 10-14 , 1987, Khartoum, Sudan.

African Development Bank, African Development Fund, African Energy Programme (1996) Energy and environment technical paper series, technical paper No. EE18.

Ahmed, Nouralla Yassin (1996) "Technical intervention in rural areas and social resistance: the case of Solar evaporators for salt extraction in El Ga’a village, North Kordofan” MSc thesis, University of Khartoum, Development Studies and Research Centre (DSRC) May 1996.

Ali, G. Elfaki and Ismail A. El Gizouli (1996) Energy Utility and Institution in Africa, the case of Sudan. In M. R. Bhagaran ed.

Asian and Pacific Development Centre (APDC) (1985) "Integrated energy planning: A manual Vol. I, II \& III) ed. By: Codoni, Rene, Hi-chum Park and K V Ramani. ISBN: APDC Kuala Lumpur Malaysia. ISBN: 967-99954-5-3.

Bailey, Jane, Maegeret Buchanan-Smith and Simon Maxwell (1990) Famine in Sudan, the proceeding of a one day symposium. Institute of development Studies Discussion paper No. 283.

Barnett, Andrew (2000) Energy and the Fight against Poverty. Lecture given at the Institute of Social Studies, The Hague, 29 ${ }^{\text {th }}$ June 2000.

Barnett, Tony (1975) The Gezira Scheme: Production of Cotton and the Reproduction of Underdevelopment. In Beyond the Sociology of Development: Economy and Society in Latin America and Africa. Oxaal, Barnett and Booth, eds. Pp. 183-207. London: Routledge and Kegan Paul.

Barnett, Tony and Abbas Abd Elkarim (eds.) (1988) "Sudan state, capital and transformation" Croom Helm in ssocaiation with Methuen Inc., 29 west $35^{\text {th }}$ street. New York, NY 10001.

Baumann, Pari (2000) "Sustainable livelihoods and political capital: Arguments and evidence from decentralization and natural resource management in India”, working paper 136, Overseas Development Institute, 111 Westminster Bridge Road, London SE1 7JD.

Bernstein, Henry, Ben Crow and Hazel Johnson (1992) Rural Livelihood Crises and Responses. Oxford University Press in association with the Open University.

Bhatnagar, B. and A. Williams (eds.) (1992) "Participatory Development and the World Bank: potential directions for change.” World Bank Discussion paper 183, Washington DC: World Bank.

Carney, Diana (1998) ed. “Sustainable rural livelihood: what contribution can we make?” Department for International Development's Natural resources advisers' conference, July 1998. ISBN: 1-86192-082-2

Carney, Diana et al. (1999) "Livelihoods approaches compared: A brief comparison of the livelihoods approaches of the UK Department for International Development (DFID), CARE, OXFAM and the United Nations.

Central Bureau of Statistics (2002) "Statistical year book for the year 2000”, Council of Ministers, Sudan Republic Khartoum 2002.

Chamber, R. (1978) Rural poverty-oriented Monitoring and Evaluation: simple is optimal? Rome, FAO. 
Chamber, R. (1983) "Rural Development: putting the last first.” Pearson Education Longman Ltd. Edinburgh Gate, Harlow, Essex CM20 2JE, England.

Chamber, R. (1992) Rural Appraisal: rapid, relaxed and participatory, Institute of Development Studies Discussion Paper No. 311, University of Sussex: IDS.

Chamber, R. (ed.) (1999) “Whose Reality Count? Putting The First Last”. IT Publications.

Chambers, R., Arnold Pacey and Ann Thrupp (eds.) (1989) "Farmer First: Farmer innovation and agricultural research.” Intermediate Technology publications. 103-105 Southampton Row, London WC1B 4HH, UK. ISBN UK paperback: 1853390070.

Cirillo, Richard R. (1982) "National energy planning for developing countries.” Centre for International Energy Development, Energy and Environmental Systems Division, Argonne National Laboratory.

Clancy, Joy S., Margaret Skutsch and Simon Batchelor (2003) "The gender - energy- poverty nexus: finding the energy to address gender concerns in development.” Prepared for DFID Project CNTR998521. http://www.sarpn.org.za/documents/d0000378/P342_Skutsch_Batchelor.pdf.

Clark, Wilson with David Howell and James K. Page, Jr. (175) 9 "Energy for survival: the alternative to extinction.” Anchor Press / Doubleday, Garden City, New York., ISBN: 0-358-03564-0.

Conyers, Diane (1993) “Guidelines on social analysis for rural area development and Planning.” Prepared for the training service policy analysis division, FAO, economic and social policy department.

Crawley, Heaven (1998) “Living up to the Empowerment Claim? The potential of PRA.” In: The Myth of Community, Guijt, Irene and Shah, Meera Kaul (eds.).

DFID (1999) “Sustainable livelihood guidance sheet.” By: Diana Carney with Michael Drinkwater and Tamara Rusinow (CARE) Koos Neefjes (Oxfam) Samir Wanmali and Naresh Singh (UNDP).

Duffield, Mark (1990) Sudan at the Crossroads, from emergency preparedness to social security. Institute for Development Studies Discussion paper No. 275.

Eisa, Eltayeb Idris (1997) Energy technologies for sustainable rural development. CYBER Economy Workshop Ministry of Finance and National Planning, Republic of Sudan.

El Gizouli, Ismail Abdel Rahim ( 1982) “Conventional energy supplies in Sudan.” In: Proceedings of the International Symposium on Energy Supply Management in Developing countries. United Nations: Department of Technical cooperation for Development, Natural Resources and Energy Division. Sophia Antipolis, France, 6-9 December 1982.

Ellis, Frank (2000), Rural Livelihoods and Diversity in developing Countries. OXFORD UNIVERSITY PRESS.

Eltigani, E. Eltigani (ed.) (1995) "War and drought in Sudan: essays on population displacement.” Gainesville: University Press of Florida.

Forest National Corporation (1995) Forest Product Consumption Survey in Sudan. Summary of Findings, Khartoum, Sudan.

Hann, Leo J. de (2002) “Livelihood locality and globalisation.” Nijmegen University Press, ISBN: 9057100886.

Harrison, M. N. and Jackson J. K. (1958) “Ecological classification of the vegetation in Sudan.” Ministry of Agriculture, forest department bulletin No. 29 Khartoum. 
Higher Council for Environment and Natural Resources (2003) "Sudan’s first national communications under the United Nations framework convention on climate change.” Ministry of Environment and Physical Development, Sudan Republic, Volume II, February 2003.

Holland, Jevery, and Blackbur, James (1998) “Whose Voice? Participatory research and policy changes.” IT publications.

Hoon, Parak and Goran Hyden (????) "Governance and Sustainable Livelihoods” http://www.undp.org/sl/publication/Govern.PDF.

Howes, Micheal (1985) "Rural Energy survey in the Third World, a critical review of issues and methods.” University of Sussex, U.K.

Ite, Uwem E (2005) "Poverty reduction in resource-rich developing countries: what have multinational corporations got to do with it?” Journal of International Development Vol. 17 No. 7 October 2005 pp 913-929.

JAM-Sudan (2005) "Synthesis framework for sustained peace, development and poverty eradication." March 18, 2005.

Jason, Leonard A. (2002) "Participatory community research: theories and methods in action.” American Psychological Association, 750 first street , NE. Washington DC 20002. ISBN: 1-59147-069-2

Long, Norman (2001) “Development sociology: actor perspective” Routledge, 11 New Fetter Lane, London EC4P 4EE ISBN: 0-415-23535-9 (hbk).

McDonald, P, R.A. Edwards and J.F.D. Greenhalgh (1981) “Animal nutrition.” Longman Publishing Group London (January 1981), ISBN-10: 0582443997 ISBN-13: 978-0582443990.

Mustafa, Mukhtar Ahmed and Ahmed Ali Mahadi (eds.) (2004) "Proceedings of the national forum for scientific research on desertification in Sudan”, UNESCO chair of desertification studies, University of Khartoum, Sudan, 16-18 / March 2004.

NEA (1985) “The national energy plan, 1985-2000.” National Energy Administration, Ministry of Energy and Mining, Khartoum, Republic of Sudan.

Newell, Peter (2000) “Governance and Sustainable Livelihoods” IDS, (rough draft for discussion: Feb 2000), www.livelihoods.org/info/docs/gov-new1.doc.

Niblock, Tim (1987) “Class and power in Sudan 1898 - 1985.” Macmillan Press Ltd. Houndmills, Basingstocke Hampshire.

North, D.C. (1990) “Institutions, Institutional Change and Economic Performance.” Cambridge: Cambridge University Press.

Oakley, P. et al. (1991) "Projects with People: the practice of participation in rural development." Geneva: ILO.

Pelto, Pertti J. and Gertel H. Pelto (1996) reprinted second edition "Anthropological research: the structure of inquiry.” Cambridge University Press, Cambridge, London New York Melbourne.

Pretty, Jules N, Irene Guijt, Ian Scoones and John Thompson (1995) “A trainer's guide for participatory learning and action.” IIED Participatory methodologies series, published by the International Institute for Environment and Development, London ISBN: 1899825002.

Proceedings International Workshop on Energy survey methodologies for developing countries. (1980) Jekll Island, Georgia National Academy Press: Washington DC. 
Saghayroun, Atif A, et al. (eds.) (1987) "Population and development in Sudan: the quest for a national policy.” Proceedings of the third population conference, October 10-14, 1987.

Sapsford R. and Jupp V. (eds.) (2006), Data Collection and Analysis (2nd edition). London: Sage Publications.

Sayed Nimeiri (1976) "The five year plan (1970-1975): Some aspects of the plan and its performance." Development Studies and Research Centre, Khartoum.

Slesser, Malcolm (1988) “Macmillan dictionary of energy.” Second edition 1988, Macmillan Press Ltd, London and Basingstoke.

Sudan Republic (1992) “The Comprehensive National Strategy 1992-2002” volume 1.

Todaro, Michael P. (1992) $3^{\text {rd }}$ edition "Economics for a developing world: An introduction to principles, problems and policies for development.” Pearson Education limited, Edinburgh Gate, Harlow.

UNDP - Area Development Scheme (1995) “Villages Profile Report 1995.” UNDP Khartoum April 1995.

UNDP (1987) “Strengthening energy planning and policy analysis capabilities.” United Nation Development Programme and the economic social commission for Asia and the Pacific august 1987. regional energy development programme (RAS/84/001).

UNDP (1988) "Brief of the country programme of the UNDP in Sudan (1988-1991).” Printed by Silv. S. Khartoum, Sudan May 1988.

UNDP/World Bank (1983) “Sudan: Issues and Options in the Energy Sector.” Report No. 4411-SU, Energy Sector Assessment Programme.

UNDP/World Bank (1987) “ESMAP-Sudan: wood energy/forestry project.” Energy Sector Management Assistance Programme (ESMAP), household energy division, energy department. The World bank, Washington D.C.

United Nations (1993) “Consolidated inter-agency appeal: Sudan.” Special Emergency Programme for the Horn of Africa (SEPHA).

World Bank (1979) “Sudan Agricultural Sector Survey.” Report No. 1836a-Su, May 18, 1979. the World Bank, Washington DC.

World Bank (1996) Technical paper no.307, “Toward participatory research.” By: Narayan Deepa. The World Bank, Washington DC, ISSN: 0253-7494; no 307.

World Bank Technical Paper No. 67 "Household Energy Hand Book: An interim guide and reference manual” www.unsudanig.org/docs/Joint\%20Assessment\%20Mission\%20(JAM)\%

20Volume\%20I.pdf.

Young, Helen, Abdul Monim Osman, Yacob Aklilu, Rebecca Dale,Babiker Badri, andAbdul Jabbar Abdullah Fuddle(2005) "Darfur - Livelihoods under Siege.” Feinstein International amine Center Friedman School of Nutrition Science and Policy, Tufts University, Medford, USA. 


\section{Summary}

This thesis is about rural energy services, the problems with accessibility and the consequences of their inaccessibility on rural livelihoods in the traditional rural areas of Sudan. The thesis is organised in six chapters. Chapter 1 starts by providing a background to the political and economic context of Sudan, and introduces the energy planning efforts made, so far, in Sudan. The chapter ends with formulating the research problem, the research objective and the research questions. It shows how traditional rural areas are excluded from the benefits of modern energy access because they are excluded at all stages of the energy planning process. Due to this exclusion, rural areas are not served by modern energy carriers (petroleum and electricity) and continue to draw their energy services from traditional energy carriers (wood, residues and animate sources). As a result, Sudanese rural areas suffer the consequences of negative livelihoods outcomes (displacement, civil unrest, war and many others hardships). The exclusion of rural areas from energy planning processes can be divided into two forms: spatial exclusion and methodological exclusion.

First, there is the spatial exclusion in not targeting certain areas for planning benefits. Clear distinctions have been made between the traditional and modern agricultural areas. All the planning efforts have been directed at servicing the modern agricultural areas and ignore serving the traditional areas. Justification for excluding the traditional rural areas is found in the views presented by planners, policymakers and international agencies (especially the World Bank) that the traditional sector has little or no contribution to make to the country's GDP, hard currency earnings, balance of payments or employment. Serving traditional areas, according to these views, will only increase the burden on the Sudanese economy, and no economic rewards could be expected from including the traditional sector. Given this background, the energy policies and plans in Sudan include no objectives that would serve the energy needs and interests of the traditional areas.

Second, there is also methodological exclusion in investigating problems related to energy planning. The country's energy data system is built in such a way that it excludes any possibility of rural problems being viewed or represented in the planning processes. This is because traditional energy sources, from which the rural population derives most of its energy needs, are simply ignored when building the energy data system. Further, even when rural energy issues are investigated through household surveys, the problem is reduced to one of cooking services. This research shows that, in the traditional rural areas of Sudan, cooking is not one of the critical energy services for rural livelihoods since households are able to obtain sufficient energy carriers to meet their basic needs. There are many other services that could contribute to the maintenance and sustainability of rural livelihoods and relieve rural areas of their vulnerability. These services are either non-existent because they require modern energy carriers for their provision (such as telecommunications) or they are insufficient because they continue to rely on human or animal power for their provision (transport of goods and people). In all the villages studied, water pumping for domestic and agriculture usage, refrigeration for the maintenance of medicines and antidotes for poisonous bites and stings, transport and communication were prioritised as the important energy services for sustaining rural livelihoods.

Chapter 2 of this thesis introduces the methodology adopted for this research. It introduces the livelihoods framework and the participation methods applied in this research for investigating energy services in traditional rural areas. The research method is intended to help identify problems related to rural energy services. Both the livelihoods framework and participation methods provide a holistic view of the problems related to energy services in rural areas. To avoid the reductionism that is part of household energy surveys, energy services is chosen as the unit of analysis, and the village is chosen as the unit of observation. In this way, the derivation of energy planning objectives that meet the needs and interests of the traditional rural areas becomes possible. To demonstrate the validity of this research method in a planning context, an investigation into types of energy 
problems found in traditional rural areas, as experienced by different population groups, was carried out in six villages representing different spatial, economic and ecological settings. Two villages were chosen from the Nile State - Dar Mali and Goz El Halag, two from El Gadarif State - Es Sadda and El Idied, and two from North Kordofan State - Um Laham and El Ga’a.

Chapter 3 elaborates on two components of the livelihoods framework: the vulnerability context and transforming structures and processes. These two components represent the wider contexts that shape livelihoods and have various influences on the flow of energy services. The section on the vulnerability context (shocks, seasonality and trends) shows that Sudanese rural areas are negatively affected by many factors such as civil conflicts and war, drought, flood, macroeconomic trends, population growth, climatic trends, and seasonality in the availability of goods and services and seasonal changes in their prices. All these factors were found to contribute to the negative livelihood outcomes prevalent in the traditional areas of Sudan. The section on transforming structures and processes, focusing particularly on those in the energy sector, shows that the exclusion of rural areas is maintained through the framework of organisations and institutions that formulate and implement energy policies and plans. There are no departments within the energy structures (energy institutions) that were set up to serve rural interests and needs, and so energy processes (policies and plans) fail to include any rural objectives. The overall result of the stresses imposed by the vulnerability context in rural Sudan and the lack of support from transforming structures and processes is that rural livelihoods witness frequent negative outcomes (civil unrest, displacement and loss of capitals).

Chapter 4 introduces the six villages included in this study, and presents selected results related to access to energy services and energy services priorities plus the main findings for each village. Within these six villages, different access to energy services is experienced by groups based on wealth, gender and age. As examples, poor families with limited access to financial capital have limited access to energy services generated by modern energy carriers, women and children do not attend clubs for entertainment and female pupils do not attend evening classes in schools. This differentiation in access to energy services suggests different sized energy service circles for groups identified by wealth, gender and age. Wealthier families have a larger energy circle than poor families, men have a larger energy circle than women and older people have a larger one than children. Further, the differences in these energy circles increase under factors of vulnerability. Poor families suffer most from vulnerability stresses on energy services and are sometimes forced to move to access the required energy services. Women and children, being responsible for the provision of energy services such as water and cooking, suffer the most negative impacts. These negative impacts include walking longer distances to obtain these services and exposure to health hazards linked to the provision of these services. Based on these differences in access to energy services, these various groups have different needs and priorities when it comes to energy services. It is important to consider these differences when planning energy services and interventions to avoid exclusion and ensure all groups participate in the benefits accruing from planning and intervention. The identification of the range of problems related to energy services and the representation of all the variations would not have been possible without using the livelihoods framework and participatory methods in investigating energy service planning in rural areas.

Chapter 5 provides an analytical comparison of the flow of energy services and the livelihood outcomes in the six villages. The comparison shows that different combinations of traditional and modern energy carriers are used to generate energy services in these villages. It also shows that the vulnerability context disrupts the flow of energy services to different extents in these villages depending on whether energy services are generated by modern or traditional energy carriers. Where traditional energy carriers dominate in the generation of energy services, disruptions in the flow of energy services are more frequent and more damaging, in the sense of interruption to the flow of services. In contrast, where modern carriers dominate, disruption in the flow of energy 
services is limited. This difference in energy service level, and consequently livelihoods outcomes, is due to the fact that traditional energy carriers are drawn from natural capital which is highly sensitive to factors of vulnerability such as drought and floods, whereas modern energy carriers are drawn from physical capital which is less sensitive to these factors. Thus, this comparison highlights the fact that planning an expansion in the use of modern energy carriers, as a replacement for traditional energy carriers, could help ensure the undisrupted flow of energy services and thus free rural areas of Sudan from frequent negative livelihood outcomes.

Chapter 6 draws together the main findings from the thesis and provides some recommendations concerning including the objectives of people in the traditional areas in the planning processes. The conclusion section shows how the flow of energy services in rural areas is frequently interrupted by stresses imposed by vulnerability context and that this is responsible for many of the negative livelihood outcomes in rural areas. This interruption in the flow of energy services is greatest in those villages that use a preponderance of traditional energy carriers, rather than modern ones, in generating their energy services. Planning that helped people in rural areas switch from using traditional energy carriers to modern ones would contribute to removing vulnerability stresses on energy services and improve livelihood outcomes. However, any such shift to modern energy carriers in rural areas is confronted with the poor functioning of the transforming structures and processes that formulate energy policies and plans. The second section of Chapter 6 provides some recommendations that would help the transforming structures and processes to include and plan for the use of modern energy carriers in rural areas to secure the flow of energy services and improve livelihood outcomes. These recommendations address both spatial and methodological exclusion in formulating energy policies and plans, and include:

- Change from shared kitchen to shared livelihoods as the unit of observation

- Adopt a broader view of energy services analysis

- Change from a fuel supply focus to a problem solving one

- Change from exclusion to inclusion of traditional economies

- Develop specific structures within energy institutions for rural energy services.

Finally, this research draws attention to the importance of considering the various livelihood modes when formulating national energy policies and plans in Sudan. These recommendations are designed to address the issue of identifying problems related to rural energy services through adopting the livelihoods framework and representing all rural groups in data collection through using participatory methods. 


\section{Summary in Dutch}

Dit proefschrift behandelt energievoorzieningen, problemen van toegang daartoe en de gevolgen van ontoegankelijkheid daarvan voor rurale huishoudingen in traditionele agrarische gebieden in Soedan. Het boek is ingedeeld in zes hoofdstukken. Hoofdstuk 1 geeft een achtergrond van de politieke en economische situatie van Soedan en geeft een inleiding van de inspanningen op het gebied van de energieplanning tot dusver in dat land. Het hoofdstuk eindigt met de formulering van een probleemstelling, het doel van het onderzoek en de onderzoeksvragen. Het toont aan dat rurale gebieden zijn buitengesloten van de voordelen van toegang tot moderne energievoorzieningen omdat deze gebieden in geen van de fasen van het energieplanning worden meegenomen. Vanwege deze uitsluiting krijgen rurale gebieden geen moderne energiedragers (petroleum producten en elektriciteit) en blijft de energievoorziening daar gebaseerd op traditionele energiedragers (hout, afval en spierkracht). Het gevolg hiervan is dat het platteland in Soedan te lijden heeft onder de gevolgen van negatieve levensomstandigheden (ontheemding, burgerlijke onrust, oorlog en vele andere zaken die het leven bemoeilijken). De uitsluiting van de rurale gebieden van energieplanning processen kent twee vormen: ruimtelijke uitsluiting en uitsluiting in de methodologie van energieplanning.

Ten eerste, ruimtelijke uitsluiting: dit houdt in dat bepaalde gebieden vanwege planning overwegingen niet worden meegenomen. Duidelijk onderscheid wordt hierbij gemaakt tussen traditionele en moderne gebieden. De hele planning is gericht op het bedienen van de moderne agrarische gebieden terwijl de traditionele agrarische sector wordt genegeerd. De rechtvaardiging hiervan is gebaseerd op de visies van de opstellers van de plannen, van beleidsmakers en van internationale instellingen (in het bijzonder van de Wereldbank), namelijk dat de traditionele sector geen, of nauwelijks enige, bijdrage levert aan het Bruto Nationaal Product van het land, aan inkomsten uit harde valuta, aan de in- en uitgaven balans of aan de werkgelegenheid. Het bedienen van die traditionele sector zal, volgens die visies, alleen de economie van Soedan verder belasten terwijl geen economische voordelen te verwachten zijn van het opnemen van de traditionele sector in het planningproces. Tegen deze achtergrond bevatten het energiebeleid en de energieplannen in Soedan geen doelstellingen die gunstig zouden zijn voor de energiebehoeften en belangen van de bevolking in de traditionele gebieden.

Ten tweede, bestaat er eveneens een methodologische uitsluiting in het vaststellen van problemen die verband houden met energieplanning. Het energie gegevensbestand van het land is zo samengesteld dat elke mogelijkheid om rurale problemen onder ogen te zien, of mee te nemen in de planningprocessen, is uitgesloten, omdat de traditionele energiebronnen, op grond waarvan de rurale bevolking grotendeels haar energievoorzieningen ontleend, eenvoudig.worden genegeerd wanneer energiegegevens worden verzameld. Bovendien, zelfs wanneer energiethema's van het platteland worden onderzocht via huishoudonderzoek dan wordt het probleem teruggebracht tot dat van koken alleen. Dit onderzoek laat zien dat in de traditionele rurale gebieden in Soedan koken niet één behoort tot de belangrijkste energiediensten voor de rurale huishoudens omdat die in staat zijn over voldoende energiedragers te beschikken om aan hun basis 
behoeften te voldoen. Er zijn veel andere voorzieningen die kunnen bijdragen aan het op peil houden en aan de duurzaamheid van plattelandhuishoudens en aan het verminderen van de kwetsbaarheid van het platteland. Die voorzieningen zijn echter of niet aanwezig, omdat zij moderne energiedragers vereisen (zoals telecommunicatie) of in onvoldoende mate aanwezig, omdat die voorzieningen afhankelijk blijven van menselijke of dierlijke spierkracht (zoals transport van goederen en mensen). In al de bestudeerde dorpen werden waterpompen voor huishoudelijk en agrarisch gebruik, koelkasten voor het bewaren van medicijnen en antistoffen tegen giftige beten en steken, en transport en communicatie als de meest belangrijke energievoorzieningen voor een duurzaam levensonderhoud op het platteland aangemerkt.

Hoofdstuk 2 van dit proefschrift beschrijft de methodologie die voor dit onderzoek is toegepast. Het introduceert het livelihoods framework (raamwerk voor de beschrijving van het levensonderhoud van huishoudens) en de participatieve onderzoeksmethoden die voor dit onderzoek zijn aangepast om de energievoorzieningen in traditionele rurale gebieden te onderzoeken. De onderzoeksmethode heeft tot doel de problemen die verband houden met rurale energievoorzieningen te helpen identificeren. Zowel het livelihoods framework als ook de participatieve methoden voorzien in een allesomvattende blik op zulke problemen. Ter voorkoming van een blikvernauwing, die optreedt bij energie onderzoek via huishoudens, zijn energievoorzieningen gekozen als eenheid van analyse en het dorp als eenheid van observatie. Op deze wijze wordt geprobeerd een energieplanning vorm te geven die beantwoordt aan de behoeften en belangen van de traditionele rurale bevolking. Om de geldigheid van deze onderzoeksmethode in de context van planning aan te tonen, werd een onderzoek verricht in zes dorpen die ieder verschillen in ruimtelijke, economische en ecologische condities. Twee dorpen, Dar Mali en Goz El Halag, liggen in de Nijlstaat; twee in de El Gadarifstaat, Es Sadda en El Idied; en twee in de staat Noord Kordofan, namelijk Um Laham en El Ga’a.

In hoofdstuk 3 worden twee componenten van het livelihoods framework uitgewerkt: de kwetsbaarheid door omgevingsfactoren en de structuren (instituten) en processen (beleid en plannen) die verandering bewerkstelligen. Deze twee componenten staan voor de bredere context die bepalend is voor het levensonderhoud en hebben verschillende invloed op de continuïteit van energievoorzieningen. De paragraaf over de kwetsbaarheid door omgevingsfactoren (schokken, als gevolg van grote gebeurtenissen, van seizoenen en van langdurige ontwikkelingen) laat zien dat het platteland van Soedan negatief wordt beïnvloed door conflicten en oorlogen tussen burgers, droogte, overstromingen, macroeconomische ontwikkelingen, bevolkingsgroei, klimaatontwikkelingen, en door de wisselende beschikbaarheid van goederen en diensten en prijsschommelingen als gevolg van seizoenontwikkelingen. Al deze factoren bleken bij te dragen aan de negatieve resultaten voor het levensonderhoud die het meest voorkomen in de traditionele gebieden van Soedan. De paragraaf over de structuren en processen die verandering bewerkstelligen, in het bijzonder die van belang zijn voor de energiesector, toont aan dat het uitsluiten van het platteland voort blijft duren vanwege de inrichting van organisaties en instituten die het energiebeleid en de energieplannen opstellen en uitvoeren. Er zijn geen afdelingen gericht op de behoeften en belangen van het platteland, en daarom wordt 
in de energieprocessen geen enkel rurale doelstelling opgenomen. Het resultaat van de druk het platteland van Soedan als gevolg van de kwetsbaarheid van de omgevingsfactoren en het ontbreken van steun van structuren en processen die verandering bewerkstelligen, is dat plattelandshuishoudens regelmatig negatieve gevolgen ondervinden, zoals onrust tussen burgers, ontheemding en verlies van kapitaal.

Hoofdstuk 4 introduceert de zes dorpen die in deze studie zijn opgenomen en presenteert geselecteerde resultaten die verband houden met toegang tot energievoorzieningen en de prioriteiten van energievoorzieningen als ook de belangrijkste bevindingen per dorp. In de bijlagen 1-6 worden meer gedetailleerde beschrijvingen per dorp gepresenteerd. In deze zes dorpen hebben groepen, die gedifferentieerd zijn naar rijkdom, geslacht en leeftijd, verschillende toegang tot energievoorzieningen. Bijvoorbeeld, arme gezinnen met een beperkte toegang tot financiële middelen hebben een beperkte toegang tot energievoorzieningen die worden opgewekt door moderne energiecarriers; vrouwen en kinderen nemen geen deel aan verenigingen voor ontspanning; en, meisjes volgen geen avondschool. De omvang van de voorraad en het niveau van de kwaliteit van energievoorzieningen op een bepaald moment in de tijd kan worden weergegeven door een cirkel waarvan de oppervlakte kan veranderen wanneer de beschikbare hoeveelheid aan kapitaalvormen toeneemt of afneemt. De variatie in toegang tot energiediensten voor groepen, ingedeeld naar rijkdom, geslacht en leeftijd, veronderstelt een verschillende omvang van de cirkels van energievoorzieningen voor elk van die groepen. Rijkere families hebben een grotere energiecirkel dan armere families, mannen een grotere energiecirkel dan vrouwen en oudere mensen een grotere dan kinderen. Verder blijkt dat de verschillen in omvang van de energiecirkels toeneemt als gevolg van de kwetsbaarheid factoren. Armere families lijden meer onder de druk van de omgevingsfactoren die de energievoorzieningen kwetsbaar maken en zijn daarom soms gedwongen te verhuizen om toegang te krijgen tot de vereiste energievoorzieningen. Vrouwen en kinderen, verantwoordelijk voor de beschikbaarheid van energievoorzieningen zoals water en koken, lijden het meest onder negatieve gevolgen. Deze negatieve gevolgen houden in: langere afstanden lopen om deze voorzieningen te verkrijgen en het bloot gesteld worden aan gezondheidsrisico's om over die voorzieningen te beschikken. Op basis van die verscheidenheid in toegang tot energievoorzieningen hebben deze verschillende groepen verschillende behoeften en prioriteiten als het gaat over energievoorzieningen. Het is van belang deze verschillen in beschouwing te nemen bij de planning van energievoorzieningen en bij het nemen van maatregelen ter voorkoming van uitsluiting en om er voor te zorgen dat alle groepen baat hebben bij de voordelen van de planning en van de maatregelen. Het vaststellen van de diverse problemen verbonden aan energievoorzieningen en het weergeven van alle variaties (met behulp van energiecirkels) zou niet mogelijk zijn geweest zonder gebruik van het livelihoods framework en de participatieve onderzoeksmethoden in de planning van energievoorzieningen voor het platteland.

Hoofdstuk 5 biedt een analytische vergelijking van de continuïteit van energievoorzieningen en van de resultaten van levensonderhoud in de zes dorpen. De vergelijking toont aan dat verschillende combinaties van traditionele en moderne energiedragers worden toegepast om energievoorzieningen op te wekken in deze dorpen. 
Het toont ook aan dat de kwetsbaarheid context die continuïteit van energievoorzieningen in verschillende mate onderbreekt, afhankelijk of die energievoorzieningen worden opgewekt door moderne of traditionele energiedragers. Daar waar traditionele energiedragers overheersen in de voorziening van energiediensten, zijn de onderbrekingen van de continuïteit van energievoorzieningen vaker en funester. In tegenstelling daarmee, daar waar moderne energiedragers overheersen blijft de onderbreking in de continuïteit van energievoorzieningen beperkt. Het verschil in niveau van energievoorziening, en als gevolg daarvan, in het verschil van de gevolgen voor levensonderhoud, wordt veroorzaakt doordat traditionele energiedragers worden ontleend aan natuurlijk kapitaal dat erg gevoelig is voor omgevingsfactoren van de kwetsbaarheid, zoals droogte en overstromingen; terwijl moderne energiedragers ontleend worden aan fysiek kapitaal dat minder gevoelig is voor die factoren. Deze vergelijking onderstreept daarom het feit dat een uitbreiding van de planning van het gebruik van moderne energiedragers, ter vervanging van de traditionele energiedragers, mee kan helpen aan het waarborgen van een ononderbroken continuïteit van energievoorzieningen en dus aan een bijdrage aan het vrijwaren van het platteland van Soedan van vaak voorkomende negatieve gevolgen voor levensonderhoud.

Hoofdstuk 6 brengt de belangrijkste bevindingen van dit proefschrift bijeen en biedt enkele aanbevelingen, verbandhoudend met het opnemen in de planningprocessen van de belangen en prioriteiten van de bevolking van het platteland. Planning die er op gericht is de plattelandsbevolking de overgang van traditionele naar moderne energiedragers te laten maken, helpt bij het verminderen van de druk van de kwetsbaarheid context op de energievoorzieningen en verbetert de levensomstandigheden. Echter, elke overgang naar moderne energiedragers op het platteland wordt geconfronteerd met een zwak functioneren van de structuren en processen gericht op verandering die het energiebeleid en de energieplannen moeten opstellen. De tweede paragraaf van Hoofdstuk 6 voorziet in enkele aanbevelingen die kunnen bijdragen aan het opnemen van het gebruik van moderne energiedragers op het platteland in de structuren en processen gericht op verandering, ter waarborging van de continuïteit van energievoorzieningen en ter verbetering van de levensomstandigheden. Deze aanbevelingen zijn zowel gericht op het ruimtelijk uitsluiten als ook op de methodologische uitsluiting bij het opstellen van het energiebeleid en de energieplannen, zij houden in:

- Verandering van 'gedeelde keuken' naar 'gedeeld levensonderhoud', als eenheid van observatie;

- Toepassing een brede visie op de analyse van energievoorzieningen;

- Verandering van een gerichtheid op brandstof voorziening naar een probleemoplossende kijk;

- Verandering van een uitsluiting van traditionele economieën naar een insluiting daarvan;

- Ontwikkeling van speciale structuren binnen de energie instituties voor rurale energievoorzieningen.

Ten slotte, dit onderzoek wijst op het belang om de diverse wijzen van levensonderhoud in beschouwing te nemen bij het opstellen van het nationale energiebeleid en de 
energieplannen in Soedan. Deze aanbevelingen zijn ontworpen om antwoord te geven op het thema van het identificeren van de problemen die verbonden zijn aan de rurale energievoorzieningen door een aangepast livelihoods framework en door de vertegenwoordiging van alle groepen op het platteland in het verzamelen van gegevens voor de energieplanning door het gebruikmaken van participatieve methoden. 


\section{Annex 1: \\ An analytical description of livelihood and energy services in the village of Es Sadda}

\subsection{Vulnerability context}

In Es Sadda, six kinds of vulnerability events are present: droughts, health shocks, floods, fire outbreaks, seasonality of goods and services, and the population trend, and their impact on livelihoods are identified.

\subsubsection{Drought}

Drought was identified by participants in this study as the most life-threatening factor for livelihoods in the village. The severe droughts mentioned were those of the years 1983/85, 1990 and 2000. The first drought extended over three successive seasons, 1983/1985, and affected large areas in Sudan. In the area of this village it affected livelihoods very severely. The serious shortage of drinking water and pasture led to the loss of large numbers of animals and the displacement of some village inhabitants. In fact, during these years, most people (about $95 \%$ of the village inhabitants) moved from the village to settle closer to sources of water: the Blue Nile, the River Atbara and the irrigation canals of the New Halfa agricultural schemes. However, the extent of displacement differed for each of the wealth categories. The very poor and some of the poor were displaced in the first year of the drought (1983), whereas the remaining groups only started to move in the years to follow when their initial wealth was exhausted.

In the later drought events, 1990 and 2000, there were fewer displaced families. The village participants in this study estimated that only 25 families were displaced in 2000, and these were from the very poor and poor groups. After the drought events, families started to come back to the village. Newcomers also started to arrive and settle in the village after they had lost all their animal wealth (financial capital) and this was the main reason given for their settlement. There were simply no more animals to follow, as one of those newly settled mentioned. Another reason for settlement was the need to register to receive the regular relief items (for example, food and medicine) distributed for villagers by the government and NGOs.

\subsubsection{Health shocks}

Health shocks are another sort of vulnerability. The serious health shock that is remembered to have had severe impacts was an outbreak of the plague in 1928, which caused a large number of deaths in the area. This event, although it has never been repeated, is still recalled by old women and men as the most serious health problem ever to have happened in the village. Due to the long time that has since passed it was difficult to trace any changes in the lives of the people as a result of that event.

Health problems that people in the village think are of greater importance nowadays are snake bites and scorpion stings during rainy seasons. During the rainy seasons these creatures come out of their normal hiding places in soil cracks and hide in the trees, shrubs, and grasses. Typically, four to six people in the village fall victims annually, particularly women and children who are responsible for working on farms, collecting wood and fetching water. The remoteness of the village to hospital services, difficult roads, and the high cost of transportation during rainy seasons further aggravate the severity of these problems. It is the lack of good health services in the village, the remoteness relative to city hospitals together with transportation difficulties that lift these health problems to within the major factors of vulnerability for the village community.

\subsubsection{Floods}

Floods occurred in 1988 and 2000. Their impact is reflected in the destruction of some family houses located close to streams and valleys, the loss of some animals in the flood water and also the blocking of transportation routes for a period of about two to three months.

\subsubsection{Fire Outbreaks}

A serious fire occurred in 1955, and destroyed vast areas of pasture and forest. This resulted in the clearance of the area where village inhabitants drew services such as animal grazing and firewood collection. Therefore, animals had to be moved away from the village to new pastures elsewhere, and 
women have to travel further to get wood.

\subsubsection{Seasonality of goods and services}

Seasonality refers to the common pattern affecting the prices and the flow of all services in the village. Figure 1.1 below shows examples of seasonal changes in the cost of water, the prices of animals and the cost of transportation. The availability and accessibility of water, food, fuelwood, transportation and health services change annually between the rainy and non-rainy seasons. Linked to these seasonal changes are the prices of good and services, which also change within the main seasons of the year. The price of water is out of phase with other prices. The cost of water drops to zero during a good rainy season, as people collect water from the streams running within the vicinity of the village, and starts to increase gradually after the rainy season when the streams begin to dry up and people start to buy water transported from other sources located outside the village.

The cost of transportation is expensive during the rainy season when ordinary transportation vehicles no longer run, leaving few transport options apart from some private cars which can be hired on a private basis. This affects all services obtained from outside the village. For example, when a family member falls victim to a snake bite, or in cases of problems related to a difficult pregnancy, the need is great to take patients to hospital as quickly as possible. In such cases, a lot of money is spent on transportation to get to health services in the hospitals. It was mentioned that a family is likely to spend about SDG 200 to 300 (€ $80-120)$ on transportation and medical services in New Halfa or Gedarif cities. This is equivalent to the price of two or three sheep, and equivalent to the amount needed for securing drinking water during the entire non-rainy season for an average family (5-7 persons) ${ }^{1}$. So, when such a health problem occurs, it degrades the family's financial capital, particularly for the poorer families. Sometimes poor families fail to secure such amounts of money and resort to traditional medicines which are less effective and risk the lives of patients.

As a result of increases in the cost of transportation, the price of delivered fuel also increases. For example, the cost of refilling a gas cylinder $(15 \mathrm{~kg})$ increases during the rainy season from SDG15 to SDG 20 ( $€ 6$ to 8). The price of refilling a gas cylinder at New Halfa is SDG 14 ( $€ 5.60$ ) and the difference reflects the cost of transportation to the village both before and during the rainy season. Fuelwood is also becoming harder to collect during the rainy season because the sticky soil makes transportation on donkeys or headloading quite difficult.

\subsubsection{Population trends}

As mentioned in the main text, the population of Es Sadda were originally nomads. The drought events that hit the area resulted in a loss of animals. Many families who lost their animals then lacked any reason to continue their travelling and so settled in the village. The village population increased from 15 families in mid-1980s to 92 families in 1995. The population has thus increased more than sixfold in ten years. This increase is having an effect on the available energy services, particularly the water service where there are more families using the same size of resources.

\footnotetext{
${ }^{1}$ These figures were obtained from a group discussion on the impacts of the lack of health services in the village.
} 
Figure 1.1

Seasonal calendar for Es Sadda: monthly changes in the price of animals, cost of water and cost of transportation as a proportion of the highest price recorded
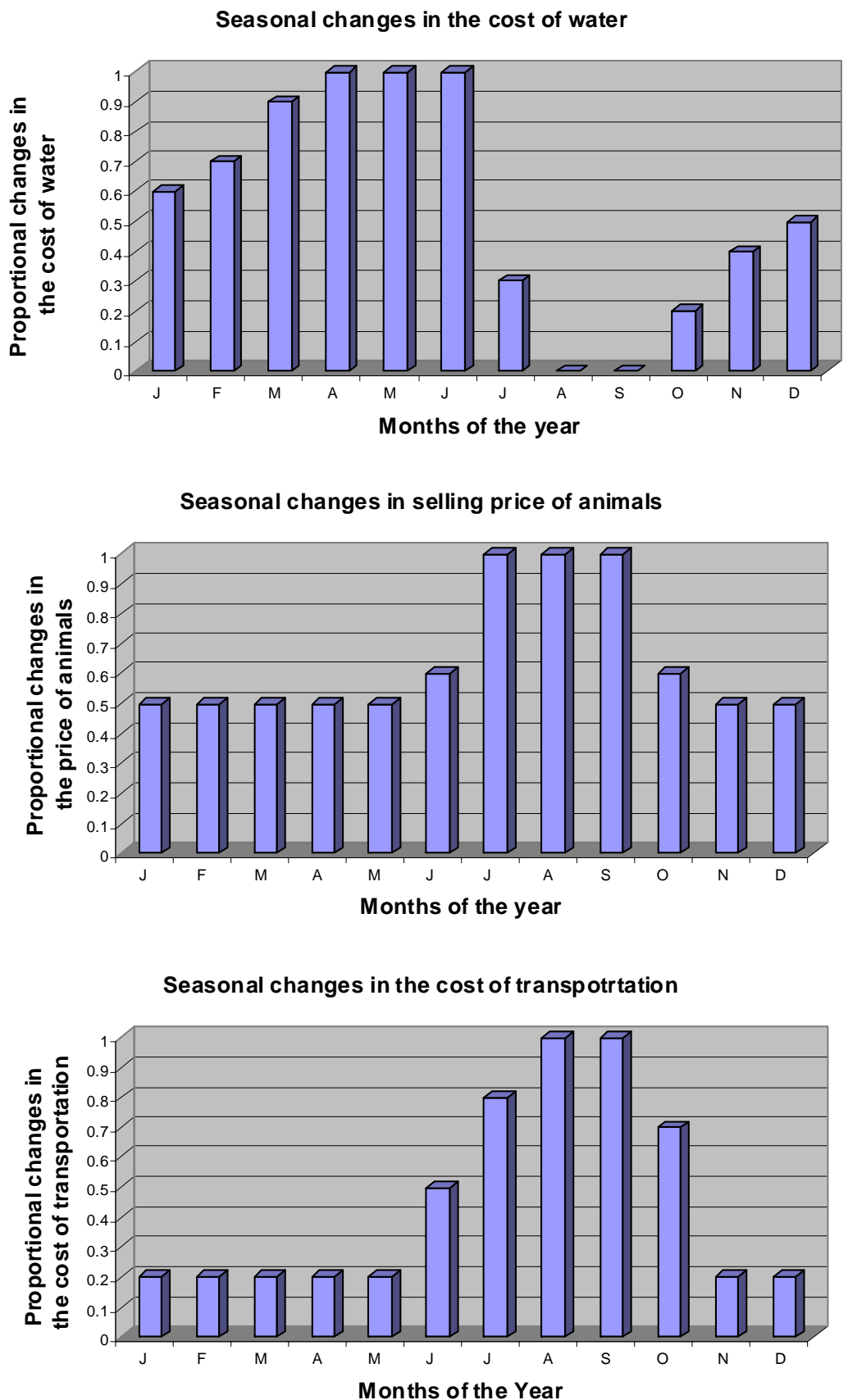

\subsection{Livelihood assets}

\subsubsection{Natural capital}

The most important components of natural capital in the village area are natural pastures, rains, seasonal streams and forests. The whole area lies in the semi-arid zone with annual rainfall ranging between 200 and $500 \mathrm{~mm}$, which arrives during the months of July to October. These rains are the most important factor in determining the availability of the other natural components. The short period of low rain intensity allows the growth of only short grasses and small shrubs. However, there are some forest areas mainly found in depressions and valleys (wadi). The nearest forest area to the village lies about $8 \mathrm{~km}$

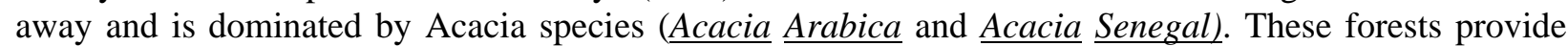
free access to firewood for cooking purposes.

So the rains are the most important component of the natural capital in the area as a source of water, and 
for which there are no local alternatives. This is mainly because the natural capital is deficient in underground water. An investigation by the National Rural Water Corporation (NRWC) showed that the lower layers are made up of Basement Complex and Basalt rocks, which have little water storage capacity (ADS Report 1998).

\subsubsection{Physical capital}

The forms of physical capital developed for use in the village include the two water reservoirs (haffir: see description below), a diesel pump, water tankers, water canals, the electrical generator, transportation and communication facilities, tools and buildings materials.

- Haffir: A haffir is a large earth basin excavated along a seasonal stream to store water for domestic use and animal watering after the rainy season is over. In good rainy seasons, these streams fill the haffir which is then capable of providing water for four to six months. Surface water is also harvested during the rainy season in earth reservoirs excavated on the sides of valleys and depressions where rainwater naturally collects. There are two haffir in the village. The volume stored in the haffir varies from 100 cubic metres to more than 50,000 cubic metres (see Photo 1.1) depending on the rainy season. Although the building of a third haffir would help to smoothe the water services in Es Sadda, it's the high cost of excavation and the technical works require present significant constraints ${ }^{2}$. Solutions for both constraints cannot be found within the village and require financial capital.

Photo 1.1

The haffir in Es Sadda

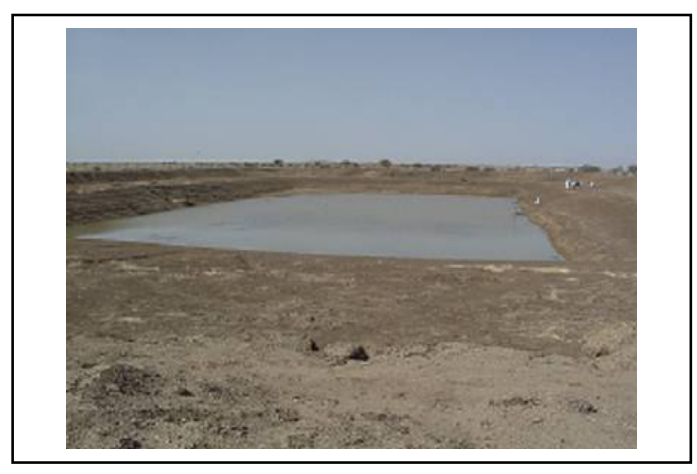

- Diesel pump: A diesel pump is installed in the haffir to pump water to a service point from which water is collected by users. The diesel pump is removed when the haffir is empty and kept in the village until the next rain season.

- The water canals: These are another type of physical capital accessed by the village inhabitants. The water canals are mainly used for irrigation in the New Halfa scheme. Since they are located about $40 \mathrm{~km}$ away from the village, drinking water has to be transported by tankers when the other sources of water (haffir) around the village are completely used up. Being located some distance from the village, access requires the availability of both labour and a means of transportation.

- Water tankers: Water tankers are used to transport water from the irrigation canals when the haffir is empty. The tankers are provided by the ADS project which serves all villages in the project area. Tankers are not available all the time but do visit the village twice a week to provide the village with water.

- The electrical generator: The village has an electrical generator which provides electricity to the village shops and the mosque. It is not used to supply village houses. The capacity of the generator is $5 \mathrm{KVA}$

\footnotetext{
${ }^{2}$ The cost of excavating one haffir is about SDG 1,200,000 (Euros 480,000) as shown by the zakat fund which established one of the ones now in use. The other difficulty is that the excavation of a haffir requires a thorough testing of soil for porosity and permeability to reduce the risk of water seepage and also requires land surveys to assess the slope of streams to excavate the haffir in a suitable location.
} 
which is more than these two services require and could be used to extend electricity to some houses in the village. However, people in the village see that they need to save the cost of electrical services in order to buy water in the dry season.

- Solar lighting system: There is a small system installed in the school composed of two modules (50 watts each) to illuminate two classrooms and two teachers' offices at night. They use the lighting system daily from $6 \mathrm{pm}$ to $10 \mathrm{pm}$ for pupils and teachers to review work and do their homework.

- Building materials: The majority of the village live in thatched huts (gutiya). The walls are made from unfired bricks (circular in shape) and the roofs are conical in shape made from grasses and crop residues. A 'house' is generally made up of several huts (2 to 5 ) surrounded by a dry grass fence. Fired bricks are only used in the school, the mosque and the health unit. Shops are made out of corrugated iron.

- Agricultural implements: The production tools and equipment are mainly the traditional hand tools (salaouka, maloud, toria) which are used to cultivate small plots around the village. However, mechanized ones such as harrows, levellers and threshers powered by tractors and combiner harvesters are also used by a small group of wealthy village families who have mechanised farms located away from the village.

- Bakery: In the village there is a bakery which uses firewood for making bread. it is privately-owned and sells its products to the village and to nearby villages.

- Grain mill: There is also a village grain mill. It is operated by a diesel engine and provides services to the village and to nearby villages.

- Transportation and communication facilities: The village is connected to the nearest cities by unpaved roads along which lorries transport people, goods and services. These roads are blocked during the rainy season. There are no telephone facilities in the village due to the lack of any coverage by a telephone network.

\subsubsection{Human capital}

Components of human capital in the village are represented by the facilities that build education, health, training and skills.

Education: In Es Sadda there are both formal and informal schools. There is an informal Kuranic School, Khalwa, and a formal one in the form of a mixed basic school ${ }^{3}$ (70 girls and 159 boys). The Kuranic School was established in 1918, along with the establishment of the village, and provides informal education and Islamic teaching. Formal education started in 1992 with the establishment of the mixed basic school. The community had started the procedure to build the school in 1972, but all their efforts prior to 1992 failed. The main reason was that, in nomadic areas, only boarding schools could have official approval. This was to be able to keep pupils in school while their families moved away following their animals. The approval of a boarding school was in turn conditioned by access to a reliable source of water inside or close to the village applying for a school. This condition could not be met in Es Sadda when they first applied. ${ }^{4}$. Later, approval for a school came as a result of the settlement in the village of enough people who should send their children to school. Pupils could stay with their families, so there was no need for a boarding school. Also, the commencement of the UNDP-funded ADS programme, which supported education, water and health services in all villages in the Butana area, increased the eligibility of the village community for its own school.

People in the village aged over 40 years are now either illiterate or have only had a khalwa education. This can be explained by the absence of a school in the village and the dominance of a nomadic lifestyle. Both made education unavailable for the older people when they were of school age. Moreover, khalwa education was only available to men. Women, thus, would receive no education at all until the

\footnotetext{
${ }^{3}$ Basic schools are the first level of education in Sudan, and they enrol children at the age of 7 years for six years of education.

${ }^{4}$ Yousif Shikeeri, the Educational Director in Es Subagh, interviewed 10th July 2002.
} 
establishment of the mixed basic school. During the period of this study, there were only two ladies who had completed secondary education. They are from the same extended family (the sheiek's) and are now employed as teachers in the school. Girls who studied in the village basic school, were traditionally not permitted to go for secondary education outside the village. For the first time, in 2001, five girls who had passed the final examination were allowed to study in Es Subagh secondary school, a boarding school where families have to contribute to the cost of staying in the school.

In the past, education in the village was limited by the nomadic style of livelihood, the unavailability of water, the lack of schools and the attitudes of the community, particularly towards women's education. Gradually, these factors have diminished and more opportunities for children's education, especially for girls, have become available. With the establishment of the school in the village, more children now receive primary basic education. At the time of this study, there are 229 pupils in the village school, 70 of them girls and 159 boys.

- Health services: In the village, minor health services are provided by a small dispensary established in 1973. It provides treatment for minor health problems, such as the treatment of wounds, and offers injections and medicines. It is staffed by a single health person 5 and it lacks storage facilities for medicines which have to be kept in wooden boxes at room temperature. Services for serious health problems are provided in one of the three rural hospitals in Gadarif and New Halfa.

- Training and skills: Before settling, all the families liked to train their children to be able to handle all aspects of animal raising, animal health and the skills necessary for their movement such as tent erection and packing their belongings on camels or oxen. All these are self-serving activities and not practised for income generation. On settling in the village, they felt the need for other skills, particularly in farm operations, that would provide opportunities for seasonal employment in agriculture schemes and so obtain cash income. Irrigation, weeding and cultivation are some of the jobs that men do in their seasonal migration to the irrigated schemes.

Other technical skills such as operation and maintenance of vehicles, diesel generators and diesel pumps and other machines are now developing in the village. These skills, however limited, provide a source of income for about 16 families in the village, mainly the drivers of cars and tractors. All these newly developed skills are exclusively men's. Women, on the other hand, maintain their traditional skills in farming, look after the animals left at home and milk them. However, women in the village do need to acquire new skills to deal with some newly-introduced household technologies such as LPG for cooking, and electrical appliances such as electrical lamps and TVs. Further, women also need to acquire new skills to increase their opportunities for income generation activities such as making clothes and sewing with electrical sewing machines.

\subsubsection{Social capital}

Two formal organisations are present in the village: the Village Popular Committee (VPC) established by the government, and the Village Development Committee (VDC) established by the ADS project. In the village, there are five sub-committees working under the above two main committees. These are the parents' educational council (responsible for education), the water sub-committee and the health subcommittee of the VPC, and the women sub-committee and youth sub-committee of the VDC. The subcommittees are responsible for the management and development of the services relevant to each of them. They determine needs for the development of these services and present them to the chairperson for action related to fund raising and contacting officials.

These committees are composed of equal numbers of representatives from the four small settlements. When forming a committee, each settlement is asked to forward the names of their representatives. As stipulated in the committee regulations, determined by the Constitution, at least $25 \%{ }^{6}$ of the membership

\footnotetext{
${ }^{5}$ A dispensary is a health unit in a small rural area which is smaller than a health centre and usually staffed by one nurse with fewer years of experience than the health assistant who is usually recruited for health centres as might be found in large rural areas.

6 The $25 \%$ of seats left to representatives of women and scientific professionals is granted by: The constitution Of The Republic Of Sudan, 1998: Chapter Two (The Federal Legislative Power) article 67-2-b (National Assembly)
} 
seats are left for women and other groups (Chapter 3). This formally ensures representation of women on the committees. However, in practice, only the chairman of these committees is active in carrying out the various committee affairs. He contacts the officials, submits applications for different government services and decides on priorities. Being the son of the sheiek means he is also the head of the informal, as the sheiek, of the village, so he holds both formal and informal positions. All these community organisations, formal and informal, play an important role in accessing resources, defining rights of use and keeping order within the community.

Some people in the village belong to formal organizations based outside the village such as the Teachers' Union which also offers some services such as financing the purchase of LPG equipment (such as gas cylinders and stoves) for repayment by instalments.

At the household level, the division between family members of the various tasks for the benefit of the whole family creates strong cohesion within the society. Family members are usually committed to meeting their family's needs. Remittances from members working outside the village, or generated through looking after a family's animal wealth plays an important role in meeting the family's basic needs particularly during times of severe vulnerability.

\subsubsection{Financial capital}

Family income in the village is gained mainly from animals raising and agriculture, plus some remittances and other sources as shown in Chapter 4 (Section 4.1.1). In performing such traditional activities there is little interaction with formal financial institutions by the village inhabitants. None of the participants in this study have ever dealt with banks or other formal financial institutions. The main reason is the lack of transferable assets that would be accepted as collateral by the banks. As we have seen, the personal wealth of the majority is in the form of animals. Land is a communal resource and bears no market value. Banks will not accept animal wealth as collateral. Another reason for the lack of use of formal financial institutions is the location of the banks, some distance from the village in the urban centres of Gedarif and New Halfa, which presents difficulties in dealing through banks particularly during the rainy season when transportation to these towns becomes difficult. Only the wealthy villagers who own large mechanized agricultural schemes have bank accounts and use banks to finance the purchase of tractors and agricultural implements. These accounts are sometimes used by other people working outside the village to transfer money to their families. Usually this is done without charge by the holder of the account, and the same amount of money as transferred will be given to the family concerned. Overall, the use of formal financial institutions like banks by people in the village is very limited.

Informal financing of goods for later payment involves of borrowing money from wealthy relatives and is limited to purchase. Remittances also make a considerable contribution to family incomes. There are 65 families, about $70 \%$ of all village families, who consider remittances (from internal or overseas migrants) as a significant part of their income. Another source of finance is the selling of animals. The animals commonly raised include sheep, cattle, camels, goats and donkeys. Usually families own a combination of animal types which serve different livelihood outcomes. Sheep, cattle and camels are considered as liquid assets, whereas goats are kept for their milk, and donkeys and camels for transportation and for carrying water. Animals are sold to meet financial obligations. to meet basic necessities and to invest in other income-generating opportunities. Some of the reasons for which animals are sold include:

- Securing cash to buy water for both animal and household use. Particularly, during years of poor rainfall and off-rainy seasons, large numbers of animals are sold to secure water.

- Obtaining health services.

- $\quad$ Buying clothes for the family.

- Buying food for the family during times of drought and low food production years.

and also by: The Interim Constitution Of Southern Sudan, 2005: Article: 58-1-b (Composition of assembly), article 112-3, (Establishment of the Council of Ministers) and article 168-6 (State organs).

http://www.sudan.net/government/constitution/english.html

http://www.cushcommunity.org/constitution.pdf (last reviewed 10 April 2007) 
- $\quad$ Paying education fees and expenses.

- $\quad$ Meeting financial needs of marriage.

- Meeting the costs of migration to countries in the Gulf to secure more income. When a family member finds work in these countries, all their travelling expenses and costs are met by selling animals.

\section{3 Energy services}

Important energy services, as identified by participants during PRA gathering, include cooking, lighting, provision of water, transportation and farm operations. For the provision of each service, different types of fuels and devices are used by different groups in various seasons of the year.

\subsubsection{Cooking}

In Es Sadda, different types of fuels and devices are used for cooking family meals. Types of fuels and devices used as well as groups that use them wereare summarised in Tables 4.1.2, 4.1.3 and 4.1.4.

Table 1.1 shows that seven types of fuels were identified for cooking, and six cooking stoves are used for cooking family meals. It shows that for each stove there are different types of fuel that can be used except with the kerosene and butogas stoves. The later two stoves use only kerosene and LPG respectively.

Table 1.1

Cooking stove and fuel type combinations used in Es Sadda

\begin{tabular}{|l|c|c|c|c|c|c|}
\hline $\begin{array}{c}\text { Types of } \\
\text { fuel }\end{array}$ & $\begin{array}{c}\text { Three- } \\
\text { stone stove }\end{array}$ & $\begin{array}{c}\text { Traditional } \\
\text { metal stove }\end{array}$ & $\begin{array}{c}\text { Improved } \\
\text { stove }\end{array}$ & $\begin{array}{c}\text { Mudwaya* } \\
\text { stove }\end{array}$ & $\begin{array}{c}\text { Kerosene } \\
\text { stove }\end{array}$ & $\begin{array}{c}\text { Butogas } \\
\text { stove }\end{array}$ \\
\hline Firewood & $\mathrm{X}$ & & & $\mathrm{X}$ & & \\
\hline Charcoal & & $\mathrm{X}$ & $\mathrm{X}$ & $\mathrm{X}$ & & \\
\hline Kerosene & & & & & $\mathrm{X}$ & \\
\hline LPG & & & & & & $\mathrm{X}$ \\
\hline $\begin{array}{l}\text { Animal } \\
\text { dung }\end{array}$ & $\mathrm{X}$ & $\mathrm{X}$ & & & & \\
\hline $\begin{array}{l}\text { Crop } \\
\text { residues }\end{array}$ & $\mathrm{X}$ & & & & & \\
\hline $\begin{array}{l}\text { Shrubs and } \\
\text { grasses }\end{array}$ & $\mathrm{X}$ & $\mathrm{X}$ & & & & \\
\hline
\end{tabular}

* Mudwaya is a local stove made of mud, grass and cow dung

Table 1.2 matches the fuel types used to family wealth groups. Natural capital provides the main fuel for the very poor families. They use firewood, crop residues, grasses, shrubs and cow dung which are collected without financial cost by women and children. However, three families that were classified as poor who also use some commercial types (Kerosene and LPG). The middle-income families combine both commercial (kerosene, charcoal and wood) and collected fuels (crop residues, shrubs and grasses). The higher income families, on the other hand, use only commercial fuel types such as kerosene, LPG, charcoal and wood. 
Table 1.2

Fuel types used by different family groups7 in Es Sadda

\begin{tabular}{|l|c|c|c|c|}
\hline \multicolumn{1}{|c|}{ Type of fuel } & $\begin{array}{c}\text { Wealthy } \\
\text { families }\end{array}$ & $\begin{array}{c}\text { Medium } \\
\text { families }\end{array}$ & $\begin{array}{c}\text { Poor } \\
\text { families }\end{array}$ & $\begin{array}{c}\text { Very poor } \\
\text { families }\end{array}$ \\
\hline $\begin{array}{l}\text { Firewood (commercial } \\
\text { and non-commercial) }\end{array}$ & $\mathrm{X}$ & $\mathrm{X}$ & $\mathrm{X}$ & $\mathrm{X}$ \\
\hline Charcoal & $\mathrm{X}$ & $\mathrm{X}$ & & \\
\hline Kerosene & $\mathrm{X}$ & $\mathrm{X}$ & $\mathrm{X}$ & \\
\hline LPG & $\mathrm{X}$ & $\mathrm{X}$ & $\mathrm{X}$ & \\
\hline Animal dung & & & $\mathrm{X}$ & $\mathrm{X}$ \\
\hline Crop residues & & $\mathrm{X}$ & $\mathrm{X}$ & $\mathrm{X}$ \\
\hline Shrubs and grasses & & $\mathrm{X}$ & $\mathrm{X}$ & $\mathrm{X}$ \\
\hline Cartoon and plastic bags & & & $\mathrm{X}$ & $\mathrm{X}$ \\
\hline
\end{tabular}

Table 1.3 shows the preference ranking of the stoves mentioned by fuel and stove type. Women in El Sadda have four preference criteria for fuel type: speed with which cooking is carried out (time to cook the meal), the convenience of using the devices (easy moving and handling and time needed to light it), the cost of the devices, and health aspects (risks during collection, injury, potential level of smoke). The preference criteria ranking of fuel types (preferred but not currently in use by most families) puts LPG first. Those who are not using it mentioned the costs of the gas cylinder and the gas stoves as too high for them to afford using it (at present there are 30 families using LPG for cooking who have purchased gas cylinders and stoves). All the women participants agreed that the price of a fuel and its availability, together with the family's income, were the main determinants of the fuel/device mix used by a family for cooking. However, as already mentioned, even within poor households there are three families using commercial fuels (LPG); and also families, which are considered wealthy, using only biomass fuels. Social capital plays an important role in enabling access to commercial fuels: the poor households using LPG have male family members working outside the village who purchased the LPG cylinder and stove as well as covering the costs of refilling the cylinder. Teachers' families are able to acquire LPG stoves and cylinders through the Teachers' Union which enables teachers to purchase the LPG equipment and pay in instalments. These wealthy households who still use biomass tend to come from the newly-settled nomadic families.

\footnotetext{
${ }^{7}$ The analysis in this table was made by the village participants in the study. First, all the fuel types used were listed then each wealth group was matched to the types of fuel commonly used by that group. This was confirmed by visits to households from each group to observe fuels types and devices used.
} 
Table 1.3

Criteria and preference ranking ${ }^{8}$ for fuel types used for cooking in Es Sadda

\begin{tabular}{|c|c|c|c|c|c|}
\hline $\begin{array}{l}\text { Fuel preference } \\
\text { Criteria }\end{array}$ & Wood & Charcoal & Animal dung & $\begin{array}{l}\text { Crop } \\
\text { residues }\end{array}$ & LPG \\
\hline Speed to light the fuel and cook the meal & 3 & 4 & 2 & 1 & 5 \\
\hline Handiness $^{9}$ & 3 & 4 & 1 & 2 & 5 \\
\hline Financial Cost & 3 & 2 & 4 & 5 & 1 \\
\hline Healthiness $^{10}$ & 3 & 4 & 1 & 2 & 5 \\
\hline Total scores & 12 & 14 & 8 & 10 & 16 \\
\hline Order & $3^{\text {rd }}$ & $2^{\text {nd }}$ & $5^{\text {th }}$ & $4^{\text {th }}$ & $1^{\mathrm{st}}$ \\
\hline
\end{tabular}

As shown from the above, traditional fuel types represent the major source of energy for cooking in the village however transition to modern fuels does occur. As components of the natural capital, the availability of traditional fuel types is affected by the factors of vulnerability prevalent in the area (drought, fire outbreaks and seasonality, see Section 1.1.1). These factors, in Es Sadda as elsewhere, affect fuel for cooking in three ways. The first impact on the availability of fuel types is linked to drought, when shrubs and grasses do not grow. Also animal dung and crop residues are not available because animals, the source of dung, move outside the area and crops, the source of residues, do not grow. Trees also become stressed but do continue to provide firewood from their dry branches and remain available during short periods of drought. The second impact is the seasonal changes in the availability of fuels which are physical capital components (kerosene and LPG). During the rainy season these fuel types are not available due to a lack of transportation to city centres from where these fuels are normally purchased. Families that use these types of modern fuels return to using firewood. This provides a source of financial capital for the poor who harvest this traditional type of fuel and sell it. So any intervention with modern energy carriers needs to consider those who base their livelihoods on supplying traditional fuel types. The third impact is specific to the group that collect and use firewood and shrubs (children and women who, during times of vulnerability, have to go further to collect these fuels and hence shoulder an additional burden in providing the cooking services for their families. Women and children also face the risk of being stung or bitten by scorpions and snakes when collecting fuel.

\subsubsection{Lighting}

Lighting inside households is usually limited to two or three hours after sunset. However, longer hours of lighting are occasionally needed, for example when a family has a new-born baby, a marriage or a funeral, or when a family has a child in the final class of basic school preparing for the final examination. On such occasions, extended times of lighting are needed. The common lighting devices found in households and the types of fuel used with these devices are listed in Table 1.4. Nearly all families, regardless of their wealth, use kerosene for lighting. This is because lighting uses small quantities which all families can afford to buy. Other types of fuel used for lighting include wood, animal dung and cooking oil.

\footnotetext{
${ }^{8}$ Twenty women from different groups participated in this process of ranking the various fuel types. They first developed criteria for use in ranking by listing the characteristics that women like or dislike in specific types of fuel. These criteria were grouped into four sets. The fuel the women felt was the best for a specific criterion was given a score of ' 5 '. The fuel that was the worst for a specific criterion was given a score of ' 1 '. The women's scores for each fuel criterion were summed to give a total score. These totals were then ranked. The fuel with the highest total was therefore considered to be the best for that particular criterion, and was ranked ' 1 st'. The fuel with the lowest total was considered to be the poorest for that particular criterion and ranked ' 5 ' '. The totals for each fuel were then added together, and this overall score was used to give the ranking order. The fuel with the highest overall score is the preferred fuel for cooking. Shrubs, grasses and plastic bags are used to start firewood and charcoal fires.

${ }^{9}$ Handiness refers to the effort exerted in preparation before using each fuel type. LPG for example needs no preparation before its use so gets a '5', charcoal needs relatively little effort to be lit and so gets a '4', wood needs to be collected and chopped into small pieces so it gets a ' 3 ', crop residues and animal dung need more effort in collection because they are scattered over wide areas, so they get ' 2 ' and ' 1 ' respectively.

${ }^{10}$ This criterion reflects the emission of smoke and smells during the use of the fuel. However, the word cleanliness may also be used to describe what the women mean by the Arabic word 'Sihi' which literally means 'healthy'.
} 
Table 1.4

Lighting devices and type of fuel used in Es Sadda

\begin{tabular}{|l|l|}
\hline Type of lamps & Type of fuel used \\
\hline Wick lamp & Kerosene \\
Kerosene lamp & Kerosene \\
Masraga $*$ & Oil \\
Candle & Wax \\
Kara** & Oil + camel dung \\
Kerosene lantern & Kerosene \\
Tugaba*** & Wood \\
\hline
\end{tabular}

* masraga is a wick lighting device fuelled by cooking oil

** kara burns camel dung co-fuelled with cooking oil

*** tugaba is a firewood plot lit in the ground inside the house

Lighting in the school is provided by a solar lighting system installed by the 'Solar School in Sudan' project in 2000. The system provides lighting for two classrooms and two offices and it allows both teachers and pupils to use the school in the evenings. Teachers prepare courses, review pupils' work and sometimes hold evening classes for their pupils. The pupils come to do their homework, review their classes, and study. However, it was observed that only boys living close to school actually attend during the evenings. Social norms do not allow girls and female teachers to go to the school in the evenings. The boys who are living further away from the school (from settlements located more than $2 \mathrm{~km}$ away) also do not go to the school in the evenings.

Khalwa education uses wood for lighting (Tugaba) as shown in Photo 1.2. Education in the khalwa is also limited to boys who live close by. This is because khalwa classes are held twice a day, once in the evening, which is too late for girls and boys living more than $2 \mathrm{~km}$ away, and another in the morning which is similarly too early for them. Walking in the darkness exposes children to risks of snake bites and scorpion stings.

Photo 1.2

Children studying in Khalwa using Tugaba as source of light in Es Sadda

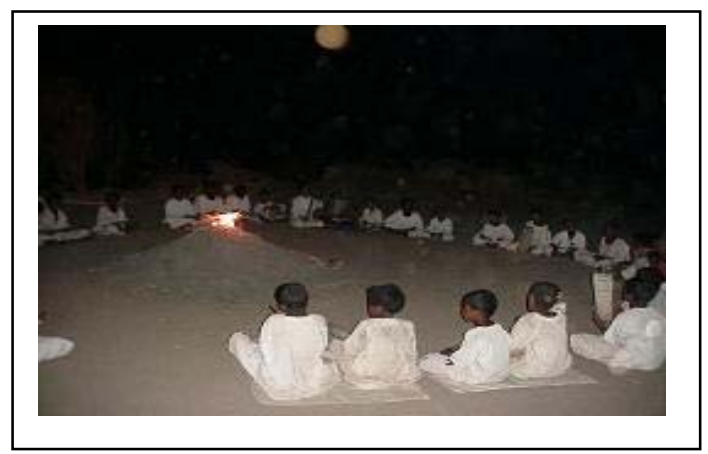

The mosque in the village is equipped with a solar system which operates a three-lamp lighting system (20 watt DC lamps) and an amplifier to call to prayers (azan). The lighting system is used during evening and early morning prayers.

Unlike fuels used for cooking, those for lighting are not so affected by the factors of vulnerability. As physical capital components, only the lack of transportation during the rainy season affects kerosene availability in the village. The solar lighting systems in the school and mosque are not affected by any of the factors of vulnerability.

\subsubsection{Water services}

As mentioned above, this form of natural capital has neither underground sources nor permanent streams from where water services can be pumped in this village. Accordingly, there is no irrigation and the only use of water is for household services (drinking, washing etc.) and for animal watering. The main sources are water harvested from rains and stored in haffir, used during the months of July to February, and, for 
the rest of year, water is obtained from the irrigation canals of the New Halfa irrigation scheme.

In the past, water was transported on camels and donkeys in containers made from animal skins (giraba). The journey to and from the canals takes 10-15 hours and involves more than one family member with two to four camels or donkeys. This approach is used to provide household needs for drinking water; animals on the other hand are moved to the source of water. However, some nomads with large herds own tankers to transport water to their animals in their normal grazing places. Further, these tanker owners sell water to villages close to their settlement. However, prices are as high as SDG 2.5 (€ 1) per barrel (approximately 180 litres) and an average family (5 to 7 family members) needs at least one barrel every two days. In 1992, the ADS project provided the community of the Central Butana area (which covers 23 villages including Es Sadda) with five large tankers to provide water at lower prices (SDG 1 (€ 0.4 )/barrel) to villages in need. However, these tankers are not always available when a village wants water. The Village Development Committee often makes a request and has to wait along with other villages for their turn. This is because each ADS tanker has to serve at least 4 villages in the project area $^{11}$. The tanker typically visits Es Sadda village once a week, but sometimes people in the village have to wait longer.

As outlined above, water is provided from different sources and uses various forms of energy during different seasons of the year. During the rainy season, when the haffir is filled, a diesel pump is used to pump water from the haffir to a service point. From there, the water is transported to the village on donkeys and camels, and sometimes using a barrel mounted on a two-wheel cart drawn by donkeys. When the haffir has emptied, people dig small shallow wells in the bottom of the haffir which provide water for another month. Water from these wells is extracted manually using a bucket and rope. When no further water can be extracted, large tankers transport water from the irrigation canals. Small petrol pumps are used to fill the tanks. Table 1.5 summarises the seasonal variations in sources and means of getting water in the village and the types of energy used in each season.

Table 1.5

Sources of water and the energy/technology mixes used in Es Sadda

\begin{tabular}{|l|l|l|l|}
\hline \multicolumn{1}{|c|}{ Months of the year } & \multicolumn{1}{|c|}{ July - January } & January - February & February - July \\
\hline Source of water & Reservoirs (haffir) & $\begin{array}{l}\text { Shallow wells inside } \\
\text { the reservoir }\end{array}$ & Irrigation canals \\
\hline $\begin{array}{l}\text { Means of water } \\
\text { pumping }\end{array}$ & Centrifugal pumps & $\begin{array}{l}\text { Manually by bucket } \\
\text { and rope }\end{array}$ & Centrifugal pump \\
\hline $\begin{array}{l}\text { Means of water } \\
\text { transportation }\end{array}$ & $\begin{array}{l}\text { Donkey drawn two- } \\
\text { wheel cart, or directly } \\
\text { loaded onto donkey's } \\
\text { back. }\end{array}$ & $\begin{array}{l}\text { Donkey drawn two- } \\
\text { wheel cart, or directly } \\
\text { loaded onto donkey's } \\
\text { back. }\end{array}$ & Tankers / lorries \\
\hline $\begin{array}{l}\text { Forms of energy used } \\
\text { in water pumping }\end{array}$ & Diesel & Human power & Petrol \\
\hline $\begin{array}{l}\text { Forms of energy used } \\
\text { in water } \\
\text { transportation }\end{array}$ & Animal draft & Animal draft & Diesel \\
\hline
\end{tabular}

\footnotetext{
${ }^{11}$ The ADS project covers the central Butana area which is composed of 23 villages. The villages are dispersed over a wide area and typically about 20 to $30 \mathrm{~km}$ from each other. The ADS project HQ is located in El Subagh and arranges its development services through the VDC of each village.
} 
Water is stored in pots and barrels inside the houses, or in large tanks and troughs outside. Tanks and troughs are used when a large quantity of water is needed for building or during social occasions (marriage festivals for example). Also two of the wealthy families use large containers to store about 50 barrels worth of water, and that is enough to meet their needs for one to two weeks (see Photo 1.3).

\section{Photo 1.3 \\ Water storage tank outside a household}

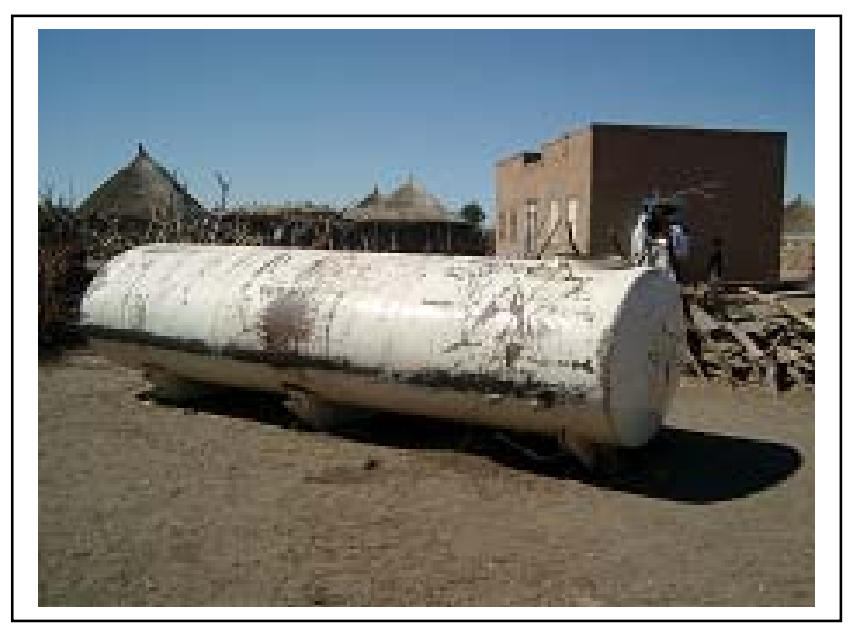

\subsubsection{Transportation and communication}

Transportation of people, water and other goods and services in Es Sadda is done using a variety of means. Transportation of people in the village depends on draft animals (donkeys and camels) for short distances between villages, and these animals are also used for transporting water from haffir or the canal. For long distances to urban centres, privately-owned cars provide transportation services. There is a truck road passing through the village connecting New Halfa to Es Subagh and beyond to Khartoum. Vehicle, trucks and buses are always passing by (except during the rainy season when the road is blocked). In the village, three people own private cars, which are also available for hiring. The availability and use of transportation is highly seasonal and affected by the rainy season as mentioned before with respect to other services, as can be seen for example with water transportation (Table 1.5). Telecommunications in the village are absent since the telephone network does not cover the area. For telephone communication people travel to other villages located within the network coverage, closer to New Halfa.

\subsubsection{Farm operations}

Agricultural production is limited to a period of three to four months during the rainy season. All the operations involved in subsistence agriculture are carried out manually. Some agricultural operations are mechanised on large farms, although only nine families own mechanised farms. Tools, implements and the type of energy used in agricultural operations in both subsistence and mechanized farming are summarised in Table 1.6. 
Table 1.6

Tools and implements used in agricultural operations in Es Sadda

\begin{tabular}{|l|l|l|l|l|l|l|}
\hline \multicolumn{1}{|c|}{$\begin{array}{c}\text { Size of plot } \\
\text { (feddans) }\end{array}$} & \multicolumn{1}{|c|}{ Ploughing } & \multicolumn{1}{|c|}{ Sowing } & Weeding & Harvesting & Threshing & $\begin{array}{l}\text { Purpose of } \\
\text { Production }\end{array}$ \\
\hline $2-10$ & Not ploughed & Hand tools & $\begin{array}{l}\text { Hand } \\
\text { tools }\end{array}$ & Hand tools & Hand tools & Subsistence \\
\hline $10-20$ & Tractors & $\begin{array}{l}\text { Hand tools }+ \\
\text { tractors }\end{array}$ & $\begin{array}{l}\text { Hand } \\
\text { tools }\end{array}$ & Hand tools & $\begin{array}{l}\text { Hand tools } \\
\text { combine } \\
\text { harvester }\end{array}$ & Subsistence \\
\hline $20-50$ & Tractors & $\begin{array}{l}\text { Tractors } \\
\text { +hand tools }\end{array}$ & Tractors & Hand tools & $\begin{array}{l}\text { Combine } \\
\text { harvester }\end{array}$ & Market \\
\hline$>50$ & Tractors & Tractors & Tractors & Hand tools & $\begin{array}{l}\text { Combine } \\
\text { harvester }\end{array}$ & Market \\
\hline $\begin{array}{l}\text { Period of } \\
\text { activity }\end{array}$ & June & July & August & Oct. - Nov. & Oct. - Dec. & \\
\hline
\end{tabular}

In subsistence farming, all the operations are done manually in small plots of 2 to 10 feddans, whereas tractors are used for ploughing in areas larger than 10 feddans. Combine harvesters are used in areas larger than 20 feddans.

Agricultural production is closely tied to the rainy season and other vulnerability factors. Early rains enable crops to reach maturity, provide earlier opportunities to carry out land preparation and other operations, and raise expectations of high production. Accordingly, a large input of family labour is required in subsistence farming in order to cultivate the largest possible land area in a short period. In mechanized farming, tractors allow the preparation of a large piece of land also in a short period. In poor or late rainy seasons, agricultural production is risky because crops may not reach maturity or mature late (November- December) during a time of increasing crop pests and diseases (birds, rats and insects). People in the village evaluate their likelihood of having a successful season in early August. If there are signs of a good rainy season, intensive effort is put into subsistence farming, otherwise male family members migrate to compensate for the loss of food (vulnerability increased by a decrease in natural capital) by earning cash (financial capital). In mechanized farming, a poor rainy season increases the risk of crop losses and the high cost of land preparation may not be recovered. In such situations, tractors will be sent to other areas, where there are good rains, to be hired out to other farmers. In this way, physical capital is converted into financial capital to reduce vulnerability. When periods of low rain extend into droughts, food production stops completely and vulnerability increases.

\subsubsection{Non-farm operations}

Non-farm activities cover small income-generating activities other than agricultural practices. In Es Sadda, these include the small-scale trade in shops, the bakery, the grain mill and the milk products when animals are still around. Small shops provide goods and services for the people in the village and open in the evening up to $8 \mathrm{pm}$. The only energy service used is lighting which runs on electricity from a local generator. A bakery in the village uses firewood to bake bread and sells it in the village. The amount of wood used is small, less than a donkey load per day. The wood for the bakery is bought from the surrounding forest by some groups from the village who sell it. During the rainy season, firewood becomes difficult to collect. The grain mill and the generator in the village are run on diesel fuel and factors of vulnerability have a high impact on the fuels' availability as the roads to the cities from where the diesel fuel is obtained are usually blocked during the rainy season.

\footnotetext{
12 The feddan is a measurement of agricultural land and equal to 4200 square metres or 0.42 hectares.
} 


\section{4 Transforming structures and processes}

In Es Sadda, the participants ${ }^{13}$ identified the role of government as the collection of taxes on crops, animals and houses. Their role in developing energy services is quite limited. All the energy services in the village were either built by the people themselves or by NGOs, charity and international organizations. An NGO built the lighting system for the school (SFM), a charity organization (the Zakat fund) built a haffir and an international development organization (UNDP-ADS) built another haffir. However, the National Rural Water Corporation (NRWC) does participate in the operation and maintenance of the haffir. NRWC collects half of the water fees paid by consumers cover maintenance costs. The maintenance of the water tankers. which were provided by the ADS project. to serve all Butan villages (23 in total) was originally carried out by the ADS project, but when the project ended in 2003, the responsibility for maintaining and managing the tankers was moved to the VDCs in the villages involved in the project. Collectively, these village VDCs formed a water committee to charge water fees and take care of running the tankers.

The role of the market in providing village energy services is also limited. Some of the small shops in the village providing consumer goods also sell kerosene but no other services are present in the village market place. Two reasons can explain this minimal role of the market in the provision of energy services. The first is the limited financial capital in the village. As was shown in Section 4.1, about half of the village population come within the poor and very poor groups. With such a large percentage of households being unable to afford modern energy services, the private sector is unlikely to see Es Sada as an attractive market in which to provide energy services on a commercial basis and make profits. The second reason is the seasonal blockage of the roads from the cities to the village during the rainy season. This makes the village unreachable for three to four months a year, which also does not encourage private businesses to develop a market for energy services in the village.

\footnotetext{
${ }^{13}$ In addition to the village participants, data for this section were obtained from officials in the education, water and health offices and from the ADS project.
} 


\section{Annex 2: An analytical description of livelihood and energy services in El Idied}

\subsection{Vulnerability context}

In El Idied, five factors of vulnerability were identified: droughts, health shocks, seasonality, pests and diseases of animals and crops, and population trends. Events linked to these vulnerabilities vary in their timing and frequency of occurrence, and in the impacts they make on different groups.

\subsubsection{Drought}

Drought events ${ }^{14}$ hit the village in 1983/85, 1990 and 2000 and resulted in negative impacts on livelihoods. The impact of the first drought on livelihoods was very serious because there was no rain for three successive years. In those years, there were no rains to allow growth of food crops, no pastures for animal to graze and essentially no water for human and animal uses. As a coping strategy, the affected people moved to areas where water could be obtained and work could be found, along the Blue Nile, the Atbara River and to irrigated schemes, where they could avail themselves of water and buy food. According to the village participants in this study, all except two families in the village were displaced during that drought. Many families entered into poverty through losing their animals, which is the main source of wealth, and through losing employment in the mechanized schemes ${ }^{15}$.

The effects of the second and third drought events, in 1990 and 2000, were less serious and the impacts were restricted to an increase in food prices and a drop in animal prices, which negatively affected financial capital. For example, people from the village mentioned that a family had to sell two sheep to buy one sack of grain whereas, in normal years, the price of one sheep is sufficient to buy three sacks of grain. Also, in these years, animal owners had to sell about one-quarter of their animals to be able to buy water and fodder for the rest. The later droughts events were less serious than the earlier one for three reasons. Firstly, the period of drought was shorter, and there has not been two successive seasons with no rainfall since 1983/85. Second, during these droughts, ADS was operating in the area and supported the provision of water using water tankers (see earlier in the Es Sadda case summary). This water service was not available during the earlier drought event. Third, there was an increase in physical assets in the form of shallow hand dug wells and a new haffir. Because of these three reasons, there were no cases of displacement from the village, and families were able to absorb the shocks of the later drought events.

\subsubsection{Health shocks}

Generally there are no serious health problems affecting the people of El Idied as a whole. The most serious threat is snake bites during the rainy season for which an antidote is not locally available due to the lack of cooling devices required to store it. The village health centre is sufficiently equipped to deal with many common illnesses and accidents. However, the most serious health problems occur during the rainy season and they cannot be dealt with in the health centre. The patient then needs to be transported to El Gedarif city hospital located about $50 \mathrm{~km}$ from the village. During the rainy seasons roads are washed away making transportation extremely difficult and costly. Hiring a private car, or even a tractor, to Gedarif, which are the only options for such distances might cost between SDG50 to SDG100 (€ 20 to 40).

\subsubsection{Seasonality}

Access to all services varies with season of the year. The most important concerns the availability of water for both human and animal use. During the rainy season (July to October) water is collected in natural ponds and running streams from which the village haffir is filled. The prices of animals follow the same seasonal pattern that was found in the previous case of Es Sadda. Other services such as employment and income opportunities also vary seasonally. However, in normal years of rain fall,

\footnotetext{
${ }^{14}$ Drought is defined locally as a year in which there are not enough rains to enable crops to mature, to enable the growth of pasture and to provide enough water for human and animal uses. In the year noted, these three characteristics of drought were witnessed by the village population.

${ }^{15}$ The mechanized schemes are based on rain-fed agriculture and, during these years of drought, there was not enough rain to cultivate these schemes and, as a result, working opportunities provided by these schemes were also lost.
} 


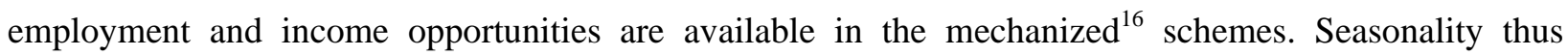
changes the availability of pasture, the availability of water, the purchase prices of goods and services and the selling prices of animals in much the same way as in Es Sadda.

\subsubsection{Animal and crop pests and diseases}

Animal and crop pest and diseases cause serious harm to people's wealth (reduce their financial capital). Diseases that have infected sheep and cows include rinder pest, which witnessed widespread outbreaks in 1988 and 1998, and scabies which infected camels and donkeys in 2001. The outbreak of animal diseases affects livelihoods in two connected ways. The first impact results from the reduced demand for animals from the area, particularly by animal exporters who immediately stop buying animals from the infected area. Thus the prices of animals drop sharply to less than half the usual prices. Owners need to sell some of their animals to buy medicines and curing treatments. Diseases also cause the death of a large number of animals which directly reduces the wealth of households.

Crop pests and diseases can also occur on a large scale and affect the harvest. Locusts have the most destructive impacts on crops; and a large infestation occurred in 1999. The year 2000 also witnessed rat, locust and insect infestations. Infestations regularly occur in some parts of the area, but the years 1999 and 2000 were unusual in showing large destruction of farm crops.

\subsubsection{Population trends}

As in Es Sadda, population trends in El Idied show new settlements of nomads who lost their animals during the droughts. As mentioned in Chapter 4 (Section 4.1.1), the population of the village increased from 6 families in 1964 to 251 families in 2004. Further, the village population is seasonally increased by nomads who stay in the village area with their animals from January to July. Also, during the rainy season, seasonal workers in the mechanized schemes increase the number of people obtaining energy services from the village.

\subsection{Livelihood assets}

\subsubsection{Natural Capital}

The main components of the natural capital are the rain water, the land that is available for rain-fed agriculture and natural pasture and the forest area. Rainfall ranges annually between $200 \mathrm{~mm}$ and $500 \mathrm{~mm}$ which is sufficient to grow grasses on which animals can graze and support short-season crops. The soil is typically clay, which cracks in the dry season and become very sticky with rain. It is, however, highly fertile soil suitable for the growth of pasture grass and crops. The landscape includes valleys and seasonal streams which eventually drain into the Blue Nile and Atbara rivers. Seasonal streams cross the area and run during the entire rainy season providing water for animal and human uses. However the valleys, when filled with water, make transportation difficult, and lorries and trucks cannot cross them during the rainy season.

The village is surrounded by forests composed of acacia trees. However, the expansion of the mechanized agriculture schemes has diminished the forests to a strip approximately six kilometres long separating El Idied from the mechanized schemes. Another natural feature is a low hilly area. At the foot of these hills, water collects in natural ponds, which last for about two months after the rainy season ends. In addition, this replenishes the shallow underground layers which store some water.

\subsubsection{Physical Capital}

Various forms of physical capital are to be found in the village, including: hand-dug wells, the haffir, an electrical generator, a grain mill and a bakery, building materials, agricultural tools and implements, and transportation and communication facilities.

- Hand-dug wells: The first and oldest form of physical capital in the village is the shallow hand-dug

\footnotetext{
${ }^{16}$ These schemes are not fully mechanized and still involve some work, such as weeding, harvesting and clearing of crop residues which is done manually and requires manual labourers. These tasks provide seasonal jobs and income for labourers from the village and from wider area.
} 
wells established close to the village at the foot of the hills. These wells are seasonally replenished by the rains and also by water that collects at the foot of the hill. The depth of these wells range from 18 to 20 metres.

- Haffir: The haffir is similar in shape and size to that in Es Sadda and was built in 1995 by an ADS project with a contribution from the village in the form of labour. It is located along a running stream at a distance of about 4 kilometres from the village.

- Water tankers: As in Es Sadda, El Idied also use the tankers that were provided by the ADS project to meet their water needs when there is lack of water from the above-mentioned local sources in poor rainy seasons. Water tankers are used to transport water from a water pumping system close to El Gedarif. They are mainly used after local sources of water have been depleted.

- Electrical generator: The village has an electrical generator and has installed a mini-grid in the village. Electricity was extended to all houses in the village and to social service centres such as the school, the health centre and the youth club.

- Agricultural implements: The production tools and equipment include traditional hand tools (salaouka, maloud, toria) and mechanized ones such as harrows, levellers and threshers powered by tractors and combiner harvesters. In 1995, a cooperative was formed in the village to buy a tractor and implements to work the small subsistence plots. The village cooperative committee owns one tractor with all the implements necessary for the agricultural operations. Wealthy families in the village can also hire machinery from the mechanized schemes for agricultural operations, usually after these operations in the mechanized schemes are completed. Mechanization allows fast land preparation and agricultural use of larger areas than could be done manually. This ability to prepare quickly is important since the rainy season is short (July to October), and crops sown late might not reach maturity.

- Building materials: Family houses, as part of the physical capital, are generally thatched-huts (gutya) which have a circular form with a conical roof. The wall is made of unfired bricks and stones, and the roof is made of grass and crop residues. The buildings of service centres (school, health centre, the mosques and the grain mill) are made from fired bricks, rocks and cement.

\section{- Market:}

The village has four shops which serve the village population with needed goods (cooking oil, kerosene, sugar, tea, coffee and the like). The shops also service the workers of the mechanized schemes during the rainy season when workers come from other areas for work. Supplies for the village are obtained from El Gedarif.

- The bakery: There is also the village bakery, as part of its physical capital, which serves the village and the workers from the mechanized schemes. The bakery uses firewood which is collected from the nearby forest.

Transportation and communication facilities: The village is connected through unpaved roads to the cities of El Gedarif and New Halfa. The villagers use the lories that pass the through village to transport people, goods and services. Lorries usually stop running during the rainy season when roads are blocked by the running streams. However, the tractors which are available for mechanized agriculture are also used occasionally as transport to El Gedarif.

\subsubsection{Human capital}

- Education: The school was established in 1957 as a nomadic school, and then later raised to a basic school. However, the level of educational is defined by the ADS project as low.

- Health services: Health services are obtained from the health centre located in El Idied. However it is not able to deal with all cases, and serious problems need to be referred to the hospital in El Gedarif. Accessibility to hospital services is greatly affected by the state of transportation, and is difficult during the rainy season. The health centre is not equipped with a refrigerator in which antidotes to snake and scorpion poisons could be stored and vaccination services could be offered regularly to children. Many of 
the difficulties in getting such health services could be solved by having a refrigerator in the health centre and arranging with the health authority at the State level to obtain these medicines before the rainy season starts. This would avoid expensive travel to the city to get these health services.

- Training and skills: Basically, life skills and training are confined to animal husbandry, animal treatment and traditional agricultural operations. New technical skills are obtained during employment on the mechanized schemes, such as driving and operating the various types of mechanical equipment. Such training and skill acquisition is exclusive to men. Women, on the other hand, have skills such as weaving and making milk products (sour milk, butter and ghee). However, these activities are only seasonally carried out when animals are available around the village. However, there are also potential sources of income through serving the workers in the mechanized schemes with some of their food needs provided energy is made available and training is directed towards building women's skills and hence financial capital. Women in the village have received training by the ADS project in infant and maternal health care and nutrition. There were two courses held on these issues for women in 2000. Also, one woman has been trained as a midwife for pregnancy check ups and deliveries.

\subsubsection{Social capital}

People in the village are connected through various forms of organizations, both formal and informal. The formal side includes the VPC and the VDC; and the informal is represented by sheieks and local organizations such as the youth association and the women's association. Further, other forms of social capital, such as family ties and reciprocity, are also present.

The VPC is the formal political body at the village level. Its role is confined to political mobilization, and it acts as the liaison body for official communications with government offices. The VPC is divided into an educational council, a water committee and a women's committee. The other formal organization is the VDC which was established by the UNDP ADS project. The VDC is divided into a grain mill committee, the show club committee and the cooperative committee. These committees are responsible for providing services in their respective fields. The grain mill committee is responsible for keeping the grain mill running, such as the provision of diesel fuel, spare parts, hiring the operator, deciding on the fees to be paid by users and keeping the financial records to present to the VDC. The show club committee is responsible for maintaining the club's equipment (TVs, tables, chairs, etc.). The cooperative committee has broader objectives including running the tractor, providing loans to the village farmers and supporting other development activities. However, at the time of this investigation, the cooperative committee in reality is only running the tractor.

Informal organizations are represented by the Shiakha committee and the mosque committee. They have the responsibility to run and upkeep the services entrusted to them by the people in the village. The Shiakha committee, for example, is responsible for allocating land among the population for agriculture, and it mediates in conflicts which arise between members due to animals trespassing and damaging crops. Here, the task of the Shiakha committee is to determine the value and the compensation for crop damage. The mosque committee, on the other hand, is mainly responsible for the rehabilitation of the mosques building and renewing its furniture.

Extended family ties, as part of the social capital, play an important role in accessing livelihood assets. A clear example is the extension of the mini-grid to all houses. The poor families who could not pay for the necessary materials, or pay the monthly fees, were helped by their relatives inside and outside the village to get connected and use the electrical services. Another form of social capital is reciprocity which, in El Idied, takes the form of communal assistance (nafeer) to a member facing difficulties,, such as sickness during the cultivation period. In such cases the whole community offers free help to cultivate the sick person's land.

\subsubsection{Financial capital}

The use and benefits accrued from financial institutions such as banks is limited. The main reason is the lack of transferable assets acceptable as collateral by banks. Wealth is generally in the form of animals which the banks do not accept as a basis on which to offer loans. Another reason is the location of banks at some distance from the village in urban centres (Gedarif and New Halfa) which would present some difficulty in dealing through banks, particularly during the rainy season when transportation to these 
towns is difficult. Only wealthy people who own large mechanized agricultural schemes have bank accounts and are able to use banks to finance the purchase of tractors and other agricultural implements.

The people in El Idied depend on local arrangements for financing investments. For example, the use of the tractor owned by the village cooperative allows cooperative members to pay the rental fees after they have harvested and sold their crops. Provision of collateral is not necessary; those who need the tractor can sign a paper showing how large their land area is to be prepared, and the cost to be paid. Such mechanisms match the local circumstances of lack of finance and lack of transferable collateral. Informal finance mechanisms are also used for the purchase of consumer goods for the family such as cooking oil, sugar, and kerosene. Shopkeepers in the village will defer payment until after the harvest or until migrating household members or relatives send remittances.

\subsection{Energy services}

Important energy services identified in the village include cooking, lighting, water, transportation and farm operations. The following sections show how these services are performed.

\subsubsection{Cooking}

The types of fuel used for cooking are firewood, crop residues, animal dung, charcoal, kerosene and LPG, ordered in terms of their frequency of use by participants from the village in this study. The three most frequently used (wood, crop residues, and animal dung) are abundant and freely collected. Wood is collected from the forest around the village; and crop residues and animal dung are also collected from the vicinity of the village. The other three types are obtained through the market, and seasonal availability and accessibility determines their use. The various fuel types are combined with different stoves. Table 2.1 matches the types of fuel used to the types of stoves used. One of the factors that affects the use of fuel type and device is the type of cooked food. For example, borage (kissra) is always cooked on threestone stoves using firewood and crop residues, while for other food items, such as soup, tea and coffee, charcoal, LPG and kerosene are used.

Table 2.1

Matching types of cooking stoves and types of fuel used in El Idied

\begin{tabular}{|l|l|l|l|l|}
\hline Types of fuel & Traditional metal stove & Three stone stove & Kerosene stove & LPG stove \\
\hline Wood & & $\checkmark$ & & \\
\hline Charcoal & $\nabla$ & & & \\
\hline LPG & & & & $\checkmark$ \\
\hline Kerosene & & & $\checkmark$ & \\
\hline Crop residues & & $\square$ & & \\
\hline Animal dung & $\nabla$ & $\square$ & & \\
\hline
\end{tabular}

Table 2.2 below links the fuel types to wealth groups. It shows that, within these groups, diverse types of fuel are used by families. There is some overlapping in the use of these types. Firewood and charcoal are used by all families irrespective of their wealth. However, they differ in their use of other types such as LPG which is used by high, moderate and above moderate income groups, but not by the low income group. The ability to pay for the various fuel types is the governing factor. Moderate and low income groups use crop residues and animal dung when they are available close to their houses. 
Table 2.2

Fuel types used by different family groups in El Idied

\begin{tabular}{|c|c|c|c|c|}
\hline Type of fuel & High income & $\begin{array}{l}\text { Above } \\
\text { Moderate }\end{array}$ & Moderate & $\begin{array}{l}\text { Low } \\
\text { income }\end{array}$ \\
\hline Fire wood & $\nabla$ & $\nabla$ & $\nabla$ & $\nabla$ \\
\hline Charcoal & $\nabla$ & $\nabla$ & $\nabla$ & $\nabla$ \\
\hline Kerosene & $\nabla$ & $\nabla$ & $\nabla$ & \\
\hline LPG & $\nabla$ & $\nabla$ & & \\
\hline Animal dung & & & $\nabla$ & $\nabla$ \\
\hline Crop residues & & & $\nabla$ & $\nabla$ \\
\hline
\end{tabular}

Table 2.3 shows women's criteria and preferences for the various fuel types for cooking. LPG scored the highest and was ranked first, followed by wood, charcoal, crop residues and animal dung. If LPG is available at an affordable price, it will compete with freely collected fuel types. A trend towards using gas is clear. At the time of this research, there were 29 families using gas. However, most of these are the wealthy families or government employees (teachers + those with employers outside the village). The use of LPG was initiated by teachers and then taken up by the wealthy families. Through the teachers' unions and other labour unions, the LPG equipment (cylinders and stoves) are made available by instalment schemes. Cylinders and a refilling service are available in Gedarif. The cost of a cylinder is SDG 120 (€ 48) and the burner SDG 30 (€ 12). The refilling of the LPG cylinder costs SDG 15 (€ 6) which increases to SDG 20 (€ 8) during the rainy season.

Table 2.3

Criteria for preference ranking ${ }^{17}$ for fuel types used for cooking in El Idied

\begin{tabular}{|l|l|l|l|l|l|}
\hline $\begin{array}{l}\text { Fuel preference } \\
\text { Criteria }\end{array}$ & Wood & Charcoal & $\begin{array}{l}\text { Animal } \\
\text { dung }\end{array}$ & $\begin{array}{l}\text { Crop } \\
\text { residues }\end{array}$ & LPG \\
\hline $\begin{array}{l}\text { Speed to light the } \\
\text { stove and cook the } \\
\text { meal }\end{array}$ & 4 & 3 & 2 & 1 & 5 \\
\hline Financial Cost & 3 & 2 & 4 & 5 & 1 \\
\hline Healthiness & 3 & 4 & 1 & 2 & 5 \\
\hline Total score & 10 & 9 & 7 & 8 & 11 \\
\hline Order & $2^{\text {nd }}$ & $3^{\text {rd }}$ & $5^{\text {th }}$ & $4^{\text {th }}$ & $1^{\text {st }}$ \\
\hline
\end{tabular}

The flow of fuels is affected by two vulnerability factors: drought and seasonality. Drought affects the availability of crop residues and animal dung: animals are moved outside the village area and crops are not grown, so both fuel types are no longer produced in the vicinity of the village. There have never been shortages of wood during the drought events witnessed in the village, even in the long-lasting drought of 1983/85 dry wood was always available. This is mainly because, the population density is sufficiently low such that wood fuel use does not outstrip the natural regeneration rate, and natural capital is not degraded. Seasonality affects all types of fuel used. LPG and kerosene are scarce during the rainy season, and their prices increase significantly (by about 30 percent) mainly due to difficulties in transporting them to the village. For example, during the study period in 2004, the price of refilling an LPG cylinder increased from SDG 15 to SDG 20 ( $€ 6$ to 8) and the price of kerosene increased from SDG 0.50 to SDG 1 ( $€ 0.2$ to 0.4 ) per litre. Wood and charcoal are also difficult to collect or make during the rainy season, but because they can be collected or bought and stored before the start of the rainy season they are not scarce. However, crop residues and animal dung are not available during the rainy seasons, even if available they get wet which makes them difficult to collect and use.

\footnotetext{
${ }^{17}$ Ranking and scoring is done in the same way as in Es Sadda.
} 


\subsubsection{Lighting}

A local electricity generator, which was installed in 2001, now provides the lighting service. All houses are connected to the village generator. It operates for about six hours a day, from $6 \mathrm{pm}$ to midnight. However, the study shows that there are six others sources used to provide lighting: kerosene lamps, torches, wick lamps, pressure kerosene lamps, candles and wood. These are used when the electrical power is not available, including on certain occasions such as when there is newly-born baby, when mothers keep a light lit all through the night. Normally, kerosene lamps are used after the diesel power is switched off. Torches are used at night when moving outside the house and for following animals during night grazing.

Electricity from the generator is extended to all social services in the village. In the school, lighting is mostly needed at night when teachers hold evening classes and students do their homework. The mosque is also connected to the village generator and equipped with an electrical lamp and a loudspeaker system. The youth club uses electricity to run, besides lighting, a satellite dish and TV sets. The village's electrical mini-grid was financed partially from the cooperative's savings (buying the generator) and partially by the people of the village (buying the wires, switches, lamps and other connecting materials). The running and maintenance costs (fuel, lubricants and spare parts) are met from monthly fees paid by users. Each month, one of the committee members is assigned/volunteers as an operator. Fees are determined by the committee according to the appliances in a family house. Lamps are charged at SDG 5 $(€ 2)$ per lamp per month, TVs are charged at SDG $10(€ 4)$ and plugs for radios and cassette players are rated as SDG 5 ( $€ 2)$. For attendance at the show club there are two options, either to pay SDG 0.25 ( $€$ $0.1)$ per visit or to pay the monthly fixed rate of SDG 5 (€ 2).

Table 2.4 shows the range of lighting devices and fuels types used in the village.

Table 2.4

Lighting devices and type of fuel used in El Idied

\begin{tabular}{|l|l|}
\hline Type of lamp & Type of fuel used \\
\hline Torch & Dry battery \\
Electrical lamp & Diesel \\
Kerosene lamp & Kerosene \\
Pressure kerosene lamp & Kerosene \\
Wick lamp & Kerosene \\
Tugaba & Wood \\
Candle & wax \\
& \\
\hline
\end{tabular}

The impact of vulnerability factors is minimal on the availability of the energy resources used to provide lighting. Since households only use small quantities of kerosene, large storage facilities are not required. Diesel fuel is also bought before the rainy season and then stored for the tractor and the generator.

\subsubsection{Water services}

Water is obtained either from the running streams, from the haffir or from the shallow wells; and when there are shortages in these sources a tanker is used. The source is linked to the technology and the fuel used to obtain the water (see Table 2.5). From the running streams it is usually women and children who collect water in small containers and then carry it on donkeys. When it is provided from the haffir, water is pumped by a diesel pump to a service point. Users take water from this service point and transport it, usually in barrels on donkey carts or in containers balanced on camels, to their homes. When the shallow wells are used, water is lifted manually using leather buckets (dallo) and ropes. Usually men draw the water from the wells when it is for animal use, while women draw water from the same wells when it is for the family use and transport it on their heads. This is because men generally take care of animals and so are responsible for animal feeding and watering, whereas women are responsible for household activities and so responsible for supplying drinking water for their family. Thus, the provision of water is divided by gender according to whether water is for household use or for animal watering. 
Table 2.5

Sources of water and the energy/technology mixes used in El Idied

\begin{tabular}{|l|l|l|l|}
\hline Months of the year & October - March & February - July & $\begin{array}{l}\text { July - } \\
\text { September }\end{array}$ \\
\hline Source of water & Reservoirs (haffir) & $\begin{array}{l}\text { Shallow wells at the footing } \\
\text { of the hill }\end{array}$ & $\begin{array}{l}\text { Seasonal } \\
\text { streams }\end{array}$ \\
\hline Means of water pumping & $\begin{array}{l}\text { Centrifugal pumps / } \\
\text { diesel engine }\end{array}$ & $\begin{array}{l}\text { Lifted manually by bucket } \\
\text { and rope }\end{array}$ & $\begin{array}{l}\text { Collected } \\
\text { Manually }\end{array}$ \\
\hline Means of water transportation & $\begin{array}{l}\text { Donkey-drawn two-wheel } \\
\text { cart, or directly balanced } \\
\text { on donkey's back. }\end{array}$ & $\begin{array}{l}\text { Not transported, animals } \\
\text { drink at the well site }\end{array}$ & $\begin{array}{l}\text { Bucket } \\
\text { balanced on } \\
\text { women } \\
\text { heads }\end{array}$ \\
\hline Forms of energy used in water pumping & Diesel & Muscle power & $\begin{array}{l}\text { Muscle } \\
\text { power }\end{array}$ \\
\hline $\begin{array}{l}\text { Forms of energy used in water } \\
\text { transportation }\end{array}$ & Animal draft & Animal & \begin{tabular}{l} 
Human \\
\hline
\end{tabular}
\end{tabular}

Drought and seasonality are the vulnerability factors with the greatest impacts on the availability of water for both human and animal use. During droughts, there is no water in the streams or in the haffir. Shallow wells also start to dry out and no water is available to refill these wells. When water from all these sources is not available, animals and people start moving out the village to other areas where there is water available, such as the Blue Nile, the Atbara River and the New Halfa irrigated schemes.

Seasonality was also found to affect the availability of water. During the rainy season, water is collected in the natural ponds and running streams from which people and animals can meet their needs. After this period, water needs for animals are met by lifting water from the shallow wells manually. Human needs of water are met from the haffir. The use of the haffir is restricted to human needs, which means it lasts until the next rainy season provided the intensity of rain and the volume of water collected is sufficient. In a poor rainy season, when there is not enough water collected in the haffir, human needs are met from the shallow wells and animals are moved outside the area to more abundant water sources.

\subsubsection{Transportation and communication}

For transportation over short distances. people use donkeys and camels, such as for going to the fields, moving between villages and carrying water from the reservoir to households. For transportation beyond outside El Idied, cars and lorries are used during the dry seasons. During the rainy season, when roads are blocked and transportation become difficult, tractors are used for transportation as well as for agricultural operations. There is no telecommunication system in the village due to the lack of coverage by the telephone network located in El Gedarif.

\subsubsection{Farm operations}

Agriculture in El Idied is of two types: subsistence and mechanized farming. El Idied is located close to the large mechanized schemes and, as a result, subsistence farming is decreasing and there is a shift towards combining subsistence farming with the cultivation of some cash crops such as sesame for the markets. The mechanized farming provides access to machinery for rapid land preparation and also larger areas can be brought under cultivation. After the large farmers have finished preparing their lands, they rent out their tractors to others. Fuel storage tanks are located throughout the mechanized schemes and store the whole season's needs for fuel. It is because of the difficult transportation situation during the rainy season that scheme owners store sufficient diesel fuel to carry out all the agricultural operations.

Table 2.6 shows the types of energy used to perform the various agricultural operations in the village. However this is conditioned by the rainfall situation in the village area. 
Table 2.6

Tools and implements used in agricultural operations in El Idied

\begin{tabular}{|l|l|l|l|l|l|l|}
\hline $\begin{array}{l}\text { Size of plots in } \\
\text { feddans }{ }^{18}\end{array}$ & Ploughing & Sowing & Weeding & Harvesting & Threshing & $\begin{array}{l}\text { Purpose of } \\
\text { Production }\end{array}$ \\
\hline $\begin{array}{l}\text { Months of } \\
\text { operation }\end{array}$ & June & July & August & Oct.- Dec. & Nov.- Dec. & \\
\hline $20-50$ & Tractors & $\begin{array}{l}\text { Hand } \\
\text { tools }+ \\
\text { tractors }\end{array}$ & $\begin{array}{l}\text { Hand } \\
\text { tools }\end{array}$ & Hand tools & $\begin{array}{l}\text { Hand tools } \\
+ \text { combine } \\
\text { harvesters }\end{array}$ & Subsistence \\
\hline $50-100$ & Tractors & $\begin{array}{l}\text { Tractors } \\
\text { hand } \\
\text { tools }\end{array}$ & Tractors & Hand tools & $\begin{array}{l}\text { Combine } \\
\text { harvesters }\end{array}$ & Market \\
\hline$>100$ & Tractors & Tractors & Hand tools & $\begin{array}{l}\text { Combine } \\
\text { harvesters }\end{array}$ & Market \\
\hline
\end{tabular}

The major vulnerability factor for agricultural production is drought, when the whole agricultural system is halted and no crops can be grown. Agricultural production fails during droughts, and poor rainy seasons reduce the level of locally produced food. As a result of not being able to produce the family's needs of food, combined with the lack of water mentioned earlier, displacement starts.

\subsubsection{Non farm operations}

Non-agricultural activities include small income-generating activities which, in El Idied, are limited to small-scale trade in shops, in the bakery and in milk products. Shops stay open until $9 \mathrm{pm}$ and the only energy service used is lighting which run on electricity obtained from the village generator. Kerosene pressured lamps are also used when power is not available.

The bakery in the village uses firewood to bake bread. The amount of wood used is about 1 cubic metre of wood per day when the bakery only services the village inhabitants; in the rainy season when there are many workers in the mechanized schemes the demand for bread, and hence wood, increases threefold or more. The wood for the bakery is bought from wood sellers who bring wood from the nearby forest and sell it before the start of the rainy season.

The grain mill and the generator in the village are run on diesel fuel. The factors of vulnerability present have little impact on the fuels' availability to run these services since the committees running the services ensure that there is a stock of fuel. However, droughts and the rainy season do affect the villagers' access to basic goods and services. Drought means a decline in income at the same time as the prices of commodities, including grain, increase. Seasonal rains increase the price of fuels. The area has not witnessed a severe drought since the generator was installed so we do not know how the demand for electrical services will change, or whether people in the village will continue to pay fees, or whether they will charge their priorities as can be expected to other necessities such as water and food as was the case in Es Sadda.

\subsection{Transforming structures and processes}

As in Es Sadda, the participants in the data gathering component of this study failed to identify any role of the province, the state or the federal government in building energy services. The energy services in use are built either by the people themselves (the generators and water wells) or by an international development agency (UNDP-ADS) which built the haffir and purchased the tractor for the village cooperative. However, the market for employment and services created by the presence of the mechanized schemes improves both the quality and the quantity of energy services provided as illustrated by the shift to LPG for cooking, and electricity for lighting, and the ability to purchase water.

\footnotetext{
${ }^{18}$ The feddan is a measurement of agricultural land equal to 4200 square metres (0.42 hectares).
} 


\section{Annex 3: An analytical description of livelihoods and energy services in Dar Mali}

\subsection{Vulnerability context}

Factors of vulnerability that face the people in Dar Mali are seen in health shocks, seasonality, floods, desertification, wind erosion and dust storms.

\subsubsection{Health shocks}

A serious health shock witnessed in the village was an outbreak of diarrhoea, mainly among children. The main cause was found to be the contamination of drinking water from the open shallow wells. That was the only serious health shock mentioned has having happened in the village as remembered by informants.

\subsubsection{Seasonality}

The effects of seasonality result from the seasonal flooding of the River Nile and from changing prices for farm products. Flooding changes the accessibility of irrigation water. During the flood periods, the waters rise and become more easily accessible than during the rest of the year when the waters recede away from the banks of the Nile and become relatively difficult to access.

There are fluctuations in the prices of farm products during the time of their harvest and in the immediate post-harvest period. Farmers usually have to sell their crops at low prices immediately after harvest to meet their financial obligations, and then prices more than double in the following three to four months after harvest. The flow of other goods and services, such as transportation, health, and communications show no such seasonal changes.

\subsubsection{Floods}

The River Nile's normal flooding period occurs during August and September. The level of impact on livelihoods depends on the severity of the flooding. Serious flooding events were seen in 1946 and 1988, when there was a complete loss of farm crops and many families' houses were destroyed. Due to those flood events, about 20 families moved their houses from their original location to an elevated area away from the bank of the River Nile. This relocation had a number of consequences for the families, including the cost incurred to rebuilt their households in different places and loss of electricity connections from the grid.

\subsubsection{Desertification, wind erosion and dust storms}

The east side of the village is exposed to the Sahara. Dust storms carry loose sand from the desert, mainly during the months of May and June. These storms affect the agricultural lands, which are seasonally covered by loose and infertile sand layers. Sand also accumulates in houses and it takes a lot of effort to remove it. Further, the dust storms cause problems such as eye irritations. Wind erosion is another factor of vulnerability that affects the agricultural land, mainly in the Karo area where the topsoil is removed leaving gravel and small stones. Thus, all the three mentioned factors have negative consequences on soil fertility, houses and the health of the village population.

\subsubsection{Population trends}

The population of this village also shows changes due to drought effects through the settlement of displaced people in 1984. The new settlers added about $14 \%$ to the original population. However, their effect on services is not always negative. They share the existing energy services with the rest of the population but add to the energy services by doing manual farm operations. 


\subsection{Livelihood assets}

\subsubsection{Natural Capital}

The village lies in the desert where there is a very low annual rate of rainfall (less than $30 \mathrm{~mm}$ ). As a consequence, there are no forest areas. The only woody biomass are the thorn trees along the valleys which drain rain water to the Nile from the eastern part of the country. The most important components of the natural capital are the River Nile, the fertile soil, the small islands and the underground water. The River Nile represents the main source of irrigation water on which depends the entire agricultural production process, either through pumping water directly from the Nile or from shallow wells which are permanently replenished from the Nile. Normally the Nile floods during the months of July to September, when the water levels rise, after which water recedes away from the river banks although it never completely stops flowing.

The agricultural land is the second most important natural capital and is locally classified according to its soil fertility and distance from the bank of the River Nile as either Girare or Karo. Girare soil is a narrow strip of highly fertile soil extending along the banks of the River Nile and is also found on islands scattered along the Nile. Karo soil is less fertile soil and located away from the river banks. The girare soil, besides being highly fertile, is also easy to work and prepare. Conversely, the Karoo soil is less fertile, compacted, and hard to work and prepare.

Islands in the river are cultivated after the floods have passed. Most of them appear annually after the flooding and completely disappear during major flooding events such as those seen during the 1946 and 1988 floods. These islands have a very fertile soil in which highly profitable cash crops are cultivated. These islands also need no irrigation and can store enough water from the flooding to support the crops grown. So, the cultivation of these islands is relatively less expensive than other land. Unlike in Es Sadda and El Idied, land in Dar Mali is individually owned and officially registered under its owner's name, entitling exclusive use. However, non-landowners, such as the settled nomads in the village, can gain access to land by entering into sharecropping arrangements with landowners or tenancy relationships to use the land in the village.

\subsubsection{Physical capital}

The physical capital components available to village include two water distribution systems (diesel pump and overhead tank), the shallow wells, the electrical grid, electrical generators, the building materials plus transportation and communication facilities.

- Shallow wells and water piping system: Until 1988, drinking water in the village had been supplied from shallow wells with depths ranging from 6 to 10 metres. Each family had its own hand-dug well inside their compound, drawing water from the well either manually using a bucket and rope or using a small electrical pump to lift water to a small overhead tank (typically 1 to 2 cubic metres in volume). The hand-dug wells are still used for irrigating trees and vegetables grown inside household compounds. The piped water is also used for laundering and dish washing, as the water from the wells contains some salt, which makes the soap less foamy. Shallow hand-dug wells are also used for irrigating the karo lands.

In 1988, two water distribution systems were built and the piped water was extended to all families in the village, including the nomads. These water distribution systems were established after an incidence of water contamination of the shallow wells, which caused widespread diarrhoea among infants and children as already mentioned in the section on vulnerability. The provision of clean water has led to a significant decrease in the incidence of water-born diseases which, in turn, has led to the building of human capital (people are able to work and children to attend school). Health shocks have never been reported since the installation of the water systems.

- The electrical grid: The electrical grid was extended to Dar Mali in 1963 from Atbara. Most of the family houses, about 300, are connected to the electrical grid. Those that are not connected, totalling 54 families, include all the houses moved from their original places after the 1988 flood, and the houses of the nomads who settled after 1984. Due to instabilities in the electrical supply from the grid, people in the village use local generators as back-up systems in all the provided social services. Electricity from the 
grid is also used in some farms for pumping irrigation water and for providing light. The power supply is unstable and the village is only scheduled to receive electrical power three days a week. This instability in supply has led to the use of local generators as back-up for the grid.

- Local generators: In Dar Mali, local generators are used to supply electricity to those who are not connected to the grid and also as a back-up for those connected to the grid for when power is not available. In addition, local generators are established in all the social service centres (school and health centre).

- Agricultural implements: Production tools and equipment comprise traditional hand tools (Wasoug, Maloud, Toria) and mechanical implements. The traditional hand tools are used to carry out some of the farm operations. Mechanical implements such as harrows, levellers and threshers, powered by tractors and combiner harvesters, are also used. Both diesel and electrical pumps are used to pump irrigation water, either directly from the Nile or from shallow hand-dug wells (matara).

- Tools and machines: There are tools and machines for use in carpentry and metal workshops. These include manual tools in carpentry workshops for carrying out small works such as repairing broken windows, doors, tables, cupboards; and electrical machines used in making furniture, buildings, doors and windows, and other large wood works. In the metal workshops, mechanical machines are used to fix and repair diesel engines, pump sets and other engines such as diesel generators and electrical motors. Further, sewing machines, both manual and electrical, are commonly used to make clothes.

- Building materials: Houses in the village are of red-brick (fired bricks). Brick kilns are found along the Nile in Atabara from which bricks are brought to the village. The services centres are also built from the same material.

- Transportation and communication facilities: The village lies along the railway line and a paved road. The railway line was extended during the colonial period to support the colonization campaign in 1889. It was extended from Old Halfa in the far north to Khartoum, and then to the eastern and western parts of the country. It was the the main means of transporting people, goods and services. However, its importance declined with the extension of the paved road and because of the poor quality of the aging trains (slow and frequently breaking down).

The paved road which connects the northern part of Sudan to Khartoum, and passes through Dar Mali, was established in 1997. It extends from Barbar in the northern part of the State to Atbara, passing through Ed Damar on its way to Khartoum. There are also communication facilities in the form of three telephone shops established in the village in 19995 by private owners from the village. The telecommunication systems were provided by the telephone company (Sudatel Company). Sudatel provide rural telecommunication facilities as a complete system including the communication system, the solar module and batteries. There is also a post office in the village established in 1950 which was equipped with a telegram facility besides delivering mail. This village also lies within the mobile phone network and two companies (Zain and Sudani) provide mobile services.

- The computer centre: The computer centre is a private business established by an engineer from the village. The centre started with 5 computers and an electrical generator to run the centre, then later a photocopier and an internet system were added. It provides training in computer operation and skills for students from the agricultural college, and both men and women can attend training courses.

\subsubsection{Human capital}

- Education: Education in Dar Mali started with the establishment of the Khalwas (Islamic teaching schools) as early as 1825. Formal education is now provided in the village by three schools: The Basic School for Boys established in 1925 (430 pupils at the time of this study), the Basic School for Girls established in 1938 (400 pupils at the time of this study) and a Mixed Secondary School established in 1991(136 boys and 57 girls at the time of this study). In 2000, a faculty for agricultural studies was established in the village. The faculty belongs to the Nile University which has its Headquarters in Atbara and faculties in several parts of the Nile State. Education services are equally available to all children in the village irrespective of gender or economic status. 
- Health services: Dar Mali has a health centre that was built in 1925. It provides health services to the people of Dar Mali and those in nearby villages. Minor health problems are treated at the health centre and major ones, that need operations or investigations with sophisticated equipment such as X-rays and ultra-sound equipment, are transferred to large hospitals in Atbara or in Khartoum. Access to the large hospitals has become less expensive and much easier after the construction of the paved road. The World Health Organization (WHO) has introduced some health programmes in the village such as primary healthcare and training in maternal and infant healthcare. These programmes were implemented between 2000 and 2005 and include monitoring of child growth and pregnancy development.

In Dar Mali, about 140 families are involved in a health insurance programme set up by the state government. These include families who have a relative (son or daughter) with permanent government employment and those are able to pay the cost of insurance. For government employees (about 97 families), the cost of the insurance is deducted from their monthly salaries. The other 43 families are insured through direct payments to the Health Insurance Fund. Insurance of the latter group is arranged through the Village Development Council (VDC) which identifies families with sufficient financial assets to pay the regularly costs of insurance. Other families, including those with no permanent jobs, the poor who cannot afford to pay for insurance, and the nomads are not included in the health insurance programme. Another facility which contributes to the healthy environment in the village is the removal of household garbage for disposal away from the village. This service is also arranged through the VDC, which collects monthly fees from families to hire a labourer with a donkey-drawn cart to collect the garbage.

- Training and skills: Skills are generally developed through agricultural activities and tge operation and maintenance of the irrigation equipment. However, there are certain farm operations that are only done by people with specific skills. These operations include using animals for land preparation and the fertilization of date palm trees, which only five people in the village can do. Additionally, ex-railway workers, who gained skills and experience in metal working, mechanics and carpentry, after retirement, have established their own workshops using the skills acquired from their work. These workshops provide services to the other villagers. Also, having had an early formal education, there are many male and female village members who have received higher education in engineering, medicine and agriculture. An example of the direct benefits from this human capital is the establishment of a computer training centre in the village. The computer centre provides training in computer skills for people in the village and hence leads to the further building of human capital, with the potential for livelihoods diversification. Access to the internet also allows for knowledge building.

\subsubsection{Social capital}

There are various forms of social capital (including formal and informal organizations) found in the village through which various development activities are arranged. Social development in Dar Mali is organised through committees which cooperate with each other and with other institutions beyond the village. The Village Popular Committee (VPC) is the governmental political institution at the village level. Alongside this, is the Village Development Council (VDC) which was formed by the WHO in 1997 and is responsible for planning and implementing development activities supported by a WHO project. These two committees have subcommittees including the Village Education Committee, the Educational Council, the Women Development Council, the Village Social and Sport Club Committee and the Families' Representative Committee. In Dar Mali, women have their own sub-organization under the VDC, namely the Women Development Council. This council has been guaranteed $40 \%$ representation in the VDC by the WHO which formed the council. However, in the VPC, only $25 \%$ of the members are women, the minimum granted by the constitution for women is participation in formal committees and organizations. An important observation is that the newly-settled nomads in the village are represented in the VDC but not the VPC, which includes only representatives from the original inhabitants. This highlights the important role of the WHO, as an international agency, in ensuring equality in access to the services it provides for the people of the village. The WHO is quite emphatic about ensuring the inclusion of all groups in any village structure through which its support is channelled. Such conditions are not found in the VPC set up to ensure the participation of all the different groups. The WHO divided the village into groups of twenty families and, for each group, there is a female representative who has been hired by the WHO and been trained in first aid and monitoring health parameters. The responsibility of 
the representative is to complete a data sheet in a standard format provided by WHO for each family, and present a monthly report on the health situation within her group. The report includes the growth of infants, state of their vaccinations and the nutritional situation.

There are also informal organization such as the Village Expatriates Sons Association and the Village Sons Association in Khartoum and in other states. So far, these associations have participated in raising funds for building up the village services such as their contributions towards establishing the piped water system, rehabilitation of the schools and the building of the youth club and the provision of its furniture and the satellite TV set. Further, these associations help in maintaining ties between their members and the village.

\subsubsection{Financial Capital}

Agriculture represents the main source of income for nearly all the families in the village, including the displaced group, although some other income activities are practised by people in the village as shown in Chapter 4 (Section 4.3.1).

Income in the village is backed by financial facilities provided by formal finance institutions (banks). Banks are located in the cities of Atbara and Barbar and provide financial facilities for agricultural production and other enterprises. In particular, agriculture is financed by the Agricultural Bank of Sudan (ABS) which provides short- to mid-term finance (usually 6 months to 2 years) to fund agricultural operations, purchase farm equipment and spare parts. The financing is based on Islamic procedures (musharka, murabaha). In musharaka (sharing) both partners (the farmer and the bank) contribute to capital in the form of fixed assets or operational expenses, and share profits or losses in specific ratios fixed before the start of the activity. The other form is murabaha in which the farmers apply to the bank for financing a specific operation. The bank buys the required materials or equipment and sells them to the farmer at prices above the market price. The farmer repays the bank the agreed amount in instalments.

The finance is needed by the farmers for land preparation and for sowing at the beginning of the each season and, later, for harvesting and transporting farm products. Since only a few farmers own tractors, the rest have to rent tractors and machines. The rate for hiring tractors for land preparation varies with soil type and at the time of the research was SDG 25 and SDG 30 ( $€ 10$ and 12) per feddan for girare soil and Karoo soil respectively. With both types of soil, the rate increases to SDG 35 (€14) per feddan if the land has previously grown alfa alfa crop. The reason for the higher charge is that alfa alfa is a perennial crop which is grown for up to four seasons, this compacts the soil making it harder to work, and so it takes a longer time to prepare.

Small enterprises such as workshops can be financed through the Nilein Industrial Development Bank (NIDB) and other businesses can be financed through various commercial banks. The Saving and Social Development Bank (SSDB) also provides finance for small income-generating activities such as buying a sewing machine or materials. With agricultural finance, the farmland is accepted as collateral, whereas with small enterprises and businesses the bank needs a guarantee from another person, known to the bank and in a good financial situation. However, in some cases, the bank will accept collateral from the Village Development Council (VDC) to finance community services. The VDC, for example, provided the collateral required by the Saving and Social Development Bank to finance LPG cylinders for 140 families and diesel generators for 10 families. In both cases, the families pay monthly instalments to the bank while the collateral is provided by the VDC.

Informal finance is also present in several forms such as borrowing from relatives (who charge no interest), buying items from local shops on credit and paying later, Sandug savings funds in which a monthly or weekly amount of money is deposited by each member and granted to one Sandug member each period until all get their turn.

In general, formal finance is used for investment purposes, whether for agricultural production or for other economic activities, whereas informal finance is often used to finance families' basic needs such as buying food items, medicine or similar needs. Since formal finance is conditional on the ability to provide collateral, and because women are not much involved in agricultural production (only males manage 
agriculture), women do not take bank finance even though they are able to inherit agricultural land ${ }^{1}$. Nomads, as a landless group, also cannot meet the conditions to get bank finance.

\subsection{Energy services}

The energy services in the village are identified as including cooking, lighting, water pumping, farm operations, and transportation and communication services.

\subsubsection{Cooking}

Since the Nile State lies within the desert region there are no natural forests to supply wood fuel for household purposes. The area of Dar Mali is one of the regions with a large deficit in firewood. The FAO report shows that annual consumption of firewood in the desert region is approximately $189,973^{2}$ cubic metres of wood of which $50.7 \%$ is collected locally and 49.3 is provided from other regions and purchased from the market (FAO 1994). Farms along the Nile provide few crop residues to be used as an energy source, since the crops that are grown are vegetables and spices, which have little residue after harvest. Until the 1990s, charcoal and firewood were the only sources of energy, which were often transported from locations 500 to $1000 \mathrm{~km}$ away. During the time of the study, all the families had switched to LPG as their main cooking fuel. Although this gas is the main cooking fuel, charcoal is still used for preparing some items such as coffee for when women from neighbouring houses gather together in the house of one of the group to chat.

An important observation here is that there is no direct link between the factors of vulnerability mentioned earlier and the flow of fuel for cooking service. The main factors which have caused the shift to LPG are the poor stock of fuelwood in the area and the high cost of procuring wood from elsewhere. In the past, the cost of meeting a family's energy needs based on wood or charcoal was at least SDG 15 ( $€$ $6)$ a month in buying charcoal or firewood, now they pay around SDG 8 (€ 3.2) per month. A cylinder of gas typically lasts 45 days and is refilled for SDG12 (€ 4.8). The difference in costs between the two fuel types is sufficient to push users to the shift to LPG in place of charcoal.

\subsubsection{Lighting}

Dar Mali was connected to the electricity grid in 1963. Initially, power was continuously available but, since the early 1980s, the availability has declined and, during the time of this study, electricity was only available 3 days a week and for a period of 6 to 9 hours a day (between 6 p.m. to 6 am). There are 54 households that are not connected to the grid (the households that moved after the flood and the nowsettled displaced households). During the periods when there is no grid supply, other sources such as electricity from small generators, kerosene lamps, candles and LPG are used for lighting. Many families, even those connected to the grid, have private electrical generators as standby systems, but the purpose is not for lighting alone. They combine this with the operation of other appliances such as radios, TVs and satellite dishes. The computer training centre has a generator which it uses to provide lighting and run home appliances besides from its main purpose of running the computer centre. Lighting in the service centres (schools, health centre and other offices) is provided from both the grid, when it is available, and from local electricity generators when the power is off.

The lighting service is not affected by any of the vulnerability factors that affect the village, except for those households that were relocated away from the grid. However, these households, together with the displaced households, are equipped with diesel generators that supply them with electrical power. Seasonality has no effects on the transportation of fuels: the village is connected by paved road to city centres (see under physical capital) and there is also no rainfall that can block the roads. So Dar Mali's connection to the city market, where diesel for running the generators can be purchased, is passable at all times. The factor that does affect the electrical lighting is the instability of the power supply.

\footnotetext{
${ }^{1}$ This is specific to areas where land is officially registered on an individual basis, as in Dar Mali, and because it then has monetary value it is accepted by banks as collateral. In the previous two villages, land is owned by the whole community and customarily allocated, so could not provide collateral.

${ }^{2}$ As mentioned in Chapter 1, the FAO estimates made in 1994 were the last carried out for forest wood production and consumption in Sudan. Although the data is old, this indicates the poor situation of the State in terms of forest resources. As part of the desert region, there is no good reason to assume any improvement in the natural forest resources in the State.
} 


\subsubsection{Water services}

As mentioned earlier, Dar Mali is equipped with two water distribution systems providing piped water to all households. Thus, there is no differentiation in the use of water between the different groups in the village. The households pay a fixed flat rate as water fees (SDG 5 (€2) per month). Water availability is also unaffected by any of the vulnerability factors mentioned as facing the village. As water is pumped from a borehole sheltered by a corrugated iron construction, it is protected from sandstorms and as the pump runs on diesel it is not affected by electrical power outages. Thus, the flow of drinking water service is maintained throughout the year.

However, as mentioned in Section 3.1.1 (health shocks), the water source once used (the shallow wells) was a source of vulnerability. The contamination of these open wells caused some health problems among children in the village. This problem was avoided by switching to another water source and a new water system (boreholes and a piped system). In the new water system, not only was the source of water changed but that change was accompanied by a change from manual drawing to pumping using a diesel pump set. In other words, the new energy system was used to improve the quality of water, and not just to ensure its continuous flow.

\subsubsection{Transportation and communication}

Given the presence of the railway, the paved road, the post office and the telephone shops, transportation and communication are readily accessible in the village. These make possible easy transportation of people and agricultural products, as well as access to outside services (health services for example) and markets. The accessibility of outside markets has had the most significant positive outcome. Farms products are now sold in distant markets in Khartoum and Madeni and, due to the reduced cost of transportation, farmers now receive a higher proportion of the selling prices than before. Moreover, vegetable crops and green fodder (alfa alfa) which are high-value cash crops and used to be produced only in small areas for local markets are now grown over large areas and reach large markets quickly. These crops are highly perishable and need to be transported rapidly to reach the markets while fresh. Thus, farmers now have more options in diversifying the crops grown and building financial capital. In the past, only crops which could be sundried such as spices and faba beans were extensively grown.

Telecommunication shops allow farmers to contact outside markets and get information about where the best prices for farm products are to be found. In this way, timely market information is obtained before moving products to market places, and this reduces the risk of taking farm products to a market where prices are low or goods cannot be sold due to large supply of the same products from other areas. In addition, the telecommunications enable family members to communicate with each other, exchanging information about family affairs and enhancing social ties with those living outside the village.

Other means of communication in the village include mail (through the post office in the village) and the internet. These provide additional options for communication in the village.

\subsubsection{Farm operations}

Energy services used in agricultural production include land preparation, irrigation, sowing and harvesting processes, as well as the transportation of farm products. Different forms of energy are used depending on the size of farm and the type of agricultural operation to be performed. For example, in large farms, diesel fuel is commonly used to run tractors for land preparation and in pumps for irrigation and, in some cases, electricity is used for pumping. Small farms, on the other hand, use diesel fuel for pumping irrigation water and draught animals (oxen) for land preparation. However, some agricultural operations such as weeding, harvesting and threshing are performed manually. A description of each operation and the energy service used is provided below:

\section{i - Land preparation}

Land is prepared is using tractors, draught animals or manually depending on farm size. Large farms are usually mechanised and use tractors for harrowing, ploughing, levelling and ridging. The tractors used are of two types, conventional tractors, which are used only for land preparation, and multi-purpose tractors. The latter can be used, apart from land preparation, as a combine harvester, a grain mill, as an electrical generator, to drive a water pump and to bind fodder crops. The Agricultural Bank of Sudan introduced the 
multipurpose tractors into the Dar Mali area in 1994. On the small farms, land preparation is still carried out using oxen to plough and by human effort for levelling and ridging. Two people are needed for the levelling and ridging operations using a wooden implement, the wasoug.

\section{ii - Irrigation}

Irrigation has been practised for centuries in the Nile area using the shadouf (manual water lifting device) and the sagia (animal powered water lifting device). The shadouf is essentially a bucket which is used to lift water manually to irrigate small plots (1000 to 2000 sq. metres). The Sagia is an animal-drawn lifting pump, which replaced the Shadouf technique and can irrigate up to two feddan. Later, the diesel pump replaced both these water lifting devices and, now, the electrical pump is replacing the diesel pump. Irrigation with electrical-powered pumps is preferred over the diesel option for several reasons as listed in Table 3.1. Interestingly, participants only placed the cost of the equipment in seventh place as a selection criteria on irrigation equipment.

Table 3.1

Users criteria for preferring electrical pumping over diesel for irrigation in Dar Mali

\begin{tabular}{|l|l|l|l|}
\hline \multicolumn{2}{|c|}{ Ranking of Criteria } & \multicolumn{2}{c|}{ Diesel } \\
\hline 1 & Size of irrigable plot & Small & Larger than by diesel \\
\hline 2 & Frequency of Maintenance & Frequently & Rarely \\
\hline 3 & Payment for power usage & Daily & Monthly \\
\hline 4 & Labour requirement & Intense & Not needed \\
\hline 5 & Pollution & High & No Pollution \\
\hline 6 & Duration of operation & $\begin{array}{l}\text { Short due to heat build up in the } \\
\text { engine particularly during summer } \\
\text { season }\end{array}$ & $\begin{array}{l}\text { Long, not affected by } \\
\text { seasonal problems }\end{array}$ \\
\hline 7 & Cost of equipment & Low & High \\
\hline 8 & Weight and ease of movement & $\begin{array}{l}\text { Heavy; requires more than seven } \\
\text { people to move it }\end{array}$ & $\begin{array}{l}\text { Light; one person can } \\
\text { move it }\end{array}$ \\
\hline 9 & Ease of operation & $\begin{array}{l}\text { Needs human power and a lot of } \\
\text { effort to start it }\end{array}$ & $\begin{array}{l}\text { No effort to start the } \\
\text { system }\end{array}$ \\
\hline
\end{tabular}

During the 1990s, two farmers started to cultivate karo land away from the Nile using underground water sources for irrigation. Water is pumped either from hand-dug wells (matra) or from drilled wells (urtawazi). Although land is available in the karo area, the cost of drilling wells, which is around SDG 80,000 ( $€ 32,000$ ), is prohibitive for most people in the village. Irrigating these areas from the Nile would require long canals and large pumping units. This option is also expensive, and there are no village plans to set up such schemes. Such a large project, as people see it, would require intervention from the government.

iii - Weeding

Weeding, the removal of grasses from the cropped area, is usually done manually. Labourers are hired to do this operation and it is slow process; one feddan require 3 or 4 labourers to weed it at an acceptable rate.

\section{iv - Harvesting}

Crops are usually harvested manually in small farms, and mechanically using combine harvesters on the relatively large farms. On small farms, production is too small to justify using the mechanical harvester. The combine harvester is powered by a multi-purpose tractor.

\section{$v$ - Transportation of farm products}

Transportation of farm products from the site of production to a storage area is done using tractors with trailers for large quantities of farm products, and by horse-drawn carts for small quantities. Transportation of products to markets in the city centres is done using lorries. Products from the small farms are either sold to traders with their own lorries, or alternatively the owners of small farms join together to hire a 
lorry. As earlier mentioned, the good quality road allows easy access to the market.

The types of energy used in agricultural operations are largely determined by farm size, its location and the agricultural operation for which the energy is needed. Various types of energy are combined to provide the different services needed in performing farm operations and practices. The types and forms of energy used in agricultural production are summarised in Table 3.2 below.

Table 3.2

Types of energy used in performing different farm operations in Dar Mali

\begin{tabular}{|l|l|l|l|l|l|l|}
\hline $\begin{array}{l}\text { Farm size } \\
\text { (Feddan) }\end{array}$ & $\begin{array}{l}\text { Land } \\
\text { preparation }\end{array}$ & Irrigation & Weeding & Harvesting & $\begin{array}{l}\text { Transportation } \\
\text { to the village }\end{array}$ & $\begin{array}{l}\text { Transportation } \\
\text { to city markets }\end{array}$ \\
\hline$<1$ & Hand tools + & Diesel pumps & Manual & Manual Hand tools & $\begin{array}{l}\text { Animal Draught } \\
\text { with cart }\end{array}$ & lorries \\
\hline $1-5$ & Oxen + Tractors & Diesel pumps & Manual & Manual Hand tools & $\begin{array}{l}\text { Animal Draught } \\
\text { with cart } \\
\text { Tractor/trailers }\end{array}$ & lorries \\
\hline $5-10$ & Tractors & $\begin{array}{l}\text { Diesel pumps } \\
+ \text { electrical } \\
\text { pumps }\end{array}$ & Manual & Combine Harvester & Tractor/trailers & lorries \\
\hline$>10$ & Tractors & $\begin{array}{l}\text { Diesel pumps } \\
\text { electrical } \\
\text { pumps }\end{array}$ & Manual & Combine Harvester & Tractor/trailers & lorries \\
\hline
\end{tabular}

Farm operations are affected by three vulnerability factors: abnormal flooding, seasonal flooding and dust storms. During times of abnormal flooding, last seen in 1988, most irrigation diesel pumps were submerged and, together with some other farm equipment and implements, were lost. Such events only impact on irrigation equipment used in the girare lands adjacent to the Nile; farm operations in the karo lands away from the Nile are not affected. The normal seasonal flooding also has impacts on irrigation services for the girare lands. Although water remains available, this imposes an additional task as the farmer has to move the irrigation equipment down the slope of the Nile bank during the off-flood season and back up the bank when flooding starts. Dust storms also have impacts on land preparation, particularly in the karo lands, while the girare is less affected. The effect the of dust storms is from moving sands, which fill the irrigation channels and change the slopes of farms, which then affects the flow of water to all parts of the farm and requires re-levelling of the cultivated area in order to smooth the flow of irrigation water. In both situations, additional work is created. This additional work and its costs have negative effects on the farmers' financial capital. However, at the same time, it has positive effects on agricultural labourers' financial capital by creating paid employment.

\subsubsection{Non-farm operations}

Income-generating activities practised by some families in Dar Mali and directly linked to energy services include the sewing of clothes and ice-cream making. Some women own pedal-operated or electric sewing machines. They sew for themselves and for neighbours besides making and selling school uniforms. One lady mentioned that peddling is hard work and if there was reliable electricity she could make clothes for the market. Some families make ice cream when they have electricity and sell it in the village, mainly to school pupils.

Dar Mali has no specific market place, and shops are scattered throughout the village. Some of them open until 9:00 p.m. The energy services used in shops are lighting and refrigeration. Lighting is provided from kerosene pressure lamps, bottled gas and electricity from the grid and/or private generators. Electricity from the grid often comes after the shops are closed; hence the need for an alternative source of electricity to cool drinks, which is one of the services that shops provide in the village. Private generators are used to power refrigerators, and are usually operated intermittently to produce ice cubes to keep goods inside the refrigerator cold. The refrigerator is turned off and switched on again whenever the ice starts to melt. Refrigerator owners prefer not to use the electricity from the grid, even when it is available, because they fear the unstable current might damage the equipment. One shop owner mentioned that he once had his deep freezers damaged by the unstable current. 
Telecommunications also have multiple benefits. They are a source of financial capital for those who own the telecommunication units and for those who work in them. It is important to note that all those who operate the telephone units are women. Thus, this builds women's financial capital and gives them training in this new field to add to their human capital. For the whole village, telecommunication is essential for tapping into social capital networks.

The computer centre also provides this benefit besides its role in human capital development: it is another way of tapping into social capital networks by providing cheap and rapid communication through the internet.

\section{4 Transforming structures and processes}

The people of Dar Mali have established a number of community service centres and initiated many activities to develop their village. There are 13 service centres in the village of which six (the health centre, the basic schools, the agricultural college, the post office, the grid and the paved road) were initiated by the government. Five of the services (Khalwa, the social club, the water yard, the water network and the secondary school) were initiated by the community and the other two were initiated by private business (the computer centre and the telephone units). Outside support from international organizations like the WHO in providing health services and monitoring health status is also a noticeable contribution to the development of energy services.

Also, the finance provided by the banks has supported the acquisition of agricultural equipment and machinery and the building of private enterprises such as the computer centre and the telephone units. The building of the piped water system was initiated by a village organization ${ }^{3}$, but its construction involved contributions from various organisations: governmental, NGOs and private (see Table 3.3). The Nile State, Khartoum State, the Zakat fund and the State Support Fund, as government structures, provided about half of the total investment. Sudatel, a joint public and private company, the village community through its various social networks (Village Sons Associations) and the Saving Bank, provided the other half.

Table 3.3

Financial contributions to the building of the piped water system in Dar Mali

\begin{tabular}{|l|c|c|}
\hline Contributors & $\begin{array}{c}\text { Size of contribution } \\
\text { in SDG }\end{array}$ & Euro Equivalent \\
\hline Village community & 90,000 & 36,000 \\
\hline Nile State & 1.65 & 6,600 \\
\hline Khartoum State & 70,000 & 28,000 \\
\hline Sudatel & 5,000 & 2,000 \\
\hline State Support Fund & 15,000 & 6,000 \\
\hline Zakat Fund & 5000 & 2,000 \\
\hline Loan from the Saving Bank & 15,000 & 6,000 \\
\hline Total Source: records of the Village Development Council & 216,500 & 86,600 \\
\hline
\end{tabular}

\footnotetext{
${ }^{3}$ At that time, the main village organization was called the Village Development Committee (VDC). The VDC was replaced by the VPC, which was formed after the new government set up in 1989. Note that this VDC is a different organization to the WHO initiated Village Development Committee (VDC) which was formed in 1997.
} 


\section{Annex 4: Analysis of livelihoods and energy services in Goz El Halag}

\subsection{Vulnerability context}

There are five factors of vulnerability experienced in the village: floods, the construction of the Khashim El Girba dam, sand storms and desertification, seasonality, and population trends.

\subsubsection{Floods}

Flooding is the most common type of vulnerability that affects Goz El Halag, with flooding often occurring during the months of July to September. The village is subject to many such events when the level of the River Atbara rises above its normal level. This leads to crop damage and the loss of irrigation pumping equipment and sometimes causes the collapse of shallow wells. The last such serious event was in 1988 when the flood waters rose to a very high level to reach areas where houses were built and this caused serious damage.

\subsubsection{The construction of the Khashim El Girba Dam}

The construction of this upstream dam has created a number of difficulties for the people of Goz El Halag. The Atbara River is seasonal, and flows heavily during the months of July to September. The Khashim El Girba Dam was built in 1961 to irrigate the New Halfa Scheme. The dam keeps most of the water upstream for irrigation and power generation, and the timing and volume of water flows is dictated by demands beyond the villagers' control. As a consequence of the change in the pattern of water flow, all the villages downstream, including Goz El Halag, have changed their practices and pump irrigation water from shallow wells dug along or close to the river bank. However, although this smoothes the flow of water throughout the year, the level of water in the wells changes and, occasionally, there is not enough water released from the dam to replenish the underground water. In this event, wells need deepening to obtain sufficient water, and this requires financial capital to pay for labour, hire the digging equipment and purchase long pipes for water delivery. At the same time, pumping water from deeper wells needs greater energy input which has a negative effect on physical capital.

\subsubsection{Sandstorm and desertification}

Sandstorms during both winter and summer seasons cause several problems. The most significant of which is the effect on farmland and irrigation practices. As in Dar Mali, the sand fills the canal and changes farms levels, which affects the flow of irrigation water. So, canals needs to be cleaned out and farms re-levelled. Sand also builds up around family houses, which also needs to be removed either by family members or by hired labour. In both cases, damage occurs to the physical capital, and financial capital is needed to maintain it. However, overall, while the financial capital of farmers is reduced that of daily labourers is increased.

\subsubsection{Seasonality}

The effects of seasonality on livelihoods in Goz El Halag are similar to, but more intense, than those in Dar Mali, namely the seasonal flooding of the River Atbara and the changing prices of farm products. The seasonal changes affect the level of the water table in the shallow wells (matara) which are generally used for pumping water for irrigation. During the flood period water is pumped from 8 to 10 metres depth depending on the closeness to the river bank (wells located away from the bank are deeper) whereas during the dry season water levels may drop to 16 to 20 metres.

The flow of goods and services, such as transportation, health and communications show no seasonal change. However, the prices of farm products change in a similar sequence to that in Dar Mali. At harvest time, and in the period following, farmers receive low prices for their products and, at other times, prices are higher.

\subsubsection{Population trends}

The village has a seasonal population change with the coming and going of nomads to graze on the crop residues. They settle for three months (April - June) close to the village and move around grazing on crop residues. During their stay, they share the energy services in the village, particularly water, but they add to the financial capital by renting harvested farms which would otherwise be used as fuel or left fallow. 


\subsection{Livelihood assets}

\subsubsection{Natural Capital}

Goz El Halag is located within an area that is predominantly desert. The River Atbara represents the most important form of natural capital for the village. As mentioned earlier, the river runs seasonally during the months of July to September, and stops flowing for the rest of the year because much of the water is held upstream by the Khashim El Girba dam.

Underground water is available at two levels. The shallow water is found at depths ranging from about 10 metres close to the river bank to more than 20 metres at the village. Water is also found in deep aquifers at around 70 metres but this has a salty taste and is not preferred for human use, but it is used for animal watering, brick making and other building purposes.

The soil is of two main types. There is a highly fertile alluvial soil along the riverbanks (girare) and a gravely soil type (karo) which occurs as one moves away from the river bank and ends at the small hilly area in the southern part of the village. Generally, the soil has many indicators of suffering from high wind erosion, such as the gravely soil and the accumulation of sand at farms and houses.

The area, as part of the desert, is free of any vegetation away from the river except for small shrubs and thorny acacia trees along the streams and valleys (wadi) which drain rainwater from the eastern part into the river. These valleys present the only source of woody biomass, at a distance of 10 to $15 \mathrm{kms}$ from the village.

\subsubsection{Physical capital}

The forms of physical capital in the village include the water pumping equipment, local electricity generation, agricultural implements and tools, buildings materials and transportation and communication facilities.

- Hand-dug wells (matara): There are 43 hand-dug wells from which water is pumped for irrigation. The hand-dug wells are square holes about 2 by 2 metres and are typically 4 metres deep, inside which a 10inch diameter tube is inserted up to the level of the water. The diesel engine and the pump are located inside the hole, and connected by inlet and outlet hoses.

- Hand pumps: Hand pumps are installed in hand-dug wells (18 to 20 metres deep) used to supply drinking water to the village. There are five hand-dug wells located on various parts of the village. However, at the time of this study, only two hand pumps were functioning. The rest were broken and had not been fixed.

- Water pumping system: In the village, there is water pumping system comprising a borehole, a diesel pump and an overhead tank. Water from the borehole is salty and not suitable for drinking, so it is only used for building purposes.

- Agricultural implements: In Goz El Halag, agricultural implements are the same as in Dar Mali - the same traditional manual tools and mechanical implements. Disk harrowers and levellers powered by tractors are used for land preparation, and manual tools for sowing, weeding, planting and harvesting. Diesel pumps are used to pump water for irrigation from the matara.

- Local electricity generators: Goz El Halag is not connected to the grid. Local electricity generators are used to power village households and social services. In the village, there are six electricity generators providing electricity to the village houses and to service centres. The first generator was brought by the youth committee for their club in 2000. Later, the village development committee facilitated the purchase of other generators for households. Each group of households, usually based around kinship networks , has its own generator. Further, there is a village generator, which provides services to the mosque, the village shops and the village youth club. A solar system was installed in the school to light three classrooms and two offices. Another solar system was installed to power the village telephone facilities. 
- building materials: Houses in the village are generally built of unfired bricks. Households are located in large compounds within which entire extended families live. The compound is usually square in shape with several rooms to accommodate all the family's extended members.

- Transportation and communication facilities: Goz El Halag lies along an unpaved road linking New Halfa to Ed Damar. Trucks and lorries pass the village all year round and provide easy transportation for the people and goods into and out of the village. Lorries owned by villagers also arrange daily trips to town markets, except during the times of wind and sandstorms.

Communication in the village is enabled by a rural telephone connected to the service provider in the town of Ed Damar. The telephone was installed in 2003 and is owned by the village cooperative.

\subsubsection{Human capital}

- Education: Education services are provided by a mixed basic school for boys and girls, and a traditional Khalwa school. In the village, there are some male university graduates; women have only relatively recently been allowed to go on to higher education outside their village and, in 1993, there were five girls studying in secondary schools. The closest secondary boarding schools to Goz El Halag are in Ed Damar and Atbara.

- Health services: The health services in the village are provided by a small health unit run by a nurse. All major health services are obtained from hospitals in Ed Damar and Atbara. Transportation to these cities is not subject to disruption due to the weather and so access to the services is not subject to interruption.

- Training and skills: The skills of the people in the village are related to agriculture. Goz El Halag is famous for the manufacture of an old irrigation technology, the Sagia, and also for hands tools for agricultural operations. Nowadays, people use and extend their skills and experiences in the installation, operation and maintenance of mechanical equipment used for various farm operations such as the diesel pumps for irrigation and the tractors for land preparation. All the agricultural machinery can be locally maintained. All these are men-only skills because women do not participate in agricultural production and so women do not gain experience in these skills. Women's skills are in making handcrafts such as mats (Broush and Masali). Based on their education, however limited, some girls have found opportunities for employment in jobs such as school teachers and so gain their own income. The ADS Lower Atbara project provided training on some food processing activities such as making jam from pumpkins and watermelons, tomato paste and related other products grown on the village farms. Although these are meant to be income-generating activities for women, there are no markets for them. Within the village, every family can make their own and the products are not marketed outside the village, so the processing is effectively only for the families' own consumption. Other than this, women's gained experiences are quite limited compared to the previous villages. For example, there are no milk products being made, as in Es Sadda and El Idied, or food and ice-cream making and selling and the sewing of clothes as was the case with women in Dar Mali.

\subsubsection{Social capital}

Both formal and informal organizations exist in Goz El Halag. Two types of committee run village affairs. These are the Village Popular Committee (VPC) and Village Development Committee (VDC). The VDC was formed by the ADS Lower Atbara project, with similar form and mandates as those in Es Sadda and El Idied which were part of the ADS Central Butana project. The VDC is subdivided into specialized services committees: the health committee, the water committee, the education committee and the cooperative committee. One research finding is that there are only two women holding seats on the VDC (2 out of 20 members) and only four women representatives on the VPC (4 out of 12 members).

The cooperative committee is investing in village assets and administers the cooperative land. It allocates cultivation land to sharecroppers, organises fuel for the irrigation pumps, provides finance for farm operations, collects the cooperative's share in the produce and then sells it. The cooperative also runs a shop, a grain mill and the telephone unit. All are run on a commercial basis and the committee hires operators from the village cooperative membership. Membership of the cooperative is exclusive to men. One reason is that women do not have financial sources, and membership of the cooperative is currently only open to men who can earn money from agricultural cultivation. A major responsibility of the cooperative committee is the allocation of agricultural land, deciding which crops to cultivate in which 
parts of the land, providing agricultural equipment and providing the finance needed for cultivation. They also contracts with sharecroppers on the cooperative land and decide how much of the returns should be distributed to the cooperative members and how much should be reinvested in other economic activities or in the rehabilitation of village service centres when that is needed, such as for the rehabilitation of the school building or the dispensary and for buying furniture.

There are also some informal organizations in the village such as the Youth Committee and the Women's Committee. The youth committee runs the village youth show club. It is responsible for the club's electricity generator, the satellite TV and the club's furniture (chairs and tables). The women's committee was formed by the ADS Lower Atbara project as part of its gender development activities. These genderspecific activities include literacy classes and training in processing some farm products such as making pumpkin jam and tomato sauce. The reality of the Native Administration is very weak. The village Sheiek has only nominal status and hence has no influence in running village affairs.

\subsubsection{Financial capital}

As shown in Chapter 4 (Section 4.4.1), income in the village is mainly gained from agricultural practices with other minor sources of income. Formal financial institutions are mainly the banks located in Ed Damar and Atbara. Financial facilities for irrigating agricultural land are provided by the Agricultural Bank of Sudan (ABS). The same types of loans and terms as explained in the study of Dar Mali apply here. However, only those who own private land or one part of the cooperative committee can borrow from the bank as to ownership of land is essential as collateral.

Informal finance is also present in several forms such as borrowing from relatives, buying items on credit from local shops, and the families' savings fund. Informal finance is always available to those who have some sort of repayment guarantee such as remittance from a migrant member, a salary and/orcrops not yet harvested.

\subsection{Energy services}

As in the other villages, energy services are identified as cooking, lighting, water pumping, farm operations and transportation and communication services. The following sections describe these various energy services accessible by the villagers.

\subsubsection{Cooking}

Cooking services are met by combining different types of fuels and stoves. Five types of fuel were observed as being used for cooking by various families and at different times of the year. Commonly used fuel types are: wood, charcoal, LPG, crop residues, kerosene and sawdust. Table 4.1 matches the different types of fuel used with the types of cookstove. All the families used more than one fuel type to match the various performed cooking services. For example, wood and crop residues are used when cooking porridge (Kissera), usually on a three stone stove, whereas charcoal is used when making soup, tea and coffee. One reason is that Kissera is often cooked in large flat cooking vessels which need a stove that can be adjusted and a fuel type than can distribute the heat to all parts of the vessel. Coffee is usually taken during social gatherings and needs to be kept hot for a lengthy period while drinking and chatting. Charcoal is more appropriate for the way soup, tea and coffee are prepared and consumed.

Table: 4.1 Matching types of cooking stoves and types of fuel used in Goz El Halag

\begin{tabular}{|c|c|c|c|c|c|}
\hline Types of fuel & $\begin{array}{c}\text { Butane gas } \\
\text { burner }\end{array}$ & $\begin{array}{c}\text { Traditional metal } \\
\text { stove }\end{array}$ & $\begin{array}{c}\text { Three-stone } \\
\text { stove }\end{array}$ & $\begin{array}{c}\text { Improved } \\
\text { stove }\end{array}$ & $\begin{array}{c}\text { Kerosene } \\
\text { stove }\end{array}$ \\
\hline LPG & $\sqrt{ }$ & & & & $\sqrt{ }$ \\
\hline Charcoal & & $\sqrt{ }$ & & & $\sqrt{ }$ \\
\hline kerosene & & & $\sqrt{ }$ & & \\
\hline Wood & & & $\sqrt{ }$ & & \\
\hline $\begin{array}{c}\text { Crop } \\
\text { residues }\end{array}$ & & & & & \\
\hline
\end{tabular}


Table 4.2 relates the types of fuel commonly used in the village to the different wealth groups in the village. As shown, both wealthy and middle-income groups use LPG together with other fuel types while the poor group uses all fuel types except LPG.

Table: 4.2

Fuel types used by different family groups1 in Goz El Halag

\begin{tabular}{|l|c|l|l|}
\hline Types of Fuel & Wealthy & Middle income & Poor \\
\hline LPG & $\checkmark$ & $\checkmark$ & \\
\hline Charcoal & $\checkmark$ & $\checkmark$ & $\checkmark$ \\
\hline Kerosene & $\checkmark$ & $\checkmark$ & $\checkmark$ \\
\hline Wood & $\checkmark$ & $\checkmark$ & $\checkmark$ \\
\hline Crop residues & $\checkmark$ & $\checkmark$ & $\checkmark$ \\
\hline
\end{tabular}

Table 4.3 provides the preference criteria for certain types of fuel for cooking purposes. While LPG is the preferred cooking fuel, only 50 families currently use it, about $60 \%$ of the families in the village. Those families not using LPG mention the initial cost of the cylinder and the gas burners as a major barrier to access. The initial cost is about SDG 120 (€ 48) and refilling the gas cylinder costs about SDG $15(€ 6)$ in Ed Damar. Those families using LPG, find that the cylinder lasts about two months on average. Other preference criteria such as the time of cooking, handling and the working conditions were found to be important in selection alongside cost.

Table: 4.3

Criteria and Preference ranking2 for fuel types used for cooking in Goz El Halag

\begin{tabular}{|l|l|l|l|l|l|}
\hline Fuel type & LPG & Charcoal & Kerosene & Wood & $\begin{array}{l}\text { Crop } \\
\text { residues }\end{array}$ \\
\hline $\begin{array}{l}\text { Speed to lit the fuel and cook } \\
\text { the meal }\end{array}$ & 5 & 4 & 3 & 2 & 1 \\
\hline Ease of handling & 5 & 4 & 3 & 2 & 1 \\
\hline Financial Cost & 1 & 3 & 2 & 4 & 5 \\
\hline Healthiness & 5 & 3 & 4 & 2 & 1 \\
\hline Total scores & 16 & 14 & 12 & 10 & 8 \\
\hline Ranking & $1^{\text {st }}$ & $2^{\text {nd }}$ & $3^{\text {rd }}$ & $4^{\text {th }}$ & $5^{\text {th }}$ \\
\hline
\end{tabular}

It was found that, in Goz El Halag, there is no direct link between the flow of fuel for cooking and the factors of vulnerability experienced in the village. However, indirectly, the seasonality of some crops affects the use of crop residues. Some crops, like vegetables and spices, which are grown in winter, leave no useable residues, while other crops such as okra, dura and legumes, grown in the summer, leave some residues which can be used for cooking after being grazed on by animals. Animals grazing on the crop residues reduce the amount available for fuel. Animals graze on leaves and small stems but leave the larger hard stem which are collected and used for cooking. At the same time, leasing the fallow farms to nomads generates some income that goes towards the cost of purchased fuel.

\footnotetext{
${ }^{1}$ The analysis is done in the same way as in Es Sadda

${ }^{2}$ the ranking is based on the same method as used in Es Sadda
} 


\subsubsection{Lighting}

Energy for lighting in houses is provided from the local electricity generators. The number of lamps used per household varies between one and four. The monthly fee per lamp is SDG 3 ( $€$ 1.2). The generators run for six hours a day, usually between $6 \mathrm{pm}$ and midnight. Although electricity is the most dominant source of lighting, other sources are used when the power is off or not available due to breakdowns etc. . The alternative energy sources for lighting are kerosene and gasoline burnt in traditional kerosene lamps or wick lamps. Torches are also occasionally used for lighting, mainly during irrigation activities which are commonly done at night. Table 4.4 shows the evaluation of fuel types used for lighting against some preference criteria developed by the village participants in this study which shows the different characteristics of the various sources of lighting. All these sources meet different purposes for lighting. For example, electricity provides high intensity lighting and is a smokeless source which is appropriate for reading and working inside households. Torches are more suitable when managing irrigation water at night because of their mobility and ease of carrying when moving from one part of the farm to another. The other sources of lighting, kerosene lamps and LPG lamps, have some disadvantages (smoke and cost), but are also valuable when the electrical power is shut off.

Table: 4.4

\section{Preference criteria and evaluation for fuel types used for lighting in Goz El Halag village}

\begin{tabular}{|l|l|l|l|l|}
\hline $\begin{array}{l}\text { Fuel type } \\
\text { criteria }\end{array}$ & $\begin{array}{l}\text { Electrical } \\
\text { lamps }\end{array}$ & $\begin{array}{l}\text { Kerosene } \\
\text { lamps }\end{array}$ & $\begin{array}{l}\text { LPG } \\
\text { lamps }\end{array}$ & Torches \\
\hline Mobility & Fixed & $\begin{array}{l}\text { Inside } \\
\text { house }\end{array}$ & Inside & Mobility high \\
\hline Light intensity & V. high & Low & High & Low \\
\hline Smokeless & Smokeless & $\begin{array}{l}\text { Emits } \\
\text { smoke }\end{array}$ & Smokeless & Smokeless \\
\hline Cost & Cheap & Moderate & Expensive & Expensive \\
\hline
\end{tabular}

Lighting in the health centre, the school, the youth club and the mosque is provided from the village generator.

The lighting service is not affected by any of the factors of vulnerability (Section 4.4.2.1). That is, there is no link between these factors and the availability of the fuel used for lighting.

\subsubsection{Water services}

The domestic water service is provided from three hand pumps in the village. Usually women and children do the pumping. Each hand pump serves about 20 families who typically have to queue for about half an hour to fill one container (about 20 litres). Since families need about six to eight containers a day, the provision of water takes about 3 to 4 hours a day.

Another important water service in the village is for making building bricks. This water is usually obtained from the water yard. As mentioned earlier, the water from the borehole is salty and not suitable for drinking. The borehole pump is operated on request, after paying for the cost of the operation to the water committee.

Factors of vulnerability that influence the water service are linked to the building of the Khashim El Girba dam which has affected the seasonal flow of water and changed the level of the water table which has fallen. However, water is still available all the year round from the hand pumps, but it now needs more effort and time to raise it from deeper levels. Here, the additional load on the provision of water falls on women and children. These groups, regardless of their economic status have to shoulder the provision of water, as there are no other means or sources to meet domestic water needs. 


\subsubsection{Transportation and communication}

As mentioned earlier, the village is connected to Ed Damar by an unpaved road. Trucks and lorries pass the village all year round. People and agricultural products are transported to local towns along this road and goods and services are also brought to the village along it. There are also lorries based in the village which provide daily and regular transportation services, except during windstorms when trips might be delayed. So, transportation is only affected by this occasional vulnerability factor which can last for 2 to 3 days.

Communication in the village is achieved through by a rural telephone connected to the service provider in Ed Damar. The telephone was installed in 2003 and is owned by the village cooperative. It provides a communication link for village farmers who get market information about their products and, at the same time, links families to members working outside the village.

\subsubsection{Farm operations}

Farm operations include land preparation, irrigation, sowing and harvesting processes as well as the transportation of farm produce. The following sub-sections show how these operations are performed.

\section{i - Land preparation}

The operations involved in land preparation include harrowing, levelling and ridging plus clearing the water channel for irrigation. In land preparation, a combination of manual, animal and mechanized tools are employed. The use of tractors has increased since the early 1990s when ABS finance enabled the purchase of the cooperative tractor with diesel fuel available in the market. However, animal and manual tools are still used. This is because some areas are too small for using tractors3 available in Sudan. Use of the tractors also varies with the type of crop being cultivated. Sorghum, peas and spices are grown on ridges which are prepared using tractors. Onions and watermelons are grown in flat basins which are levelled using a manual tool (the wasoug).

\section{ii - Irrigation}

Irrigation traditionally involved the Shadouf and the Sagia, as in Dar Mali. Now diesel pumps have replaced both of them. Irrigation water is generally pumped from shallow hand-dug wells using diesel pumps. Water is only pumped directly from the river during the flood season and then only for the land adjacent to the river. The construction of the Khashim El Girba Dam enforced two changes in irrigation practices in the village. First, the changing of the source of irrigation water from river water to underground water and, second, an increase in the size of the irrigation pumpsets from a two-inch pump to three-inch pump. This forced change was accompanied by an increase in the demand for diesel fuel. As villagers reported, pumping from the river to irrigate one feddan required approximately four litres of diesel fuel whereas irrigating the same area by pumping water from a matara requires on average 12 litres.

\section{iii - Harvesting}

Harvesting and threshing of all crops are carried out manually. The lack of mechanisation can be attributed to the areas involved being relatively small and each farmer growing different crops to the others, even in the same season. For example, in winter, one farmer might grow faba beans while his neighbours grow onions.

\section{iv - Transportation of farm products}

Transporting goods to markets is by lorries, while from farms to households is by donkey or horse carts. The form of transport is also determined by how the produce is shared with the cooperative. If a farmer gets little produce, he will usually transport his share on his donkey (several journeys) but if he has a large quantity of crops he will either transport it directly to the city market by lorry, or hire a horse-drawn cart to transport it to his home and then later it will be taken to the market. The cooperative, on the other hand, collects its shares from all the farmers and then transports it directly to the market.

\footnotetext{
${ }^{3}$ However, there are smaller tractors ('iron buffalo') which would be appropriate for small pieces of land but these are not available in Sudan.
} 
In Goz El Halag, different types of energy are used for carrying out farm operations. In land preparation, harrowing is done using tractors for the whole area of cooperative land. Following the harrowing operation, the levelling of the land is done by oxen or manually, weeding and harvesting are carried manually, and irrigation is provided by diesel pumps.

Important vulnerability factors affecting farm operations in Goz El Halag include primarily the building of the Khashim El Girba Dam which has affected the water sources from which irrigation water is obtained. It has resulted in a shift from pumping water from the river to using hand-dug wells which is now the only source of irrigation water used continuously and pumping directly from the river is now only seasonal. The control of river water by the dam and the change this has made to natural seasonal flooding also affects the level of the water table. Another important vulnerability is to dust storms which affect the level of land and block water channels in the same way as that reported for Dar Mali.

\subsubsection{Non-farm operations}

Non-farm activities in Goz El Halag include some income-generating activities other than agriculture. These are limited in this village to the three shops, the telephone service and the bakery. Each of the shops is connected to one of the electricity generators in the village. Shops usually open until 9:00 pm and during darkness lighting is supplied from electricity and, when electricity is not available, pressurized kerosene lamps are used. The bakery uses firewood which is bought in Ed Damar where wood obtained from the Blue Nile and Southern states is marketed. The telephone is operated on a solar system which powers the communication devices and at the same time provides light for the telephone room. Usually, the telephone operates until 9:00 pm.

\subsection{Transforming structures and processes}

It is observed that, in this village, there is little role for the transforming structures and processes at any level. The only physical capital improved by the state is the water distribution system which was established by the National Rural Water Corporation (NRWC). There is also a role for the Agricultural Bank of Sudan in financing the provision of agricultural implements, tractors, water pumps and fertilizers for the village cooperative and individual farmers. Other than that, all the physical capital components were established by NGOs, particularly the ADS project which contributed to the building of the grain mill, the cooperative shop and the establishment of the hand pumps. The government does provide teachers and the nurse. There is also an agricultural extension service unit which visits the village occasionally and provides advice on agricultural practices and crops to be grown. 


\section{Annex 5: Analysis of livelihoods and energy services in Um Laham}

\subsection{Vulnerability context}

Five factors of vulnerability occur in the village. These are droughts, crop pests, health shocks, seasonality and population trends.

\subsubsection{Drought}

Rainfall is erratic in the area and differs from one season to the next both in intensity and timing, which affects the growth of natural pasture and the ability of crops to reach full maturity. People in the village refer to drought events when there is not enough rain over several seasons such as in the period 1983/1985. The participants were able to recall to several years of drought when there was not enough rain to support the growth to maturity of their food crops (1920, 1925, 1930, 1975, 1983/85 and 1992). These droughts affected the availability of water, pasture and food products. In particular, the extended drought of the 1983/85 had a larger impact on these services than the other shorter droughts.

Water in the village is provided from hand-dug wells which are annually replenished by the rains. When there are no rains, the level of water in the wells starts to drop, and with long periods of no rain, wells dry out completely. In long periods of drought, water is brought from the Bara area on camels. The very poor families who lack the means to transport water from Bara leave the village and go to areas where they can more easily meet their water needs.

Locally produced food is also in short supply during years of drought. Even in the short periods of drought (one season) families cannot produce enough food. However, it is then possible to buy food items from Bara market. Thus, in short periods of drought, only male family members migrate from the village in order to earn money that will allow their families to purchase their needed food. So, during short periods of drought, families can withstand the situation by relying on migrant members and by selling some of their animals to get the necessary finance to buy food.

Only in the drought of 1983/85 had the village witnessed wholesale displacement of its inhabitants. It is estimated that one hundred families left the village to seek refuge in other areas. All of them were from the poor and very poor family categories. They settled in refugee camps (El Muwailih and Abu Zied) west of Um Durman. After the drought was over, most families returned to the village although some family members remained settled around Um Durman to work and send remittances to their families. The 1983/85 drought event also had an impact on the wealth of the village inhabitants. Before the drought, most of the animal wealth in the village was composed of cows and sheep, followed by camels and goats. However, because cows and sheep are sensitive to severe shortages of pasture and water they either died or were sold. In one year, all the cows kept in the village were lost. When the drought was over, the village inhabitants retuned and started to rebuild their animal wealth, but they now kept only camels and goats. Cows have completely disappeared from the whole Bara area.

\subsubsection{Health shocks}

Three significant health shocks were recalled: in 1950 there was an outbreak of meningitis and, in 1970, an outbreak of cholera. In both cases the government established quarantine areas in a nearby village (Um Ushar) to detain people with symptoms. The third event related to health shocks was a village lorry accident in 2003. This took place when a lorry carrying people from the village to a weekly market in a nearby village hit a tree and turned upside down killing 15 villagers.

\subsubsection{Crop pests}

Crops pests present another form of vulnerability to Um Laham. Their effects are large in some years, causing extensive damage to crops and resulting in food shortages. The first such incident recalled was in 1970, when the damage to the crops was caused by the larvae of butterflies and moths, which are locally called Surfa. Hence the year became known as the year of the Surfa (Sanat Umsurfa). During this period, crops were totally lost and pasture was also affected despite the availability of sufficient rains in that year. 
This resulted in long periods of food shortages and people had to travel long distances on camels to bring in food supplies. The other recalled incidence was an infestation of rats, which took place in 1982, and so that year became known as the year of the rat (Sanat El Far).

These pests had similar impacts to those of droughts such as a shortage in produced food crops. However, the impact was not as severe, being more localized than the shortages due to drought, and affecting only the production of crops but not animals. The shortages in locally-produced crops could easily be compensated for by buying food crops from areas that were not affected. In such events, families resort to selling some of their animals to buy food. However, not all families have animals to sell but they can generally depend on remittances from migrant family members to buy food.

\subsubsection{Seasonality}

Seasonality affects the availability of food, pasture and water. The rainy season is an important determinant of the amount of food produced. During the rainy season, both water and pasture are available but supply starts to decline after that. However, water from the shallow wells is still available although the water table starts to drop. Being close to the twon of Bara, goods and other services show no seasonal changes. Transportation is not affected by rains as the soil is predominantly sandy and so roads are not blocked even when there are heavy rains. This means that transportation of good and services to the village continues even during heavy rains, as does the movement of people and products from the village to the city market or other areas.

Seasonality also affects market prices for both the produced crops and animals. The prices of other goods and services remain unaffected by seasonality. The prices change considerably for crops and animals from season to season. For cereal crops, prices start to increase in May/June and continue rising until reaching their peak in July/August. However, in years of drought, the prices remain high until a good rainy season arrives and prices return to the cyclical pattern of increasing in the off season and decreasing after harvest.

Animal prices follow the same cycle. The only difference is that peaks and troughs are reversed. Animal prices decrease with drought events and increase in good rainy seasons. Farmers sell crops immediately after harvest in order to meet their financial obligations, thus selling their surpluses at low prices. For animals, although reversed in time, the same pattern prevails, matching the times of high needs for cash with low animal prices.

\subsubsection{Population trends}

Um Laham, unlike other villages in the survey, shows no increase in population due to newly settled people following drought events. Here, the population decreased during the extended drought event (Section 5.1.1 above).

\subsection{Livelihood assets}

\subsubsection{Natural Capital}

The village lies within an area characterized by sand dunes. It lies in the eastern part of the Bara basin, which is rich in underground water resources. Shallow wells reach water at depths of 20 to 30 metres $^{1}$. The typical annual rainfall is between 400 and $600 \mathrm{~mm}$, which comes during the rainy season between July and October.

The vegetation is composed of various types of grasses and thorny trees which dominate in depressions and low laying land. Typical species are Acacia Mellifera (kitter), Acacia Senegal (Hashab) and Acacia Seyal (talih), and occasionally Balanites Aegyptica (hejlej) and Hyphaene Thebaica (Dom). All these types can be used as fuel. However Acacia Seyal and Acacia Senegal are preferred as dead wood from

\footnotetext{
${ }^{1}$ The term shallow well indicates depths that can be manually dug and the water then retrieved by manual means using buckets and ropes. In contrast, a deep well is a borehole with depths of more than 50 metres.
} 
these species is easy to collect (in terms of being less thorny and easy to break off), easy to light and produces good charcoal if carbonized in local kilns. Acacia Senegal is left to grow for at least 10 years to produce Gum Arabic, when it is cleared in order to harvest the raisin. Once the raisins have been collected, some of the remaining wood is used for producing charcoal or as firewood, while the larger branches and trunks are used as building poles for making houses.

\subsubsection{Physical Capital}

The physical capital of the village includes water pumping systems (the drilled bore holes and hand-dug water wells and a solar pump), the electrical generator, a grain mill, oil mills, building materials and transportation and communication facilities.

Hand-dug wells: There are three hand-dug wells, one in each settlement (Um Laham and El Rukab) plus a third one for the solar pump that irrigates the village's small farm plot. The depths of these shallow wells range from 20 to 30 metres.

Boreholes wells: There are two boreholes in the village. One is part of the water pumping system and was not working at the time of this study. The submersible pump installed in this borehole had broken and had fallen down inside the well. Rehabilitation would involve the old pump being removed, cleaning of the well and the installation of a new pump. The cost of carrying out these maintenance tasks is estimated as SDG 900,000 (€ 4500) which is more than the village could collect. The other borehole in the village was drilled by a UNDP-financed project (the Mitigation of Drought Impacts Project) which was active during the period 1986-1995. The project's objective was to introduce irrigated agriculture after the drought and famine of 1983/85. Although, the project drilled the well, the other parts of the irrigation work such as buying the pump set and irrigation pipes were never completed and the borehole has remained unused. The project was phased out before the other work could be completed, and the UNDP stopped financing the project. It was not even handed over to the village people, and they cannot use it because they do not have the money to complete the other work that is needed to operate it.

- Village shops: Um Laham has no market place. There are only two small shops, one in each settlement. In these shops, the goods needed by the villagers are made available and sold. However, in nearby villages there are two weekly markets which people from Um Laham visit to sell their animals and buy their needs.

- Solar pump: The village has a solar pump which is used to irrigate a small farm, owned by the Um Laham settlement, which is divided into small plots for vegetables, crops and citrus trees. The Swedish Sudanese Association (SSA) installed this in 1992 and it was still working during the time this study was carried out. The well in which the solar pump is installed is a shallow well dug by the people of the village. The solar pump has continued to run with no major drawbacks in the system except that the well needs regular clearingn of deposited sands to prevent the pump wearing.

- Electrical Generator: The electrical generator is operated on a private basis and supplies a mini-grid of eight houses and the mosque of the village. In order to obtain a connection, families have to buy wire, dig a trench to bury it in and then the owner of the generator will do all the connection work. The charge to families is based on the number of lamps installed in the house. The rate is SDG 5 (€ 2) per 20W fluorescent lamp per month. The charge for other appliances is calculated by assuming an equivalence to a specific number of lamps. For example, if a family has a TV, this is rated as equivalent to two lamps and thus the owner pays SDG 10 (€ 4) per month. The generator is operated 3 hours a day from 7 to 10 p.m.

- Oil mills: The village has 22 sesame oil mills which are all are privately owned and operated. The oil mills are used to extract sesame oil, are driven by camels, and operate for four months a year (October to February). Outside this period, sesame is either unavailable or too expensive.

- Agricultural implements: Tools and equipment used in agriculture include traditional hand tools (salaouka, maloud) which are used to cultivate the small plots around the village. There are no mechanical implements in the village to prepare land or for the other farm operations. 
- Building materials: Houses in the village are thatched huts (gutyia) made out of grasses and tree branches. The gutyia is circular in shape with a conical roof. A family's accommodation is composed of a number of gutyia to accommodate all the family members plus one for male guests. All are enclosed by a tall grass fence supported by wooden branches. The services centres (the school and the health centre) are built from red bricks.

- Transportation and communication: The village lies along a track which previously linked Khartoum and the northern part of the state to El Obied. With the establishment of the Khartoum-El Obied paved road in 1988 and the El Obied-Bara road in 2003, transportation moved away from the track passing through the village. Transportation to and from the village is now channelled through Bara.

There are two telephone units in the village, one in each settlement. Both telephone units are privately owned by families in the village. The telephones were obtained from the Sudatel Company which provided complete systems including, the telecom equipment, a solar module, a charge regulator and batteries, which are installed in simple grass huts as shown in Photographs 4.5.1 and 4.5.2 below. 
Photo 5.1: Outside view of a telephone unit in Um Laham

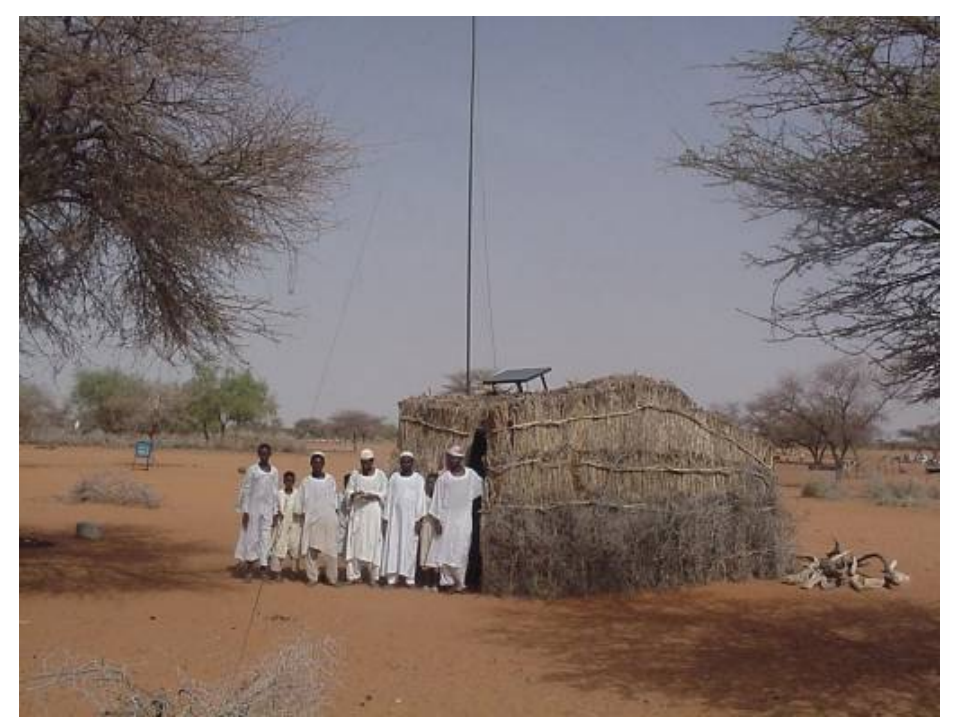

Photo 5.2

Internal view of a telephone unit in Um Laham

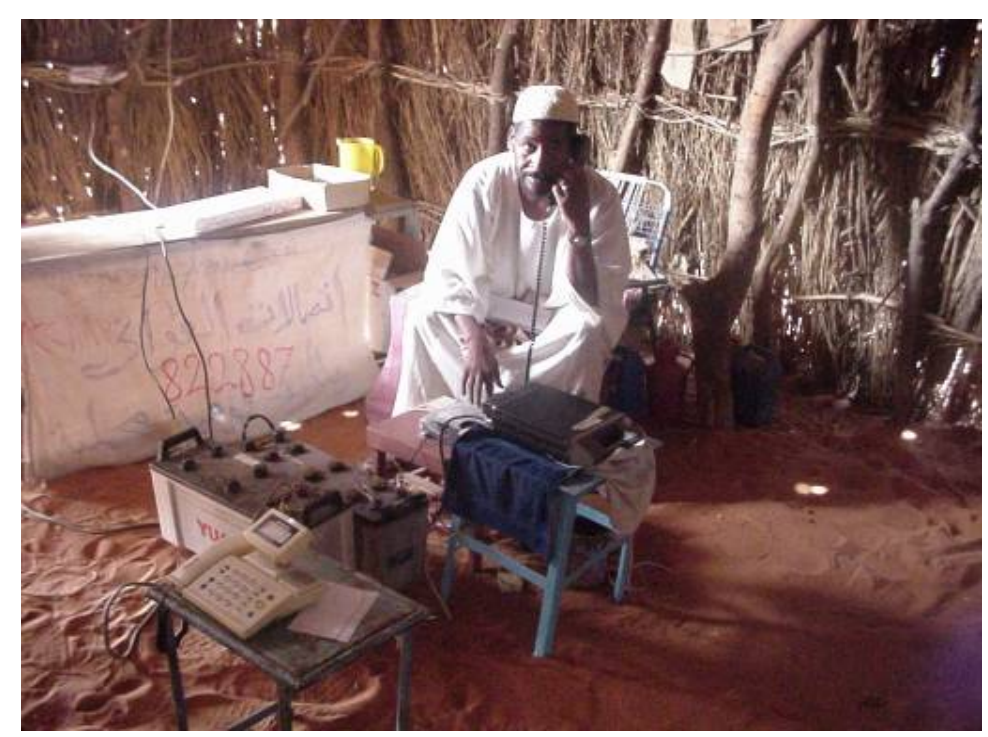




\subsubsection{Human capital}

Education: Education started with an informal Khalwa school in 1932 which provides Quranic and Islamic teachings alongside writing and reading. Girls do not usually attend the Khalwa education system, mostly because it takes place at inappropriate times for them, in the evenings and early mornings. Formal education started with a mixed school, which was established in 1943 as a sub-grade ${ }^{2}$ school, and later in 1972 it was developed into the existing basic school. This early start with education has resulted in build up of human capital. There are university graduates from the village of both sexes; 25 males and 10 females. However, none of them have settled in the village. They either hold positions in the cities and are permanently settled in them, or they have migrated to another country. For example, the representative of the Bara area in the Popular Council (the National Assembly) is from Um Laham, but is permanently settled in Khartoum. However, occasionally the emigrants return to the village in the Eid (religious festival) and for social occasions (marriages or funerals) with close relatives. Formal education is conceived by the people in the village as a way of getting a permanent job and a way out of poverty. Families which were once considered poor are no longer considered so if they have graduate sons or daughters with permanent jobs. Although emigrants deplete the human capital they help build financial capital. Attempts to provide literacy and adult education classes were made on four occasions but none of these attempts functioned for more than two years. The first attempt was in 1965 and aimed to educate male adults during the evenings. The first literacy class for women was established in 1983. However, in both cases there was a lack of continuity and the classes stopped without completing the prescribed literacy courses.

Health services: There are currently no health services provided in the village. However, at the time of data collection, a health centre had just been completed but was not yet staffed or equipped. The building of the health centre was supported by an IFAD project working in the area. Currently medical and health services are obtained from Bara and El Obied hospitals.

Training and skills: Being dependent on agriculture and livestock for their livelihoods, the villagers have skills linked to animal husbandry and rain-fed agriculture. However, through education and employment, other opportunities are created. Newly introduced technologies in the village such as telephones, electrical generators, welding works and solar pump irrigation brought new experiences, skills and work for some men in the village. Women only carry out the cultivation and irrigation work on the vegetable plots. The introduction of the solar pump was accompanied by some new activities involving irrigation, fertilization and improved horticultural practices. All these newly introduced tasks are carried out by most of the people in the village but not the maintenance of the solar pump itself. In the event of a breakdown, a technician has to be brought by the SSA to maintain the pump.

\subsubsection{Social capital}

Formal and informal organizations co-exist in the village. The formal organizations include the Village Popular Committee (VPC), the Cooperative Society and the Village Development Committee (VDC). The informal organizations include the Tribal and Native Administration, the Village Sons' Society and the Women's Society. In this village, the representation of women varies in the different village organizations: $25 \%$ on the VPC, $50 \%$ on the VDC and none at all on the Cooperative Committee. Where existing, women's representation was imposed by external actors. In the VPC, they form the minimum percentage imposed by the law. The VDC was formed by the SSA ${ }^{3}$, which demanded equal representation for women. However, in the Society Cooperative ${ }^{4}$, membership was given to households, represented by

\footnotetext{
${ }^{2}$ The sub-grade schools were established in the early 1940s, and only offered three years of schooling. After completing the third class of study pupils moved to a city school, usually in Bara, to complete a fourth year and then sit an examination to advance to the intermediate level.

${ }^{3}$ An additional reason was that the head of the SSA in Bara was a woman (Miss Nadra Ayoub) who tried to give women an equal share and representation in the VDCs of all villages that the SSA worked with, and granted women equal benefits.

${ }^{4}$ The Cooperative Society was formed by the village people in the early 1970s. Its main objective was to provide goods and services at a time when many goods were distributed through a quota system. Currently, the Cooperative Society's role is diminishing although it still owns a grain mill which is the only thing that it still runs.
} 
their male members. This denies any role for women in the running of the cooperatives, or that different interests could be forwarded by women for tackling in the cooperative.

The VPC, as in other villages, is the formal political organization at the village level. There are also VPC subcommittees responsible for water, health and education services. The informal organizations include a tribal-based native administration and voluntary societies. In Um Laham there are two Sheiks, one for each settlement. They are responsible for keeping social order in the village, allocating agricultural land and mediating in disputes between individuals and groups. Work on the village farm irrigated by the solar pump is also organised arranged by the Sheik of one of the Um Laham settlements. Each family is responsible for irrigating and taking care of five trees. The irrigation is done manually by carrying water on donkeys or on heads to irrigate the trees. The farm is run and supervised by the Village Development Committee which is responsible for the supervision of working groups on the farm, the meeting of financial needs, and selling products and keeping revenues from crop selling. A member of each family is expected to irrigate the family's trees or to hire someone else to do it for them. Irrigation of the Hashab trees is continued for 15 months after sowing, but after that no irrigation is required. The irrigation of the fruit trees is a group activity. Eleven groups of eight people were formed, and each group has a head who is responsible to the village Sheikh. Each group is responsible for irrigating 12 trees and a plot of vegetables. Fruits grown are lemon and guava, and vegetables include cucumber, rocket, pumpkin and okra. The priority in selling the produce is first to village families, who pay nominal prices, and any surplus is sent to the markets in Bara or El Obied. The typical annual net returns are between SDG 3000 to SDG 5000 ( $€ 1200$ to 2000). The revenues are used to finance repairs and maintenance work in addition to other work in the village such as rehabilitation of the school and the mosque.

Kinship is an important element of the social capital of the village, and supports the financial capital through the remittance of money or through building physical capital which in turn generates money, such as with the diesel generator and the telephone unit. The owner of the generator received it from his son working in the Kadougli area (South Kordofan state) who sent him the generator to provide additional income for his family. The son also sent his family a telephone unit. His aim is to enable his family to generate their own income and thus decrease their financial dependency on his remittances.

\subsubsection{Financial capital}

Income is mainly generated from animals, agriculture and the other sources described in Chapter 4 (Section 4.5.1). Formal financial capital, as represented by banks and local moneylenders, does not play a major role in the village economy. There are banks in Bara, but the lack of collateral prevents their use. Although land is available, it cannot be accepted as collateral because it is not officially registered to individuals and no-one in the village has any official documents relating to land ownership. This situation means that the land has no monetary value to individuals or households, and hence cannot be sold or purchased. Further, the bank does not accept animals (which are the other assets of most people) as collateral for loans. A local informal finance system, as in other villages, exists. There is a shale ${ }^{5}$ system, which allows farmers to sell farm products before harvest time. This informal financial system is often used to meet urgent financial needs.

Remittances received by families from members working outside the village usually come in the form of a direct money transfer but, in this village, there are examples of indirect transfers in the form of physical capital which is then used to generate income locally, such as the electrical generator and telephone discussed above. Another form of financial capital comes from the sale of farms products irrigated by the solar pump. Revenues are used to finance the repairs and maintenance of all the services in the village, such as the rehabilitation of classrooms and the mosque, and any surplus is divided among families.

\subsection{Energy services}

\footnotetext{
${ }^{5}$ Shale is the advanced selling of farm products before harvest time. The prices received by farmers are often less than the expected prices at harvest time. In Um Laham, a farmer cultivating cash crops such as sesame or gum Arabic can sell some of his produce in advance using this system. At the time of the harvest, the lender receives the sum raised by selling the farm produce.
} 
As in the other villages, the energy services identified were cooking, lighting, water pumping, transportation and agricultural operations.

\subsubsection{Cooking}

For cooking, firewood is the common fuel type, supplemented by other fuel types and various stoves are used with these fuel types as shown in Table 5.1, which matches fuel type to stove. There are only four types of fuel used and there are six types of cooking stoves used.

Table 5.1

Matching types of cooking stoves and types of fuel used in Um Laham

\begin{tabular}{|l|c|c|c|c|c|}
\hline $\begin{array}{c}\text { Types of } \\
\text { fuel }\end{array}$ & $\begin{array}{c}\text { Three- } \\
\text { stone stove }\end{array}$ & $\begin{array}{c}\text { Traditional } \\
\text { metal stove }\end{array}$ & $\begin{array}{c}\text { Improved } \\
\text { stove }\end{array}$ & $\begin{array}{c}\text { Kerosene } \\
\text { stove }\end{array}$ & $\begin{array}{c}\text { Butogas } \\
\text { stove }\end{array}$ \\
\hline Firewood & $\square$ & & & & \\
\hline Charcoal & & $\nabla$ & $\nabla$ & & \\
\hline Kerosene & & & & $\nabla$ & \\
\hline LPG & & & & & $\square$ \\
\hline
\end{tabular}

Table 5.2 relates the types of fuel used to the various economic groups in the village. All wealth groups use firewood as their main cooking fuel. The other three fuels are supplementary and either used for specific purposes (e.g. charcoal for coffee) or rarely used in the case of LPG and kerosene. It is important to note that wood is available within waking distances from the village and charcoal is made by the villagers themselves.

Table 5.2

Fuel types used by different family groups ${ }^{6}$ in Um Laham

\begin{tabular}{|l|c|c|c|c|}
\hline \multicolumn{1}{|c|}{ Type of fuel } & $\begin{array}{c}\text { Wealthy } \\
\text { families }\end{array}$ & $\begin{array}{c}\text { Medium } \\
\text { families }\end{array}$ & $\begin{array}{c}\text { Poor } \\
\text { families }\end{array}$ & $\begin{array}{c}\text { Very poor } \\
\text { families }\end{array}$ \\
\hline Firewood & $\square$ & $\square$ & $\nabla$ & $\square$ \\
\hline Charcoal & $\square$ & $\square$ & $\square$ & $\square$ \\
\hline Kerosene & $\square$ & & & \\
\hline LPG & $\square$ & & & \\
\hline
\end{tabular}

Table 5.3 ranks fuels according to identified preference criteria. Unlike in the other villages, in Um Laham, the preferred fuel type was found to be firewood. Firewood is preferred for cooking because it is free and can cook all types of food. Here, LPG is considered to have the disadvantage of being risky and unsafe, resulting in a lower ranking.

Table 5.3

Criteria and preference ranking ${ }^{7}$ for fuel types used for cooking in Um Laham Village

\begin{tabular}{|l|c|c|c|c|}
\hline & Firewood & Charcoal & Kerosene & LPG \\
\hline Fast firing & 2 & 1 & 3 & 4 \\
\hline Smoky & 1 & 2 & 3 & 4 \\
\hline Cooking all meals & 4 & 3 & 1 & 2 \\
\hline Cost & 4 & 3 & 2 & 1 \\
\hline
\end{tabular}

\footnotetext{
${ }^{6}$ The analysis is the same as in Es Sadda

${ }^{7}$ The analysis is the same as in Es Sadda. However, in this village, two additional criteria, cooking all meals and risks, were included by the women in the village as factors that affect the acceptance of cooking fuel and stoves.
} 


\begin{tabular}{|l|c|c|c|c|}
\hline Risk free & 2 & 4 & 3 & 1 \\
\hline Total scores & 14 & 13 & 12 & 12 \\
\hline Ranking & $1^{\text {st }}$ & $4^{\text {th }}$ & $2^{\text {nd }}$ & $3^{\text {rd }}$ \\
\hline
\end{tabular}

Although the village is close to Bara and El Obied, where LPG cylinders and burners are sold, the use of gas is not very common. Only six families possess gas cylinders and stoves. This is mainly due to the free availability of firewood and locally made charcoal, which provide free alternative sources of fuel to the modern ones (kerosene and LPG). Even the families who own LPG devices do not use them all the time for cooking purposes. Only soup and tea are prepared using LPG; porridge is cooked over firewood and coffee is made using charcoal. The availability of wood in the vicinity to the village means it is used by all families regardless of their economic status and wealth. Even women from wealthy families collect firewood for their own use.

The availability of fuelwood was not found to be affected by any of the vulnerability factors mentioned for this village. Even in the drought of 1983/85, wood was still available.

\subsubsection{Lighting}

Kerosene lamps are commonly used in all houses. However, other devices such as torches are also used. Lighting is also provided by the electrical generator to eight houses which belong to wealthy families, including the one owning the generator set. It was noticed that the electrical lamps installed outside the rooms are put in the fence to attract flying insects, away from where the family sleeps, particularly during the rainy season when insect numbers increase. The main indoor use of electricity is TVs, rather than lighting.

In the mosque, lighting is now obtained from the electrical generator. The school in the past did not use any source of energy and so pupils were called to attend about one to two hours before the sun set for evening study. However, the extension of electricity to the school allows boys to now study into the evenings. Lighting is another service that is not affected by the factors of vulnerability. Kerosene is available in the village shops and transporting it from the city market is not affected by seasonal conditions.

\subsubsection{Water services}

Water is obtained by using two means: drawing water from the shallow wells using draught animals (donkeys and camels) using a rope and bucket, and by a solar pump. The first option is usually for domestic uses (drinking and washing). Women and children are responsible for obtaining the water. They use animals to draw the water and transport it to their homes. A third option is a pumping system using a diesel pump but this was broken during the study. Even when the water pumping system is operating, women still have to transport water to their houses on donkeys.

Two factors of vulnerability were found to affect the flow of water services: drought and seasonality. The water service is severely affected when there is a long drought, such as in 1983/85. When there was no water for three successive years, the water level in the shallow wells started to drop. The decease in water levels started after the second dry and people started to dig down to get water until they reached a depth of 40 metres when they stopped because it became dangerous. After the second year, villagers started to move away. Those who stayed transported water from Bara on camels. Seasonality has also shown impacts. During the rainy season, water is available in small ponds and streams which animals drink. During the dry season, water has to be drawn manually from the shallow wells for the animals. So, both drought and seasonality affect the flow of water services in the village. The groups mostly affected by these factors are the women and children who are responsible for providing water for households and the men who draw the water for their animals.

\subsubsection{Transportation and communication}


As mentioned earlier, transportation in the village was affected by the establishment of the two paved roads (Khartoum - El Obied and El Obied - Bara). Lorries used to pass through the village every day, but this has ceased with the building of the paved roads and changes in transportation routes. The transportation of people, goods and services between the village and Bara is now done using camels. At Bara, it is possible to switch to other means of transport (buses and lorries). Communication is possible through the two telephones shops located in the village. Telephones are used during the period of harvesting crops (sesame) and when tapping gum Arabic to find out prices in various markets around the village. Transportation and communication are both unaffected by the vulnerability factors impinging on the village. Unlike in the villages of Es Sadda and El Idied, the rainy season does not block transportation routes.

\subsubsection{Farm operations}

Agriculture is generally practiced in small plots of approximately 2 to 4 feddans. The main crops are millet and sorghum which are grown as family food (subsistence crops). Alongside these, some crops such as sesame, ground nut and water melon are grown to earn cash. Family members provide most of the labour for agricultural operations. The characteristics of the soil, which is generally sandy, make farm operations relatively easy. Usually, land preparation tasks are unnecessary, and agricultural operations start with sowing followed by weeding and harvesting. All these operations are carried out manually by women. On the irrigated farm, land is prepared manually so as to smooth the flow of water. The other operations are also carried out manually by women in the village. Transportation of farm products is on camels from the fields close to the village. Since production is mostly on a subsistence basis, there is only a small surplus which is only transported to the market when families feel they have a surplus. Factors of vulnerability that affect farming are drought, seasonality and crop pests. All these factors influence the level of food produced.

\subsubsection{Non-farm activities}

Um Laham has a small-scale industry in the form of 22 privately-owned sesame oil mills. These are made of wooden parts: a large fixed component which serves as a container in which the sesame seeds are pressed and a small part which rotates inside the larger one to crush the sesame seeds and extract the oil. The oil mills are powered by camels. Usually this activity is practiced during the months of December to April. Sesame seeds are bought from El Obied market at times when prices are relatively low. The extracted oil is sold in Bara and nearby villages. The operation stops during droughts, when sesame seeds are not available, or when prices are too high. Other services include a grain mill which is privately owned and operated using a diesel engine. Fuel for the grain mill is obtained from Bara.

\subsection{Transforming structures and processes}

In Um Laham, as in the other villages in the study, the government's energy structures and processes are absent. The water distribution system, which is composed of a borehole, an overhead tank and a service point, was built by an international organization (UNDP), the solar pump was provided by an NGO (SSA), and the rest of the services such as the generator and the telephones were privately installed. However, the state government has provided the teachers for the school in the village. The village can also be seen as having been negatively affected by government intervention through the building of the paved roads which caused the transportation routes to be diverted away from the village. This not only affected the transportation facilities open to the villagers but also some income activities were lost. For example, when lorries were passing through the village, there were tea, coffee and food shops from which passengers could satisfy their needs.

There is no market place in the village, and there are only two small shops. However, electricity and telephone communication are provided on a market basis. Being close to the market in Bara and some villages with weekly markets, people in Um Laham get some of their energy services from these markets. They are also able to sell charcoal, so there is an exchange of energy services between the village and city. 


\section{Annex 6: An analytical description of livelihoods and energy services in El Ga'a}

\subsection{Vulnerability context}

Factors of vulnerability in El Ga'a include droughts, health shocks, floods, fire outbreaks and population trends. It is important to note that seasonality has no major effects on livelihoods in the village. The salt extraction process is not affected by rain, which is usually of low intensity in the village area. Also, because the area is sandy, transportation is not seasonally affected. Thus, neither the extraction of salt nor its price exhibit major seasonal fluctuations. So seasonality is not a source of vulnerability for the village. However, seasonality was a source of vulnerability before the introduction of the solar evaporator technology. In the traditional process, the firewood used to boil the brine became scarce during the rainy season. This was because the forest from which firewood had been brought was located in valleys which become wet in the rainy season making it difficult to both cut and transport wood.

\subsubsection{Drought}

As people in El Ga'a draw their livelihoods from salt extraction rather than from agriculture and animal raising, drought events have no direct impacts on them. Their natural capital, the brine wells, is not affected by short drought events. The only drought, as recalled by the people, that had an impact on their livelihoods was the long drought of 1983/86. During that long period of drought, the incoming migrants from surrounding areas had negative impacts on the producers of salt (who are non-well owners) and on those who carry out the manual tasks. The competition for the available work from the migrants caused a significant drop in the labour wage. This had positive impacts on the incomes of the well owners, who saw higher profits due to the lower wages paid to the brine drawers and for other labour work. Also, the merchants who, besides owning wells, would sell fuelwood and market the salt saw gains. So, the vulnerability imposed by the drought in the village is in the form of changing price ratios (prices of inputs, labour, selling and buying) rather than in the level of production.

\subsubsection{Health shocks}

Generally, the only severe health shock recalled by the people was an outbreak of cholera in 1970. Also, when the traditional salt extraction process was used, there were common health problems related to working conditions ${ }^{1}$. From the health centre records it was found that $73 \%$ of women and children who visited the centre in 1993 complained of respiratory diseases and eye irritations (Ahmed, 1996).

\subsubsection{Floods}

Flooding in the village is mainly seen as accumulated rain water covering the brine well site. During heavy rains, water from all sides drains into the low land of the well sites. In some years, the water levels rise to cover the well site. Severe flooding in the village was witnessed in 1970, 1980, 1988 and 1992. The first two events saw the collapse of some wells (no exact figures were recalled), but the worst year was 1988 when the whole well site was covered by water and nearly 182 wells collapsed. In the 1992 flood, only 12 wells collapsed.

In the context of vulnerability, floods represent a severe economic shock to the owners of wells as well as for those who extract salt. For the well owners, particularly those who cannot afford to rehabilitate their well or dig a new one, it is a significant loss of financial capital. For the other salt producers, the collapse of a large number of wells results in a higher price for the brine. Although the price of salt increases, it is not to a level that can offset the increase in the cost of the brine.

The only segment of the population that is not negatively affected is the well diggers (dahawa) who have their economic position strengthened by the high return they receive for rehabilitating old wells and digging new ones. After 1988, the rate for a dahawa (working from six in the morning until midday)

\footnotetext{
${ }^{1}$ Smoke and high temperatures resulting from burning large quantities of wood. The inside temperature of the cottages would exceed $50 \mathrm{C}^{\circ}$ (Ahmed, 1996)
} 
digging a well increased from 50 to $100 \mathrm{Ls}^{2}$, (roughly from SDG 10 to SDG 20 (€ 4 to $€$ 8) and, after 1992, from SDG 30 to SDG 50 ( $€ 12$ to $€ 20$ ). Thus, in the case of a flood, all groups, other than the well diggers, see large negative impacts due to the loss of the source of the brine from which to extract salt. Losses fall directly on the well owners and, indirectly, on the rest of the population.

\subsubsection{Fire outbreaks}

Fire outbreaks have also been one of the great shocks affecting the village inhabitants. As most houses are made from thatched grasses, and large quantities of firewood were burnt within them in the traditional salt extraction process, at least ten houses had caught fire. The worst event was in 1981 when the whole village was burnt to the ground. On that occasion, there were strong winds which facilitated the spread of fire and prevented people from extinguishing it. Although, there were no causalities or loss of life, all household physical assets and furniture were completely lost.

\subsubsection{Population trends}

Population trends in El Ga'a show a large increase in population. The number of families living in the village increased from 800 in 1994 to 1060 during the study period in 2004. This increase resulted from the drought that had affected livelihoods in surrounding areas (mainly due to a loss of animals) and the income-earning opportunities in the village from salt extraction. The major effect of this population trend is pressure on the available services, particularly drinking water which has increased in price. Also the competition for work has led to a fall in the wages of daily labourers.

\subsubsection{Seasonality}

In El Ga'a seasonality has no major effects on the flow of energy services. The only service that is affected is the firewood used in cooking. During the rainy season, collection of dry firewood becomes difficult. Other services are not seriously affected by seasonality. There are transportation facilities throughout the year which makes it possible to acquire all services that are not locally produced.

\subsection{Livelihood assets}

\subsubsection{Natural Capital}

The El Ga'a area is characterized by low rainfall with an annual average of only $100 \mathrm{~mm}$. Precipitation occurs mainly during the months of June to September (El Samani, 1982 p. 11). Annual fluctuations in rain fall are high, with several seasons of poor precipitation and resulting droughts. The natural vegetation is affected by both soil type and the intensity of the rainfall. The area is described as poor savannah woodland, with sparsely distributed acacia trees and short to medium grasses along the valleys and land depressions. The soil and the underground water have very high salt concentrations, which makes the latter unsuitable for drinking or agricultural production. However, this characteristic provides the brine from which the salt is extracted. The area from which the brine is obtained is called El Idd and is 5 kilometres long and 2 kilometres wide. There have been no geological investigations of the sources or nature of the formation of the brine (Ahmed, 1996).

\subsubsection{Physical capital}

The physical capital in the village includes: the brine wells, the tools used in the processes of salt extraction, the evaporators, water tankers, generators, bakeries, grain mills plus transportation and communication facilities.

- Brine wells: There are about 600 wells from which the brine water for salt extraction is drawn. Wells are dug in three areas: an old one (El Idd El Gadeem) with about 300 wells, and two new areas (El Idd Shalateen) with 100 wells and (El Idd El Ingath) with about 200 wells. The last two areas were newly

\footnotetext{
${ }^{2}$ Ls stands for Sudanese pounds which was the currency at that time, and the exchange rate was roughly Ls 5 per US\$ 1 .
} 
established in 2000. Wells are positioned with a certain distance between them ranging between 10 and 20 metres. A new well starts to produce 10 tins $^{3}$ of saline water per day at a depth of 20 metres, but output decreases annually unless the well owners dig deeper. Wells stop providing water after 50 to 60 years of exploitation when they reach a depth where they cannot be dug any deeper using manual tools. The brine is extracted from 20 to 90 metres below the surface.

- Salt extraction technology: Traditionally salt was extracted by boiling the brine in large pans over firewood. Pans used to be filled with the brine, placed on a three stone stove, and firewood lit below as shown in Photo 6.1. This traditional process continued from when salt was first found until 1994. In 1994, a new technology, solar evaporators, was introduced by the Energy Research Institute (ERI) to replace firewood use. The solar evaporator is simply an earth basin covered by a polythene sheet as shown in Photo 6.2. About one cubic metre of brine is poured into the evaporator and, about 9 days later, all the water has evaporated leaving white crystals of salt. An evaporator cycle gives on average about three kuntars $(150 \mathrm{~kg}$ ) of salt. The evaporator design was intended to maintain the existing level of production by providing nine evaporators to each family to be filled on consecutive days, enabling families to have salt from one evaporator ready to sell each day.

\footnotetext{
${ }^{3} \mathrm{~A}$ tin is approximately 18 litres in volume
} 
Photo 6.1: Boiling brine in the traditional salt extraction process in El Ga'a

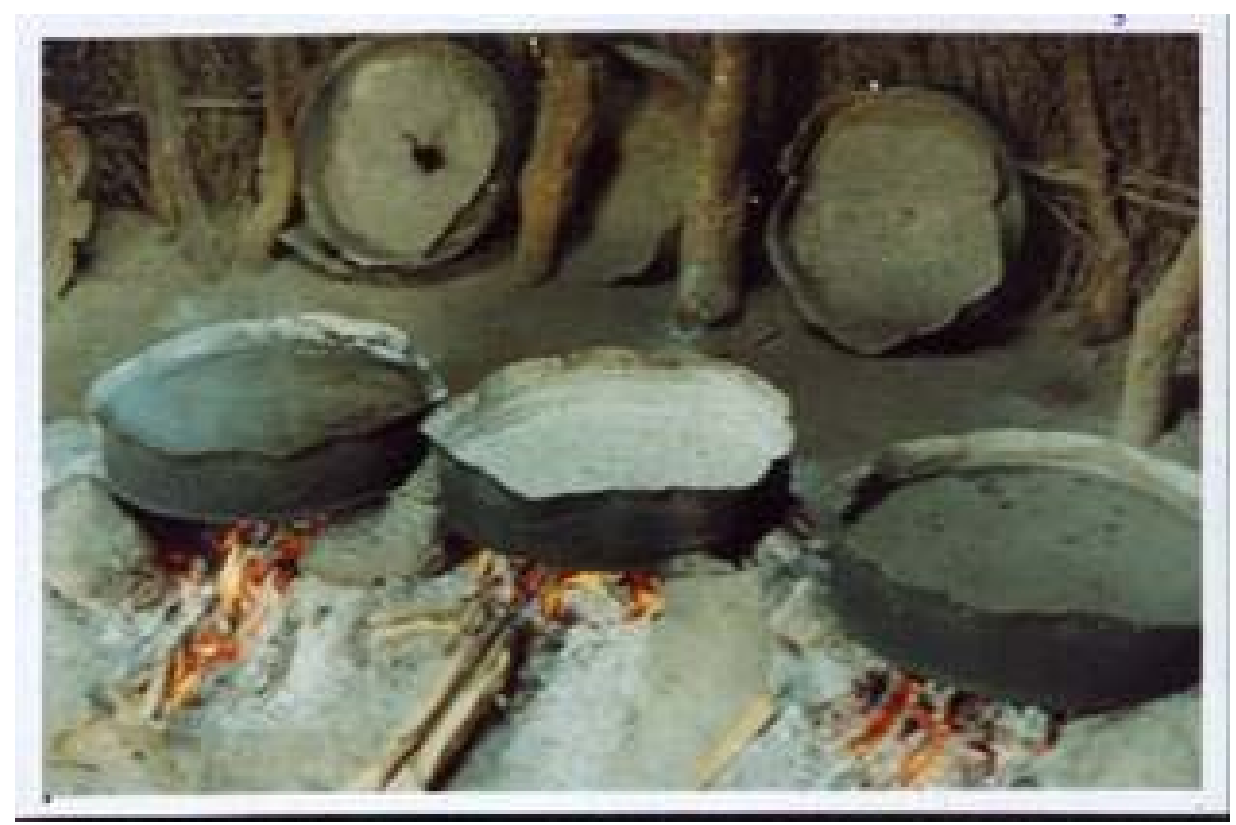

Photo 6.2: Evaporators in a family cmpound in El Ga'a

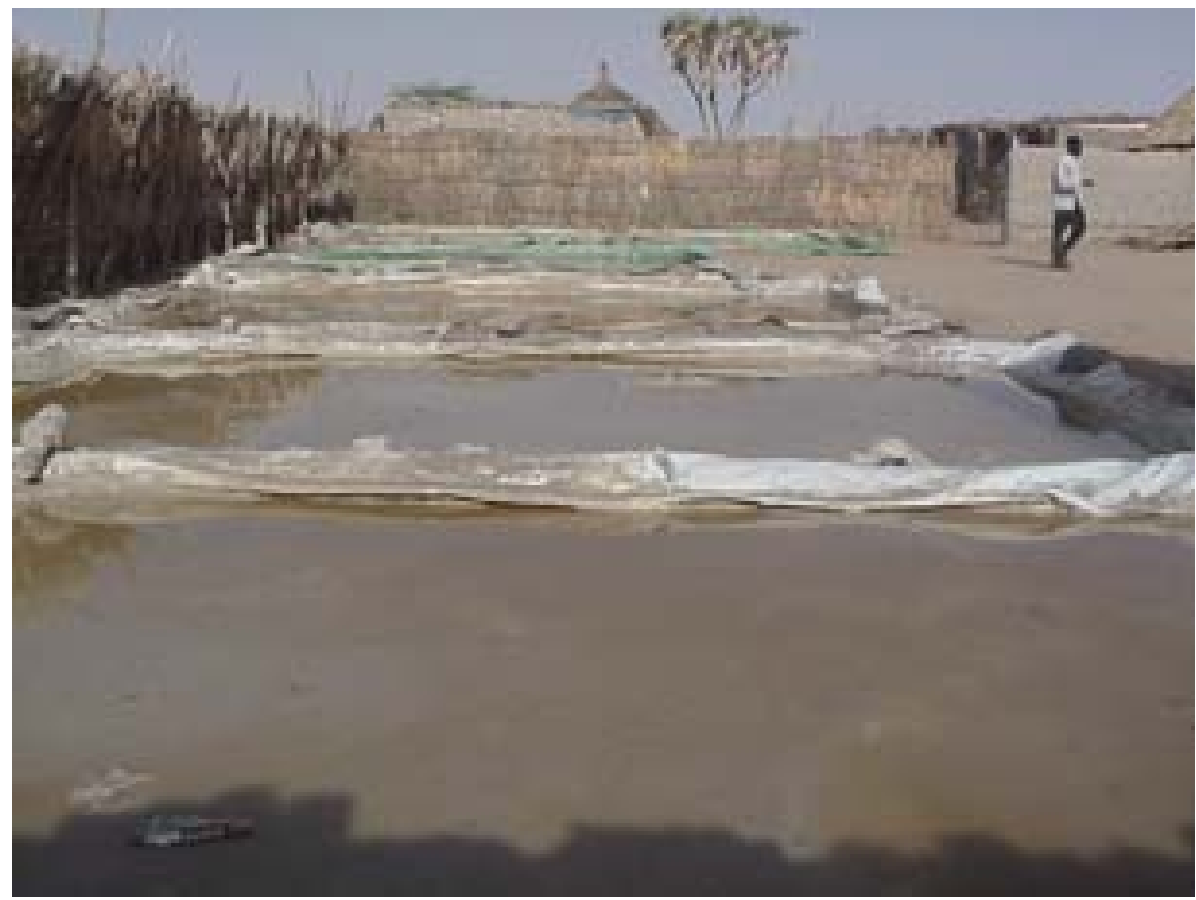


- Drinking water boreholes: Because of the high salt content in the underground water in the village, drinking water is brought from the villages of Um Sadoon and Nakur which are located about $28 \mathrm{~km}$ and $11 \mathrm{~km}$ from El Ga'a respectively. The physical capital components used in the provision of water include boreholes and pumps.

- Water tankers: Because the water boreholes are located away from the village, tankers are used to transport water, and water reservoirs used to store water in the village before distribution. Three large tankers (15 barrels each) transport water from the well sites to the village. Water from the tankers is emptied into five water reservoirs (about 30 cubic metres volume) before it is sold to the villagers. Of these water facilities, the Village Development Committee owns one tanker and one reservoir, and the rest are privately owned.

- Transportation and communication: Salt is transported by lorries to the consumer sites. These lorries will also carry passengers to the destination the lorry is going. There are no regular routes and passengers have to wait for lorries to take them either directly to their destination or elsewhere where they can find onward transportation. On market days, lorries come from surrounding villages. Further, there are many private cars that can be hired when there is a critical situation such as a health emergency or other occasions in the village. In the village, there are three satellite TV sets, one of which is for private use by a family. The other two are operated in the public market place with an entrance fee to attend the shows.

In terms of communication, there are three telephone units plus a satellite telephone (El Thuriya) which is also used for public communications. Salt dealers use the telephones quite often to discuss salt prices and information on the market situation in different areas. In 2003, the Sudan Telephone Company (Sudatel) started to build a large service unit in the village, telephones poles were erected and more than 200 families had registered to subscribe to the telephone service. The service had yet to be connected at the time of this study.

- Agricultural implements: Agriculture is not the dominant profession in the village and so its practice is limited. The production tools and equipment used in agriculture are only traditional hand tools (Salaouka, Malou and Toria) which are used to cultivate small plots around the village.

- Building materials: There are two types of materials from which the village house are built. About 90\% of households are built of grasses and wood. The other $10 \%$ are built from fired red bricks or unfired bricks. In the past, it was only the wealthy families who could afford brick houses but now middleincome families have also begun to build brick houses. Both fired and unfired bricks are transported to the village from Abu Hashiem which lies about $30 \mathrm{~km}$ from the village. One of the village merchants has a brick kiln in that area and transports bricks to sell in the village (Khamies Abdalla, owner of the brick kiln, visited in April 2004). Nearly all the village service centres (4 mosques, 1 health centre, 2 schools, 6 grain mills and 5 generators) are built from red bricks.

- The market: El Ga'a has a market place used for salt trading. Most of the shops are constructed from permanent materials (bricks, cement and corrugated iron). The market is located in the centre of the village and surrounded by houses on all sides. Therefore, the number of shops in the market is limited, and there is no opportunity to extend the market or have newcomers join the market. This spatial restriction on the marketplace means that many people dealing in salt have their 'shops' inside their houses.

- Electricity generators: In El Ga'a there are five diesel generator sets, one owned by the VPC and four privately owned. The VPC generator provides electricity to village service centres including the schools, the mosques, the khalwa, the market and the youth club. The private electrical generators provide electricity to households with each generator connected to a number of households.

\subsubsection{Human capital}

- Education: As in all the villages in this study, both formal and informal educational institutions are present. Formal education in El Ga'a is provided by two basic schools, one for boys and another for girls. The numbers of children enrolled in these schools are 270 and 240 respectively. 
- Health services: Health services in the village are provided by a health centre built in the village in 1979. The health centre is equipped with a solar vaccine fridge provided by UNICEF through the Extended Programme of Immunization (EPI), and installed by ERI through its Rural Solar Energy Development (RSED) project in 1994. However, at the time of this study, there were no vaccines in the fridge and there had, according to the health assistant, not been any for about four years. The main reason given was that the provision of vaccines was shifted to the state government which did not have enough finance to distribute vaccines to all villages on a regular basis. The health centre is also equipped with a delivery theatre and facilities. A health assistant, aided by a nurse and two midwives, runs the health centre.

- Training and skills: Training and skills found in the village are related to the processes of salt extraction. People want to know the potential sites for brine with high salt concentrations when deciding where to dig wells. Often, before anyone digs a well, old people in the village are consulted and their advice is used to locate places with potentially high salt concentrations. The concentration of salt in the brine varies with the location and depth of the well. The location of wells within El Idd and their depth determine the concentration of salt in the brine. Generally, the wells located at the lower end of El Idd have higher salt concentrations than those on the upper site. Salt concentration also varies with the depth of the well. The deep wells, about 60 to 90 metres, give the highest salt concentrations (tagiela); the moderate well depths, 30 to 60 metres, give moderate salt concentrations (mutgawza); and the shallow depths, less than 30 metres, give low salt concentrations (khafifa). The developed skills include well digging, salt extraction processes, handling the brine and determining sites of good brine quality and quantity. Well digging is carried out manually, and usually involves three people. One digger goes down the well, digging out the rocks using hand tools and putting the pieces of broken rock in a bucket. Another one waits at the top to grab the bucket, and then empties its contents outside the well. The third, usually a child, using a donkey draws up the rope and bucket. Due to the increase in demand for brine, people in the village have opened two new sites.

Other skills, such as driving and mechanical practices, are present in the village and are indirectly related to salt extraction. There are 20 truck drivers and 37 men with mechanical skills. Lorries first entered the village in 1940 brought by salt traders. When merchants from outside the village came with their lorries, to transport salt, water and firewood, villagers were exposed to new means of transportation and opportunities arose to provide repair and maintenance services. Some of the men in the village have adopted these skills as their main professions, and developed further services in the village, while the other their family members continue to depend on salt as their main source of income.

\subsubsection{Social capital}

The social capital in the village is organised through both formal and informal organisations. The only formal organization is the Village Popular Committee (VPC). The VPC has 20 members equally representing the old settlements of El Rwais and Um Safari. The newly-settled groups in the village are not represented on the committee. Five members of the VPC are women (25\% of the committee's seats). Unlike the other villages in this study, El Ga'a has no Development Committee. The VPC has four subcommittees: the educational subcommittee, the water subcommittee, salt subcommittee and the health subcommittee. The responsibilities of these subcommittees, with the exception of the salt subcommittee, are similar to those in the other villages. The responsibility of the salt subcommittee is to give permission for new well digging, allocate sites, and collect the appropriate fees. Although women are represented on the VPC, there are some subcommittees that do not have women representatives. These include the salt subcommittee even though they were involved in salt extraction before men, and they were the only actors when salt was traditionally extracted.

The informal organization is based on the village Sheieks. El Ga'a has four Sheieks representing different lineage groups. The Sheikhs undertake two important tasks in the village. The first task is the calculation and collection of the Zakat and taxes. The second is that they take part in the resolution of conflicts between groups and individuals in the village., There is also a Youth Association as another form of informal organization. This has two important roles, the first is managing and looking after the youth club with its satellite TV and furniture. The second role is to determine the fees for attending the club. Another 
form of informal organization as part of social capital is the women's fund groups (sandug) which each have between 5 to 15 members and are usually formed by neighbouring families. These groups make savings through a weekly allocation of some of their salt extracted. The salt collected from all members of the sandug is taken by one of them.

\subsubsection{Financial capital}

The nearest formal financial institutions (banks) are in the towns of Bara and El Obied and therefore, only the merchants and large salt traders in the village use them. In the village, merchants play the role of moneylenders. Families can borrow money from the merchants, or take goods from their shop against their salt produce. A person can take, in advance, money equivalent to the value of a certain quantity of salt which he will bring to the merchant when his salt is ready. It was observed that borrowers receive the current market price of salt without any interest being charged. Normally, the length of time given to deliver the salt does not exceed one week: the length of time needed to evaporate all the water in an evaporator leaving the salt ready to be collected and sold.

Another form of finance already noted is the weekly sandug which is practised by nearly all the women in the village. The women give one kuntar of salt weekly to the sandug to be sold by one of them. The process continues until all the women have taken their turn, and then a new round starts. The money from the sale of the salt is usually used to purchase a variety of items such as personal items of gold or household goods such as furniture, LPG devices or kitchen utensils. The process of salt extraction provides employment through several tasks such as well digging, water drawing and water transportation. Well digging involves three people who are contracted on a daily basis (dahawa). A dahawa is five to seven hours of work and the wages vary with the task performed in the process. The person who enters the well to do the digging is paid SDG 5 (€2) per dahawa, the one who stands at the top of the well gets SDG 3 (€ 1.20) and the child responsible for drawing the donkey gets SDG $1(€ 0.40)$. A new well takes about three to four months to reach the depth of he saline water and the total cost is about SDG 1000 (€ $400)$ to SDG 1500 (€ 600).

The drawing of water is done by hired labour or family labour. Water is drawn by using a bucket and a rope pulled by a donkey. Two people are required for this task; one who operates the bucket and a child who drives the donkey pulling the rope. The water is deposited in a small reservoir by the side of the well, from which the water is sold to users. The water drawers are paid according to the number of barrels sold. For each barrel, the drawers receive SDG $0.5(€ 0.20)$. This is shared between them; the one controlling the bucket takes SDG 0.25 (€ 0.10), the child takes SDG 0.15 (Euro 0.06) and the remaining SDG 0.1 (Euro 0.04) is used to buy fodder and water for the donkey.

The brine is carried to the house compounds on donkey carts in a barrel. The cost of transportation varies according to the distance travelled. There is a specified price of transportation for each area in the village. Transporting one barrel of brine typically costs about SDG 1 ( $€$ 0.40). The cost of the donkey’s food and water is first deducted and then the rest is divided equally between the cart owner and the labourer driving it. The labourer is usually a child in the 10 to 15 year age range. The transportation activity was providing work for about 60 children at the time of the study.

The brine in the evaporator has to be stirred remove the thin film of salt that forms on the surface of the evaporator since this film reduces the rate of evaporation and extends the period needed to obtain dry salt. This layer starts to form on the third day after filling the evaporator and its formation becomes more frequent as the water evaporates. Stirring the water three to five times a day reduces the evaporation time by two to three days. The stirring process takes 5 to 10 minutes for each evaporator. Usually family members do this task, but people who own a large number of evaporators hire labourers to do it. An owner will pay a labourer SDG 0.25 ( $€$ 0.10) per day for each evaporator. Collecting the salt from the evaporator and packing it into sacks is another task for which some people use hired labour. The rate paid is SDG 0.25 per sack of salt (approximately weight $50 \mathrm{~kg}$ or one Kuntar).

Loading the salt onto lorries employs some people in the village, who are paid SDG 0.5 (€ 0.20$)$ per sack. A lorry takes about 350 sacks gathered from different salt dealers, and it takes about 4 hours to complete 
the loading of the lorry. There are generally one to three lorries loaded with salt every day for distribution to different parts of Kordofan and Dar Fur states.

As seen from the above, the salt extraction process provides employment for many people in the village of both sexes. Further, as the area's marketing centre for this salt, many other services are also provided in the market. Drinking water, metal and repair workshops, lorry maintenance services, electrical services provided from local electricity generation, food, tea and coffee outlets, cold drinks and home building services are all available. This makes the village a destination for many from the surrounding areas in search of work.

\subsection{Energy services}

Energy services in the village are composed of cooking, lighting, water pumping, transportation, well digging, salt extraction and communication.

\subsubsection{Cooking}

It was observed that only three types of fuels are used for cooking services: wood, charcoal and LPG. Estimates by participants in this study from the village show that about $80 \%$ of families in the village are using LPG for their cooking services. However, wood is still used for cooking certain types of food such as porridge. The families who mainly use fuelwood are those recently settled in the village with little or no access to the salt extraction process. Their income is insufficient to buy LPG cylinders and burners. However, even these families buy their fuelwood from the market.

It was also observed that all the women in the market who sell food, coffee and tea use firewood and charcoal. One reason they gave for using firewood in their businesses instead of LPG is that they come from outside the village and work only on market days. If they were to use LPG, as the cylinder would be too heavy to take home every day, the cylinder would need to be left in a safe place, or it might be stolen. Traditional devices, on the other hand, which either have no monetary value (the three-stone stove) or cost very little (the traditional metal stove) can just be left in place until the next market day. For them, fuelwood is also collected at no financial cost. They simply collect enough wood the day before the market and bring it with them on their donkeys to the market place.

Since the cooking service is mostly met from sources other than natural capital, it is not affected by the vulnerability factors listed for El Ga'a. The continuous availability of transportation between the village and city centres allows the easy transportation of LPG cylinders from the city centres to the LPG agents in the village.

\subsubsection{Lighting}

Lighting in the village is obtained from electrical generators and from traditional sources. All the houses are connected to one of the five generators in the village. Shops in the market place also use electric lighting, and both schools and the health centre are connected to the VPC generator. Given the limited hours of availability of electricity, between 6:00 pm and 12:00 midnight, kerosene lamps and torches are also used outside these hours. Traditional lighting devices are needed as backup since the system is unreliable due to breakdowns, absence of operators, or there are delays in operation. As with cooking, lighting is not found to be affected by the vulnerability factors affecting the village. Transportation for the diesel fuel to run the generators is available all the year round and not subject to any seasonal problems.

\subsubsection{Water services}

Traders bring water in tankers for sale to consumers. In Um Sadoon, there is a water distribution system which just provides water for the tankers from El Ga'a. This system was constructed by the National Rural Water Corporation (NRWC). There are five tankers in the village; four of them are owned by merchants in the village and the fifth was provided to the village by Tayba Rural Council. The latter is run by the Village Water Committee. Each of the tankers makes two to three trips a day and brings about 6000 litres in each trip. The average family consumption of water is about 7 tins (20 litres volume) per 
day. The water fees at the water yard are SDG 0.5 (€ 0.20) per tin and it is sold to the consumers at the rate of SDG 1 ( $€ 0.40)$ per tin in the village. The water fees at the water distribution point are collected by the NRWC.

The supply of water is not affected by any of the vulnerability factors mentioned earlier. However, despite the five tankers, the village sometimes witnesses stresses in the water supply. This happens when there is breakdown in the water pumping systems (pump or engine failure). Breakdowns often take several days to be fixed and the village faces water shortages although not a complete lack.

\subsubsection{Salt extraction}

Salt extraction was in the past done by boiling the brine in ceramic, and then later metal, pans using fuelwood. In 1994, the process changed from boiling water over wood to solar evaporators. Before switching to the solar evaporator technology, large quantities of wood had been burned annually to extract salt. Table 6.1 illustrates the amount of fuelwood used annually in the village prior to the introduction of the evaporator technology and how it was transported.

Table 6.1

Annual quantities of fuelwood formerly consumed in the traditional salt extraction process in El Ga'a

\begin{tabular}{||c|c|c||}
\hline \hline $\begin{array}{l}\text { \% out of the } \\
\text { total wood demand }\end{array}$ & $\begin{array}{l}\text { Quantity of Wood } \\
\text { in Cubic Metres }\end{array}$ & Means of Transportation \\
\hline $75.0 \%$ & 5785 & Lorries \\
$13.4 \%$ & 1036 & Camels \\
$11.6 \%$ & 900 & Donkeys \\
\hline $100 \%$ & 7721 & TOTAL \\
\hline
\end{tabular}

Source: Forestry Records for the Year 1992 compiled by Ahmed, 1996.

Although solar evaporators have changed the source of the energy used in salt extraction, the types of energy used in other processes such as water drawing and transportation remain the same. Table 6.2 summarizes the types of energy services required in the process and the types of energy used in each process.

Table 6.2

Different energy services and types of energy used in the process of salt extraction in El Ga'a

\begin{tabular}{|l|l|l|}
\hline \multicolumn{1}{|c|}{ No. } & Energy services & \multicolumn{1}{c|}{ Type of energy } \\
\hline 1 & Well digging & $\begin{array}{l}\text { Manual + animals + } \\
\text { dynamite denotation }\end{array}$ \\
\hline 2 & Drawing & Manual + animal \\
\hline 3 & $\begin{array}{l}\text { Transportation of } \\
\text { the brine }\end{array}$ & $\begin{array}{l}\text { Animal (containers } \\
\text { balanced on the back of a } \\
\text { donkey) }\end{array}$ \\
\hline 4 & Evaporation & $\begin{array}{l}\text { Wood (in traditional) / Solar } \\
\text { (in the evaporators) }\end{array}$ \\
\hline 5 & Stirring & Manual \\
\hline 6 & Collection of salt & Manual \\
\hline 7 & $\begin{array}{l}\text { Transportation of } \\
\text { salt to the market }\end{array}$ & Animal \\
\hline 8 & $\begin{array}{l}\text { Distribution of } \\
\text { salt to } \\
\text { consumption } \\
\text { areas }\end{array}$ & Lorries \\
\hline
\end{tabular}


The process of salt extraction as described above is affected only by the vulnerability factor of flooding. Flooding destroys the wells from which the brine is obtained. However, generally, not all wells collapse during flooding events. Extraction of salt has witnessed a complete halt only once - during the 1988 flooding which lasted for two months. The impacts are felt by the owners of the collapsed wells and those producers who are not well owners.

Other vulnerability factors such as droughts have indirect impacts on the wages of daily labours. The health problems of women and children related to the traditional salt extraction process (boiling the brine) were completely removed by the introduction of solar evaporators. However, women saw some negative impacts of the new technology. Salt extraction in the traditional process was totally controlled by women; they extracted the salt and sold it, so they had some control over the income generated. The process is now becoming everyone's task in the family. Each member of the family can have his or her own evaporator and control what he or she produces. However, although women's control over the process has been reduced, they still have a financial gain. As mentioned in Section 6.2.4, women have created revolving funds (sandug) which are used to save money for buying special items.

\subsubsection{Farm operations}

The area is in the semi-desert region and so agriculture is not a major economic activity in the village, and because of the high risks and uncertainties they do not use mechanization or automated equipment. All operations, when there is sufficient rain to cultivate, are carried out manually, mostly by family labour. Unlike other areas women are not involved intensively in agricultural practices. This is because women in the past (before the introduction of solar evaporators) were involved in salt extraction processes. Mainly men form the labour force in agricultural production.

\subsection{Transforming structures and processes}

In this village, there are some energy services that were built by government agencies such as the water yard built by NRWC in 1990 and the evaporator technology provided by ERI in 1994. There is also a role for international agencies such as UNICEF, which provided the vaccine fridge for the health centre in the village. As in other villages, the government provides the teachers for the schools, the police officers, the forestry officers and the health assistant. Unlike in other villages in this study, in El Ga'a there is also a tax officer who collects taxes from the salt sellers.

The market for services in the village is relatively well developed compared to the other villages. Unlike all the other villages, El Ga'a has a local market which provides nearly all the necessary energy services. People in the village depend on the market for drinking water, LPG, electricity and communication facilities. The market in El Ga'a is different from those of the other studied villages in some respects. Although there are specified market days (Sundays and Wednesdays), the market is effectively permanently open with traders and customers coming from distant areas. 
Annex: 7: Views of the six villages downloaded from the Google Earth website:

\section{1: Es Sadda}

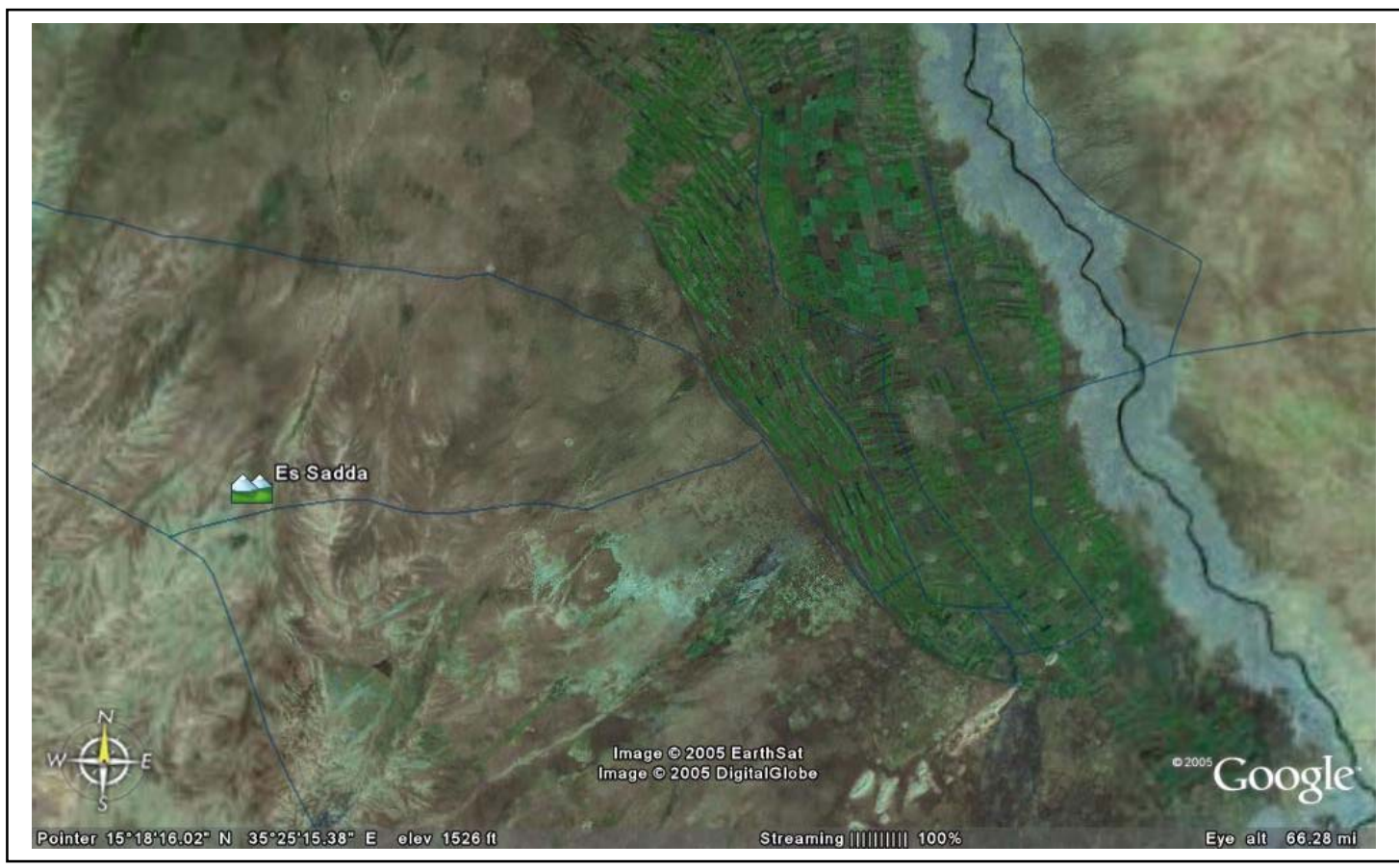

\section{2: El Idied}

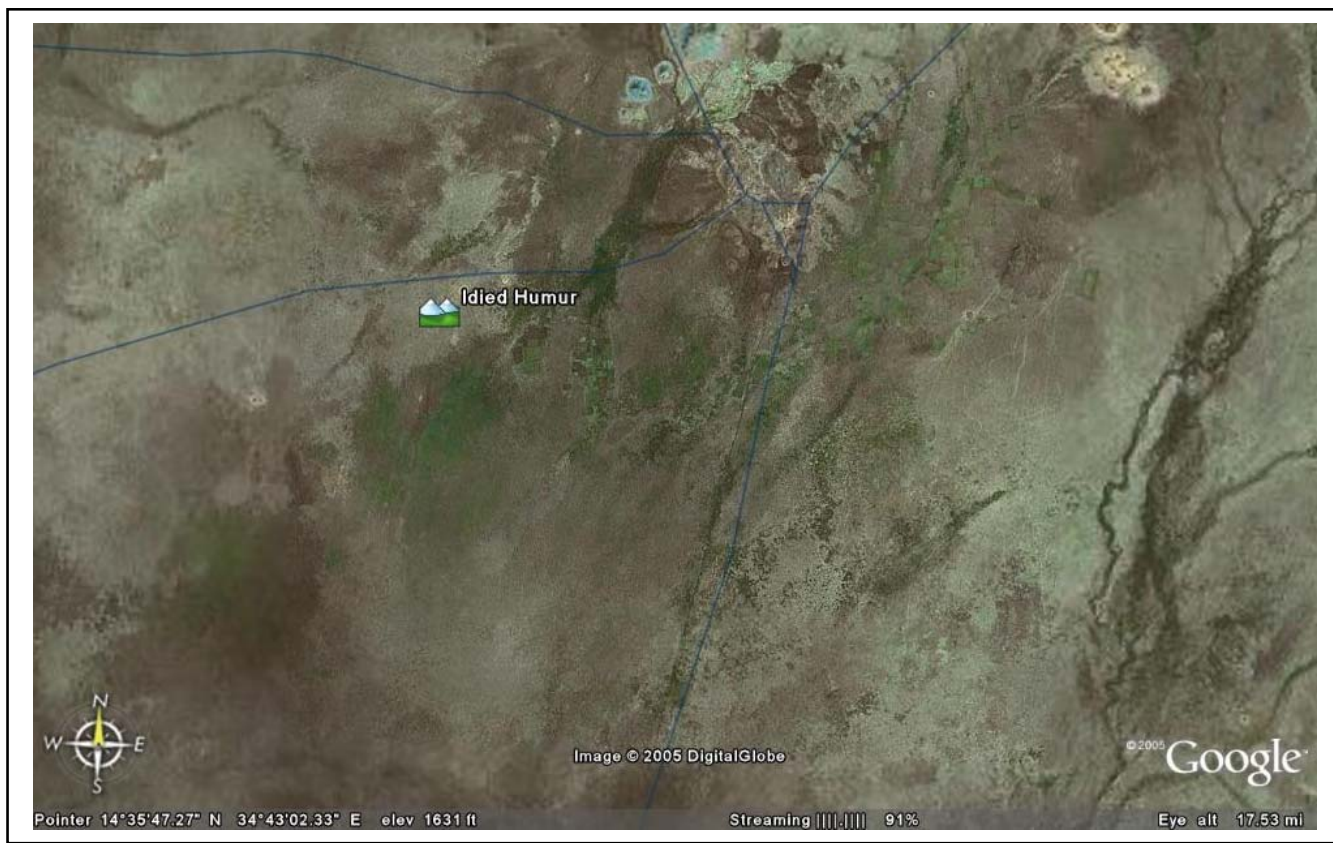




\section{3: Dar Mali}

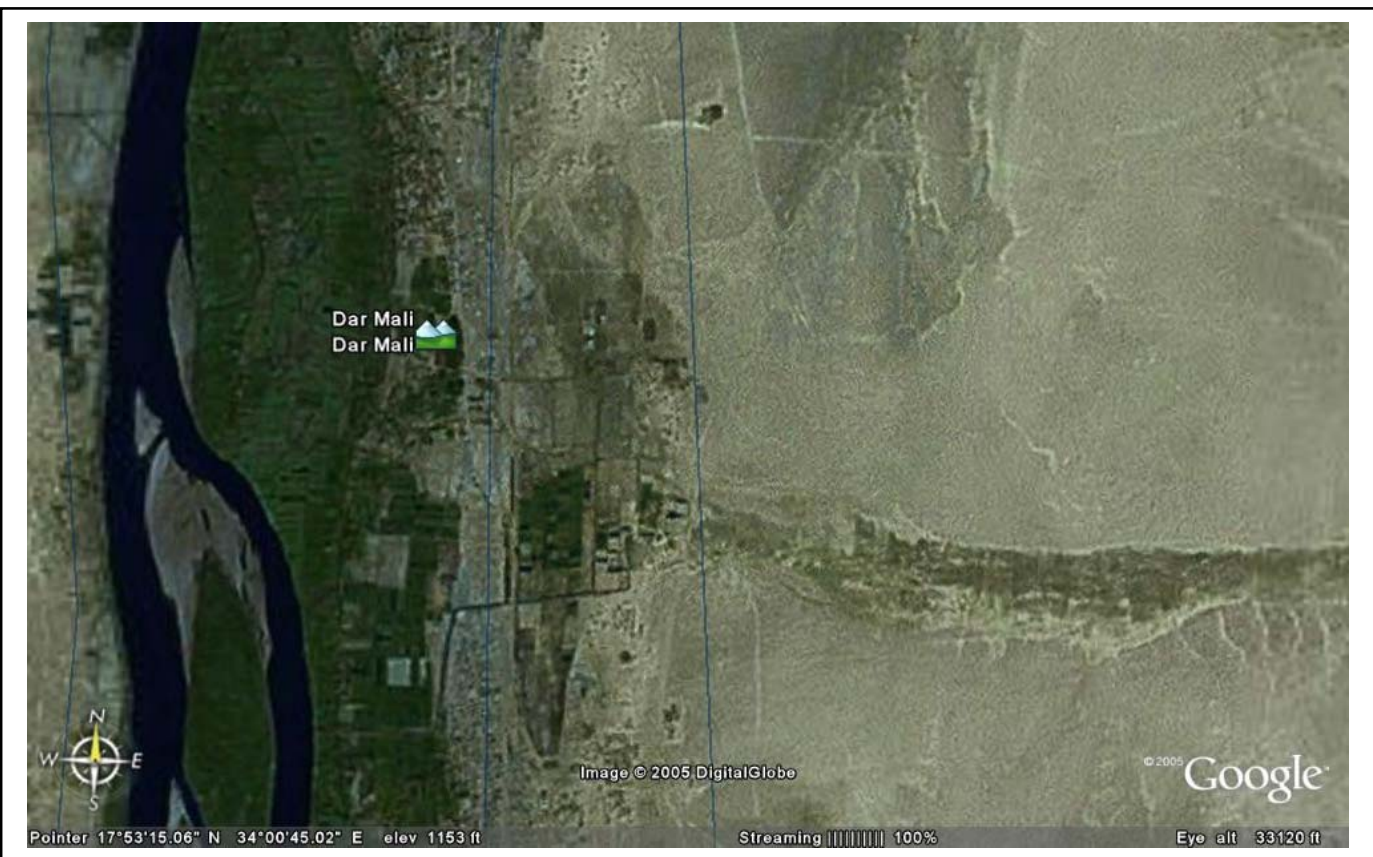

\section{4: Goz El Halag}

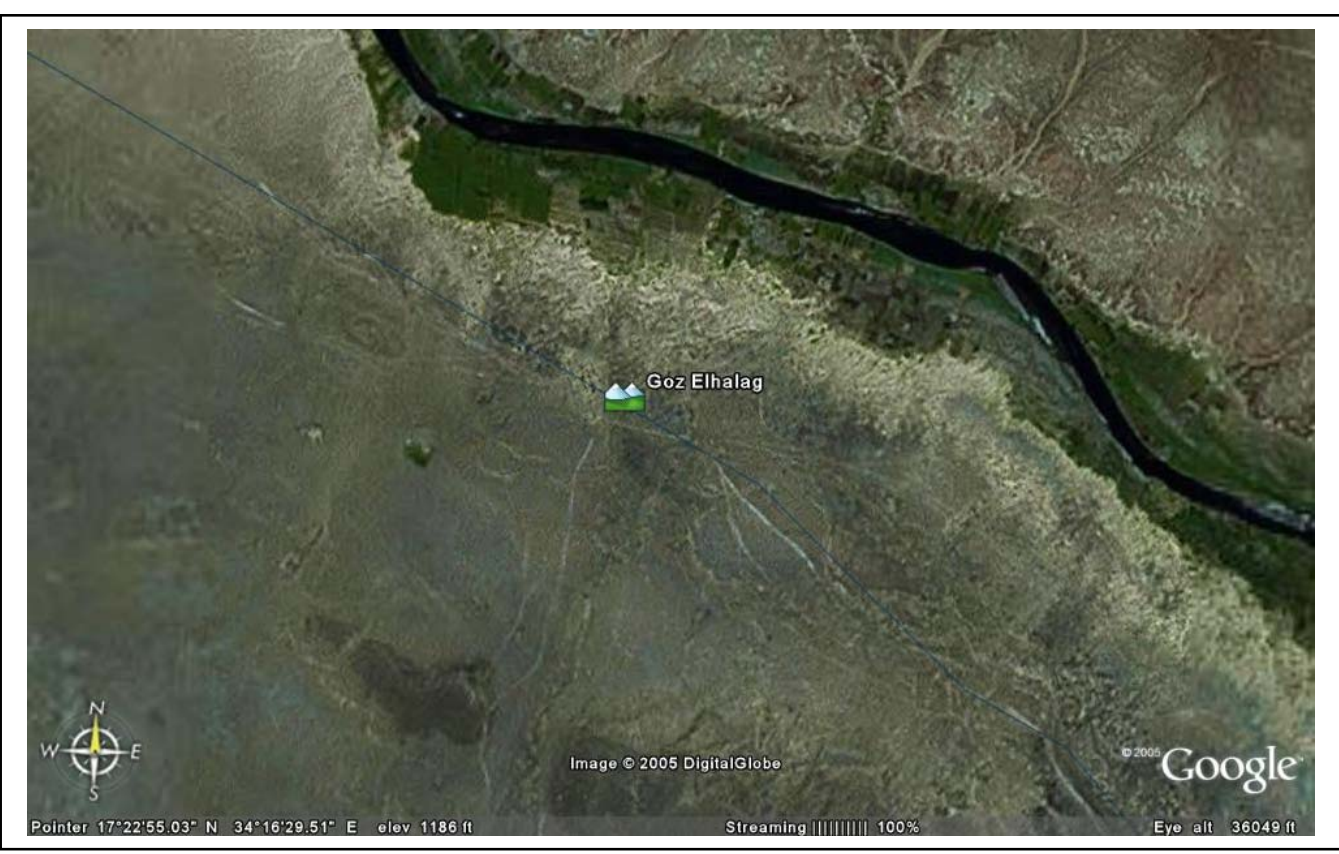


7.5: Um Laham

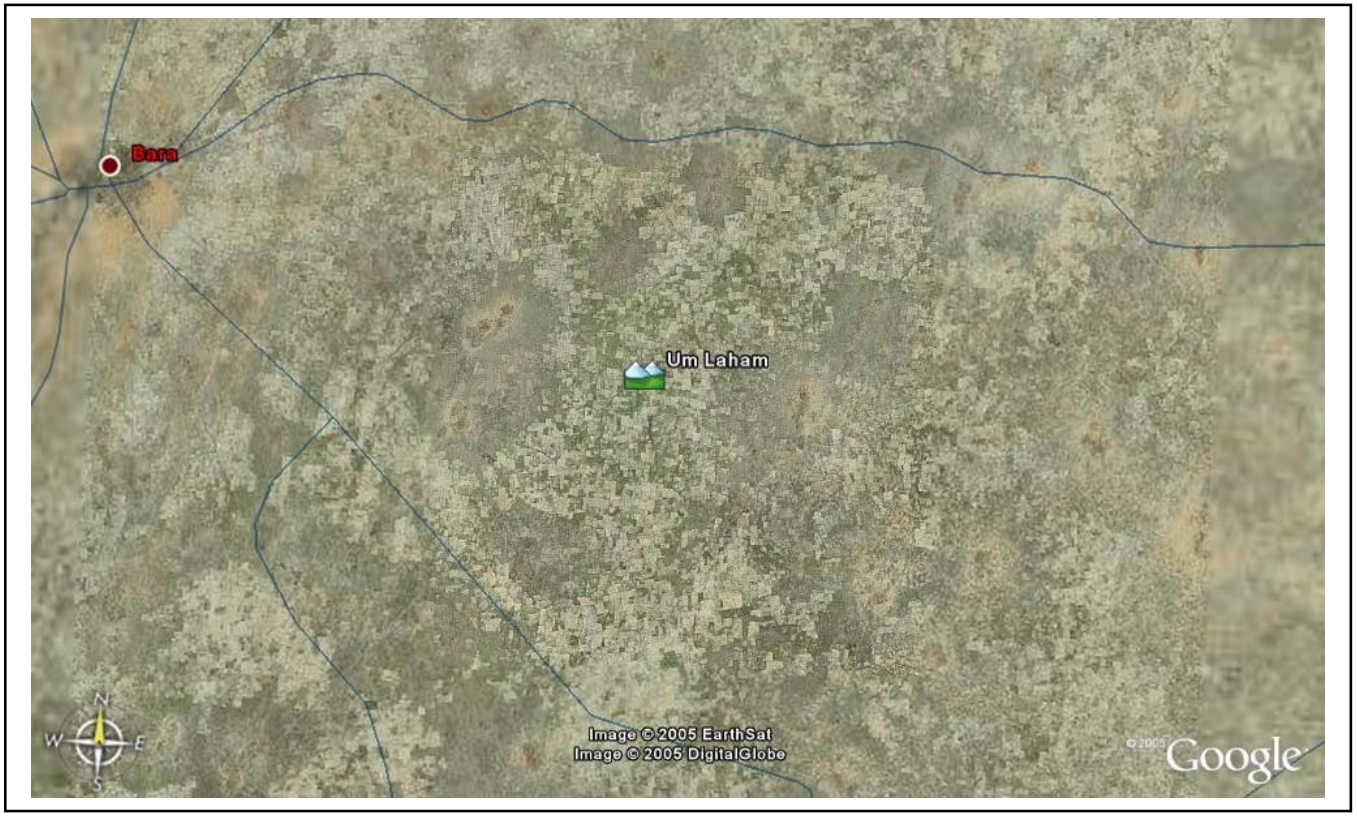

7.6: El Ga’a

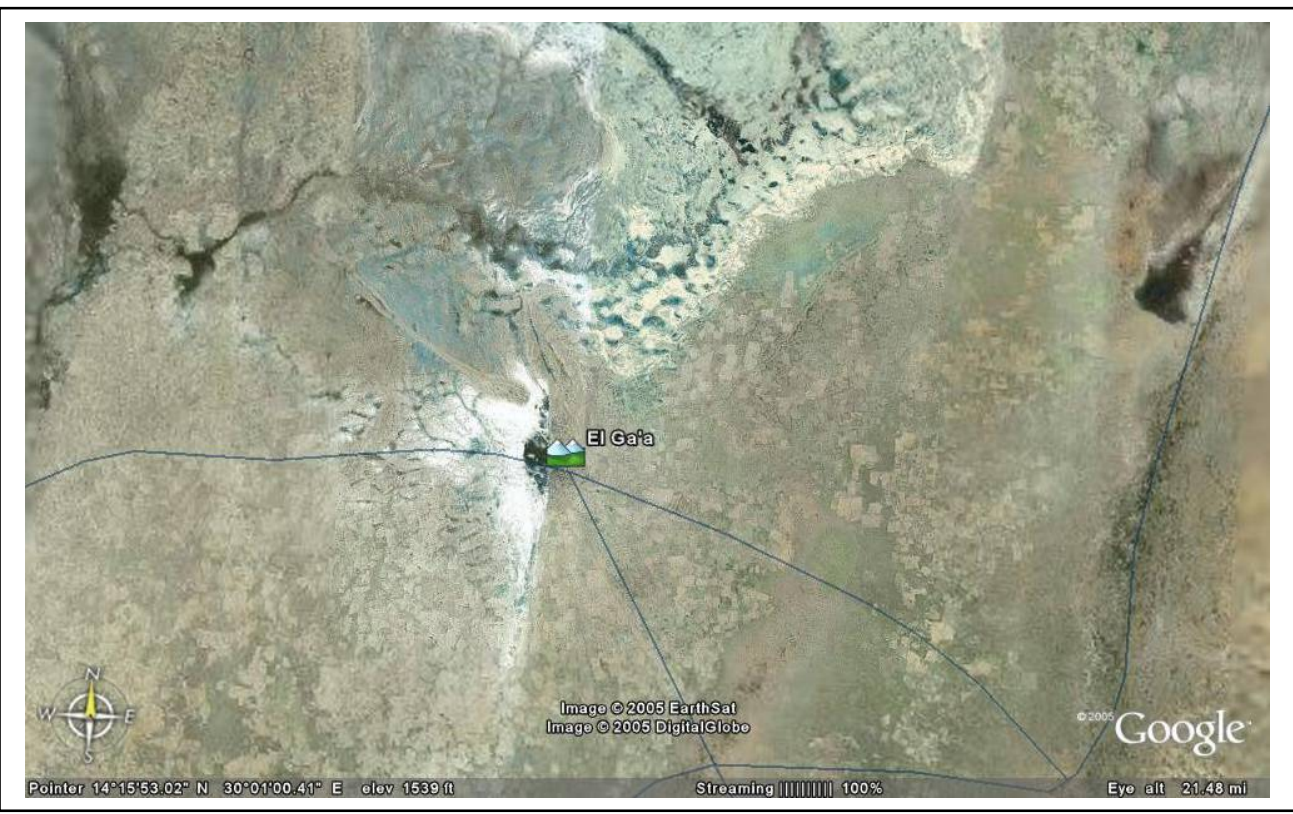




\section{Annex 8: Development of energy institutions and their defined roles and objectives in Sudan}

\begin{tabular}{|c|c|c|}
\hline No. & Institution & Defined Role and Objectives \\
\hline 1 & $\begin{array}{l}\text { National } \\
\text { Electricity } \\
\text { Corporation } \\
\text { (NEC) }\end{array}$ & $\begin{array}{l}\text { Developed from Light Company (1908). The } 1982 \text { act defined the following objectives for NEC: } \\
\text { - Utilization of the national energy resources economically in order to secure the country's needs of electric power } \\
\text { for different sectors and to grow and expand in proportion to the growth of these needs. } \\
\text { - Carry out its business on a commercial basis and achieve an annual rate of return as specified by the Board of } \\
\text { Directors to provide the necessary funds for implementing its development plans. } \\
\text { - Construction and management of the power facilities of the national grids and Khartoum distribution areas. } \\
\text { - Generation and distribution of the electricity on the National Electric Grid and wholesale (bulk supply) to } \\
\text { regional administrations in accordance with tariff and technical specifications determined by the corporation. } \\
\text { - Establishment of technical standards for electricity installation and operation to ensure uniformity throughout } \\
\text { - Sudan. } \\
\text { - Provision of consultancy and technical services to regional electricity organizations on a commercial basis. }\end{array}$ \\
\hline 2 & $\begin{array}{l}\text { Energy } \\
\text { Research } \\
\text { Institute (ERI) }\end{array}$ & $\begin{array}{l}\text { Established in } 1972 \text { with the following mandate: } \\
\text { - Carry out applied research and technology transfer in energy in general and renewable energy in particular, } \\
\text { energy conservation and environmental aspects focussing on rural basic needs and women's development. } \\
\text { - Appropriate technology development, adaptation and indigenisation in the concerned specializations. } \\
\text { - Encouragement and support of energy research and development in relevant areas. } \\
\text { - Encouragement and support of the private sector to locally produce and market relevant appropriate energy } \\
\text { technologies in areas of renewables, conservation and environment protection. } \\
\text { - Provision of technical support and consultation in areas of specialization. } \\
\text { - Holding conferences, seminars, symposiums and workshops to disseminate research results. } \\
\text { - Cooperation and communication with relevant organizations locally and abroad. } \\
\text { - Execution of development plans, programmes, studies and projects that are assigned to it by the board of the } \\
\text { institute or the National Centre for Research or the government. }\end{array}$ \\
\hline 3 & $\begin{array}{l}\text { General } \\
\text { Petroleum } \\
\text { Corporations } \\
\text { (GPC) }\end{array}$ & $\begin{array}{l}\text { The } 1976 \text { act stipulated the role of the GPC as follows: } \\
\text { - Exploring, producing, refining, selling, distribution and transportation of petroleum after obtaining the necessary } \\
\text { licenses and leases. } \\
\text { - Importing crude oil and its products and by-products, and exporting surplus crude products and by-products. } \\
\text { - Acquiring, purchasing, selling and leasing land and estates and the construction of buildings thereon, } \\
\text { maintenance thereof, and the construction of all industrial establishments necessary for realizing its objectives. } \\
\text { - Acquiring a share of any national or foreign companies in order to attain any of its objectives. } \\
\text { - Borrowing from banks or other corporations in/or outside Sudan to attain its objectives. } \\
\text { - Carry out its business by depending on its own revenues and on a commercial basis. } \\
\text { - Establishing branches or offices inside or outside Sudan as deemed necessary. } \\
\text { - Entering into contracts or other obligations as necessary, whether with the government or any other person inside } \\
\text { - } \text { or outside Sudan. }\end{array}$ \\
\hline 4 & $\begin{array}{l}\text { National } \\
\text { Energy } \\
\text { Administration } \\
\text { (NEA) }\end{array}$ & $\begin{array}{l}\text { Established by Presidential Decree in 1980: its Roles and Objectives are stipulated as: } \\
\text { - Act as energy planning, analysis and coordination arm of the Ministry of Energy and Mining. } \\
\text { - Initiate and operate programmes in areas outside the sphere of GPC and NEC, particularly with respect to } \\
\text { conservation and renewable energy. } \\
\text { - Assessment and development of energy resources. } \\
\text { - Conducting demand and supply studies. } \\
\text { - Formulation of energy conservation and demand management policies. } \\
\text { - Formulation of national policies issued to develop renewable energies. } \\
\text { - Building a national energy information system to serve the policy and decision makers, energy sectors and } \\
\text { related institutions. } \\
\text { - Carrying out national and regional energy planning. } \\
\text { - Identification of feasible energy projects and presentation for financing. } \\
\text { - Working with institutions in the energy and energy using sectors. }\end{array}$ \\
\hline
\end{tabular}




\begin{tabular}{|c|c|c|}
\hline 5 & $\begin{array}{l}\text { Sudan } \\
\text { Petroleum } \\
\text { Corporation } \\
\text { (SPC) }\end{array}$ & $\begin{array}{l}\text { Established in 1998, with the following purposes and mandates: } \\
\text { - The development of oil resources and their good exploitation. } \\
\text { - Management of all petroleum operations all over the country, controlling } \\
\text { and supervising them. SPC is the sole owner of concessions in all petroleum operations. } \\
\text { - Has responsibility to secure the country’s needs for petroleum products. } \\
\text { - Conducting various exploration operations and oil production activities in or outside Sudan by itself or through its } \\
\text { affiliated companies or by participating with other companies. } \\
\text { - Refining crude oil, marketing and distribution of petroleum products. } \\
\text { - Controlling and supervising all petroleum operations. } \\
\text { - Signing oil agreements and exploration licenses according to the policies approved by the Council of Petroleum } \\
\text { - Affairs. }\end{array}$ \\
\hline 6 & $\begin{array}{l}\text { National } \\
\text { Petroleum } \\
\text { Commission }\end{array}$ & $\begin{array}{l}\text { Established 2005, with following responsibilities: } \\
\text { - Formulate public policies and guidelines in relation to the development and management of the petroleum sector. } \\
\text { - Monitor and assess the implementation of those policies to ensure that they work in the best interests of the people } \\
\text { of Sudan. } \\
\text { - Develop strategies and programmes for the petroleum sector. } \\
\text { - Negotiate and approve all oil contracts for the exploration and development of oil in Sudan, and ensure that they } \\
\text { are consistent with the National Petroleum Commission's principles, policies and guidelines. } \\
\text { - Develop internal regulations and procedures. }\end{array}$ \\
\hline
\end{tabular}

